\title{
Evaluation of a Generalized Basal Area Stand Table Projection Model for Appalachian Hardwoods Growth and Yield Systems
}

Aaron M. Holley

West Virginia University

Follow this and additional works at: https://researchrepository.wvu.edu/etd

Part of the Wood Science and Pulp, Paper Technology Commons

\section{Recommended Citation}

Holley, Aaron M., "Evaluation of a Generalized Basal Area Stand Table Projection Model for Appalachian Hardwoods Growth and Yield Systems" (2015). Graduate Theses, Dissertations, and Problem Reports. 8156.

https://researchrepository.wvu.edu/etd/8156

This Thesis is protected by copyright and/or related rights. It has been brought to you by the The Research Repository @ WVU with permission from the rights-holder(s). You are free to use this Thesis in any way that is permitted by the copyright and related rights legislation that applies to your use. For other uses you must obtain permission from the rights-holder(s) directly, unless additional rights are indicated by a Creative Commons license in the record and/ or on the work itself. This Thesis has been accepted for inclusion in WVU Graduate Theses, Dissertations, and Problem Reports collection by an authorized administrator of The Research Repository @ WVU. For more information, please contact researchrepository@mail.wvu.edu. 


\title{
Evaluation of a Generalized Basal Area Stand Table Projection Model for Appalachian Hardwoods Growth and Yield Systems
}

\author{
Aaron M. Holley \\ Thesis submitted to the \\ Davis College of Agriculture, Natural Resources and Design \\ At West Virginia University \\ In partial fulfillment of the requirements for the degree of \\ Master of Science \\ in \\ Forestry \\ John R. Brooks, Ph.D., Chair \\ Shawn Grushecky, Ph.D. \\ Gary Miller, Ph.D. \\ Jamie Schuler, Ph.D. \\ Jingxin Wang, Ph.D.
}

Division of Forestry and Natural Resources

Morgantown, West Virginia

2015

Keywords: Basal Area Projection, Growth and Yield, Central Appalachian Hardwoods 


\begin{abstract}
Evaluation of a Generalized Basal Area Stand Table Projection Model for Appalachian Hardwoods Growth and Yield Systems
\end{abstract}

Aaron M. Holley

A generalized stand table projection algorithm was used to disaggregate species group level data for the Fernow Experimental Forest in the Allegheny Front physiographic region of the Central Appalachian Hardwoods region. The generalized stand table projection method has proved effective in projecting multi and uni-modal distributions in single species stands. Exploration into the potential for use in mixed species Central Appalachian Hardwoods thinned and unthinned stands proved promising. When compared to basal area projections using SILVAH, generalized stand table projection outperformed SILVAH at the plot level. Generalized stand table projection produced smaller errors on non-overlapping growth projections for both thinned and unthinned stands. For unthinned non-overlapping growth projections, species group root mean squared errors ranged from 0.791 to $3.643 \mathrm{ft}^{2} / \mathrm{ac}$. For unthinned overlapping projections, species group root mean squared errors ranged from 2.003 to $16.365 \mathrm{ft}^{2} / \mathrm{ac}$. For thinned non-overlapping projections, species group root mean squared errors ranged from 0.652 to 2.661 $\mathrm{ft}^{2} / \mathrm{ac}$. For thinned overlapping projections, species group root mean squared errors ranged from 1.818 to $14.994 \mathrm{ft}^{2} / \mathrm{ac}$. Kolmogorov-Smirnov tests indicated that 48.6 percent of the predicted diameter distributions for individual species groups were not significantly different that observed distributions while 51.3 percent of the SILVAH distributions were not significantly different. The generalized stand table projection system provided future basal area estimates as good as SILVAH for the northern red oak, maples, white oaks, hickory and ash, yellow-poplar, striped maple and pin cherry, black cherry, other, scarlet and black oaks, and birch species groups in at least one dataset and projection type combination, and better than SILVAH for the hickory and ash, yellow-poplar, black cherry, other, and birch species groups in at least one dataset and projection type combination. 


\section{Acknowledgements}

I would like to give thanks to the West Virginia University Division of Forestry and Natural Resources, the Appalachian Hardwood Forest Research Alliance, the Appalachian Hardwood Center, and the USDA Forest Service for their collective funding and support throughout this research project. Dr. Shawn Grushecky, Dr. Gary Miller, Dr. Jamie Schuler, and Dr. Jingxin Wang have all been enthusiastically supportive and a wealth of knowledge in their individual fields of expertise. I owe my discovery of the field of forestry to Dr. Ray Hicks. Doctor Hicks found me as a lost freshman, discovered my propensity to be a forester, referred me to Dr. John R. Brooks, and has encouraged me all along the way. Doctor Brooks has guided me throughout my forestry education experience. It was he that guided me into the forestry field as an undergraduate, and he that took me under wing to educate me not only on the technical aspects of forestry, but also on the professional and social skills necessary to be successful. I count it a blessing of paramount scale to have studied under him. I would also like to thank my girlfriend, family, and friends who have given me so much support and have provided a listening ear and loving encouragement. Lastly, and most importantly, I thank my savior Jesus Christ for not only carrying me through the tough times, but for giving me eternal hope. I owe Him all. 


\section{Table of Contents}

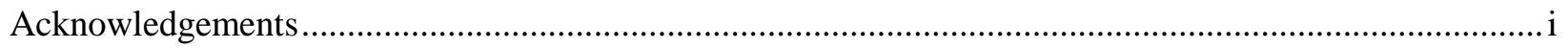

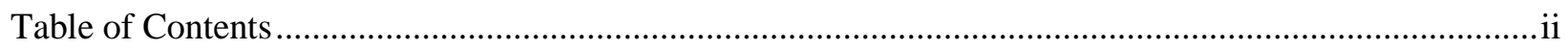

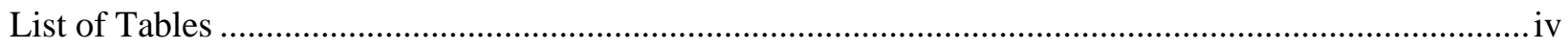

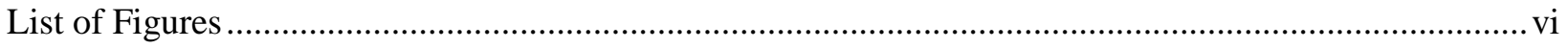

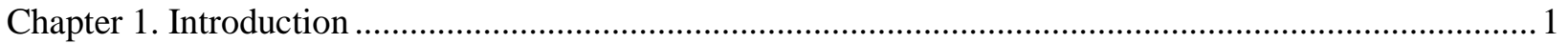

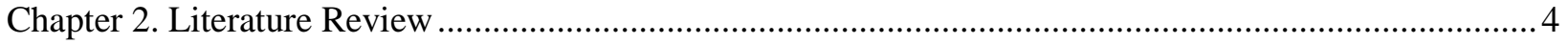

Growth and Yield in the Central Appalachian Hardwoods Region ....................................................... 4

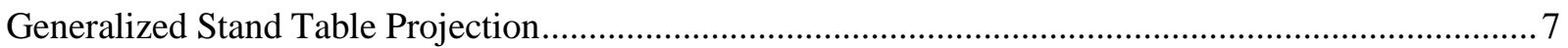

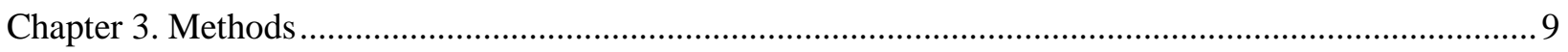

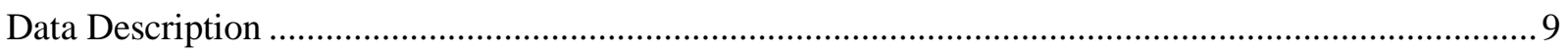

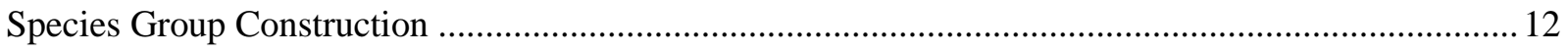

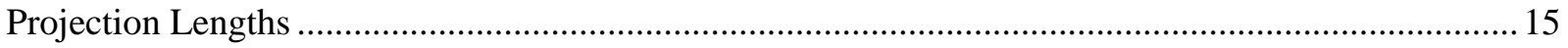

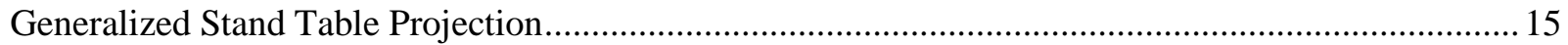

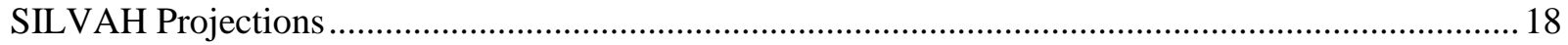

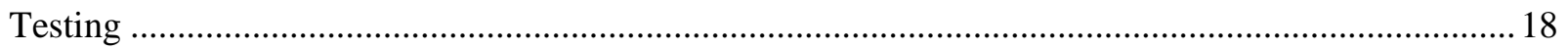

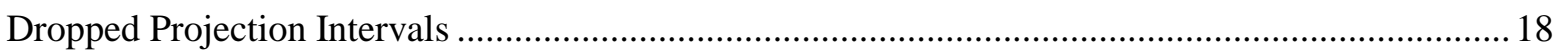

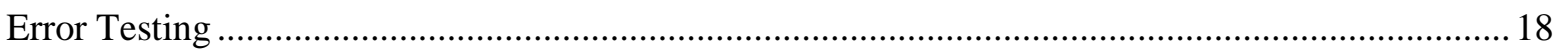

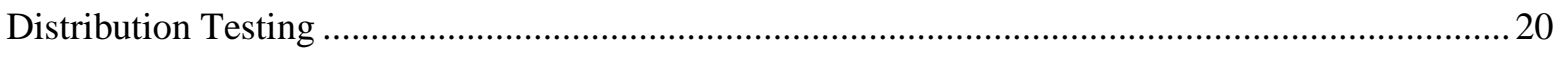

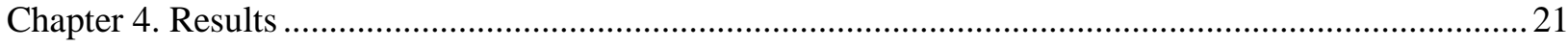

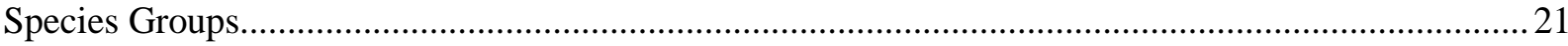

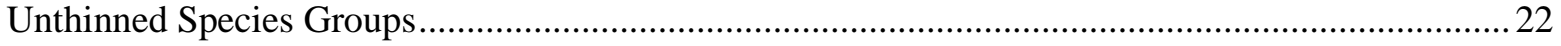

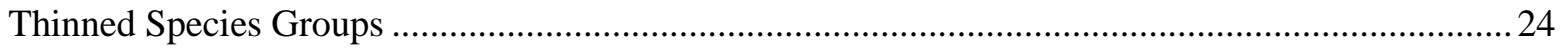

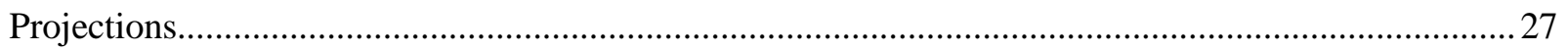

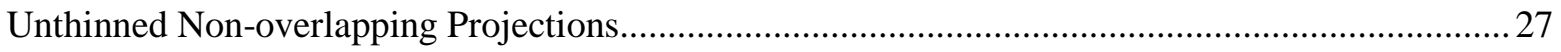

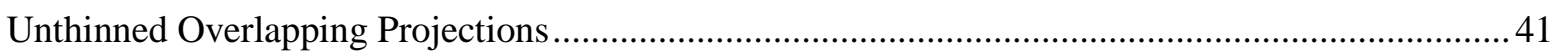

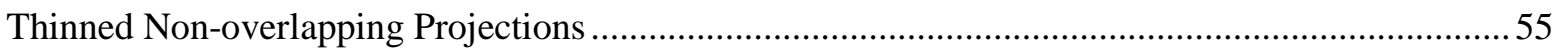

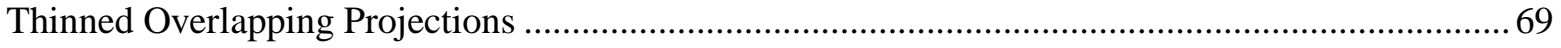

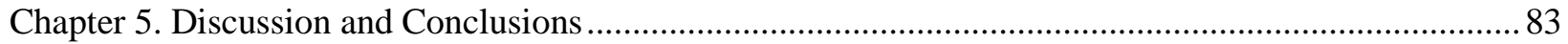

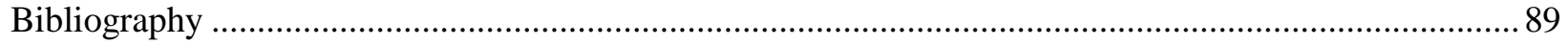

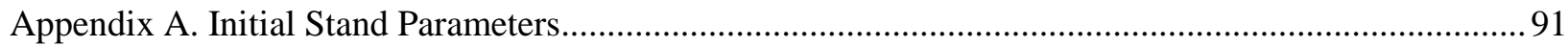

Appendix B. Additional Species Group Parameter Relative Basal Area Projection Error Plots ................93 
Unthinned Parameters Relative Basal Area Projection Error Plots .................................................... 94

Thinned Parameter Relative Basal Area Prediction Error Plots ......................................................... 101

Appendix C. Additional Basal Area Projection Graphs............................................................................ 109

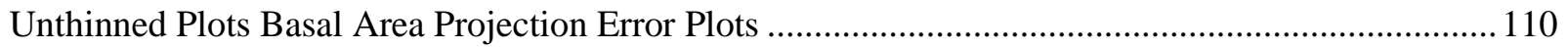

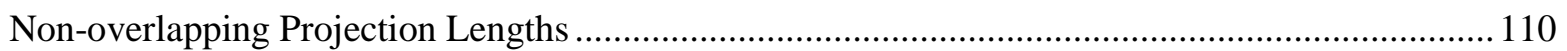

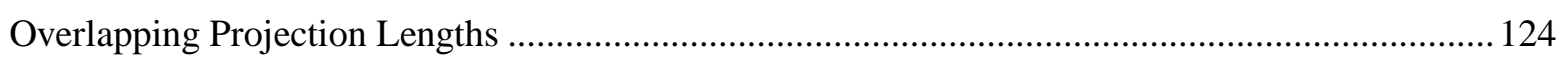

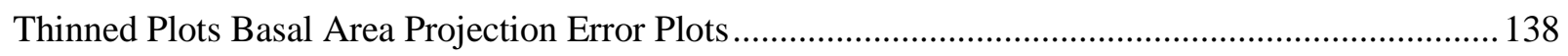

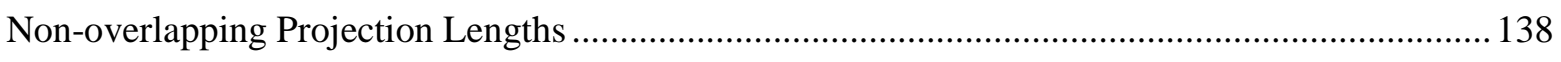

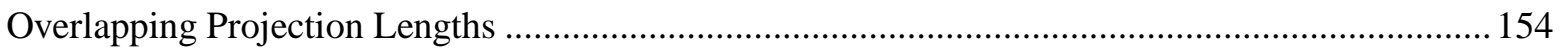




\section{List of Tables}

Table 1. Compartment summary. .11

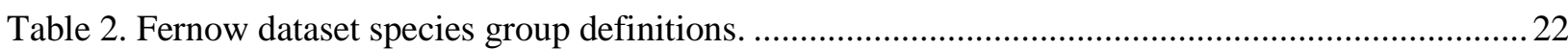

Table 3. Unthinned species groups parameter estimates and fit statistics. ...........................................22

Table 4. Thinned species groups parameter estimates and fit statistics.................................................25

Table 5. Unthinned non-overlapping plot level summary statistics...............................................28

Table 6. Summary statistics for species group 1 in unthinned non-overlapping projections......................33

Table 7. Summary statistics for species group 2 in unthinned non-overlapping projections...................... 33

Table 8. Summary statistics for species group 3 in unthinned non-overlapping projections...................... 34

Table 9. Summary statistics for species group 4 in unthinned non-overlapping projections..................... 34

Table 10. Summary statistics for species group 5 in unthinned non-overlapping projections....................35

Table 11. Summary statistics for species group 6 in unthinned non-overlapping projections.....................35

Table 12. Summary statistics for species group 7 in unthinned non-overlapping projections...................36

Table 13. Summary statistics for species group 8 in unthinned non-overlapping projections.....................36

Table 14. Summary statistics for species group 10 in unthinned non-overlapping projections.................. 37

Table 15. Unthinned overlapping plot level summary statistics......................................................... 42

Table 16. Summary statistics for species group 1 in unthinned overlapping projections.........................47

Table 17. Summary statistics for species group 2 in unthinned overlapping projections..........................47

Table 18. Summary statistics for species group 3 in unthinned overlapping projections.......................... 48

Table 19. Summary statistics for species group 4 in unthinned overlapping projections......................... 48

Table 20. Summary statistics for species group 5 in unthinned overlapping projections.......................... 49

Table 21. Summary statistics for species group 6 in unthinned overlapping projections......................... 49

Table 22. Summary statistics for species group 7 in unthinned overlapping projections.........................50

Table 23. Summary statistics for species group 8 in unthinned overlapping projections...........................50

Table 24. Summary statistics for species group 10 in unthinned overlapping projections........................51

Table 25. Thinned non-overlapping plot level summary statistics. ....................................................56

Table 26. Summary statistics for species group 1 in thinned non-overlapping projections.........................61

Table 27. Summary statistics for species group 2 in thinned non-overlapping projections........................61

Table 28. Summary statistics for species group 3 in thinned non-overlapping projections......................62

Table 29. Summary statistics for species group 4 in thinned non-overlapping projections........................62

Table 30. Summary statistics for species group 5 in thinned non-overlapping projections.......................63

Table 31. Summary statistics for species group 6 in thinned non-overlapping projections......................63

Table 32. Summary statistics for species group 7 in thinned non-overlapping projections........................64

Table 33. Summary statistics for species group 8 in thinned non-overlapping projections........................64

Table 34. Summary statistics for species group 9 in thinned non-overlapping projections.......................65

Table 35. Summary statistics for species group 10 in thinned non-overlapping projections......................65

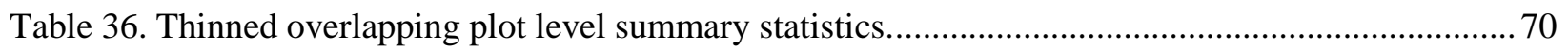

Table 37. Summary statistics for species group 1 in thinned overlapping projections............................ 75

Table 38. Summary statistics for species group 2 in thinned overlapping projections............................ 75

Table 39. Summary statistics for species group 3 in thinned overlapping projections.............................76

Table 40. Summary statistics for species group 4 in thinned overlapping projections............................. 76

Table 41. Summary statistics for species group 5 in thinned overlapping projections...............................77

Table 42. Summary statistics for species group 6 in thinned overlapping projections............................. 77

Table 43. Summary statistics for species group 7 in thinned overlapping projections.............................. 78 
Table 44. Summary statistics for species group 8 in thinned overlapping projections........................... 78

Table 45. Summary statistics for species group 9 in thinned overlapping projections............................. 79

Table 46. Summary statistics for species group 10 in thinned overlapping projections........................... 79

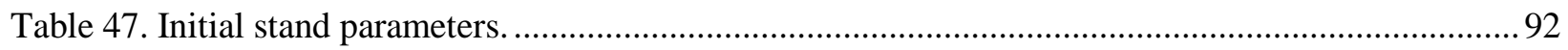




\section{List of Figures}

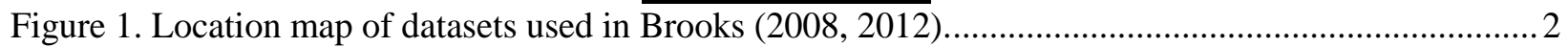

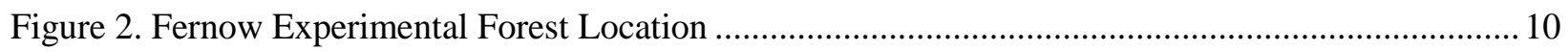

Figure 3. Basal area per acre by plot by measurement year for all plots. ............................................. 12

Figure 4. Illustration example of non-overlapping and overlapping projection lengths...........................15

Figure 5. Species group 4 (hickory/ash) relative basal area prediction error at age 2 for unthinned data. . 23

Figure 6. Species group 7 (black cherry) relative basal area prediction error at age 2 for unthinned data. 24 Figure 7. Species group 9 (black and scarlet oaks) relative basal area prediction error at age 2 for thinned

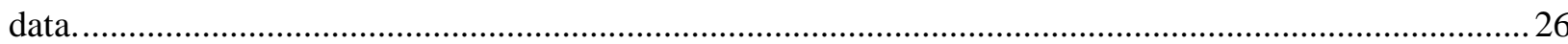

Figure 8. Species group 5 (yellow-poplar) relative basal area prediction error at age 2 for thinned data. .27

Figure 9. Unthinned non-overlapping plot level projection errors by projection age (age 2)...................22

Figure 10. Unthinned non-overlapping plot level projection errors by projection length. .........................30

Figure 11. Unthinned non-overlapping plot level projection error as a percent of total observed BAAC by projection length.

31

Figure 12. Unthinned non-overlapping plot level projection error as a percent of total observed BAAC at age 2 .

Figure 13. Species group 6 (striped maple/pin cherry) projection errors by projection age (age 2) for unthinned non-overlapping projections.

Figure 14. Species group 6 (striped maple/pin cherry) projection errors by projection length for unthinned non-overlapping projections.

Figure 15. Species group 5 (yellow-poplar) projection errors by projection age (age 2) for unthinned nonoverlapping projections

Figure 16. Species group 5 (yellow-poplar) projection errors by projection length for unthinned non-

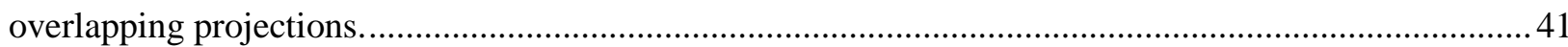

Figure 17. Unthinned overlapping plot level projection error by projection age (age 2)........................43

Figure 18. Unthinned overlapping plot level projection error by projection length. .............................44 Figure 19. Unthinned overlapping plot level projection error as a percent of total basal area per acre at age 2 by projection length.

Figure 20. Unthinned overlapping plot level projection error as a percent of total basal area per acre at age 2 by age 2 .

Figure 21. Species group 6 (striped maple/pin cherry) projection errors by projection age (age 2) for unthinned overlapping projections.

Figure 22. Species group 6 (striped maple/pin cherry) projection errors by projection length for unthinned overlapping projections.

Figure 23. Species group 5 (yellow-poplar) projection errors by projection age (age 2) for unthinned overlapping projections.

Figure 24. Species group 5 (yellow-poplar) projection errors by projection length for unthinned overlapping projections. .55

Figure 25. Thinned non-overlapping plot level projection errors by projection age (age 2)...................57

Figure 26. Thinned non-overlapping plot level projection errors by projection length. .58 Figure 27. Thinned non-overlapping plot level projection errors as a percent of total basal area per acre by projection length.

Figure 28. Thinned non-overlapping plot level projection errors as a percent of total basal area per acre at age 2 . 
Figure 29. Species group 4 (hickory/ash) projection errors by projection age (age 2) for thinned overlapping projections.

Figure 30. Species group 4 (hickory/ash) projection errors by projection length for thinned overlapping projections.

Figure 31. Species group 5 (yellow-poplar) projection errors by projection age (age 2) for thinned overlapping projections.

Figure 32. Species group 5 (yellow-poplar) projection errors by projection length for thinned overlapping projections. .69

Figure 33. Plot level projection errors by projection age (age 2) for thinned overlapping projections. .....71

Figure 34. Plot level projection errors by projection length for thinned overlapping projections.............. 72

Figure 35. Thinned overlapping plot level projection errors as a percent of total basal area per acre by projection length.

Figure 36. Thinned overlapping plot level projection errors as a percent of total basal area per acre by projection age (age 2)

Figure 37. Species group 9 (black and scarlet oaks) projection errors by projection age (age 2) for thinned overlapping projections.

Figure 38. Species group 9 (black and scarlet oaks) projection errors by projection length for thinned overlapping projections.

Figure 39. Species group 5 (yellow-poplar) projection errors by projection age (age 2) for thinned overlapping projections.

Figure 40. Species group 5 (yellow-poplar) projection errors by projection length for thinned overlapping projections.

Figure 41. Species group 1 (northern red oak) relative basal area prediction error by age 2 for unthinned plots.

Figure 42. Species group 2 (maples) relative basal area prediction error by age 2 for unthinned plots. .... 95 Figure 43. Species group 3 (white oaks) relative basal area prediction error by age 2 for unthinned plots.

Figure 44. Species group 5 (yellow-poplar) relative basal area prediction error by age 2 for unthinned plots.

Figure 45. Species group 6 (striped maple/pin cherry) relative basal area prediction error by age 2 for unthinned plots..................................................................................................................98

Figure 46. Species group 8 (other) relative basal area prediction error by age 2 for unthinned plots. ....... 99 Figure 47. Species group 10 (birches) relative basal area prediction error by age 2 for unthinned plots. 100 Figure 48. Species group 1 (northern red oak) relative basal area prediction error by age 2 for thinned

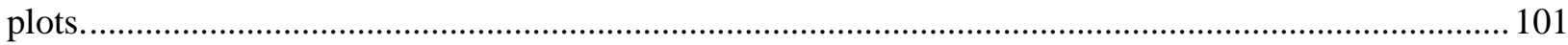

Figure 49. Species group 2 (maples) relative basal area prediction error by age 2 for thinned plots. ...... 102 Figure 50. Species group 3 (white oaks) relative basal area prediction error by age 2 for thinned plots. 103 Figure 51. Species group 4 (hickory/ash) relative basal area prediction error by age 2 for thinned plots. 104 Figure 52. Species group 6 (striped maple/pin cherry) relative basal area prediction error by age 2 for thinned plots. 105

Figure 53. Species group 7 (black cherry) relative basal area prediction error by age 2 for thinned plots. 106

Figure 54. Species group 8 (other) relative basal area prediction error by age 2 for thinned plots. ......... 107 Figure 55. Species group 10 (birches) relative basal area prediction error by age 2 for thinned plots..... 108 
Figure 56. Species group 1 (northern red oak) projection error by projection age (age 2) for unthinned non-overlapping projections.

Figure 57. Species group 1 (northern red oak) projection error by projection length for unthinned nonoverlapping projections.

Figure 58. Species group 2 (maples) projection error by projection age (age 2) for unthinned nonoverlapping projections.

Figure 59. Species group 2 (maples) projection error by projection length for unthinned non-overlapping projections.

Figure 60. Species group 3 (white oaks) projection error by projection age (age 2) for unthinned nonoverlapping projections.

Figure 61. Species group 3 (white oaks) projection error by projection length for unthinned nonoverlapping projections.

Figure 62. Species group 4 (hickory.ash) projection error by projection age (age 2) for unthinned nonoverlapping projections.

Figure 63. Species group 4 (hickory/ash) projection error by projection length for unthinned nonoverlapping projections.

Figure 64. Species group 7 (black cherry) projection error by projection age (age 2) for unthinned nonoverlapping projections.

Figure 65. Species group 7 (black cherry) projection error by projection length for unthinned nonoverlapping projections.

Figure 66. Species group 8 (other) projection error by projection age (age 2) for unthinned nonoverlapping projections.

Figure 67. Species group 8 (other) projection error by projection length for unthinned non-overlapping projections.

Figure 68. Species group 10 (birches) projection error by projection age (age 2) for unthinned nonoverlapping projections

Figure 69. Species group 10 (birches) projection error by projection length for unthinned non-overlapping projections.

Figure 70. Species group 1 (northern red oak) projection error by projection length for unthinned overlapping projections.

Figure 71. Species group 1 (northern red oak) projection error by projection age (age 2) for unthinned overlapping projections.

Figure 72. Species group 2 (maples) projection error by projection length for unthinned overlapping projections.

Figure 73. Species group 2 (maples) projection error by projection age (age 2) for unthinned overlapping projections.

Figure 74. Species group 3 (white oaks) projection error by projection length for unthinned overlapping projections

Figure 75. Species group 3 (white oaks) projection error by projection age (age 2) for unthinned overlapping projections

Figure 76. Species group 4 (hickory/ash) projection error by projection length for unthinned overlapping projections.

Figure 77. Species group 4 (hickory/ash) projection error by projection age (age 2) for unthinned overlapping projections 
Figure 78. Species group 7 (black cherry) projection error by projection length for unthinned overlapping projections. 132

Figure 79. Species group 7 (black cherry) projection error by projection age (age 2) for unthinned overlapping projections.

Figure 80 . Species group 8 (other) projection error by projection length for unthinned overlapping projections.

Figure 81 . Species group 8 (other) projection error by projection age (age 2) for unthinned overlapping projections.

Figure 82. Species group 10 (birches) projection error by projection length for unthinned overlapping projections.

Figure 83. Species group 10 (birches) projection error by projection age (age 2) for unthinned overlapping projections.

Figure 84. Species group 1 (northern red oak) projection error by projection age (age 2) for thinned nonoverlapping projections. 138

Figure 85. Species group 1 (northern red oak) projection error by projection length for thinned nonoverlapping projections.

Figure 86. Species group 2 (maples) projection error by projection age (age 2) for thinned nonoverlapping projections.

Figure 87. Species group 2 (maples) projection error by projection length for thinned non-overlapping projections.

Figure 88. Species group 3 (white oaks) projection error by projection age (age 2) for thinned nonoverlapping projections.

Figure 89. Species group 3 (white oaks) projection error by projection length for thinned non-overlapping projections.

Figure 90. Species group 6 (striped maple/pin cherry) projection error by projection age (age 2) for thinned non-overlapping projections.

Figure 91. Species group 6 (striped maple/pin cherry) projection error by projection length for thinned non-overlapping projections.

Figure 92. Species group 7 (black cherry) projection error by projection age (age 2) for thinned nonoverlapping projections.

Figure 93. Species group 7 (black cherry) projection error by projection length for thinned nonoverlapping projections.

Figure 94. Species group 8 (other) projection error by projection age (age 2) for thinned non-overlapping projections.

Figure 95. Species group 8 (other) projection error by projection length for thinned non-overlapping projections.

Figure 96. Species group 9 (black and scarlet oaks) projection error by projection age (age 2) for thinned non-overlapping projections.

Figure 97. Species group 9 (black and scarlet oaks) projection error by projection length for thinned nonoverlapping projections.

Figure 98. Species group 10 (birches) projection error by projection age (age 2) for thinned nonoverlapping projections.

Figure 99. Species group 10 (birches) projection error by projection length for thinned non-overlapping projections. 
Figure 100. Species group 1 (northern red oak) projection error by projection age (age 2) for thinned overlapping projections....

Figure 101. Species group 1 (northern red oak) projection error by projection length for thinned overlapping projections....

Figure 102. Species group 2 (maples) projection error by projection age (age 2) for thinned overlapping projections. 156

Figure 103. Species group 2 (maples) projection error by projection length for thinned overlapping projections.

Figure 104. Species group 3 (white oaks) projection error by projection age (age 2) for thinned overlapping projections.

Figure 105. Species group 3 (white oaks) projection error by projection length for thinned overlapping projections.

Figure 106. Species group 4 (hickory/ash) projection error by projection age (age 2) for thinned overlapping projections.

Figure 107. Species group 4 (hickory/ash) projection error by projection length for thinned overlapping projections.

Figure 108. Species group 6 (striped maple/pin cherry) projection error by projection age (age 2) for thinned overlapping projections.

Figure 109. Species group 6 (striped maple/pin cherry) projection error by projection length for thinned overlapping projections. 163

Figure 110. Species group 7 (black cherry) projection error by projection age (age 2) for thinned overlapping projections.

Figure 111. Species group 7 (black cherry) projection error by projection length for thinned overlapping projections.

Figure 112. Species group 8 (other) projection error by projection age (age 2) for thinned overlapping projections 166

Figure 113. Species group 8 (other) projection error by projection length for thinned overlapping projections.

Figure 114. Species group 10 (birches) projection error by projection age (age 2) for thinned overlapping projections.

Figure 115. Species group 10 (birches) projection error by projection length for thinned overlapping projections 


\section{Chapter 1. Introduction}

In its simplest form, a growth and yield model provides a technique for forecasting stand dynamics (Avery and Burkhart 2002). A series of growth and yield models that act together are referred to as growth and yield systems. The system may be further analyzed by studying its two parts; growth and yield. The growth portion of the system involves projecting a stand dynamic forward in time. The yield portion involves using the projected stand dynamic in a table or equation to predict some metric of product available for the future stand.

Growth and yield systems are essential to forest management and planning and are widely used in the southeastern southern pine region. Shiver and Borders (1996) report that growth and yield systems are common in even-aged natural and plantation-type stands. While much development of growth and yield systems in the United States has centered on the southern pine region, the Central Appalachian Hardwoods region has not benefitted from the same scope of development.

In order to test the feasibility of an improved growth and yield system for the Central Appalachian Hardwoods region, Brooks and others (2008) published a whole stand basal area projection model for Appalachian hardwoods. Basal area projections for remeasured plot data from north central West Virginia and from Schnur (1937) were within \pm 10 percent of observed basal area per acre. Through this region specific research, it became apparent that, at least at the stand level, new and improved growth and yield models could be developed for the central Appalachian region.

Later in 2008, in an effort to tabulate precision and accuracy of available computer-based Appalachian growth and yield systems, Brooks (2008) produced a report on commonly available and widely used growth and yield systems specific to the central Appalachian region. This report compared SILVAH (Marquis and Ernst, 1992 version 4.4), the northeast variant of FVS (Bush, 1995 Version 6.21 release 
07.05.06), and the Stand Damage Model Version 2.0 (Colbert and Racin, 1995) to observed remeasured plot data. The study found that projected basal area per acre ranged anywhere from 2 to 65 percent of observed basal area at age 2, with SILVAH providing the most accurate projections (Brooks, 2008). Referring to two earlier works (Brooks and Wiant, 2004, 2008), Brooks further implied that projections within \pm 10 to 15 percent of stand volume are feasible, and that estimates with over 20 percent error should be unacceptable in the central Appalachian region (Brooks, 2008).

These incremental studies led to the creation of new whole stand growth and yield models (Brooks 2012) for the central Appalachian hardwoods region, based on remeasured plot data. The data were collected from four distinct physiographic regions in central Appalachia; Allegheny Plateau and Mountains (Allegheny National Forest), Western Allegheny Plateau and Mountains (OAKSIM data), Allegheny Front (Fernow Experimental Forest data, West Virginia University Research Forest data), and Southern Appalachian Ridge and Valley (MeadWestvaco data). Their distribution is shown in Figure 1.

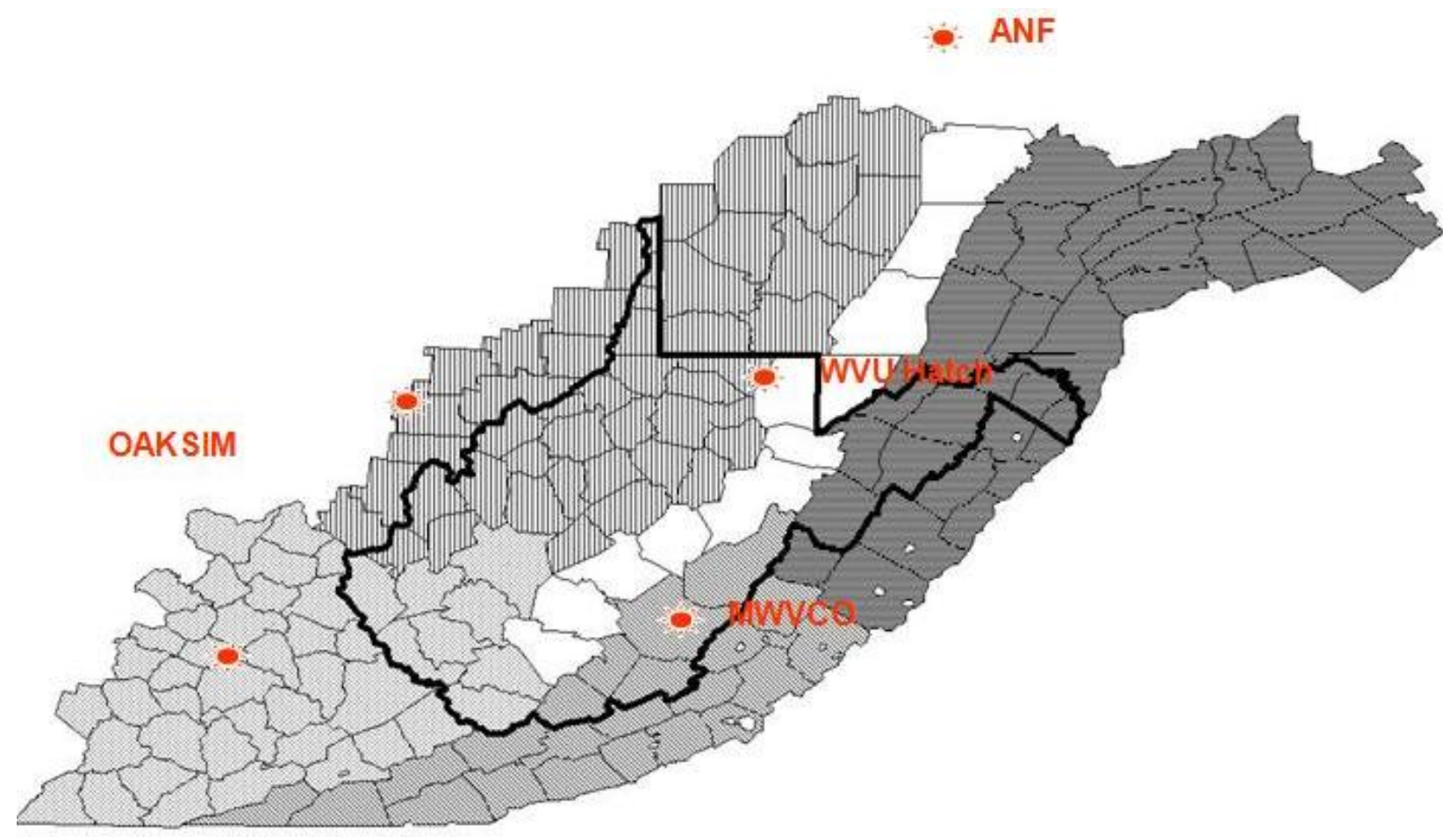

Figure 1. Location map of datasets used in Brooks (2008, 2012). 
The dataset includes remeasurements for both thinned and unthinned plots based on thinning studies installed at these locations. Since the Brooks (2008) study found SILVAH to be the most accurate in projecting stand dynamics for the data, the purpose of the 2012 study was to create new whole stand projection equations for dominant height, trees per acre, basal area per acre, and volume per acre for both thinned and unthinned stands, for all physiographic regions and to compare them to the SILVAH 5.6 projections. While previous Central Appalachian Hardwoods growth and yield models did not include separate equations for thinned and unthinned stands, the whole stand models produced in the Brooks (2012) study did, adding to the accuracy of projections. The equations were fit as a family of seemingly unrelated regressions for thinned and unthinned stands. The proposed models produced smaller errors for all projection lengths for all physiographic regions for both thinned and unthinned stand conditions. Projection lengths were defined as the number of years between the initial measurement age and the age to which the stand was projected.

While whole-stand models are more accurate than individual tree models at the stand level, the availability of detailed stand structure information needed to accurately plan and implement forest management activities are found wanting in whole stand models. In order to effectively plan management activities and conduct stand valuations, more specific information, such as species-level data, is needed than simply a diameter distribution for the entire stand or simple stand level attributes. If species-level data is available, more accurate estimates of volume and price may be calculated. In order to glean that information from the projections, the whole stand model must be disaggregated into species (or species groups) by diameter class distributions.

The purpose of this research was to disaggregate the whole stand models presented by Brooks (2012) into diameter class distributions by species groups, thus providing a higher level of specificity desired in growth and yield model output. In addition, the feasibility of a generalized stand table projection as a means of basal area growth projection was examined. The same data used to develop the whole stand models (Brooks 2012) was utilized in this study, and was projected using the generalized stand table 
projection approach introduced by Pienaar and Harrison (1988). Since SILVAH was found to be the most accurate projection system commonly available in the Central Appalachian Hardwoods region (Brooks 2008), the disaggregation of the whole stand models using the generalized stand table projection process was tested against the output predicted by SILVAH.

\section{Chapter 2. Literature Review}

\section{Growth and Yield in the Central Appalachian Hardwoods Region}

In order to understand the need for efficient, accurate individual tree growth and yield models for the Central Appalachian Hardwoods region, a study of the history of growth and yield systems in this region must be examined. Most development has occurred in the last three decades, and most of the available systems today were developed in the first half of that time span.

Before the 1980's, limited growth and yield information was published for the central Appalachian hardwoods region. One of the earliest yield estimation procedures for the central hardwoods region was published by Schnur in 1937. Schnur's publication provided normal yield tables for even-aged, second growth, fully -stocked upland oak stands based on age and site index. The term "upland oak" refers to the central Appalachian hardwoods forest with data collected from central Pennsylvania to northern Georgia. While still a popular method for estimating future yield, the limiting factor in Schnur's method is the restrictions on stand type and the limits associated with normal yield data.

In the 1960's, Schlaegel (unpublished) produced whole stand growth and yield models for yellow-poplar (Liriodendron tulipifera L.) stands in West Virginia, where at least 75 percent of the dominant and codominant trees were yellow-poplar. Amongst other equations, Schlaegel developed whole stand basal area prediction equations. A basal area growth model was first fit to the data. The basal area prediction model was then solved by integration of the basal area growth model. 
In 1972, Dale published a whole stand model for even-aged upland oak basal area growth from plots located in Iowa, Missouri, Illinois, Indiana, Ohio, and Kentucky. The initial basal area growth model was combined with a cubic foot volume prediction equation to create a growth and yield system, available in a FORTRAN IV computer program. The program predicted growth and yield estimates for any even-aged upland oak stand up to 30 years after thinning based on initial stand age, basal area, number of trees per acre over 2.6 inches dbh, and site index. The models provided sufficient accuracy for most field uses, despite a coefficient of determination of 0.518 for the basal area growth model.

OAKSIM was developed and released in 1985 by Donald Hilt as an individual-tree growth and yield system for upland oak stands. The system included an individual-tree growth and yield model, mortality models, height prediction models, bark ratio models, volume based on taper equations, as well as thinning options. OAKSIM could import data either from a tree list or from a stand table. The growth models used were published by Hilt in 1983, and were developed from remeasurement plots from a thinning study located in southern Ohio and eastern Kentucky, between the ages of 29 and 93 years for even-aged stands. Growth was applied in five year intervals, while projections could include up to 10 five-year intervals. Basal area growth for a given diameter class within a species was first calculated, then assigned a random growth rate centered on the mean growth rate, which allowed variation within diameter classes. After predicting basal area growth, mortality was accounted for through models developed for the system. The system constrained the basal area growth to feasible limits. If the estimates exceeded predicted maxima, modifiers would adjust the predictions.

In 1987, Yandle and others produced a whole stand model based on summation of past diameter growth and shade tolerance. This model was fit using data from the Muskingum Watershed in Ohio and the Fernow Experimental Forest, and assumed that future diameter growth was a function of past diameter growth. This model was fit specifically for mixed hardwood stands, and produced favorable results when validated with the Fernow Experimental Forest dataset. The shade-tolerance aspect of the model allowed for accurate application when used outside the species composition range in which the model was fit. 
When the model was fit as a disaggregated species-level model, it performed poorly for the Fernow dataset from which the model was fit, but performed well for the Muskingum validation dataset. This was partially due to the fact that the model relied on a measure of shade tolerance as a variable in the growth process to account for change in species composition.

In 1991, Teck and Hilt published an individual tree model for the northeastern United States utilizing Forest Inventory and Analysis plot data from the United States Forest Service from 14 northeastern states. In this basal area projection model, potential growth was estimated using diameter and site index and incorporated a relative competitive position in the stand as an independent variable. Once the basal area was projected, it could be converted back into diameter classes. The model performed well, and was incorporated into NE-TWIGS, a growth and yield system developed for computer simulation for the northeastern United States.

Utilizing the basal area growth models first introduced by Hilt in 1983 and previously used in OAKSIM, as well as models previously developed by David Marquis (1982), Marquis and Ernst (1985) published the Silviculture of Allegheny Hardwoods, or "SILVAH" computer silvicultural prescription simulator and growth and yield system for the IBM PC. The computer-based system has since been upgraded to a Windows based graphical user interface (GUI). SILVAH is a modified stand table projection algorithm built-in to a larger system that provides prescription recommendations and modeling for cherry-maple, beech-birch-maple, and oak-hickory forests found in the Allegheny regions. While SILVAH is a commonly employed system in the Central Appalachian Hardwoods region, it is inefficient in data input and output generation. The inefficiencies stem from the data input stage. Data may only be input on an individual tree basis in SILVAH, or through timely manipulation of the input file. Also, the projection results are displayed only on SILVAH's GUI, making it difficult to transfer the results into other computer programs. 
Incorporating the models published by Teck and Hilt (1991), Bush published the Northeast Variant of the USDA Forest Service Forest Vegetation Simulator, or "FVS" in 1995. The northeastern variant of FVS is an individual tree system. FVS allows the user to include many other options in the growth and yield functions, including insect and pathogen damage, fire and fuels implications, and understory development (Dixon and Keyser 2008). After years of updating models, the only remaining vestige of NE-TWIGS is the large diameter growth equations.

The two most commonly available and widely used growth and yield systems in the Central Appalachian Hardwood region today include SILVAH and FVS. Since SILVAH has proven to produce more accurate basal area projections (Brooks 2008), it could be assumed to be the system of choice. However, improvements concentrating on data input and results reporting can be made.

\section{Generalized Stand Table Projection}

The basis for the generalized stand table projection system originates with Clutter and Jones (1980). In this work, Clutter and Jones propose a new method of stand structure projection in which instead of trees "moving" from one diameter class to another over time, the diameter class statistics themselves change over time (Clutter and Jones, 1980). The authors also proposed a method that is crucial to the generalized stand table projection algorithm: relative basal area. Relative basal area is defined as the relationship between average basal area of a tree or diameter class to the total basal area for the stand. In 1988, Pienaar and Harrison proposed a method of projecting current stand tables utilizing the relative basal area theory from Clutter and Jones (1980). The process includes a whole stand model and a survival function, and is commonly referred to as generalized stand table projection. The method was developed using slash pine (Pinus elliottii Engelm.) thinning data. In generalized stand table projection, the current stand table is projected to a future age while constraining this estimate to the whole-stand model estimate. Pienaar and Harrison updated the relative basal area relationship to predict relative basal area at age 2 using a nonlinear model where $\beta$ is estimated from the remeasured sample data. The general model form is shown as Equation 1. 


$$
\frac{b_{2 i}}{\overline{b_{2}}}=\frac{b_{1 i}}{\overline{b_{1}}}\left(\frac{A_{2}}{A_{1}}\right)^{\beta}
$$

This equation form follows evidence that relative basal area changes predictably over time. Younger trees change more in relative size than do older stands (Pienaar and Harrison 1988). The $\beta$ parameter may be interpreted as the future contribution of a diameter class to the future stand. If $\beta$ is positive, it means that the relative contribution of larger diameter classes will increase, while the relative contribution of smaller diameter classes will decrease over time. If $\beta$ is negative, the inverse is true (Knowe 1994).

The construction of the projected stand table follows the hypothesis stated in Equation 2.

$$
B_{2}=\sum_{i=1}^{n} b_{2 i}=n \bar{b}_{2}
$$

In other words, the model is constrained to the whole-stand estimate of basal area at age 2 . If $B_{2}$ is set as the whole-stand estimate, and n, or survivors at age 2 is known, then the average basal area for a singular tree or diameter class may be calculated. A diameter midpoint may then be calculated from the projected basal area for each diameter class, to which the surviving trees are applied.

Generalized stand table projection has been proven to be an accurate method for projecting monospecific stand tables. Borders and Patterson (1990) compared a distance independent stand table projection algorithm with a Weibull probability density function and a percentile based algorithm. A loblolly pine (Pinus taeda L.) stand table was projected by all three methods. Borders and Patterson found that the stand table projection method produced more accurate projections, a smaller Reynolds error index (Reynolds 1988), and less bias than the other two methods tested. They also reported that generalized stand table projection performs better on multimodal distributions than the Weibull approach, and just as well on uni-modal distributions. 
Generalized stand table projection was selected as the method of basal area projection for this project based on its potential to accurately project diameter distributions and its flexibility with multi-modal distributions. Since the Central Appalachian Hardwoods region mainly consists of mixed species stands, and generalized stand table projection performs well with uni-modal and multimodal diameter distributions, such as are common in the region, the generalized stand table projection system was selected to investigate its ability to improve individual tree basal area projection models for this region.

\section{Chapter 3. Methods}

\section{Data Description}

Data for development and testing of the generalized stand table projection system, consisted of tree lists from the United States Forest Service Northern Research Station at the 4,600 acre Fernow Experimental Forest in Parsons, West Virginia. The Fernow Experimental Forest lays in the Allegheny Front of the Appalachian Mountains (Figure 2), and was established in 1934 to research timber and water quality. The compartments in this dataset range from 1,761 feet to 2,980 feet in elevation. On average, the Fernow receives approximately 57 inches of rainfall per year (Adams et. al., 2012). 


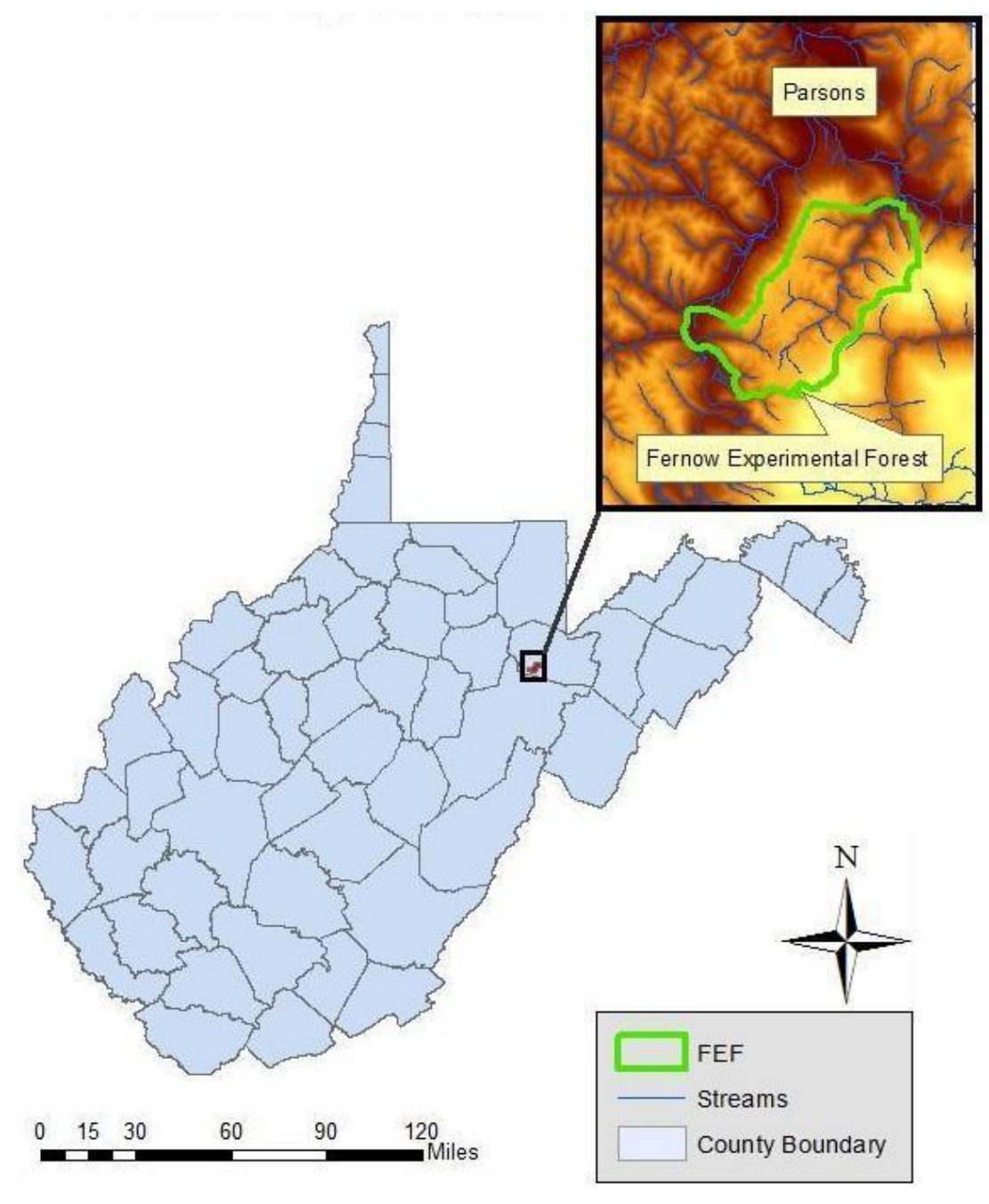

Figure 2. Fernow Experimental Forest Location

The dataset is based on an even-aged thinning study conducted at the Fernow Experimental Forest. In this dataset, there were 8 compartments with 6 plots within each compartment for a total of 48 plots. Of those 48 plots, 2 per compartment were unthinned, while 4 plots per compartment were thinned, for a total of 16 and 32 plots, respectively. Thinned plots were 0.50 acre in size, while unthinned plots were 0.25 acre in size. Northern red oak (Quercus rubra L.) site index ranged from 61 on western facing slopes to 77 on north east facing slopes. Thirty-five species were represented in the data, constituting a mixed hardwoods forest type. 
All of the compartments were established in 1960, with stand initiations between 1960 and 1962. During this two year span, 62-80 percent of the basal area in these stands was removed, with the remaining seed tree basal area removed 4 years later. Stand age is based on the initial harvest year. Thinning treatments were installed between 1980-1991 in which 38-73 percent of the remaining basal area was removed on the thinned plots.

The data consist of remeasurements of the stands between 18 and 49 years in age. Remeasurement increments vary in length from 2 to 10 years with an average of approximately 5 years for all periods (Table 1). Initial stand parameters are displayed in Appendix A, Table 47.

Table 1. Compartment summary.

\begin{tabular}{|c|c|c|c|c|c|c|c|c|c|c|}
\hline Compartment & Min Elevation (ft.) & Max Elevation (ft.) & Area (ac.) & Aspect & NRO Site Index (ft.) & Forest Type & Establishment Year & Min BAAC (ft. ${ }^{2} /$ ac.) & Max BAAC (ft. ${ }^{2} / \mathrm{ac}$.) & Age (yrs.) \\
\hline 32 & 2580 & 2980 & 21.73 & $\mathrm{~N}$ & 76 & Mixed Hardwoods & 1960 & 49.80 & 185.56 & $20-49$ \\
\hline 33 & 2480 & 2860 & 12.83 & $\mathrm{NE}$ & 77 & Mixed Hardwoods & 1960 & 40.04 & 174.63 & $19-48$ \\
\hline 34 & 2480 & 2680 & 8.84 & NW & 63 & Mixed Hardwoods & 1960 & 37.77 & 136.28 & $19-49$ \\
\hline 35 & 2500 & 2645 & 11.09 & w & 61 & Mixed Hardwoods & 1960 & 31.37 & 155.01 & $19-48$ \\
\hline 36 & 1840 & 2160 & 11.08 & SE & 68 & Mixed Hardwoods & 1960 & 46.77 & 152.97 & $19-44$ \\
\hline 37 & 1760 & 2160 & 12.58 & SE & 68 & Mixed Hardwoods & 1960 & 34.58 & 145.18 & $19-44$ \\
\hline 38 & 2360 & 2680 & 11.89 & $E$ & 63 & Mixed Hardwoods & 1960 & 41.20 & 149.85 & $20-45$ \\
\hline 43 & 2760 & 2980 & 11.05 & NW & 77 & Mixed Hardwoods & 1960 & 48.73 & 181.27 & $18-47$ \\
\hline
\end{tabular}

The minimum diameter for this dataset was $1.0 \mathrm{inch}$, while the maximum diameter was 27.3 inches. The minimum basal area per acre by plot and measurement period was $31.37 \mathrm{ft}^{2} / \mathrm{ac}$, while the maximum was $185.56 \mathrm{ft}^{2} / \mathrm{ac}$. Figure 3 provides basal area per acre distribution by plot by measurement year for all plots. 


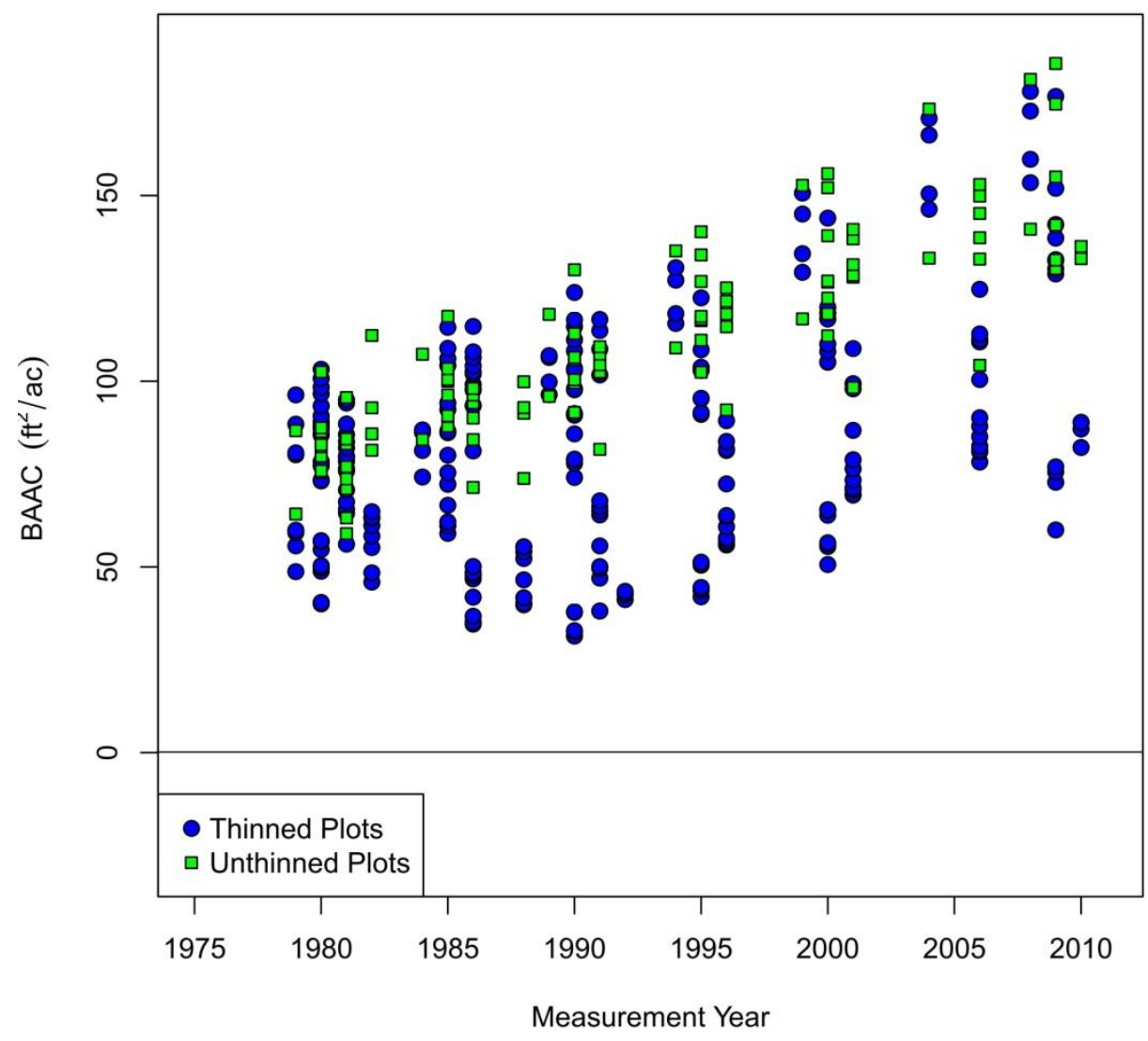

Figure 3. Basal area per acre by plot by measurement year for all plots.

The generalized stand table projection approach utilizes the tree list from each sample plot at a specific remeasurement period. Each tree list contained plot number, measurement date, tree number, species, diameter at breast height, trees per acre, basal area per acre, thinning intensity, and age at thinning. Thinning intensity was defined as the proportion of basal area removed during a thinning operation to the basal area present before the thinning. If the stand was not thinned, then the values for age at thinning and thinning intensity were assigned to zero.

\section{Species Group Construction}

The Fernow Experimental Forest dataset contained 35 species. Since some species did not constitute a large enough proportion of the data to foster accurate modeling, individual species were combined into 
species groups for analysis. The species groups were combined based on several criteria. First, species were combined based on inherent ecological, silvical, and basal area growth similarities. For example, it was assumed that red maple and sugar maple would be grouped into a "maple" group, while white oak and chestnut oak would constitute a "white oak" group. Noting the similarities between species, many such groups were formed. Secondly, species were combined based on initial parameter fitting. Initial parameter fitting was completed for both thinned and unthinned data separately for only non-overlapping growth interval data.

The groups were constructed by fitting the generalized stand table projection equation (Pienaar and Harrison, 1988) (Equation 3) to the data for each species:

$$
\left(\frac{b_{2_{i j}}}{\overline{b_{2_{i}}}}\right)=\left(\frac{b_{1_{i j}}}{\overline{b_{1_{i}}}}\right)^{\left(\frac{A_{2}}{A_{1}}\right)^{\left(\beta_{j}\right)}}
$$

Where:

$$
\begin{aligned}
& b_{1_{i j}}=\text { basal area per acre at age } 1 \text { for } i^{\text {th }} \text { plot } j^{\text {th }} \text { species, } \\
& \overline{b_{1_{i}}}=\text { average basal area per acre at age } 1 \text { for } i^{\text {th }} \text { plot, } \\
& b_{2_{i j}}=\text { basal area per acre at age } 2 \text { for } i^{\text {th }} \text { plot } j^{\text {th }} \text { species, } \\
& \overline{b_{2_{i}}}=\text { average basal area per acre at age } 2 \text { for } i^{\text {th }} \text { plot, } \\
& \beta_{j}=\text { single species parameter. }
\end{aligned}
$$


Once the above parameter was fit for all species, the aggregation of species into groups based on arithmetic evidence was explored. In order to discover whether the ecological similarities amongst species would inhibit or assist a more accurate parameter fit as a species group, parameters for all species were compared to parameters for all other species using a dummy variable approach as shown in Equation 4:

$$
\left(\frac{b_{2_{i j}}}{\overline{b_{2_{i}}}}\right)=\left(\frac{b_{1_{i j}}}{\overline{b_{1_{i}}}}\right)^{\left(\frac{A_{2}}{A}\right)^{\left(\beta_{j}+\alpha_{p}^{* x}\right)}}
$$

Where:

$$
\begin{aligned}
& \beta_{j}=\text { species specific constant }, \\
& \alpha_{p}=\text { additive parameter estimate }, \\
& x=\text { indicator variable: } x=\left\{\begin{array}{l}
1 \text { if } \mathrm{sp}=\mathrm{p} \\
0 \text { else }
\end{array}\right.
\end{aligned}
$$

The single-species parameter, previously fit for the target species, was employed as a constant $\left(\beta_{j}\right)$. Then, each additional species $(p)$ was compared to this constant $\left(\beta_{j}\right)$. All species were compared in each subsequent iteration until all species had been analyzed.

If the additive parameter was significant, then there was evidence that the two species did not have similar basal area growth patterns, and thus were not combined in a species group. If the additive parameter was not significant, then there was evidence that the two species compared had similarities in basal area growth patterns, and were combinable into a single species group. The initial ecological species groups 
were then adjusted to incorporate the results of these comparisons. Lastly, the parameter was fit by species group utilizing only non-overlapping data.

\section{Projection Lengths}

When projecting, a projection length was defined as the time from the first measurement or remeasurement (age 1) to the target remeasurement (age 2). For thinned data, all remeasurements prior to thinning were excluded. Two types of projection lengths were used: non-overlapping and overlapping. Non-overlapping projection lengths are the shortest length between remeasurements. Overlapping projection lengths start from the earliest remeasurement and project in ever-lengthening projections up until the final remeasurement. Figure 4 provides a graphical explanation of projection lengths.

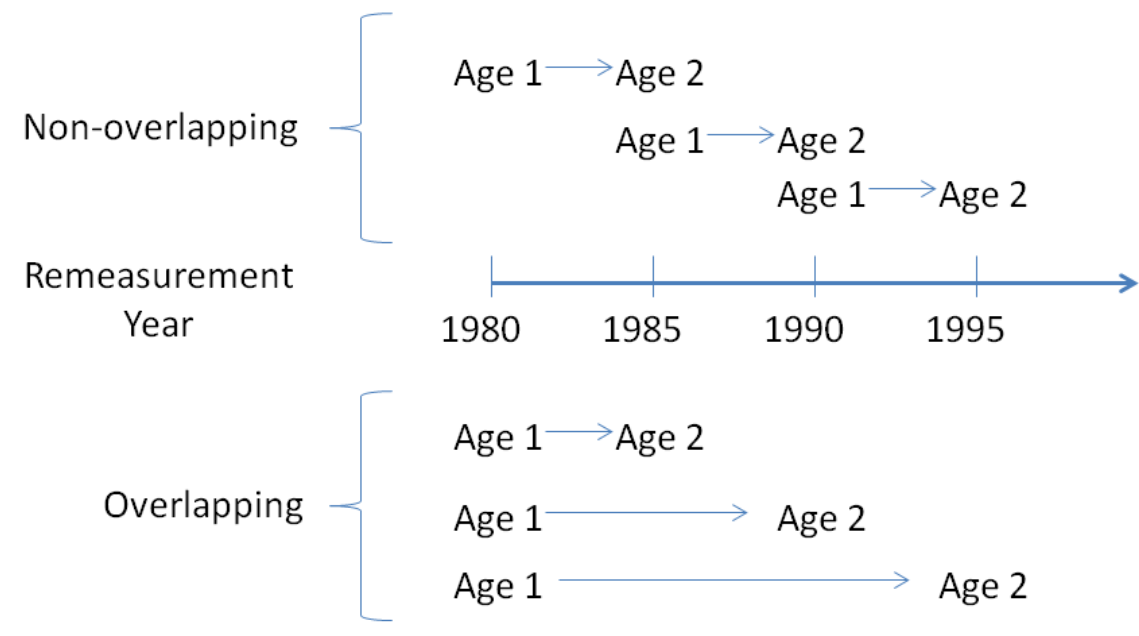

Figure 4. Illustration example of non-overlapping and overlapping projection lengths.

\section{Generalized Stand Table Projection}

The generalized stand table projection method was applied for each growth interval for each plot. The following explains the method for any given growth interval in any given plot from the beginning of the growth interval (age 1) to the end of the growth interval at age 2.

Several assumptions were made in the projection process: 
1. One inch diameter classes ranged from 0.4 inches below the midpoint to 0.5999 inches above the midpoint. For example, the 2 inch class would range from 1.6 inches to 2.5999 inches.

2. Mortality was based on observed data, not predicted by a mortality function.

The first step in the generalized stand table projection method is to calculate mortality for the growth interval. Since this project did not include the development of new survival models, the observed mortality during the growth interval was utilized. Individual tree numbers from the tree list were tracked from the first age of the interval to the second age of the interval. If the tree number did not appear at the end of the growth interval, then it was counted as mortality. Mortality basal area per acre and trees per acre were summed by diameter class within species group. Total basal area at age 2 was calculated by summing the observed basal area at age 2 for all species groups.

Observed mortality by species group and diameter class between ages 1 and 2 was applied at age 1 . Surviving trees per acre was defined as the existing trees per acre at age 1 less observed mortality for each species group and diameter class. Surviving basal area was defined as the basal area of the midpoint of the diameter class multiplied by the surviving trees per acre. The average basal area for the stand was calculated by dividing the sum of surviving trees per acre by the surviving basal area per acre.

Pienaar and Harrison's (1988) generalized stand table projection equation was modified to be used to project basal area for multi-species stands (Equation 5):

$$
\left(\frac{b_{2_{i j}}}{\overline{b_{2}}}\right)=\left(\frac{b_{1_{i j}}}{\overline{b_{1}}}\right)^{\left(\frac{A_{2}}{A_{1}}\right)^{\beta_{i}}}
$$

Where:

$$
b_{1_{i j}}=\text { basal area per acre at age } 1 \text { for } i^{\text {th }} \text { species group, } j^{\text {th }} \text { diameter class, }
$$




$$
\begin{aligned}
& \overline{b_{1}}=\text { average basal area per acre at age } 1, \\
& b_{2_{i j}}=\text { basal area per acre at age } 2 \text { for } i^{\text {th }} \text { species group, } j^{\text {th }} \text { diameter class, } \\
& \overline{b_{2}}=\text { average basal area per acre at age } 2, \\
& \beta_{i}=\text { species group parameter. }
\end{aligned}
$$

The projected basal area at age 2 could then be converted into a new diameter class midpoint for each original diameter class. In other words, through projecting the basal area of any given diameter class from age 1, the new implied diameter class midpoint can be determined from the new basal area for that original class at age 2 .

Since the projected projection diameter class midpoints do not necessarily match traditional 1-inch classes, new diameter class endpoints were established. The technique employed by Pienaar and Harrison (1988) was utilized in this study. The new diameter class limits were set based on half the distance between consecutive new diameter class midpoints, derived from the projection of the original basal area by diameter.

The new diameter classes next were partitioned back into traditional one- inch diameter classes with integer midpoints. The proportion of each new diameter class that fell within each one-inch class about the integer midpoint was multiplied by the surviving trees per acre for each corresponding diameter class midpoint at age 1 . In other words, the traditional one inch class may contain proportions of multiple new diameter classes. The proportions of those new classes that fell within the one inch classes previously defined were multiplied by the surviving trees per acre. If the traditional one inch class contained more than one of the new classes, the surviving trees per acre multiplied by the proportions falling in the new classes were summed to give total trees per acre for the traditional one inch class. Basal area for the one 
inch class was calculated by multiplying the trees per acre by the basal area for that the midpoint of that class. In this manner, a traditional one-inch diameter distribution was constructed for a species group within a plot.

\section{SILVAH Projections}

All growth intervals were projected using SILVAH (Marquis and Ernst, 1992 version 6). Individual species were entered into the program, then the output was summed into the species groups developed for this project and compared with the results from the generalized stand table projection. All species in the dataset were accounted for in SILVAH, except for American hornbeam (Carpinus caroliniana W.), which was assigned to the "other hardwoods" category.

\section{Testing}

\section{Dropped Projection Intervals}

Projection intervals in which the observed basal area was zero at age 2 were dropped for data analysis purposes by species group. Both generalized stand table projection and SILVAH projections were dropped in order to avoid undefined denominators when testing values based on the observed trees at age 2.

\section{Error Testing}

Projected diameter distributions were tested for accuracy against observed diameter distributions from the Fernow dataset. Projected basal area error for both SILVAH and the generalized stand table projection was analyzed by calculating bias (Equation 6) and the absolute bias for each species group within each projection length within each plot. Absolute bias is simply the absolute value of bias.

$$
B I A S=\sum_{d=d \min }^{d \max }\left(B A A C_{\text {Pred }_{d}}-B A A C_{\text {Obs }_{d}}\right)
$$

Where:

$d$ min $=$ minimum diameter class for species group within projection length and plot, 
$d \max =$ maximum diameter class for species group within projection length and plot,

$B A A C_{\text {Pred }}=$ Projected basal area at age 2,

$B A A C_{O b s}=$ Observed basal area at age 2.

Mean bias (Equation 7), mean absolute bias (Equation 8), root mean squared error (RMSE) (Equation 9), and variance of bias (Equation 10) were calculated at the species group level, across all plots and projection lengths to evaluate the accuracy by species group.

$$
\overline{B I A S}=\frac{\sum_{i=1}^{n} B I A S_{i}}{n}
$$

Where:

$$
\begin{aligned}
& \begin{array}{l}
B I A S_{i}=\text { Bias calculated for the } i^{\text {th }} \text { projection period within species group within plot for all } \\
\text { plots, }
\end{array} \\
& n=\text { Number of projection periods within plot for all plots for species group. }
\end{aligned}
$$

Mean absolute bias was defined as:

$$
|\overline{B I A S}|=\frac{\sum_{i=1}^{n}\left|B I A S_{i}\right|}{n}
$$

Where:

$|B I A S|_{i}=$ Absolute bias for the $i^{\text {th }}$ projection period within species group within plot for all plots, $n=$ number of projection periods within plot for all plots for species group.

RMSE was defined as: 


$$
R M S E=\sqrt{\frac{\sum_{i=1}^{n}\left(B I A S_{i}^{2}\right)}{n}}
$$

Where:

$B I A S_{i}=$ Bias calculated for the $i^{\text {th }}$ projection period within species group within plot for all plots,

$n=$ number of projection periods within plot for all plots for species group.

Prediction variance was defined as:

$$
s^{2}=\frac{\sum_{i=1}^{n}\left(B I A S_{i}-\overline{B I A S}\right)^{2}}{n-1}
$$

\section{Distribution Testing}

In addition to error testing, nonparametric distribution testing methods were utilized. The Kolmogorov-

Smirnov test, or "KS test", for cumulative distributions, first published by Massey (1951), was used to compare the observed distribution to the projected distributions at age 2. In this test, cumulative diameter distributions were established for each species group within each growth period on each plot for the proposed algorithm projections, SILVAH projections, and the observed data. If the maximum difference between the cumulative distributions was greater than the critical value (Equation 11), or if the maximum difference of the cumulative distributions skewed by one index was greater than the critical value, as described by Zar (1999), then it was 95 percent certain that the distributions were not similar.

$$
D_{\text {Crit }}=\sqrt{\frac{\left(-1 * \ln \left(\frac{\alpha}{2}\right)\right)}{2 n}}-\left(\frac{0.16693}{n}\right)
$$


Where:

$$
\begin{aligned}
& D_{\text {Crit }}=\text { Kolmogorov-Smirnov Test critical value, } \\
& n=\text { number of trees observed at age } 1, \\
& \alpha=\text { significance level. }
\end{aligned}
$$

Using a 95 percent confidence level, this test provided statistical evidence for similarity or dissimilarity between the observed and the proposed algorithm projections and between observed and SILVAH projections. Similarity indicates that both cumulative distribution functions originated from the same underlying distribution.

\section{Chapter 4. Results}

\section{Species Groups}

Ten species groups were formed based on ecological and statistical similarities of basal area growth. While the initial parameter fitting process was applied to both thinned and unthinned data, the species groups remained the same for both datasets. Two species were placed in their own single-species groups; northern red oak and black cherry (Prunus serotina Ehrh.). These two species constituted a large enough proportion of the data and commercial importance to justify a separate group for each species. Table 2 lists the species groups determined using Equations 3 and 4. 
Table 2. Fernow dataset species group definitions.

\begin{tabular}{|c|c|c|c|c|}
\hline \multicolumn{5}{|c|}{ Species Group } \\
\hline 1. Northern red oak & 2. Maple & 3. White oak & 4. Hickory/Ash & 5. Yellow-poplar \\
\hline \multirow[t]{7}{*}{ Quercus rubra $\mathrm{L}$. } & Acer saccharum Marsh. & Quercus alba L. & Juglans cinerea $\mathrm{L}$. & Liriodendron tulipifera $\mathrm{L}$. \\
\hline & Acer rubrum L. & Quercus montana Willd. & Carya ovata Mill. & Tilia americana $\mathrm{L}$. \\
\hline & & & Carya cordiformis Wangenh. & Magnolia acuminata L. \\
\hline & & & Carya glabra Mill. & Platanus occidentalis L. \\
\hline & & & Fraxinus americana $\mathrm{L}$. & \\
\hline & & & Ulmus rubra Muhl. & \\
\hline & & & Juglans nigra L. & \\
\hline 6. Striped maple/Pin cherry & 7. Black cherry & 8. Other & 9. Scarlet and Black oaks & 10. Birch \\
\hline Acer pensylvanicum L. & Prunus serotina Ehrh. & Oxydendrum arboreum L. & Quercus coccinea Muenchh. & Betula lenta $\mathrm{L}$. \\
\hline \multirow{9}{*}{$\begin{array}{l}\text { Prunus pensylvania L.f. } \\
\text { Magnolia fraseri Walter }\end{array}$} & & Sassafras albidum Nutt. & Quercus velutina Lam. & Betula alleghaniensis Britton \\
\hline & & Nyssa sylvatica Marsh. & & \\
\hline & & Cornus florida $\mathrm{L}$. & & \\
\hline & & Amelanchier arborea Michx. f. & & \\
\hline & & Ostrya virginiana Mill. & & \\
\hline & & Carpinus caroliniana Walter & & \\
\hline & & Fagus grandifolia Ehrh. & & \\
\hline & & Robinia pseudoacacia L. & & \\
\hline & & Tsuga canadensis $\mathrm{L}$. & & \\
\hline
\end{tabular}

\section{Unthinned Species Groups}

Model parameters for all unthinned species groups were significant at the $\mathrm{p}<0.0001$ level. Species group 9 was not present in the unthinned dataset. Table 3 provides parameter estimates and fit statistics for unthinned species groups parameters.

Table 3. Unthinned species groups parameter estimates and fit statistics.

\begin{tabular}{|c|c|c|c|c|}
\hline Species Group & B Estimate & $\underline{\text { MSE }}$ & $\underline{\text { p-Value }}$ & $\underline{\mathbf{n}}$ \\
\hline $\mathbf{1}$ & -1.604 & 68.26 & $<0.0001$ & 511 \\
\hline $\mathbf{2}$ & -0.6959 & 82.65 & $<0.0001$ & 942 \\
\hline $\mathbf{3}$ & -0.7898 & 137.40 & $<0.0001$ & 222 \\
\hline $\mathbf{4}$ & -0.7786 & 58.30 & $<0.0001$ & 396 \\
\hline $\mathbf{5}$ & -0.6723 & 266.90 & $<0.0001$ & 765 \\
\hline $\mathbf{6}$ & -0.9334 & 83.21 & $<0.0001$ & 243 \\
\hline $\mathbf{7}$ & -0.9568 & 283.20 & $<0.0001$ & 444 \\
\hline $\mathbf{8}$ & -0.6869 & 80.09 & $<0.0001$ & 753 \\
\hline $\mathbf{9}$ & \multicolumn{5}{|c|}{ Not Represented } \\
\hline $\mathbf{1 0}$ & -0.4478 & 52.96 & $<0.0001$ & 511 \\
\hline
\end{tabular}

Figures 5 and 6 show relative basal area prediction error at age 2 for species groups with the lowest (species group 4 - hickory/ash) and highest mean squared error (species group 7 - black cherry), 
respectively from the unthinned data. All other unthinned parameter prediction error plots are provided in Appendix B, Figures 41-47.

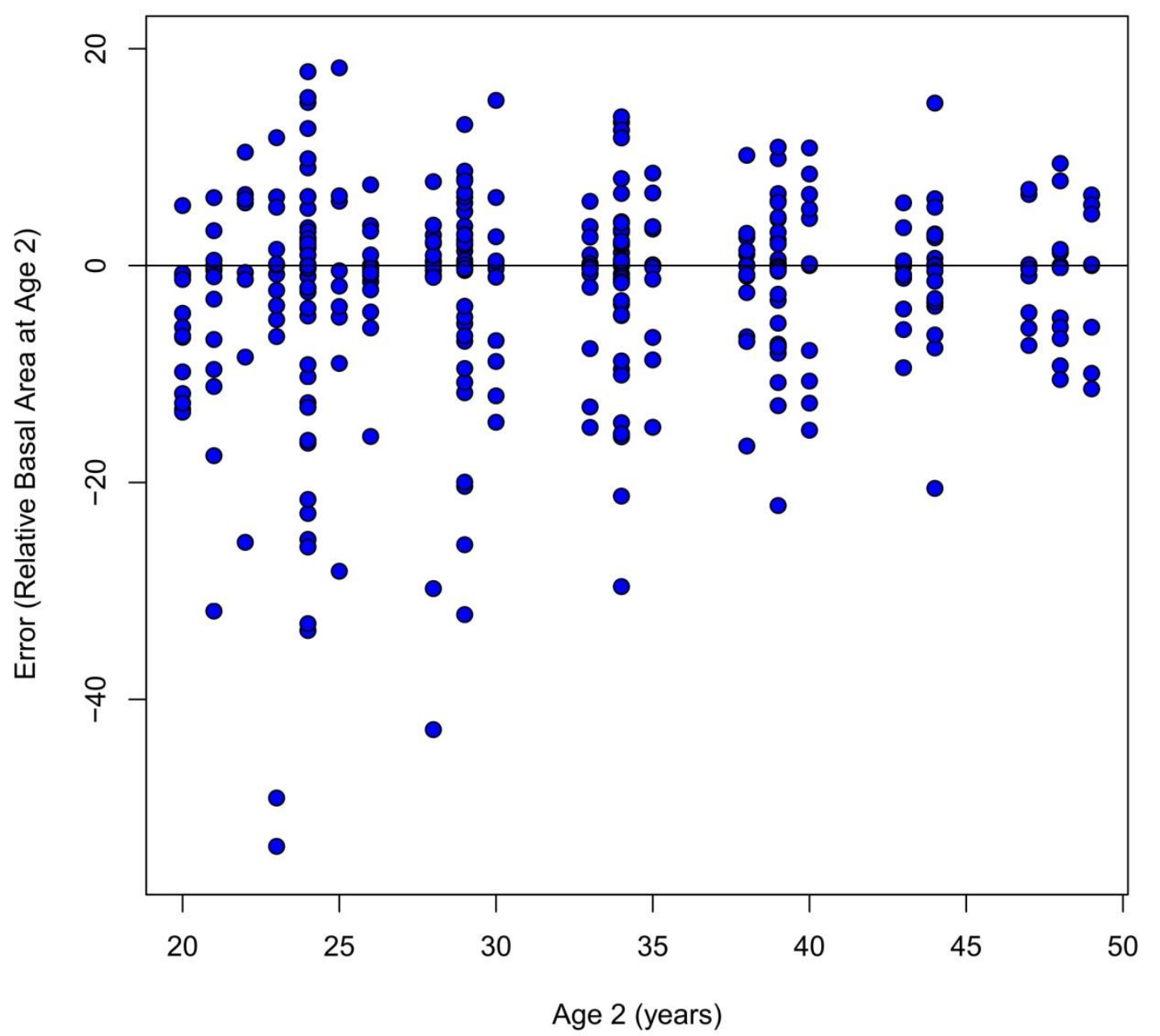

Figure 5. Species group 4 (hickory/ash) relative basal area prediction error at age 2 for unthinned data. 


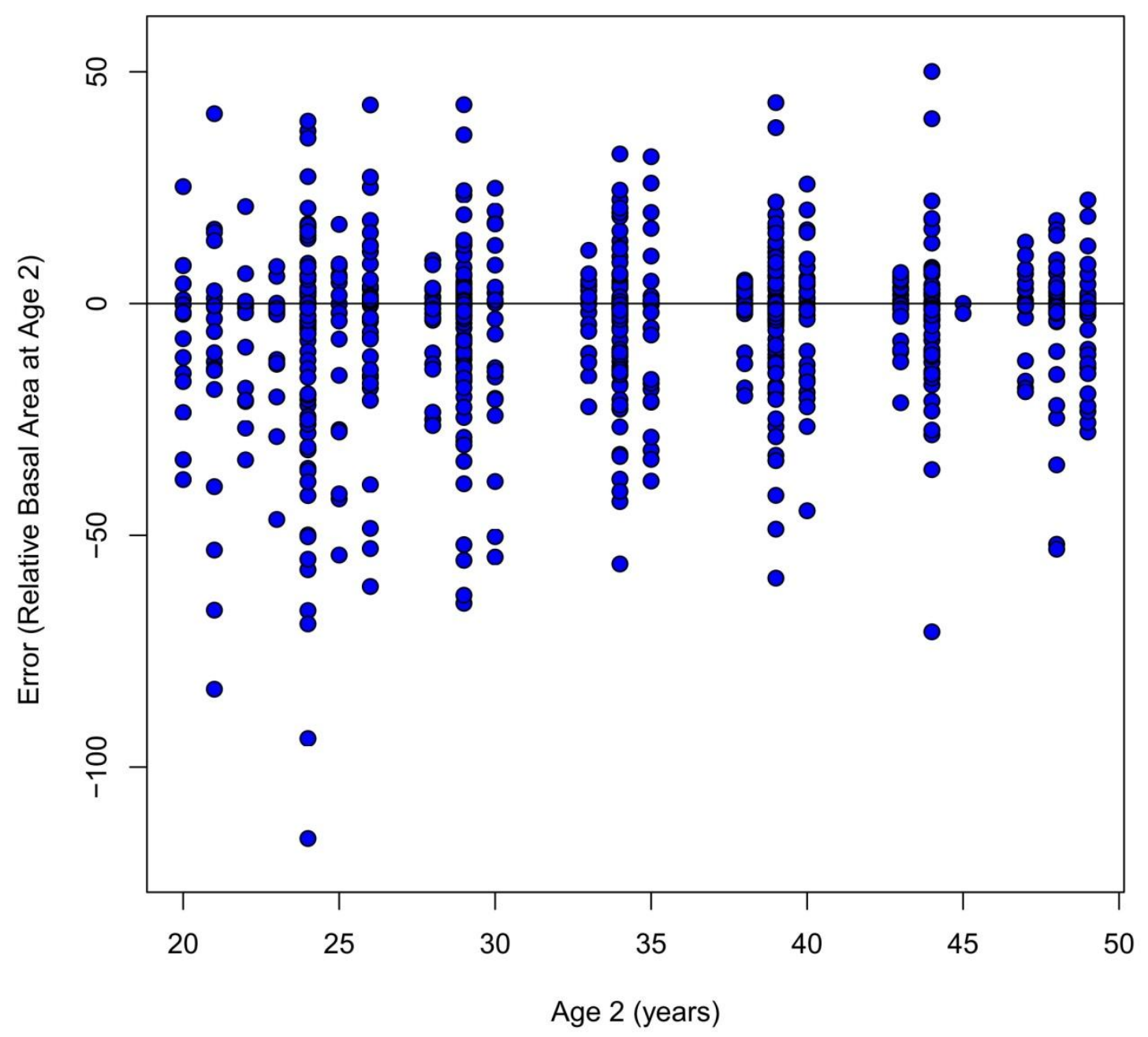

Figure 6. Species group 7 (black cherry) relative basal area prediction error at age 2 for unthinned data.

\section{Thinned Species Groups}

All thinned species group parameters were significant at the $\mathrm{p} \leq 0.0001$ level. The black and scarlet oaks group had the least amount of data of all species groups, but was still significant at the $p=0.0001$ confidence level. Table 4 provides parameter estimates and fit statistics for thinned parameters. 
Table 4. Thinned species groups parameter estimates and fit statistics.

\begin{tabular}{|c|c|c|c|c|}
\hline Species Group & B Estimate & $\underline{\text { MSE }}$ & $\underline{\text { p-Value }}$ & $\underline{\mathbf{n}}$ \\
\hline $\mathbf{1}$ & -2.0248 & 22.50 & $<0.0001$ & 1226 \\
\hline $\mathbf{2}$ & -1.0371 & 85.34 & $<0.0001$ & 1766 \\
\hline $\mathbf{3}$ & -1.6161 & 27.87 & $<0.0001$ & 540 \\
\hline $\mathbf{4}$ & -1.2657 & 13.33 & $<0.0001$ & 694 \\
\hline $\mathbf{5}$ & -0.6989 & 225.50 & $<0.0001$ & 1470 \\
\hline $\mathbf{6}$ & -0.7287 & 37.73 & $<0.0001$ & 299 \\
\hline $\mathbf{7}$ & -0.6180 & 110.20 & $<0.0001$ & 1155 \\
\hline $\mathbf{8}$ & -0.5714 & 56.41 & $<0.0001$ & 1099 \\
\hline $\mathbf{9}$ & -6.1590 & 6.74 & 0.0001 & 52 \\
\hline $\mathbf{1 0}$ & -0.6483 & 52.06 & $<0.0001$ & 808 \\
\hline
\end{tabular}

Figures 7 and 8 show relative basal area prediction error at age 2 for species groups with the lowest (species group 9 - black and scarlet oaks) and highest mean squared error (species group 5 - yellowpoplar), respectively from the thinned data. All other thinned parameter prediction error plots are provided in Appendix B, Figures 48-55. 


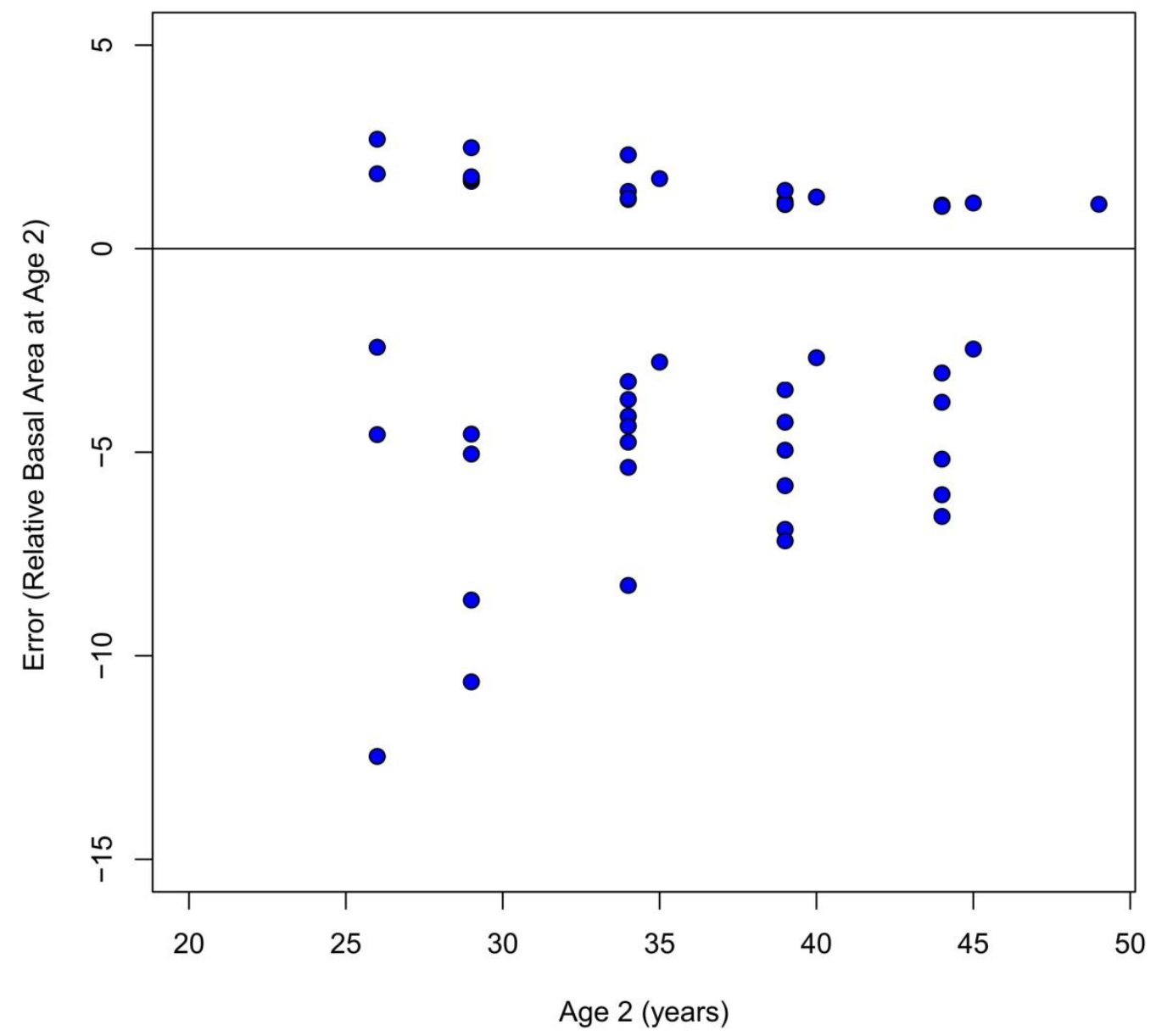

Figure 7. Species group 9 (black and scarlet oaks) relative basal area prediction error at age 2 for thinned data. 


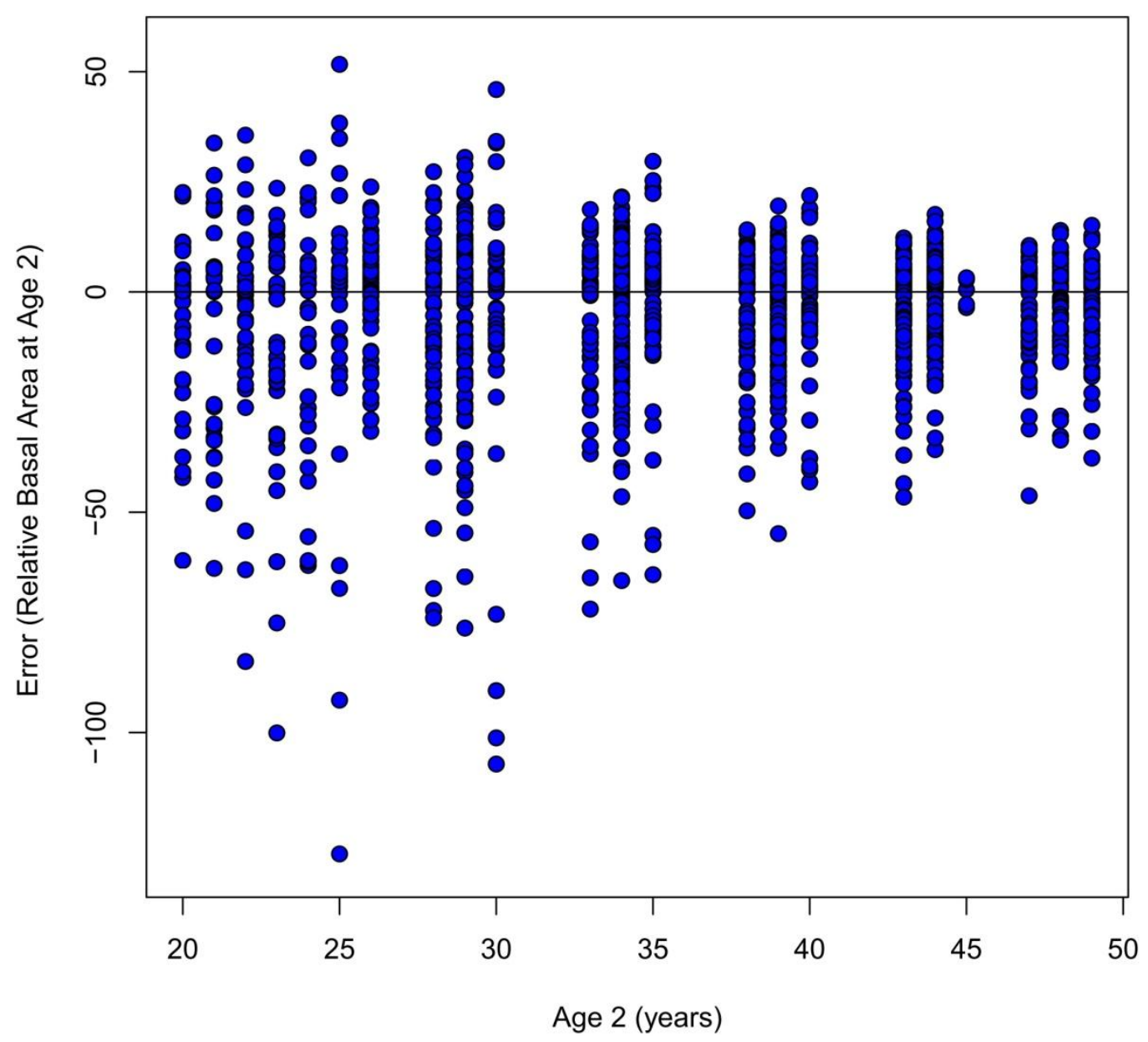

Figure 8. Species group 5 (yellow-poplar) relative basal area prediction error at age 2 for thinned data.

\section{Projections}

\section{Unthinned Non-overlapping Projections}

\section{Plot Level}

Generalized stand table projection basal area results and SILVAH basal area results were compared with observed basal area at age 2.When compared across all species groups and diameter classes, the generalized stand table projection method produced a more accurate basal area projection. Generalized 
stand table projection basal area projections had a smaller root mean squared error, a smaller average absolute bias, and less variance than the SILVAH basal area projections. Table 5 provides summary statistics at the plot level.

Table 5. Unthinned non-overlapping plot level summary statistics.

\begin{tabular}{|c|c|c|}
\hline & GSTP & SILVAH \\
\hline $\bar{n}$ & \multicolumn{2}{|c|}{92} \\
\hline RMSE ( $\left.\mathrm{ft}^{2} / \mathrm{ac}\right)$ & 2.784 & 6.872 \\
\hline Avg Abs Bias ( $\mathrm{ft}^{2} / \mathrm{ac}$ ) & -3.653 & 33.692 \\
\hline Avg Bias ( $\left.\mathrm{ft}^{2} / \mathrm{ac}\right)$ & 28.857 & 367.703 \\
\hline Var Bias $\left(\mathrm{ft}^{2} / \mathrm{ac}\right)^{2}$ & 53.195 & 1192.799 \\
\hline
\end{tabular}

Figures 9 and 10 show that the generalized stand table projection method error was almost exclusively within $10 \mathrm{ft} .{ }^{2} / \mathrm{ac}$. of observed basal area per acre and is slightly negatively skewed. 


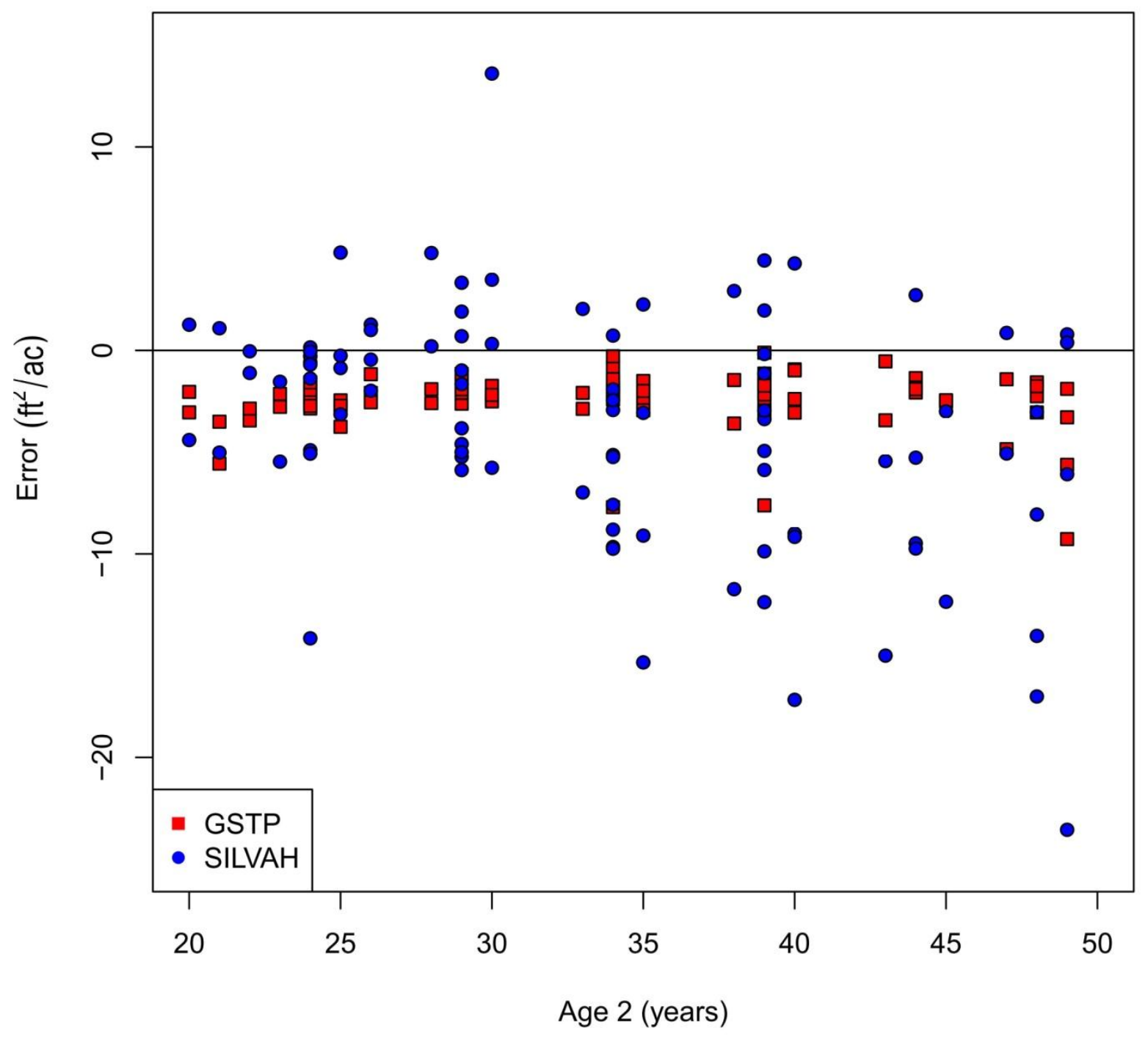

Figure 9. Unthinned non-overlapping plot level projection errors by projection age (age 2). 


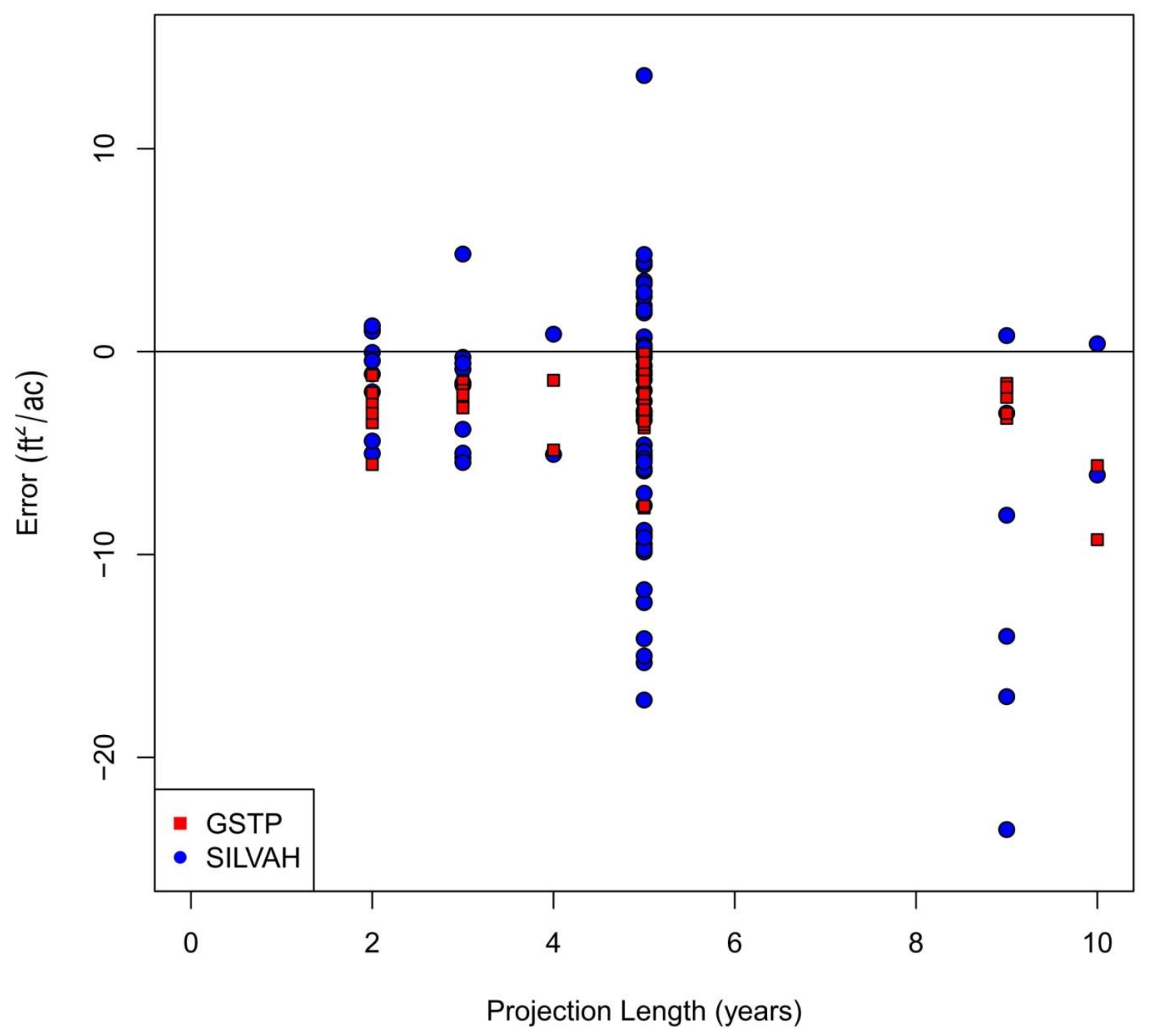

Figure 10. Unthinned non-overlapping plot level projection errors by projection length.

Figures 11 and 12 show that the basal area projection error for the generalized stand table projection method was within \pm 5 percent of total basal area per acre, while SILVAH projection error was within \pm 10 percent total basal area per acre, when summed across all species groups and diameter classes within a plot. 


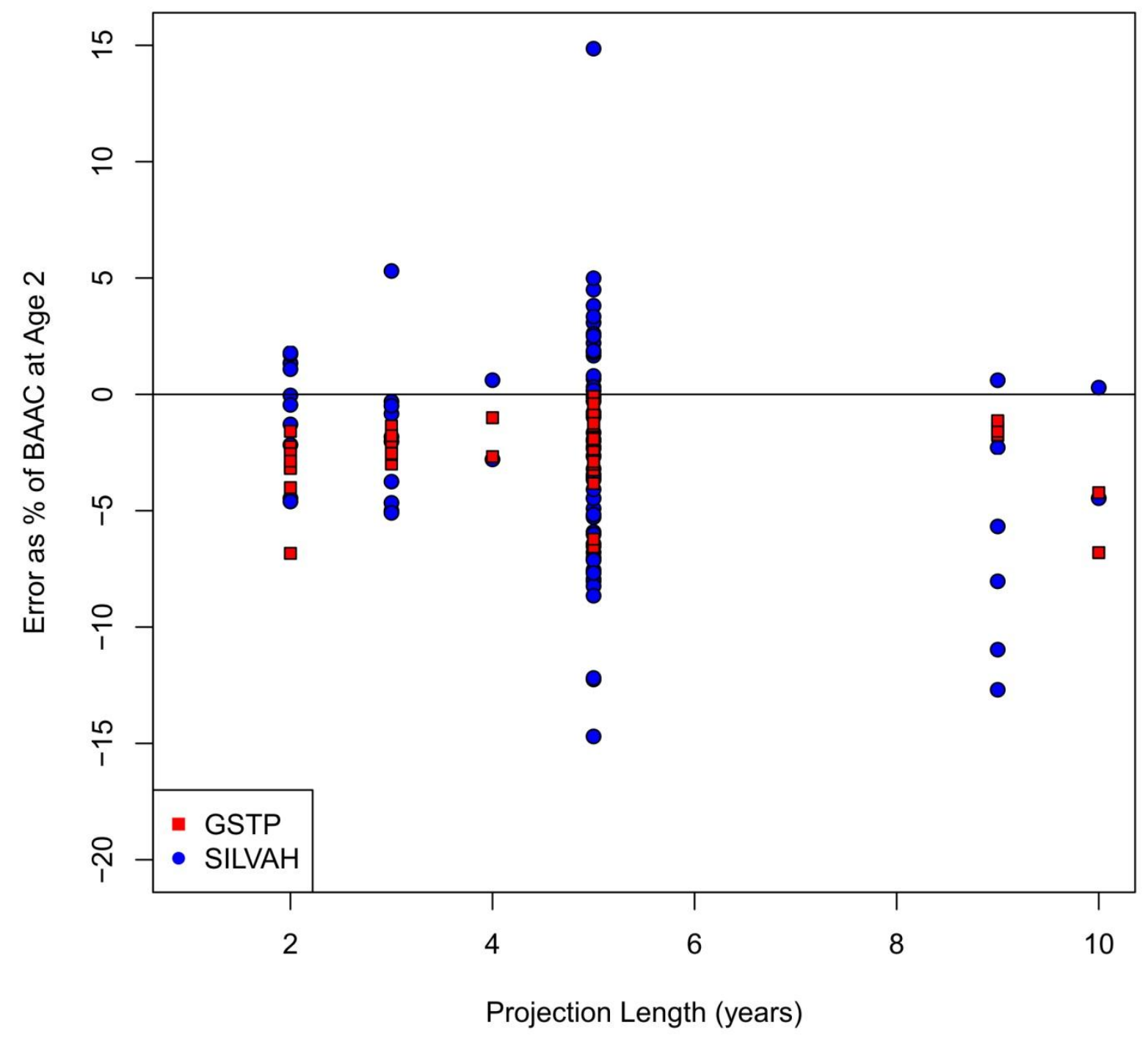

Figure 11. Unthinned non-overlapping plot level projection error as a percent of total observed BAAC by projection length. 


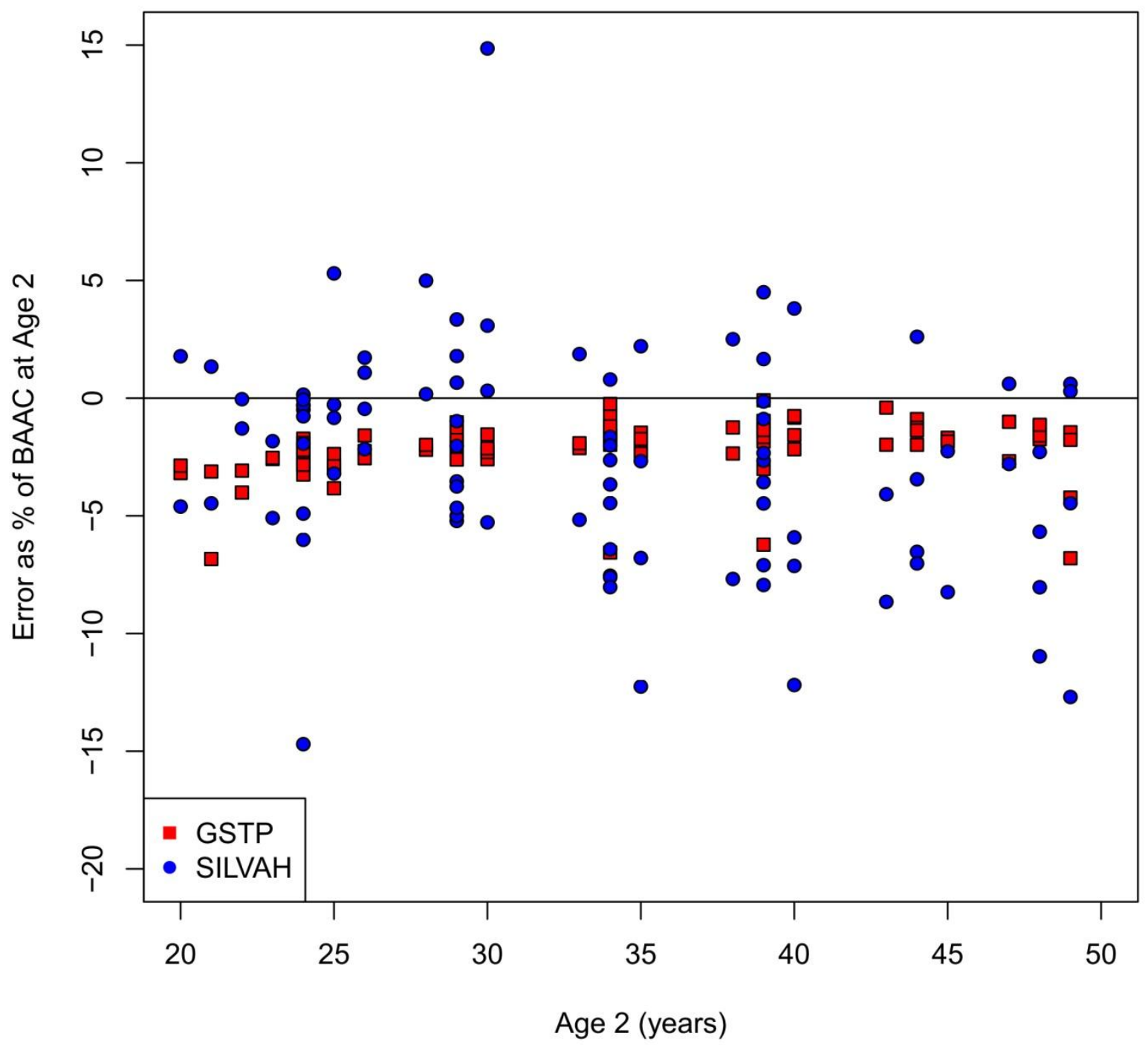

Figure 12. Unthinned non-overlapping plot level projection error as a percent of total observed BAAC at age 2.

\section{Species Group 1 - Northern red oak}

SILVAH produced a smaller root mean squared error, a smaller average absolute bias, and smaller variance of bias, while having a larger proportion of similar distributions to observed distributions at the 95 percent level. Table 6 provides summary statistics for species group 1. 
Table 6. Summary statistics for species group 1 in unthinned non-overlapping projections.

\begin{tabular}{|c|c|c|}
\hline & GSTP & $\underline{\text { SILVAH }}$ \\
\hline $\mathrm{n}$ & \multicolumn{2}{|c|}{83} \\
\hline RMSE ( $\mathrm{ft}^{2} / \mathrm{ac}$ ) & 2.083 & 1.786 \\
\hline Avg Abs Bias ( $\mathrm{ft}^{2} / \mathrm{ac}$ ) & 8.223 & 7.139 \\
\hline Avg Bias ( $\mathrm{ft}^{2} / \mathrm{ac}$ ) & -1.002 & -0.648 \\
\hline Var Bias $\left(\mathrm{ft}^{2} / \mathrm{ac}\right)^{2}$ & 3.374 & 2.804 \\
\hline \%K-S Similar & $65.1 \%$ & $71.8 \%$ \\
\hline
\end{tabular}

\section{Species Group 2 - Maple}

The generalized stand table projection errors were similar to the SILVAH projections for species group 2. SILVAH produced a smaller root mean squared error, average absolute bias and variance of bias, while having a larger proportion of similar distributions to observed distributions at the 95 percent level based on the KS test. However, the error values and significant distributions were not much improved over generalized stand table projection results. Table 7 provides summary statistics for species group 2 .

Table 7. Summary statistics for species group 2 in unthinned non-overlapping projections.

\begin{tabular}{|c|c|c|}
\hline & GSTP & $\underline{\text { SILVAH }}$ \\
\hline $\mathrm{n}$ & \multicolumn{2}{|c|}{92} \\
\hline RMSE ( $\mathrm{ft}^{2} / \mathrm{ac}$ ) & 2.116 & 1.966 \\
\hline Avg Abs Bias ( $\mathrm{ft}^{2} / \mathrm{ac}$ ) & 13.404 & 11.381 \\
\hline Avg Bias ( $\mathrm{ft}^{2} / \mathrm{ac}$ ) & 0.750 & -0.632 \\
\hline Var Bias $\left(\mathrm{ft}^{2} / \mathrm{ac}\right)^{2}$ & 3.956 & 3.505 \\
\hline \%K-S Similar & $70.7 \%$ & $75.0 \%$ \\
\hline
\end{tabular}

\section{Species Group 3 - White oak}

The generalized stand table projection errors were similar to the SILVAH projections for species group 3. The generalized stand table projection procedure produced a smaller root mean squared error and variance of bias. SILVAH projections produced a smaller average absolute bias and a larger proportion of similar distributions to observed distributions at the 95 percent level based on the results of the KS test. Table 8 provides summary statistics for species group 3. 
Table 8. Summary statistics for species group 3 in unthinned non-overlapping projections.

\begin{tabular}{|c|c|c|}
\hline & GSTP & $\underline{\text { SILVAH }}$ \\
\hline $\mathrm{n}$ & \multicolumn{2}{|c|}{36} \\
\hline RMSE ( $\mathrm{ft}^{2} / \mathrm{ac}$ ) & 1.235 & 1.307 \\
\hline Avg Abs Bias ( $\mathrm{ft}^{2} / \mathrm{ac}$ ) & 9.008 & 7.406 \\
\hline Avg Bias ( $\mathrm{ft}^{2} / \mathrm{ac}$ ) & -0.745 & -0.479 \\
\hline Var Bias $\left(\mathrm{ft}^{2} / \mathrm{ac}\right)^{2}$ & 0.997 & 1.521 \\
\hline \%K-S Similar & $75.0 \%$ & $77.8 \%$ \\
\hline
\end{tabular}

\section{Species Group 4 - Hickory/Ash}

The generalized stand table projection procedure produced a smaller root mean squared error, smaller variance of bias, and a larger proportion of similar distributions to observed distributions at the 95 percent level based on the results of the KS test. SILVAH projections produced a smaller average absolute bias. Table 9 provides summary statistics for species group 4.

Table 9. Summary statistics for species group 4 in unthinned non-overlapping projections.

\begin{tabular}{|c|c|c|}
\hline & GSTP & SILVAH \\
\hline $\bar{n}$ & \multicolumn{2}{|c|}{62} \\
\hline RMSE ( $\left.\mathrm{ft}^{2} / \mathrm{ac}\right)$ & 0.862 & 1.246 \\
\hline Avg Abs Bias ( $\left.\mathrm{ft}^{2} / \mathrm{ac}\right)$ & 6.268 & 5.519 \\
\hline Avg Bias ( $\left.\mathrm{ft}^{2} / \mathrm{ac}\right)$ & 0.277 & 0.055 \\
\hline Var Bias $\left(\mathrm{ft}^{2} / \mathrm{ac}\right)^{2}$ & 0.678 & 1.574 \\
\hline \%K-S Similar & $66.1 \%$ & $56.5 \%$ \\
\hline
\end{tabular}

\section{Species Group 5 - Yellow-poplar}

The generalized stand table projection procedure produced a smaller root mean squared error and variance of bias. SILVAH projections produced a smaller average absolute bias and a larger proportion of similar distributions to observed distributions at the 95 percent level based on the results of the KS test. Table 10 provides summary statistics for species group 5. 
Table 10. Summary statistics for species group 5 in unthinned non-overlapping projections.

\begin{tabular}{|c|c|c|}
\hline & GSTP & $\underline{\text { SILVAH }}$ \\
\hline $\mathrm{n}$ & \multicolumn{2}{|c|}{87} \\
\hline RMSE ( $\mathrm{ft}^{2} / \mathrm{ac}$ ) & 3.643 & 4.010 \\
\hline Avg Abs Bias ( $\mathrm{ft}^{2} / \mathrm{ac}$ ) & 17.813 & 15.595 \\
\hline Avg Bias ( $\mathrm{ft}^{2} / \mathrm{ac}$ ) & -2.455 & -2.422 \\
\hline Var Bias $\left(\mathrm{ft}^{2} / \mathrm{ac}\right)^{2}$ & 7.327 & 10.330 \\
\hline \%K-S Similar & $47.1 \%$ & $51.7 \%$ \\
\hline
\end{tabular}

\section{Species Group 6 - Striped maple/Pin cherry}

The generalized stand table projection procedure produced a smaller root mean squared error and variance of bias while SILVAH projections produced a smaller average absolute bias and a larger proportion of similar distributions to observed distributions at the 95 percent level based on the results of the KS test. Table 11 provides summary statistics for species group 6 .

Table 11. Summary statistics for species group 6 in unthinned non-overlapping projections.

\begin{tabular}{|c|c|c|}
\hline & GSTP & $\underline{\text { SILVAH }}$ \\
\hline $\bar{n}$ & \multicolumn{2}{|c|}{52} \\
\hline RMSE ( $\left.\mathrm{ft}^{2} / \mathrm{ac}\right)$ & 0.791 & 1.193 \\
\hline Avg Abs Bias ( $\left.\mathrm{ft}^{2} / \mathrm{ac}\right)$ & 4.680 & 3.944 \\
\hline Avg Bias ( $\left.\mathrm{ft}^{2} / \mathrm{ac}\right)$ & -0.036 & 0.132 \\
\hline Var Bias $\left(\mathrm{ft}^{2} / \mathrm{ac}\right)^{2}$ & 0.637 & 1.434 \\
\hline \%K-S Similar & $78.8 \%$ & $84.6 \%$ \\
\hline
\end{tabular}

\section{Species Group 7 - Black cherry}

The generalized stand table projection procedure produced a larger root mean squared error, larger average absolute bias, and larger variance of bias. SILVAH projections produced a larger proportion of similar distributions to observed distributions at the 95 percent level based on the results of the KS test. Table 12 provides summary statistics for species group 7 . 
Table 12. Summary statistics for species group 7 in unthinned non-overlapping projections.

\begin{tabular}{|c|c|c|}
\hline & GSTP & SILVAH \\
\hline$n$ & \multicolumn{2}{|c|}{57} \\
\hline RMSE (ft ${ }^{2} / \mathrm{ac}$ ) & 3.152 & 2.702 \\
\hline Avg Abs Bias ( $\left.\mathrm{ft}^{2} / \mathrm{ac}\right)$ & 15.078 & 12.409 \\
\hline Avg Bias ( $\left.\mathrm{ft}^{2} / \mathrm{ac}\right)$ & -2.045 & -1.598 \\
\hline Var Bias $\left(\mathrm{ft}^{2} / \mathrm{ac}\right)^{2}$ & 5.854 & 4.831 \\
\hline \%K-S Similar & $43.9 \%$ & $56.1 \%$ \\
\hline
\end{tabular}

\section{Species Group 8 - Other}

The generalized stand table projection procedure produced a smaller root mean squared error, variance of bias, and a larger proportion of similar distributions to observed distributions at the 95 percent level based on the results of the KS test. SILVAH projections produced a smaller average absolute bias. Table 13 provides summary statistics for species group 8.

Table 13. Summary statistics for species group 8 in unthinned non-overlapping projections.

\begin{tabular}{|c|c|c|}
\hline & GSTP & SILVAH \\
\hline $\mathbf{n}$ & \multicolumn{2}{|c|}{92} \\
\hline RMSE ( $\mathrm{ft}^{2} / \mathrm{ac}$ ) & 1.597 & 1.959 \\
\hline Avg Abs Bias ( $\mathrm{ft}^{2} / \mathrm{ac}$ ) & 10.120 & 8.441 \\
\hline Avg Bias ( $\left.\mathrm{ft}^{2} / \mathrm{ac}\right)$ & 1.081 & 0.639 \\
\hline Var Bias $\left(\mathrm{ft}^{2} / \mathrm{ac}\right)^{2}$ & 1.399 & 3.468 \\
\hline \%K-S Similar & $77.2 \%$ & $56.5 \%$ \\
\hline
\end{tabular}

\section{Species Group 10 - Birch}

The generalized stand table projection procedure had a smaller root mean squared error, variance of bias, and a larger proportion of similar distributions to observed distributions at the 95 percent level based on the results of the KS test. SILVAH projections produced a smaller average absolute bias. Table 14 provides summary statistics for species group 10. 
Table 14. Summary statistics for species group 10 in unthinned non-overlapping projections.

\begin{tabular}{|c|c|c|}
\hline & GSTP & $\underline{\text { SILVAH }}$ \\
\hline $\mathrm{n}$ & \multicolumn{2}{|c|}{92} \\
\hline RMSE ( $\mathrm{ft}^{2} / \mathrm{ac}$ ) & 0.869 & 2.053 \\
\hline Avg Abs Bias ( $\mathrm{ft}^{2} / \mathrm{ac}$ ) & 4.682 & 4.221 \\
\hline Avg Bias ( $\mathrm{ft}^{2} / \mathrm{ac}$ ) & 0.387 & 0.033 \\
\hline Var Bias $\left(\mathrm{ft}^{2} / \mathrm{ac}\right)^{2}$ & 0.611 & 4.260 \\
\hline \%K-S Similar & $78.3 \%$ & $67.4 \%$ \\
\hline
\end{tabular}

\section{Unthinned Non-overlapping Summary}

The generalized stand table projection procedure produced a combination of smaller errors, smaller variance, or a larger proportion of significant distributions in a manner that would suggest performance as good as or better than SILVAH for species groups 2 (maples), 3 (white oaks), 4 (hickory/ash), 8 (other), and 10 (birches) and on plot level summaries for unthinned plots with non-overlapping projections. While SILVAH produced smaller errors on species groups 1 (northern red oak), 5 (yellow-poplar), 6 (striped maple/pin cherry), and 7 (black cherry), the differences in errors were not large. Figures 13 and 14 show the projection errors for the species group with lowest generalized stand table projection root mean squared error (species group 6 - striped maple/pin cherry) for unthinned non-overlapping projections. Figures 15 and 16 show projection error for the species group with highest generalized stand table projection root mean squared (species group 5 - yellow poplar) error for unthinned non-overlapping projections. The remaining projection error plots may be found in Appendix C, Figures 56-69. 


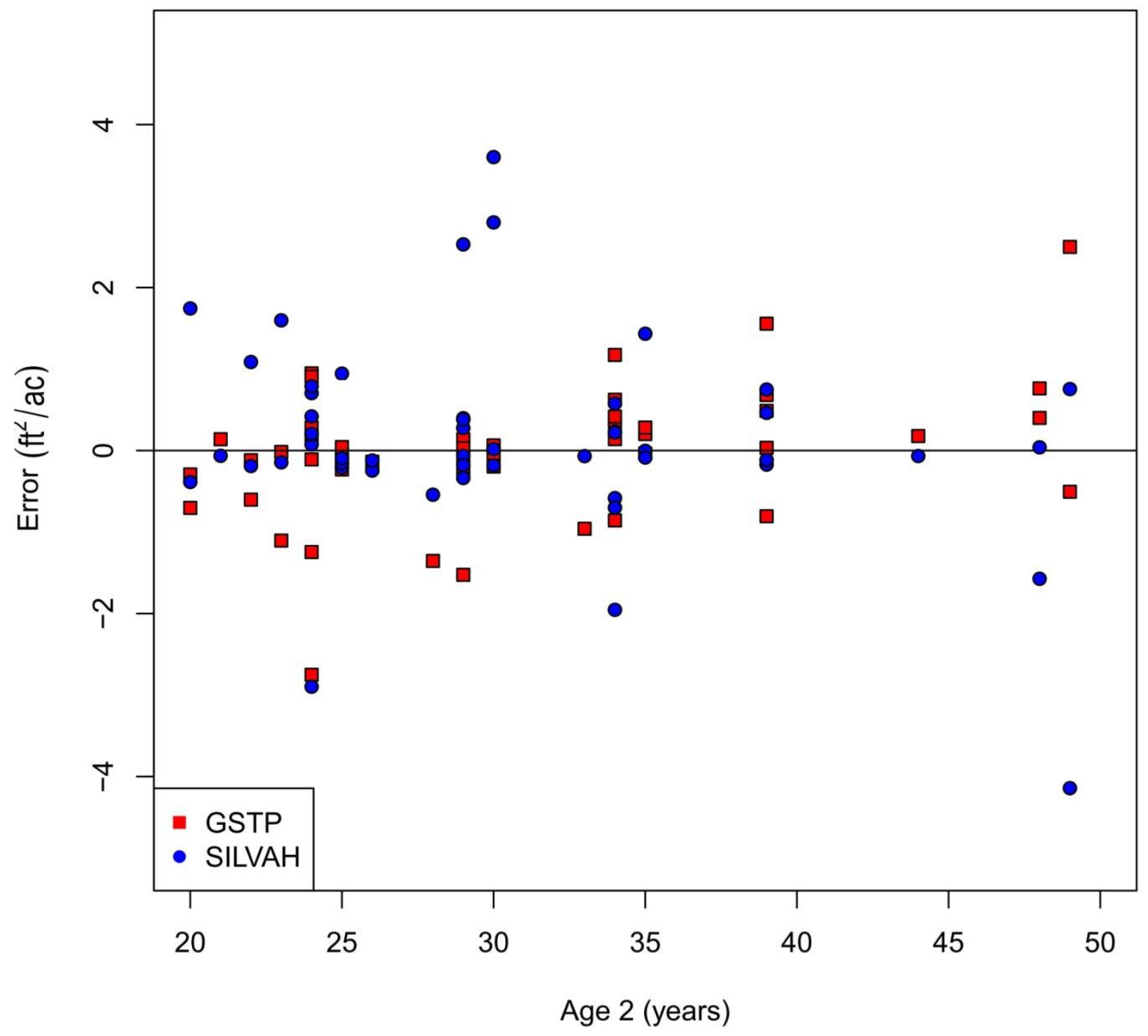

Figure 13. Species group 6 (striped maple/pin cherry) projection errors by projection age (age 2) for unthinned non-overlapping projections. 


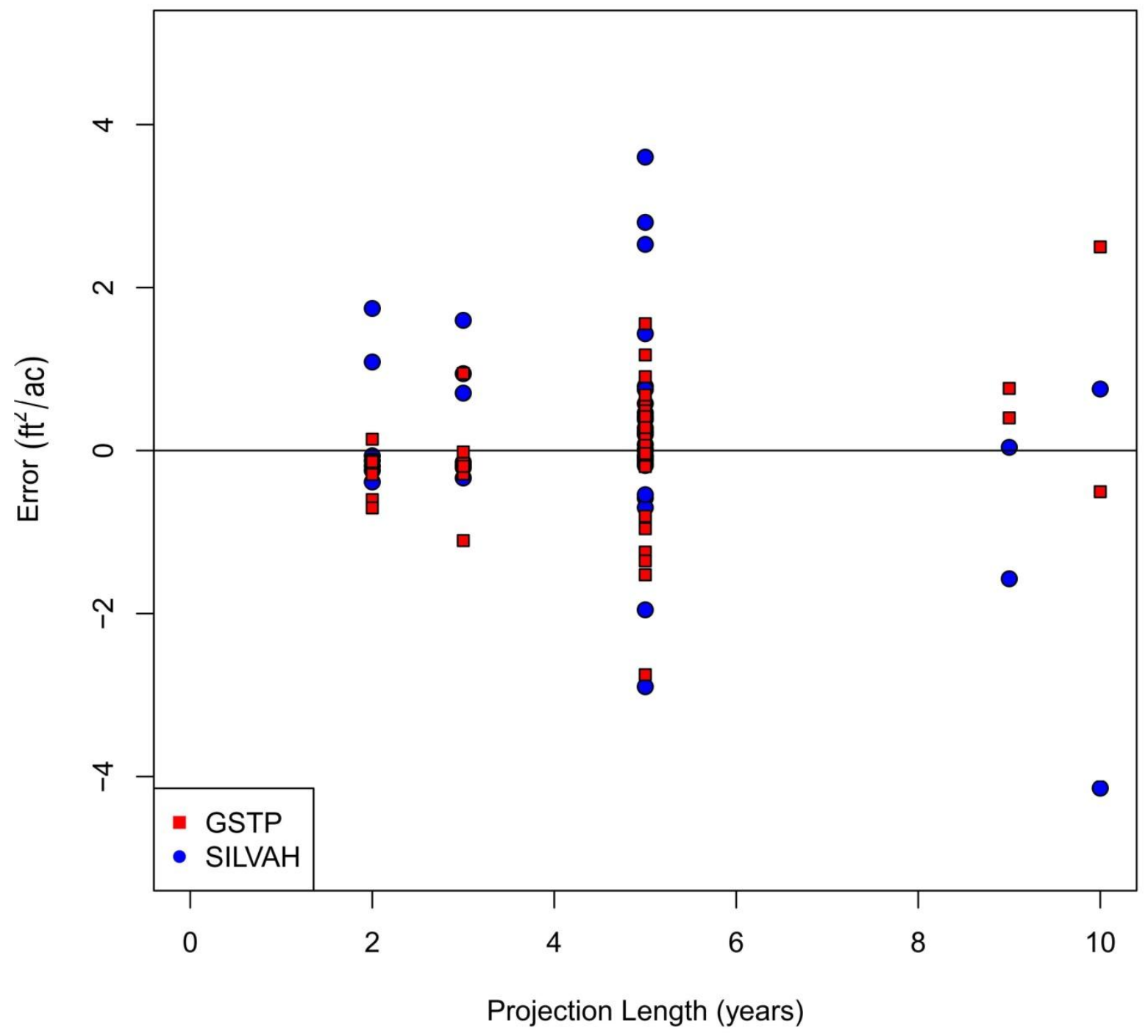

Figure 14. Species group 6 (striped maple/pin cherry) projection errors by projection length for unthinned non-overlapping projections. 


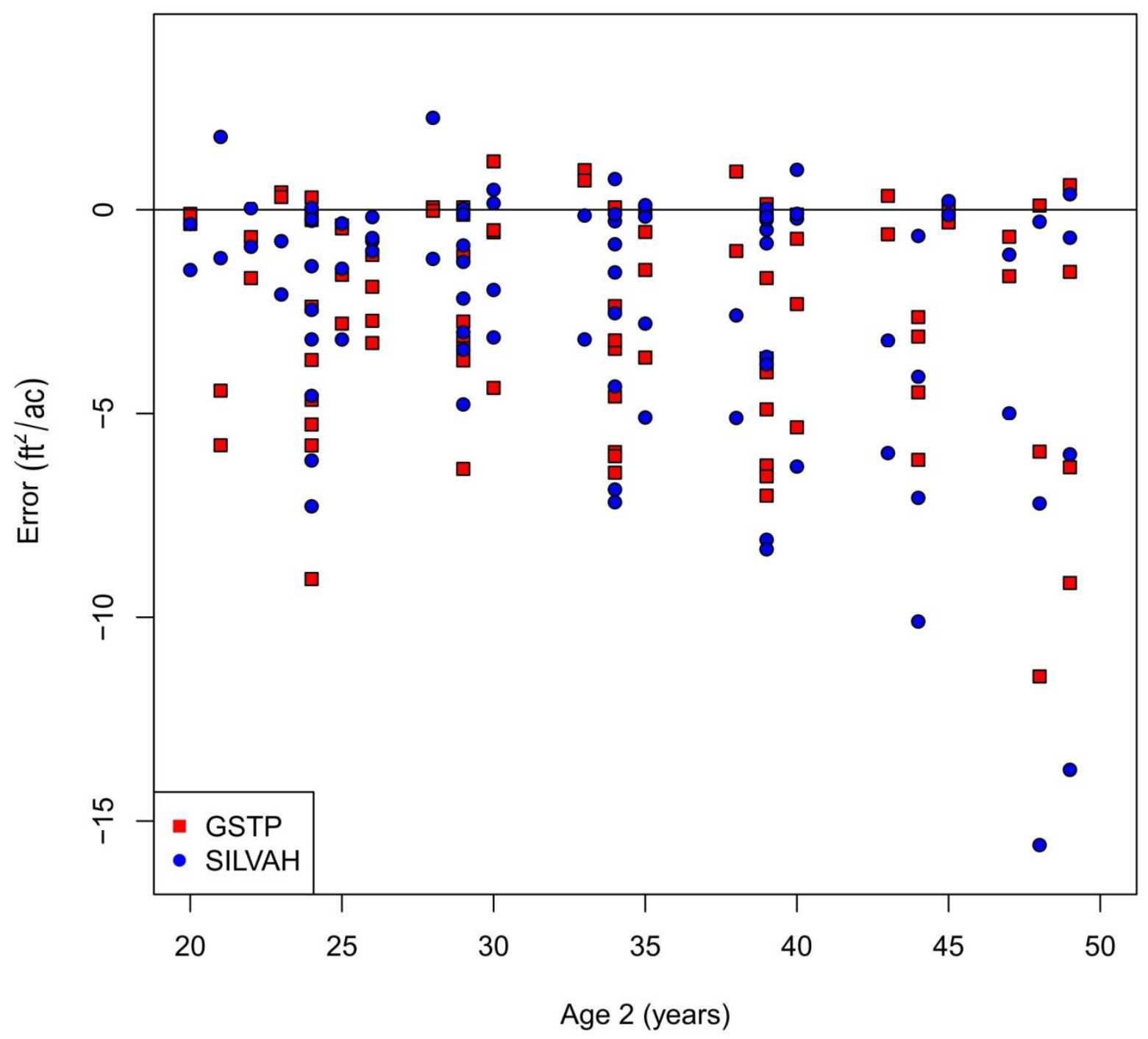

Figure 15. Species group 5 (yellow-poplar) projection errors by projection age (age 2) for unthinned non-overlapping projections. 


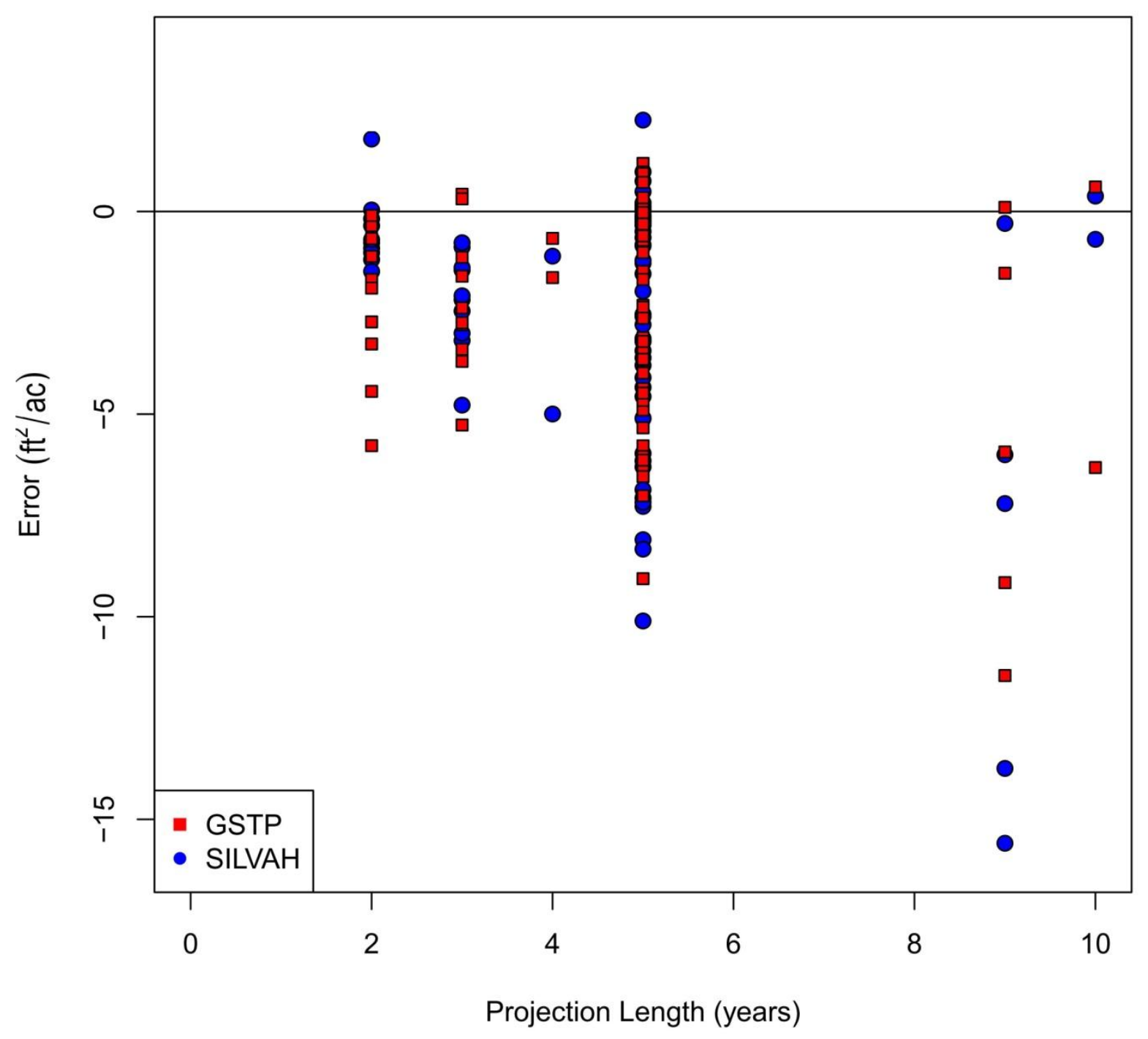

Figure 16. Species group 5 (yellow-poplar) projection errors by projection length for unthinned non-overlapping projections.

\section{Unthinned Overlapping Projections}

\section{Plot Level}

At the plot level (across all species groups and diameter classes), the generalized stand table projection method produced a more accurate basal area projection when compared to observed values. The basal area projections for the generalized stand table projection method had a smaller root mean squared error 
and less variance of bias than the basal area projections using SILVAH. Table 15 provides these summary statistics at the plot level.

Table 15. Unthinned overlapping plot level summary statistics.

\begin{tabular}{|c|c|c|}
\hline & GSTP & SILVAH \\
\hline $\mathbf{n}$ & \multicolumn{2}{|c|}{92} \\
\hline RMSE & 4.255 & 13.658 \\
\hline Avg Abs Bias & 116.545 & 132.122 \\
\hline Avg Bias & 91.452 & -4.022 \\
\hline Var Bias & 1.946 & 141.420 \\
\hline
\end{tabular}

Figures 17 and 18 show that the generalized stand table projection method error at the plot level was almost exclusively within $10 \mathrm{ft} .2 / \mathrm{ac}$ of observed total basal area per acre and was slightly negatively skewed. 


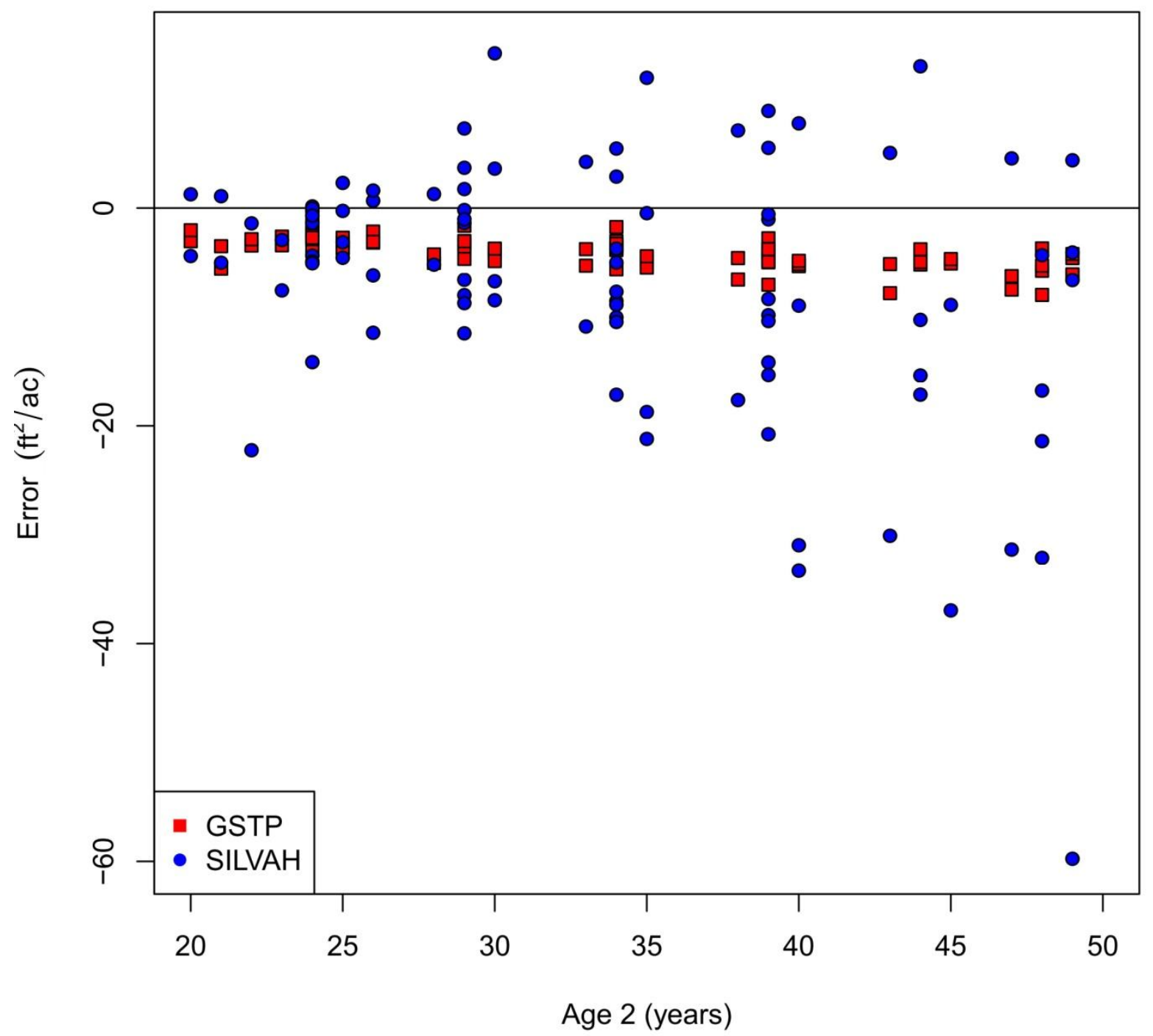

Figure 17. Unthinned overlapping plot level projection error by projection age (age 2). 


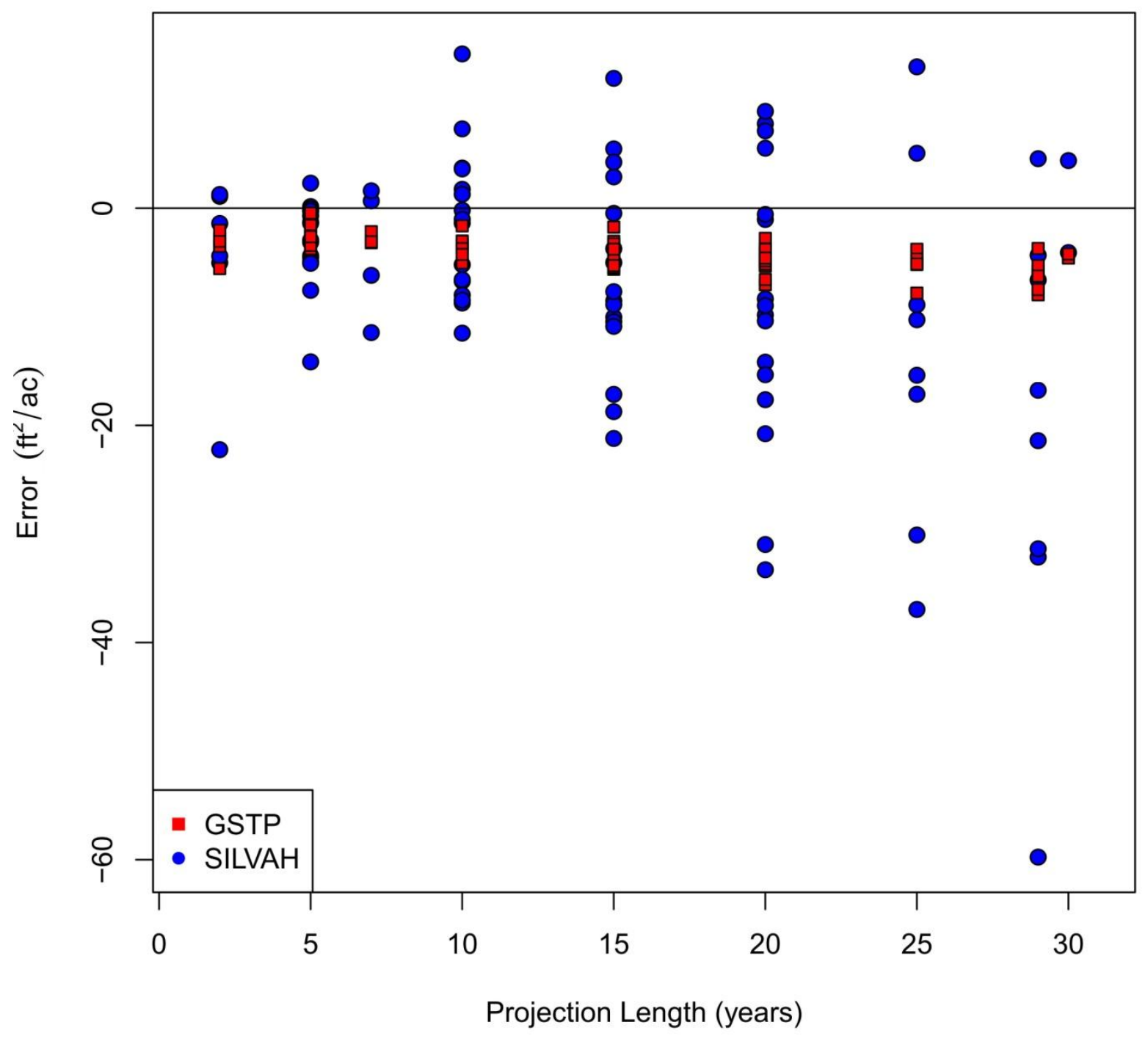

Figure 18. Unthinned overlapping plot level projection error by projection length.

Figures 19 and 20 show that the basal area projection error for the generalized stand table projection method was within \pm 10 percent of total basal area per acre, while SILVAH projection error was within \pm 20 percent, when summed across all species groups and diameter classes at the plot level. 


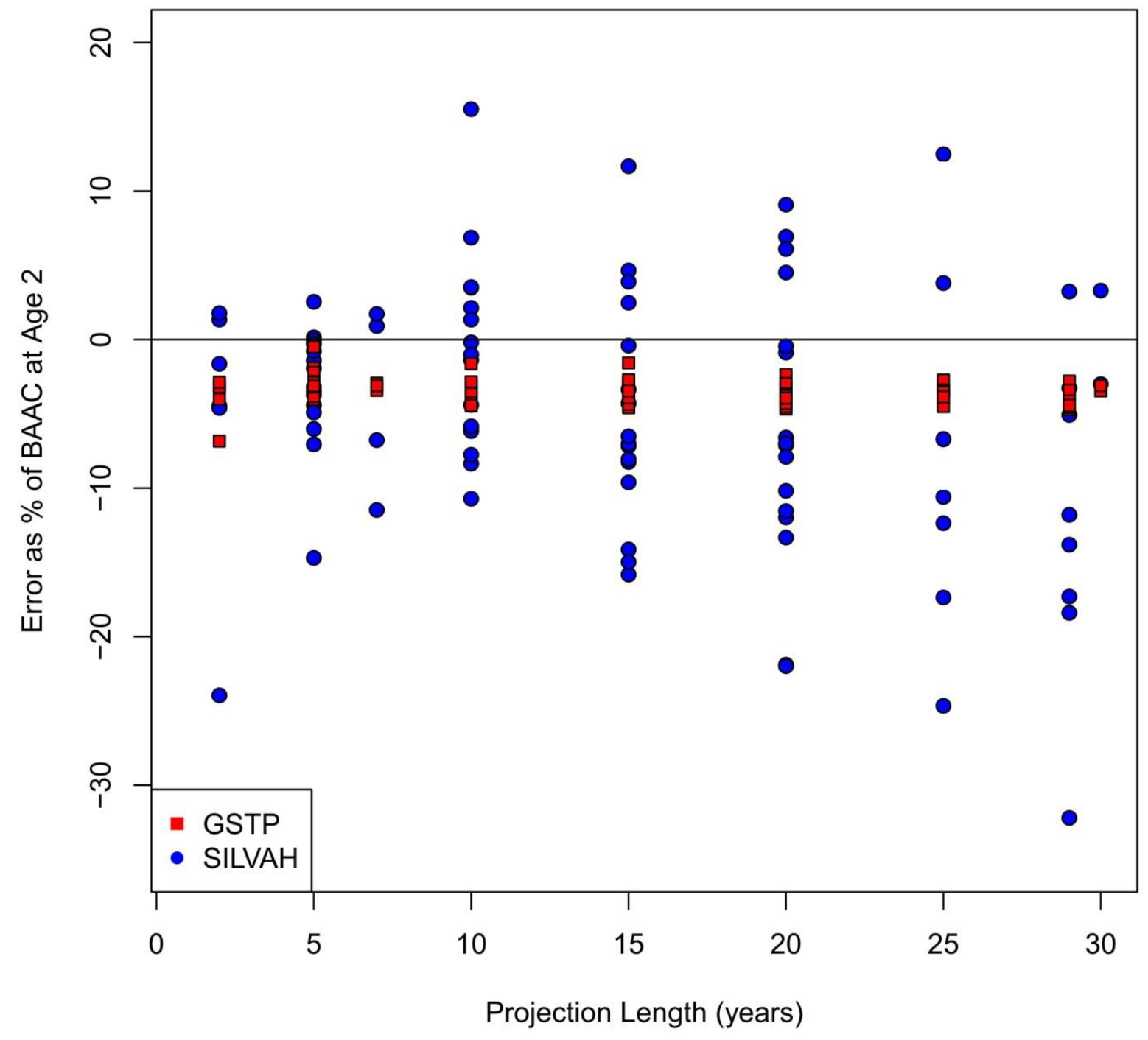

Figure 19. Unthinned overlapping plot level projection error as a percent of total basal area per acre at age 2 by projection length. 


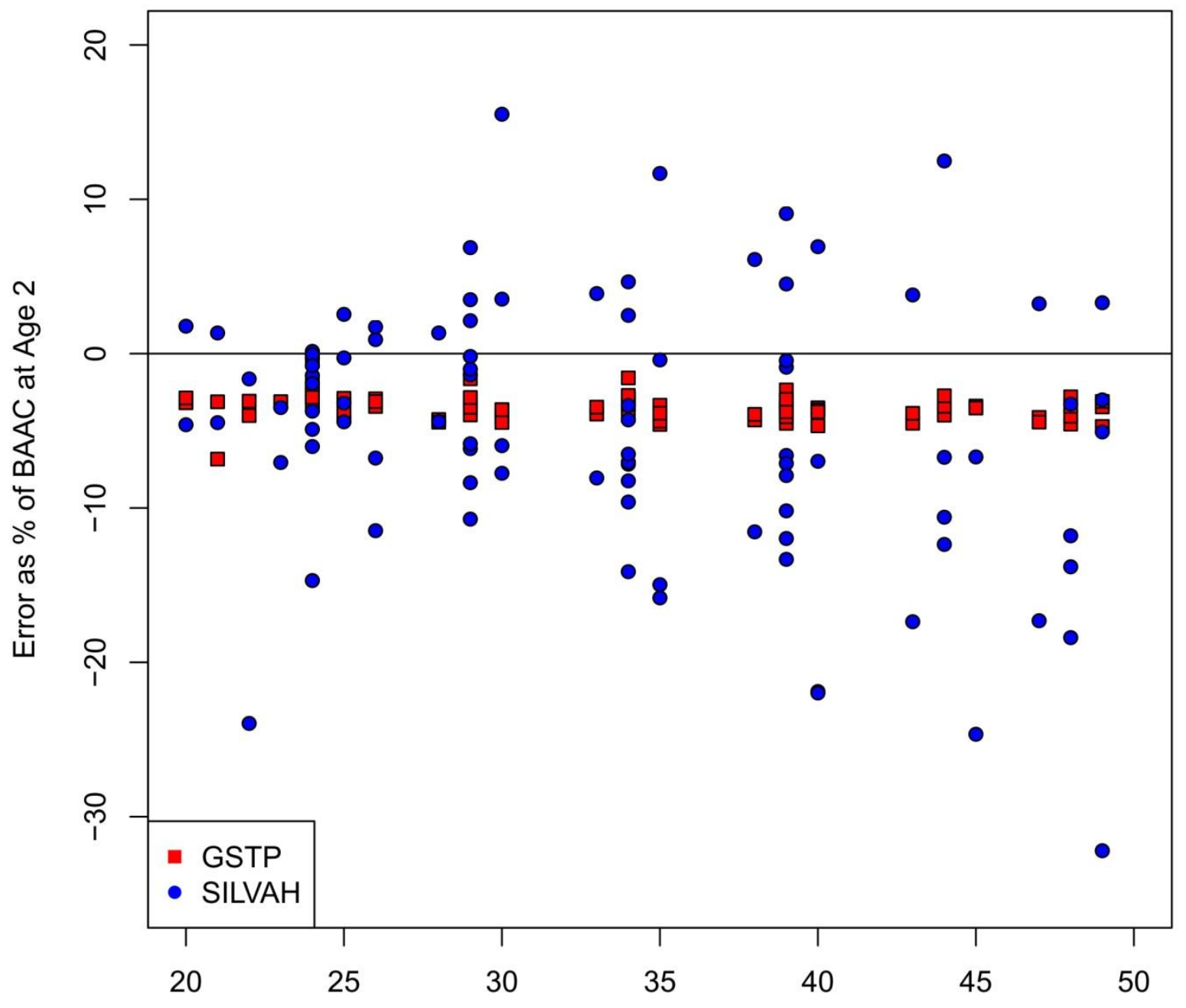

Age 2 (years)

Figure 20. Unthinned overlapping plot level projection error as a percent of total basal area per acre at age 2 by age 2 .

\section{Species Group 1 - Northern red oak}

The generalized stand table projection procedure produced smaller root mean squared error and smaller variance of bias. SILVAH produced smaller average absolute bias and had a larger proportion of similar distributions at the 95 percent level based on the results of the KS test. Table 16 provides summary statistics for species group 1. 
Table 16. Summary statistics for species group 1 in unthinned overlapping projections.

\begin{tabular}{|c|c|c|}
\hline & GSTP & SILVAH \\
\hline $\mathbf{n}$ & \multicolumn{2}{|c|}{83} \\
\hline RMSE & 4.732 & 5.530 \\
\hline Avg Abs Bias & 13.385 & 10.074 \\
\hline Avg Bias & -0.615 & -1.681 \\
\hline Var Bias & 22.282 & 28.090 \\
\hline \%K-S Similar & $44.6 \%$ & $60.9 \%$ \\
\hline
\end{tabular}

\section{Species Group 2 - Maple}

SILVAH produced a smaller root mean squared error, smaller average absolute bias, and smaller variance of bias, while having a larger proportion of similar distributions to observed distributions at the 95 percent level based on the results of the KS test. Table 17 provides summary statistics for species group 2.

Table 17. Summary statistics for species group 2 in unthinned overlapping projections.

\begin{tabular}{|c|c|c|}
\hline & GSTP & $\underline{\text { SILVAH }}$ \\
\hline $\mathbf{n}$ & \multicolumn{2}{|c|}{92} \\
\hline RMSE (ft²/ac) & 6.989 & 4.558 \\
\hline Avg Abs Bias ( $\left.\mathrm{ft}^{2} / \mathrm{ac}\right)$ & 23.014 & 15.217 \\
\hline Avg Bias ( $\left.\mathrm{ft}^{2} / \mathrm{ac}\right)$ & -0.078 & -1.430 \\
\hline Var Bias $\left(\mathrm{ft}^{2} / \mathrm{ac}\right)^{2}$ & 49.375 & 18.936 \\
\hline \%K-S Similar & $9.8 \%$ & $50.0 \%$ \\
\hline
\end{tabular}

\section{Species Group 3 - White oak}

SILVAH projections produced a smaller average absolute bias, smaller root mean squared error, smaller variance of bias, and a larger proportion of similar distributions to observed distributions at the 95 percent level, based on the results of the KS test. Table 18 provides summary statistics for species group 3 . 
Table 18. Summary statistics for species group 3 in unthinned overlapping projections.

\begin{tabular}{|c|c|c|}
\hline & GSTP & $\underline{\text { SILVAH }}$ \\
\hline $\mathbf{n}$ & \multicolumn{2}{|c|}{36} \\
\hline RMSE (ft $\left.{ }^{2} / \mathrm{ac}\right)$ & 5.008 & 2.929 \\
\hline Avg Abs Bias ( $\left.\mathrm{ft}^{2} / \mathrm{ac}\right)$ & 15.315 & 11.817 \\
\hline Avg Bias ( $\left.\mathrm{ft}^{2} / \mathrm{ac}\right)$ & -3.071 & -0.943 \\
\hline Var Bias $\left(\mathrm{ft}^{2} / \mathrm{ac}\right)^{2}$ & 16.098 & 7.911 \\
\hline \%K-S Similar & $43.2 \%$ & $70.3 \%$ \\
\hline
\end{tabular}

\section{Species Group 4 - Hickory/Ash}

SILVAH projections produced a smaller root mean squared error, smaller variance of bias, smaller average absolute bias, and a larger proportion of similar distributions to observed distributions at the 95 percent level, based on the results of the KS test. Table 19 provides summary statistics for species group 4.

Table 19. Summary statistics for species group 4 in unthinned overlapping projections.

\begin{tabular}{|c|c|c|}
\hline & GSTP & SILVAH \\
\hline $\mathbf{n}$ & \multicolumn{2}{|c|}{62} \\
\hline RMSE (ft $\left.{ }^{2} / \mathrm{ac}\right)$ & 7.108 & 3.739 \\
\hline Avg Abs Bias (ft ${ }^{2} / \mathrm{ac}$ ) & 13.971 & 8.036 \\
\hline Avg Bias ( $\mathrm{ft}^{2} / \mathrm{ac}$ ) & 2.556 & 0.378 \\
\hline Var Bias $\left(\mathrm{ft}^{2} / \mathrm{ac}\right)^{2}$ & 44.716 & 14.061 \\
\hline \%K-S Similar & $25.8 \%$ & $41.9 \%$ \\
\hline
\end{tabular}

\section{Species Group 5 - Yellow-poplar}

SILVAH projections produced a smaller average absolute bias, smaller root mean squared error, smaller variance of bias, and a larger proportion of similar distributions to observed distributions at the 95 percent level, based on the results of the KS test. Table 20 provides summary statistics for species group 5 . 
Table 20. Summary statistics for species group 5 in unthinned overlapping projections.

\begin{tabular}{|c|c|c|}
\hline & GSTP & SILVAH \\
\hline $\mathbf{n}$ & \multicolumn{2}{|c|}{87} \\
\hline RMSE ( $\mathrm{ft}^{2} / \mathrm{ac}$ ) & 16.365 & 10.085 \\
\hline Avg Abs Bias ( $\mathrm{ft}^{2} / \mathrm{ac}$ ) & 31.982 & 22.555 \\
\hline Avg Bias ( $\left.\mathrm{ft}^{2} / \mathrm{ac}\right)$ & -9.534 & -6.522 \\
\hline $\operatorname{Var}$ Bias $\left(\mathrm{ft}^{2} / \mathrm{ac}\right)^{2}$ & 178.998 & 59.844 \\
\hline \%K-S Similar & $25.3 \%$ & $32.2 \%$ \\
\hline
\end{tabular}

\section{Species Group 6 - Striped maple/Pin cherry}

The generalized stand table projection procedure produced a smaller root mean squared error and smaller variance of bias. SILVAH projections produced a smaller average absolute bias and a larger proportion of similar distributions to observed distributions at the 95 percent level, based on the results of the KS test. Table 21 provides summary statistics for species group 6.

Table 21. Summary statistics for species group 6 in unthinned overlapping projections.

\begin{tabular}{|c|c|c|}
\hline & GSTP & $\underline{\text { SILVAH }}$ \\
\hline $\mathrm{n}$ & \multicolumn{2}{|c|}{52} \\
\hline RMSE ( $\mathrm{ft}^{2} / \mathrm{ac}$ ) & 2.003 & 2.324 \\
\hline Avg Abs Bias ( $\mathrm{ft}^{2} / \mathrm{ac}$ ) & 9.198 & 5.980 \\
\hline Avg Bias ( $\mathrm{ft}^{2} / \mathrm{ac}$ ) & 0.695 & 0.474 \\
\hline Var Bias $\left(\mathrm{ft}^{2} / \mathrm{ac}\right)^{2}$ & 3.599 & 5.277 \\
\hline \%K-S Similar & $69.6 \%$ & $78.3 \%$ \\
\hline
\end{tabular}

\section{Species Group 7 - Black cherry}

The generalized stand table projection procedure produced a larger root mean squared error, larger average absolute bias, and larger variance of bias. SILVAH projections produced a larger proportion of similar distributions to observed distributions at the 95 percent level, based on the results of the KS test. Table 22 provides summary statistics for species group 7. 
Table 22. Summary statistics for species group 7 in unthinned overlapping projections.

\begin{tabular}{|c|c|c|}
\hline & GSTP & SILVAH \\
\hline $\mathbf{n}$ & \multicolumn{2}{|c|}{57} \\
\hline RMSE & 14.619 & 10.822 \\
\hline Avg Abs Bias & 26.875 & 17.519 \\
\hline Avg Bias & -8.285 & -6.401 \\
\hline Var Bias & 147.671 & 77.498 \\
\hline \%K-S Similar & $31.3 \%$ & $40.6 \%$ \\
\hline
\end{tabular}

\section{Species Group 8 - Other}

SILVAH produced a smaller root mean squared error, smaller variance of bias, smaller average absolute bias, and a larger proportion of similar distributions to observed distributions at the 95 percent level, based on the results of the KS test. Table 23 provides summary statistics for species group 8 .

Table 23. Summary statistics for species group 8 in unthinned overlapping projections.

\begin{tabular}{|c|c|c|}
\hline & GSTP & SILVAH \\
\hline $\mathbf{n}$ & \multicolumn{2}{|c|}{92} \\
\hline RMSE & 9.414 & 5.868 \\
\hline Avg Abs Bias & 18.715 & 13.332 \\
\hline Avg Bias & 5.919 & 4.170 \\
\hline Var Bias & 54.185 & 17.235 \\
\hline \%K-S Similar & $28.3 \%$ & $39.1 \%$ \\
\hline
\end{tabular}

\section{Species Group 10 - Birch}

SILVAH produced a slightly smaller root mean squared error, smaller average absolute bias, smaller variance of bias, and a larger proportion of similar distributions to observed distributions at the 95 percent level, based on the results of the KS test. Table 24 provides summary statistics for species group 10. 
Table 24. Summary statistics for species group 10 in unthinned overlapping projections.

\begin{tabular}{|c|c|c|}
\hline & GSTP & SILVAH \\
\hline $\mathbf{n}$ & \multicolumn{2}{|c|}{92} \\
\hline RMSE & 5.871 & 5.346 \\
\hline Avg Abs Bias & 9.576 & 6.612 \\
\hline Avg Bias & 2.688 & 0.327 \\
\hline Var Bias & 27.542 & 28.787 \\
\hline \%K-S Similar & $40.2 \%$ & $43.5 \%$ \\
\hline
\end{tabular}

\section{Unthinned Overlapping Summary}

The generalized stand table projection method produced a combination of smaller errors, smaller variance, or a larger proportion of significant distributions in a manner that would suggest performance as good as or better than SILVAH projections for species groups 1 (northern red oak), 6 (striped maple/pin cherry), and 10 (birches) and at the plot level for unthinned plots with overlapping projections. While SILVAH produced smaller errors on species groups 2 (maples), 3 (white oaks), 4 (hickory/ash), 5

(yellow-poplar), 7 (black cherry), and 8 (other), the differences in errors were not large. Figures 21 and 22 show projection errors for the species group with lowest generalized stand table projection root mean squared error (species group 6 - striped maple/pin cherry) for unthinned overlapping projections. Figures 23 and 24 show projection error for the species group with highest generalized stand table projection root mean squared error (species group 5 - yellow-poplar) for unthinned overlapping projections. The remaining projection error plots may be found in Appendix C, Figures 70-83. 


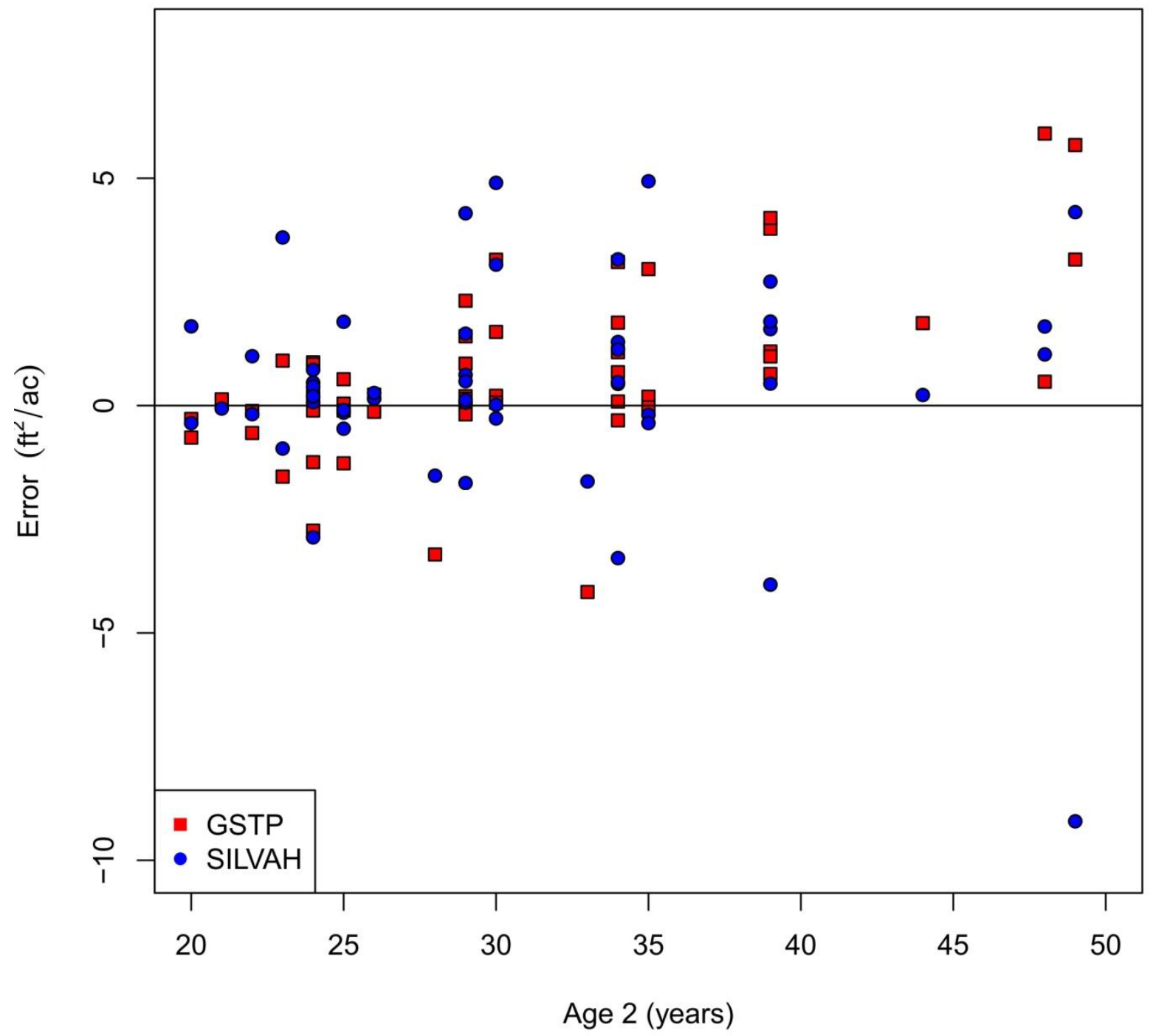

Figure 21. Species group 6 (striped maple/pin cherry) projection errors by projection age (age 2) for unthinned overlapping projections. 


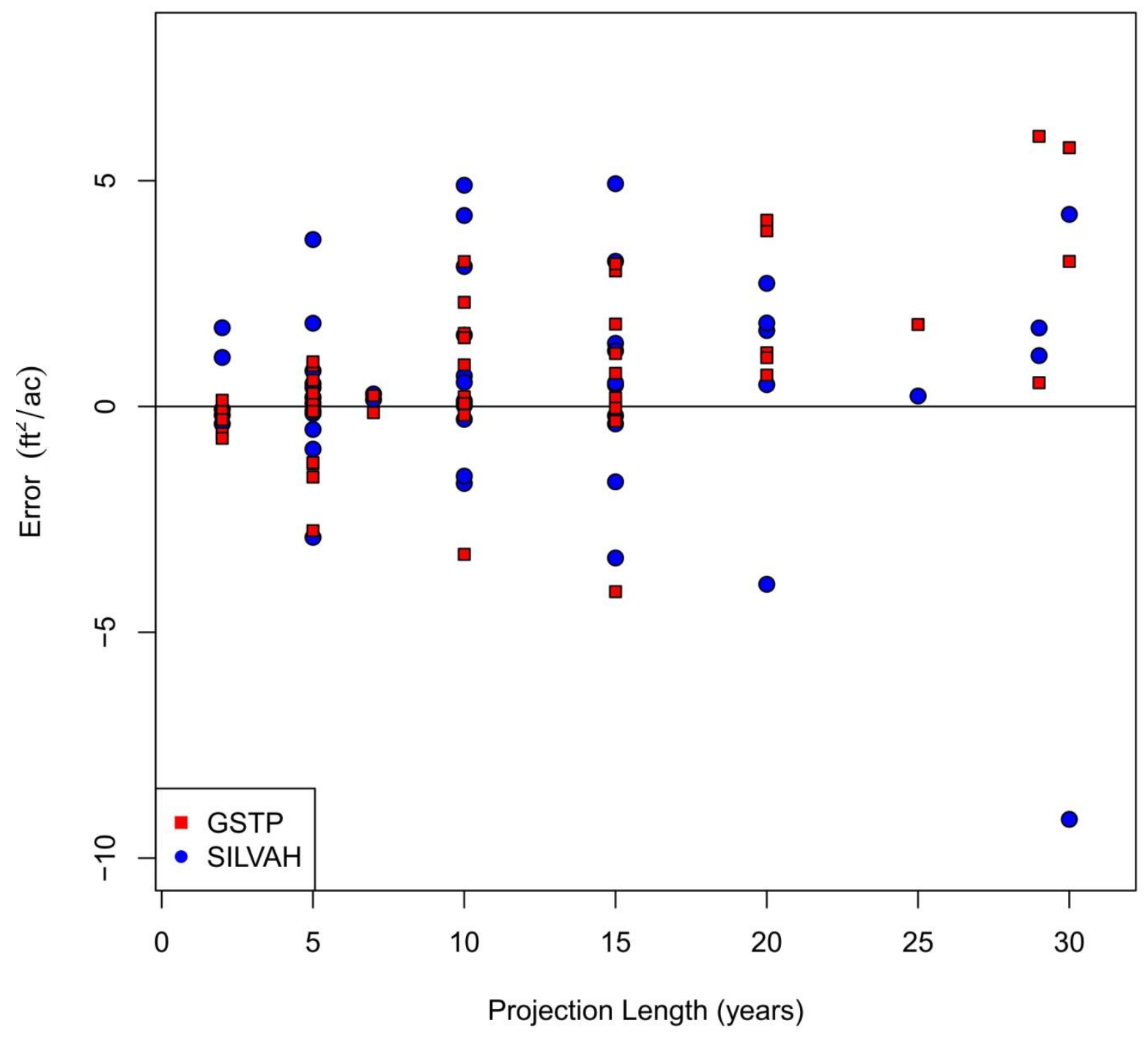

Figure 22. Species group 6 (striped maple/pin cherry) projection errors by projection length for unthinned overlapping projections. 


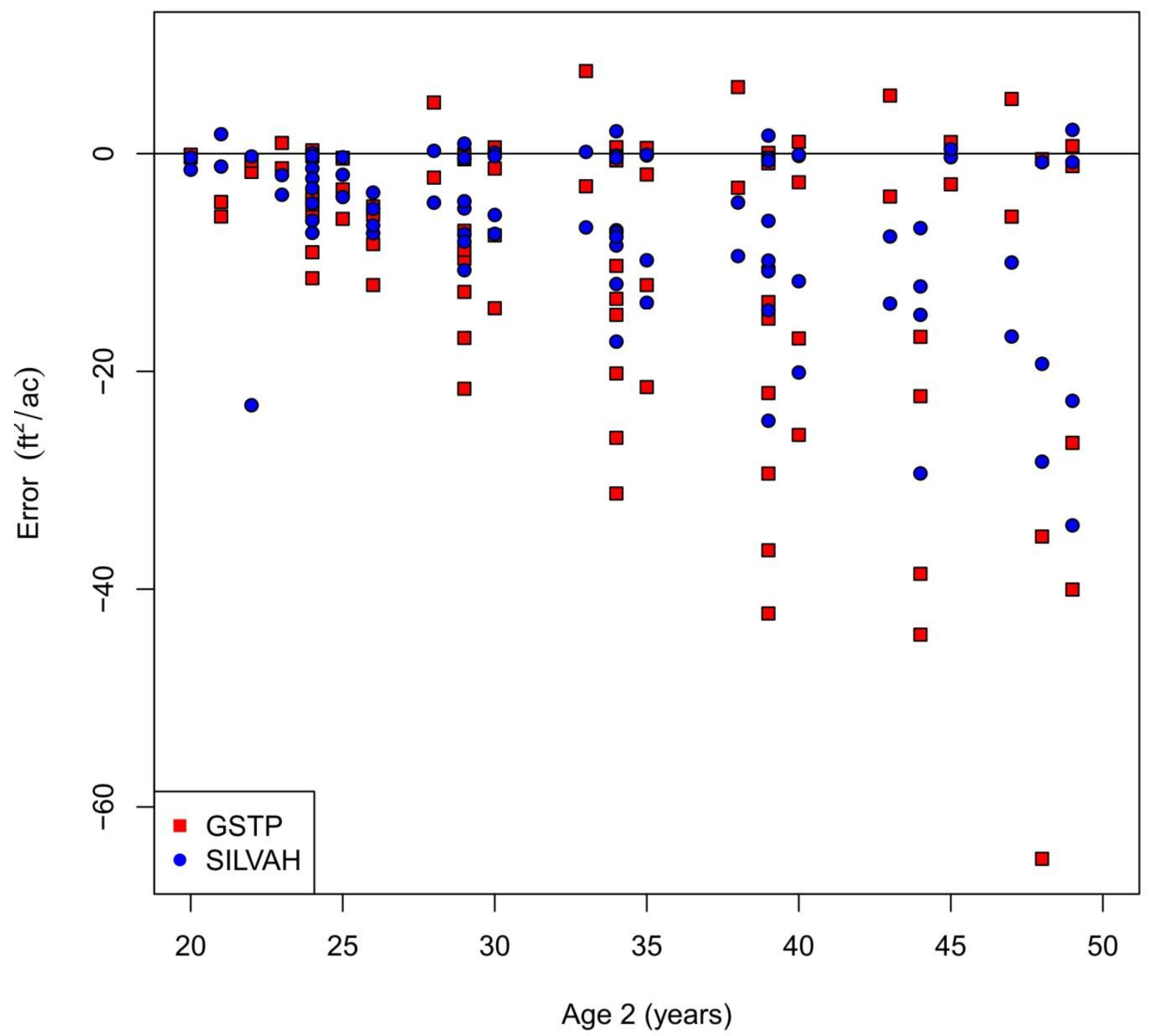

Figure 23. Species group 5 (yellow-poplar) projection errors by projection age (age 2) for unthinned overlapping projections. 


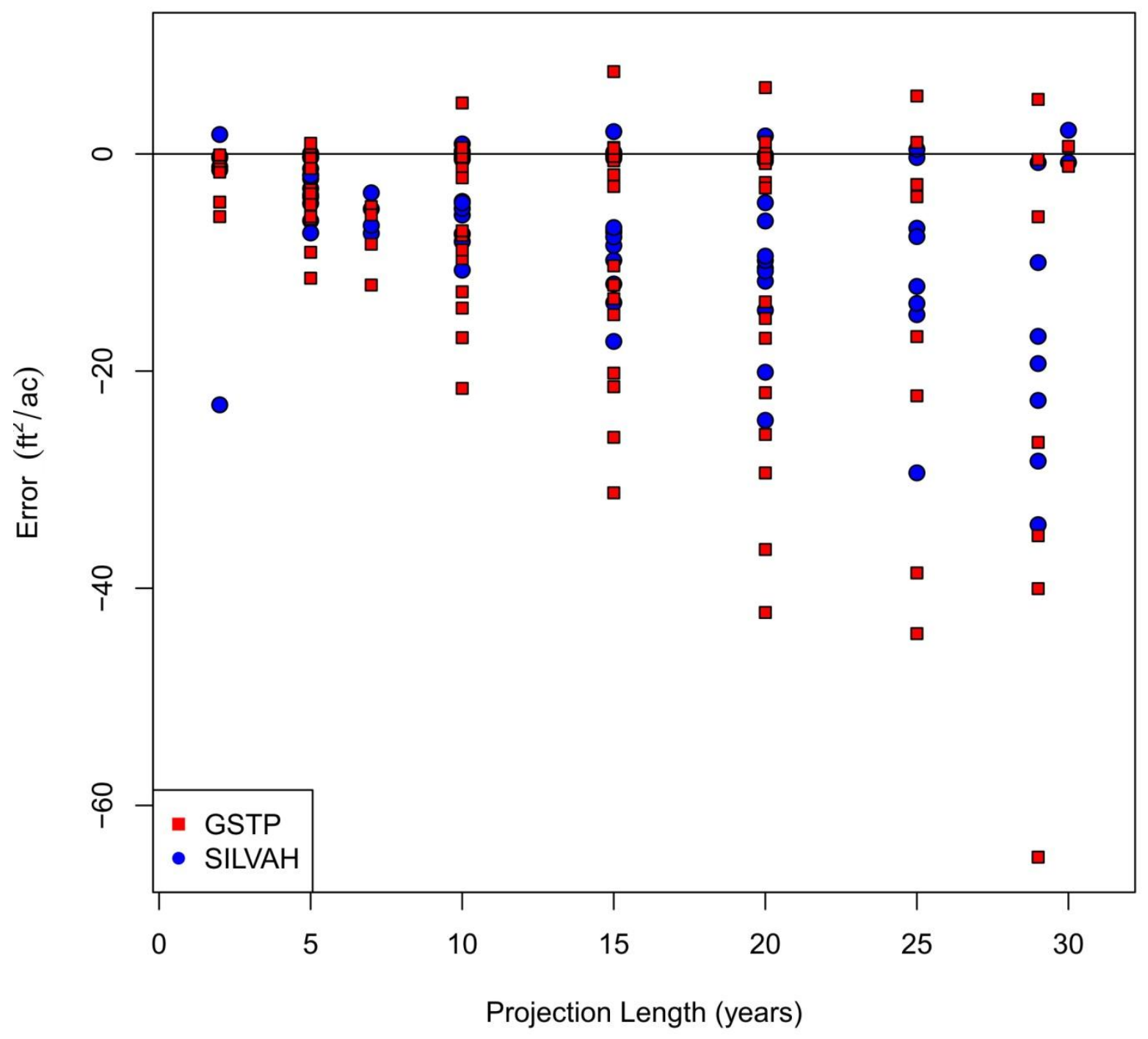

Figure 24. Species group 5 (yellow-poplar) projection errors by projection length for unthinned overlapping projections.

\section{Thinned Non-overlapping Projections}

\section{Plot Level}

At the plot level, the basal area projections for the generalized stand table projection method had a smaller root mean squared error, smaller average bias, and less variance of bias than the basal area projections 
using SILVAH for thinned non-overlapping projections. Table 25 provides summary statistics at the plot level.

Table 25. Thinned non-overlapping plot level summary statistics.

\begin{tabular}{|c|c|c|}
\hline & GSTP & SILVAH \\
\hline $\bar{n}$ & \multicolumn{2}{|c|}{152} \\
\hline RMSE & 2.657 & 6.359 \\
\hline Avg Abs Bias & 54.219 & 48.708 \\
\hline Avg Bias & -1.929 & -5.162 \\
\hline Var Bias & 3.361 & 13.879 \\
\hline
\end{tabular}

Figures 25 and 26 show that the errors for the generalized stand table projection method were almost exclusively within $5 \mathrm{ft} .^{2} / \mathrm{ac}$. and were slightly negatively skewed. 


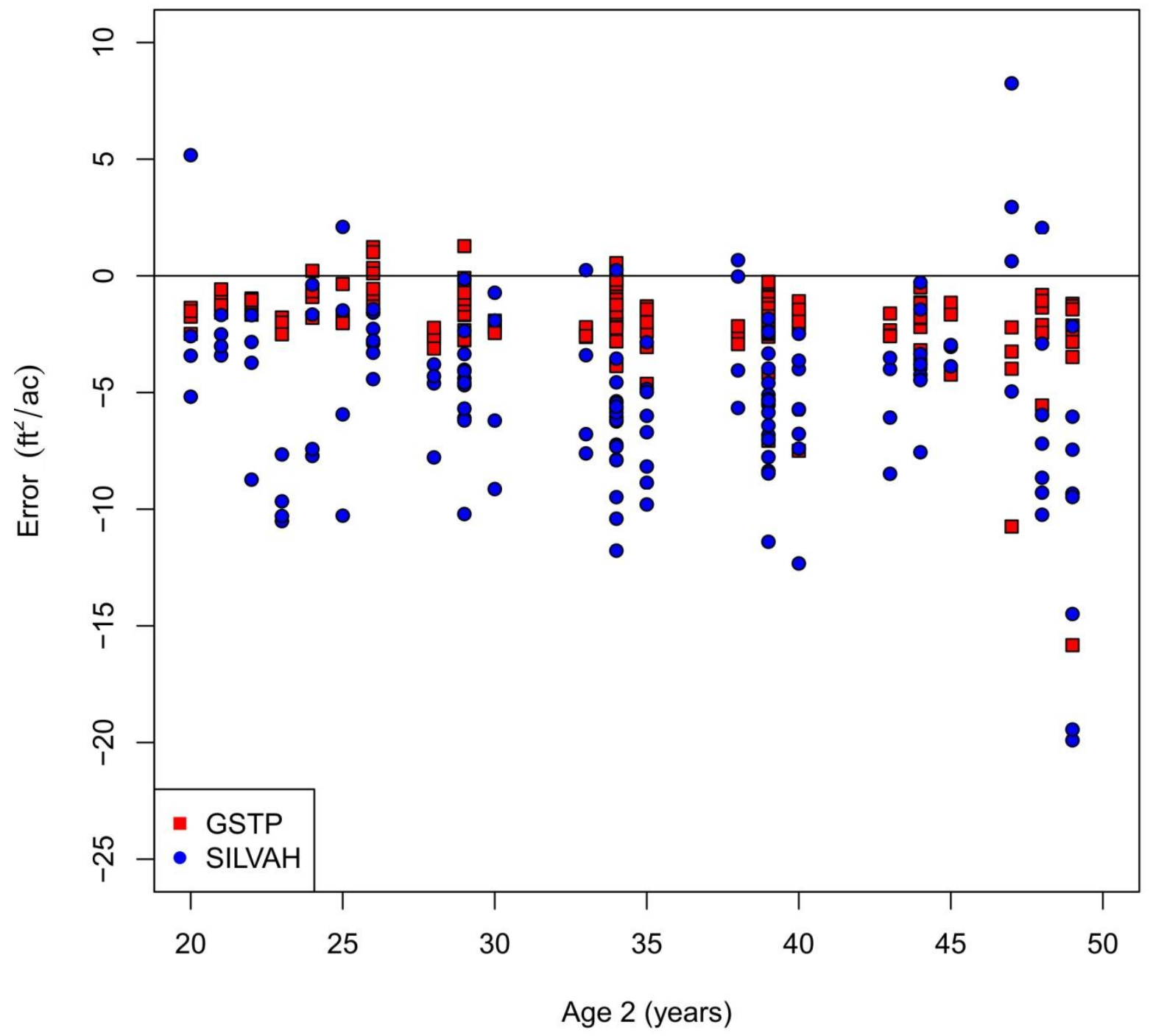

Figure 25. Thinned non-overlapping plot level projection errors by projection age (age 2). 


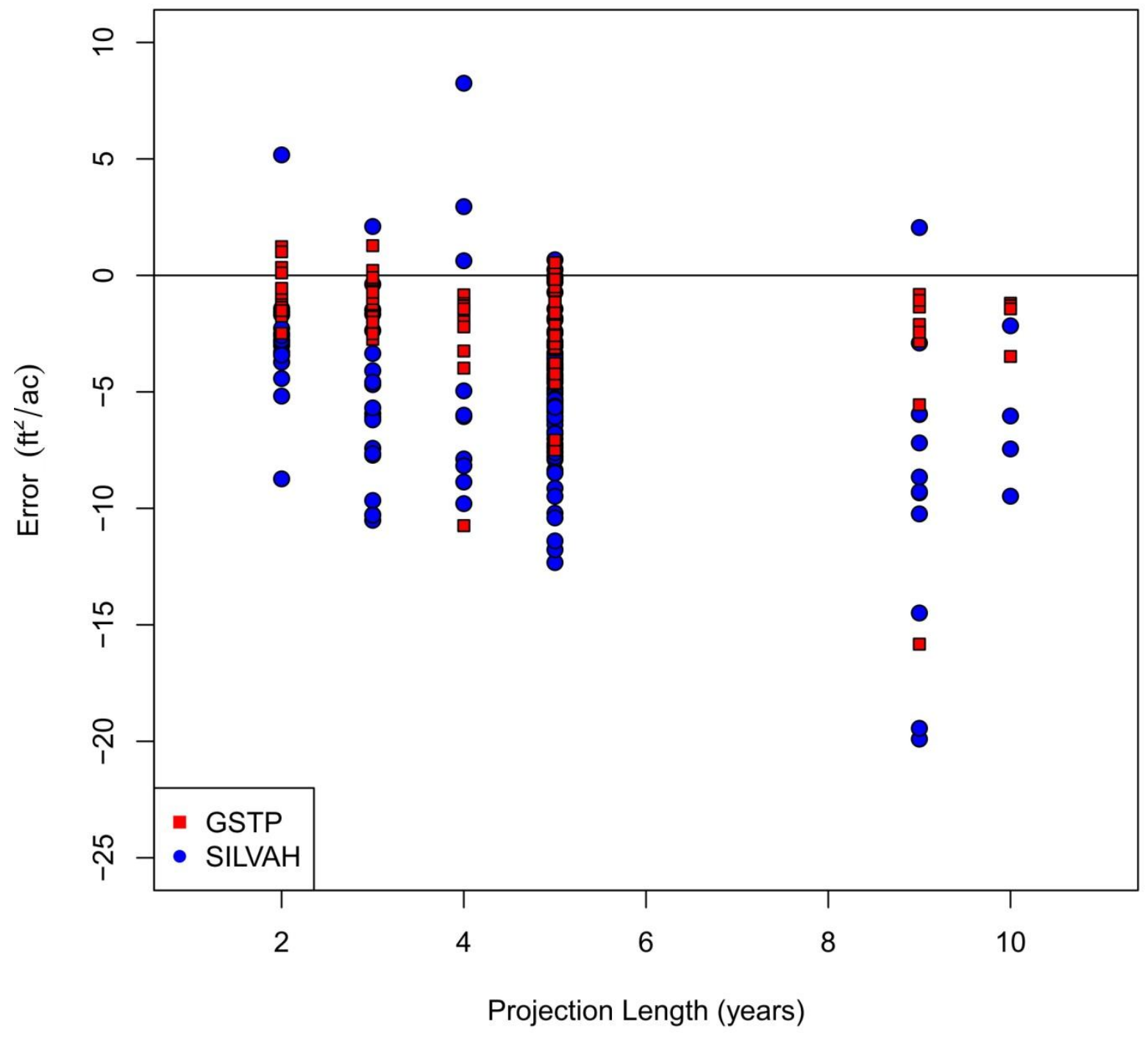

Figure 26. Thinned non-overlapping plot level projection errors by projection length.

Figures 27 and 28 show that the basal area projection error for the generalized stand table projection method was mostly within \pm 5 percent of the total basal area per acre, while SILVAH projection error was mostly within \pm 15 percent of the total basal area per acre, when summed across all species groups and diameter classes at the plot level. 


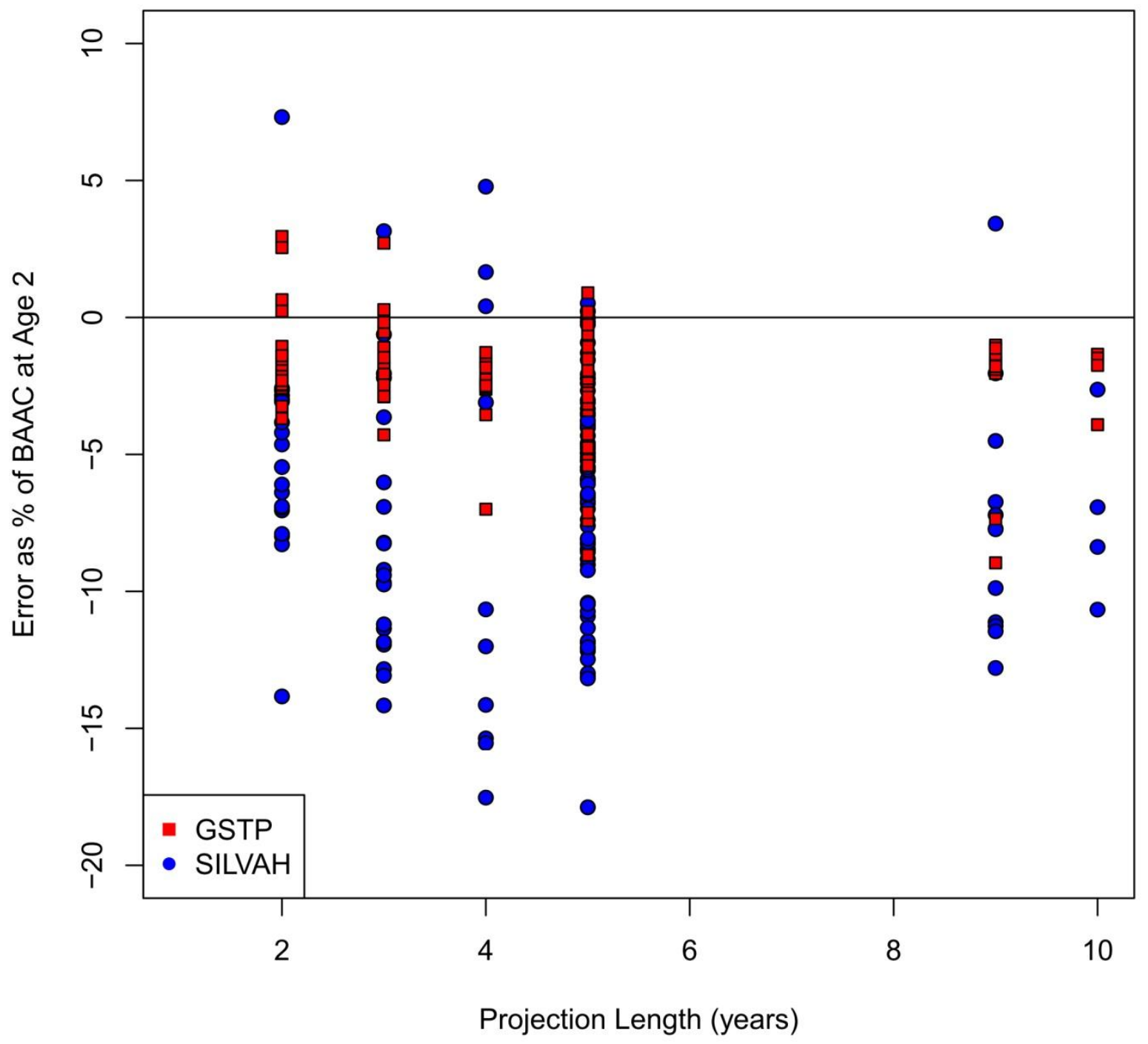

Figure 27. Thinned non-overlapping plot level projection errors as a percent of total basal area per acre by projection length. 


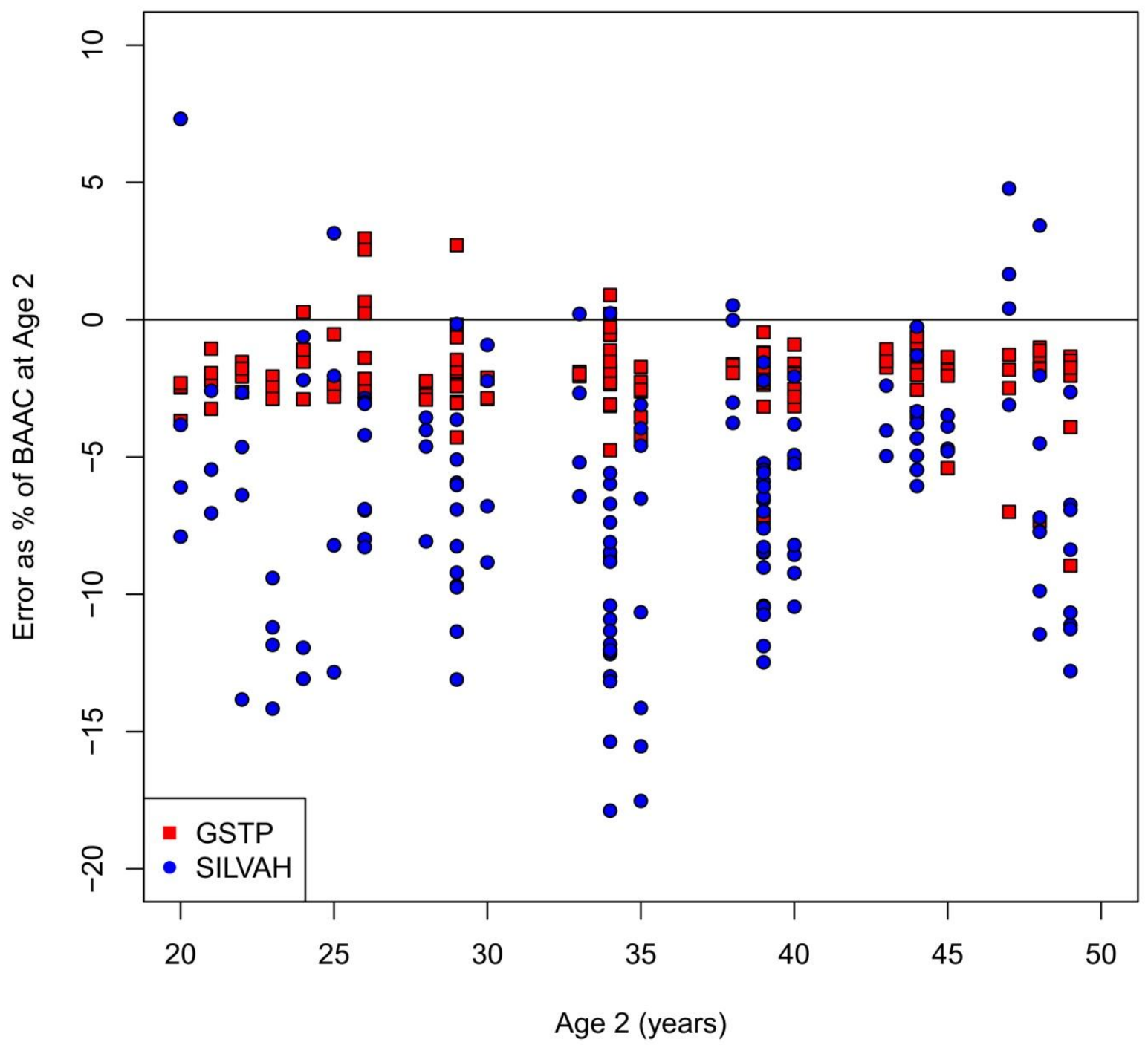

Figure 28. Thinned non-overlapping plot level projection errors as a percent of total basal area per acre at age 2.

\section{Species Group 1 - Northern red oak}

SILVAH produced a smaller average absolute bias while having a larger proportion of similar distributions at the 95 percent level, based on the results of the KS test. However, the generalized stand table projection method had a smaller root mean squared error and variance of the bias. Table 26 provides summary statistics for species group 1. 
Table 26. Summary statistics for species group 1 in thinned non-overlapping projections.

\begin{tabular}{|c|c|c|}
\hline & GSTP & $\underline{\text { SILVAH }}$ \\
\hline $\mathbf{n}$ & \multicolumn{2}{|c|}{138} \\
\hline RMSE (ft $\left.{ }^{2} / a c\right)$ & 2.248 & 2.409 \\
\hline Avg Abs Bias ( $\mathrm{ft}^{2} / \mathrm{ac}$ ) & 8.612 & 7.737 \\
\hline Avg Bias ( $\mathrm{ft}^{2} / \mathrm{ac}$ ) & -1.403 & -0.940 \\
\hline Var Bias $\left(\mathrm{ft}^{2} / \mathrm{ac}\right)^{2}$ & 3.109 & 4.956 \\
\hline \%K-S Similar & $39.1 \%$ & $52.9 \%$ \\
\hline
\end{tabular}

\section{Species Group 2 - Maple}

The generalized stand table projection procedure produced a smaller root mean squared error and variance of bias, while having a larger proportion of similar distributions to observed distributions at the 95 percent level, based on the results of the KS test. Table 27 provides summary statistics for species group 2.

Table 27. Summary statistics for species group 2 in thinned non-overlapping projections.

\begin{tabular}{|c|c|c|}
\hline & GSTP & SILVAH \\
\hline $\mathbf{n}$ & \multicolumn{2}{|c|}{152} \\
\hline RMSE (ft²/ac) & 2.112 & 2.114 \\
\hline Avg Abs Bias ( $\mathrm{ft}^{2} / \mathrm{ac}$ ) & 12.339 & 9.741 \\
\hline Avg Bias ( $\left.\mathrm{ft}^{2} / \mathrm{ac}\right)$ & 0.990 & -1.180 \\
\hline Var Bias $\left(\mathrm{ft}^{2} / \mathrm{ac}\right)^{2}$ & 3.505 & 3.097 \\
\hline \%K-S Similar & $33.6 \%$ & $25.0 \%$ \\
\hline
\end{tabular}

\section{Species Group 3 - White oak}

The generalized stand table projection method produced a larger root mean squared error and variance of bias. SILVAH projections produced a smaller average absolute bias and a larger proportion of similar distributions to observed distributions at the 95 percent level, based on the results of the KS test. Table 28 provides summary statistics for species group 3. 
Table 28. Summary statistics for species group 3 in thinned non-overlapping projections.

\begin{tabular}{|c|c|c|}
\hline & GSTP & SILVAH \\
\hline $\mathbf{n}$ & \multicolumn{2}{|c|}{75} \\
\hline RMSE (ft $\left.{ }^{2} / \mathrm{ac}\right)$ & 0.758 & 0.708 \\
\hline Avg Abs Bias (ft ${ }^{2} / \mathrm{ac}$ ) & 4.885 & 4.135 \\
\hline Avg Bias ( $\mathrm{ft}^{2} / \mathrm{ac}$ ) & -0.308 & -0.336 \\
\hline Var Bias $\left(\mathrm{ft}^{2} / \mathrm{ac}\right)^{2}$ & 0.486 & 0.394 \\
\hline \%K-S Similar & $73.3 \%$ & $77.3 \%$ \\
\hline
\end{tabular}

\section{Species Group 4 - Hickory/Ash}

The generalized stand table projection method produced a smaller root mean squared error, variance of bias, and a larger proportion of similar distributions to observed distributions at the 95 percent level, based on the results of the KS test. SILVAH projections produced a smaller average absolute bias. Table 29 provides summary statistics for species group 4.

Table 29. Summary statistics for species group 4 in thinned non-overlapping projections.

\begin{tabular}{|c|c|c|}
\hline & $\underline{\text { GSTP }}$ & $\underline{\text { SILVAH }}$ \\
\hline $\bar{n}$ & \multicolumn{2}{|c|}{119} \\
\hline RMSE ( $\left.\mathrm{ft}^{2} / \mathrm{ac}\right)$ & 0.652 & 0.833 \\
\hline Avg Abs Bias ( $\mathrm{ft}^{2} / \mathrm{ac}$ ) & 2.846 & 2.432 \\
\hline Avg Bias ( $\left.\mathrm{ft}^{2} / \mathrm{ac}\right)$ & 0.366 & 0.113 \\
\hline Var Bias $\left(\mathrm{ft}^{2} / \mathrm{ac}\right)^{2}$ & 0.293 & 0.688 \\
\hline \%K-S Similar & $83.2 \%$ & $75.6 \%$ \\
\hline
\end{tabular}

\section{Species Group 5 - Yellow-poplar}

The generalized stand table projection method produced a smaller root mean squared error and variance of bias. SILVAH projections produced a smaller average absolute bias and a larger proportion of similar distributions to observed distributions at the 95 percent level, based on the results of the KS test. Table 30 provides summary statistics for species group 5. 
Table 30. Summary statistics for species group 5 in thinned non-overlapping projections.

\begin{tabular}{|c|c|c|}
\hline & $\underline{\text { GSTP }}$ & $\underline{\text { SILVAH }}$ \\
\hline $\mathbf{n}$ & \multicolumn{2}{|c|}{137} \\
\hline RMSE (ft $\left.{ }^{2} / \mathrm{ac}\right)$ & 2.661 & 3.828 \\
\hline Avg Abs Bias (ft ${ }^{2} / \mathrm{ac}$ ) & 13.985 & 13.851 \\
\hline Avg Bias ( $\mathrm{ft}^{2} / \mathrm{ac}$ ) & -1.982 & -2.265 \\
\hline Var Bias $\left(\mathrm{ft}^{2} / \mathrm{ac}\right)^{2}$ & 3.174 & 9.597 \\
\hline \%K-S Similar & $35.8 \%$ & $40.1 \%$ \\
\hline
\end{tabular}

\section{Species Group 6 - Striped maple/Pin cherry}

SILVAH projections produced a smaller average absolute bias, smaller root mean squared error, and a smaller variance of bias. The generalized stand table projection procedure produced a larger proportion of similar distributions to observed distributions at the 95 percent level, based on the results of the KS test. Table 31 provides summary statistics for species group 6.

Table 31. Summary statistics for species group 6 in thinned non-overlapping projections.

\begin{tabular}{|c|c|c|}
\hline & GSTP & SILVAH \\
\hline $\mathbf{n}$ & \multicolumn{2}{|c|}{61} \\
\hline RMSE (ft²/ac) & 0.951 & 0.852 \\
\hline Avg Abs Bias ( $\left.\mathrm{ft}^{2} / \mathrm{ac}\right)$ & 1.872 & 1.745 \\
\hline Avg Bias ( $\left.\mathrm{ft}^{2} / \mathrm{ac}\right)$ & 0.356 & 0.351 \\
\hline Var Bias $\left(\mathrm{ft}^{2} / \mathrm{ac}\right)^{2}$ & 0.792 & 0.613 \\
\hline \%K-S Similar & $73.8 \%$ & $54.1 \%$ \\
\hline
\end{tabular}

\section{Species Group 7 - Black cherry}

The generalized stand table projection method produced a smaller root mean squared error, smaller average absolute bias, and smaller variance of bias. Generalized stand table projection produced a larger proportion of similar distributions at the 95 percent level. Table 32 provides summary statistics for species group 7 . 
Table 32. Summary statistics for species group 7 in thinned non-overlapping projections.

\begin{tabular}{|c|c|c|}
\hline & GSTP & SILVAH \\
\hline $\mathbf{n}$ & \multicolumn{2}{|c|}{124} \\
\hline RMSE (ft $\left.{ }^{2} / \mathrm{ac}\right)$ & 2.123 & 3.717 \\
\hline Avg Abs Bias (ft ${ }^{2} / \mathrm{ac}$ ) & 10.272 & 10.325 \\
\hline Avg Bias ( $\mathrm{ft}^{2} / \mathrm{ac}$ ) & -1.307 & -1.858 \\
\hline Var Bias $\left(\mathrm{ft}^{2} / \mathrm{ac}\right)^{2}$ & 2.822 & 10.445 \\
\hline \%K-S Similar & $69.4 \%$ & $63.7 \%$ \\
\hline
\end{tabular}

\section{Species Group 8 - Other}

SILVAH produced a smaller root mean squared error, smaller variance of bias, and smaller average absolute bias. Generalized stand table projection produced a larger proportion of similar distributions at the 95 percent level. Table 33 provides summary statistics for species group 8 .

Table 33. Summary statistics for species group 8 in thinned non-overlapping projections.

\begin{tabular}{|c|c|c|}
\hline & GSTP & SILVAH \\
\hline $\mathbf{n}$ & \multicolumn{2}{|c|}{147} \\
\hline RMSE ( $\left.\mathrm{ft}^{2} / \mathrm{ac}\right)$ & 1.520 & 1.385 \\
\hline Avg Abs Bias ( $\mathrm{ft}^{2} / \mathrm{ac}$ ) & 5.051 & 4.116 \\
\hline Avg Bias ( $\left.\mathrm{ft}^{2} / \mathrm{ac}\right)$ & 0.605 & 0.133 \\
\hline Var Bias $\left(\mathrm{ft}^{2} / \mathrm{ac}\right)^{2}$ & 1.957 & 1.914 \\
\hline \%K-S Similar & $67.3 \%$ & $49.0 \%$ \\
\hline
\end{tabular}

\section{Species Group 9 - Black and Scarlet oaks}

SILVAH produced a smaller root mean squared error, smaller variance of bias, smaller average absolute bias, and a larger proportion of similar distributions to observed distributions at the 95 percent level, based on the results of the KS test. Table 34 provides summary statistics for species group 9. 
Table 34. Summary statistics for species group 9 in thinned non-overlapping projections.

\begin{tabular}{|c|c|c|}
\hline & GSTP & SILVAH \\
\hline $\mathbf{n}$ & \multicolumn{2}{|c|}{20} \\
\hline RMSE ( $\mathrm{ft}^{2} / \mathrm{ac}$ ) & 1.044 & 0.435 \\
\hline Avg Abs Bias ( $\mathrm{ft}^{2} / \mathrm{ac}$ ) & 2.824 & 1.673 \\
\hline Avg Bias ( $\mathrm{ft}^{2} / \mathrm{ac}$ ) & -0.686 & -0.204 \\
\hline Var Bias $\left(\mathrm{ft}^{2} / \mathrm{ac}\right)^{2}$ & 0.652 & 0.156 \\
\hline \%K-S Similar & $75.0 \%$ & $85.0 \%$ \\
\hline
\end{tabular}

\section{Species Group 10 - Birch}

The generalized stand table projection procedure produced a smaller root mean squared error, smaller variance of bias, and a larger proportion of similar distributions to observed distributions at the 95 percent level, based on the results of the KS test. Table 35 provides summary statistics for species group 10.

Table 35. Summary statistics for species group 10 in thinned non-overlapping projections.

\begin{tabular}{|c|c|c|}
\hline & $\underline{\text { GSTP }}$ & SILVAH \\
\hline $\mathbf{n}$ & \multicolumn{2}{|c|}{142} \\
\hline RMSE (ft²/ac) & 0.803 & 1.323 \\
\hline Avg Abs Bias ( $\left.\mathrm{ft}^{2} / \mathrm{ac}\right)$ & 2.601 & 2.204 \\
\hline Avg Bias ( $\left.\mathrm{ft}^{2} / \mathrm{ac}\right)$ & 0.465 & 0.141 \\
\hline Var Bias $\left(\mathrm{ft}^{2} / \mathrm{ac}\right)^{2}$ & 0.432 & 1.743 \\
\hline \%K-S Similar & $78.2 \%$ & $64.8 \%$ \\
\hline
\end{tabular}

\section{Thinned Non-overlapping Summary}

The generalized stand table projection method produced a combination of smaller errors, smaller variance, or a larger proportion of significant distributions in a manner that would suggest performance as good as or better than SILVAH for species groups 1 (northern red oak), 2 (maples), 3 (white oaks), 4 (hickory/ash), 5 (yellow-poplar), 6 (striped maple/pin cherry), 7 (black cherry), 8 (other), 10 (birches), and across all species groups and diameter classes. SILVAH produced smaller errors for species group 9 (scarlet and black oaks). Figures 29 and 30 show projection errors for the species group with lowest 
generalized stand table projection root mean squared error (species group 4) for thinned non-overlapping projections. Figures 31 and 32 show projection error for the species group with highest generalized stand table projection root mean squared error (species group 5) for thinned non-overlapping projections. The remaining projection error plots are found in Appendix C, Figures 84-99.

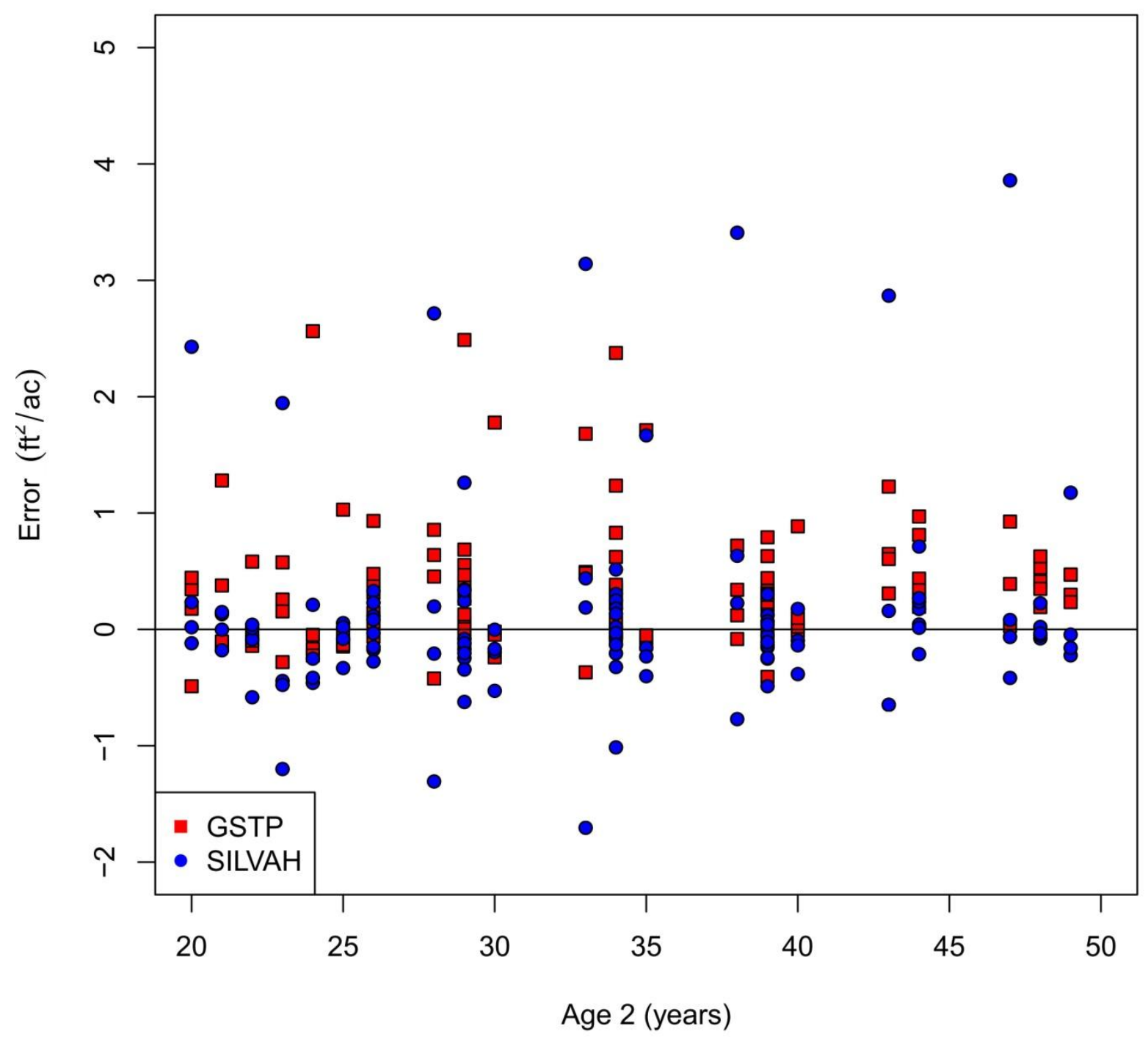

Figure 29. Species group 4 (hickory/ash) projection errors by projection age (age 2) for thinned overlapping projections. 


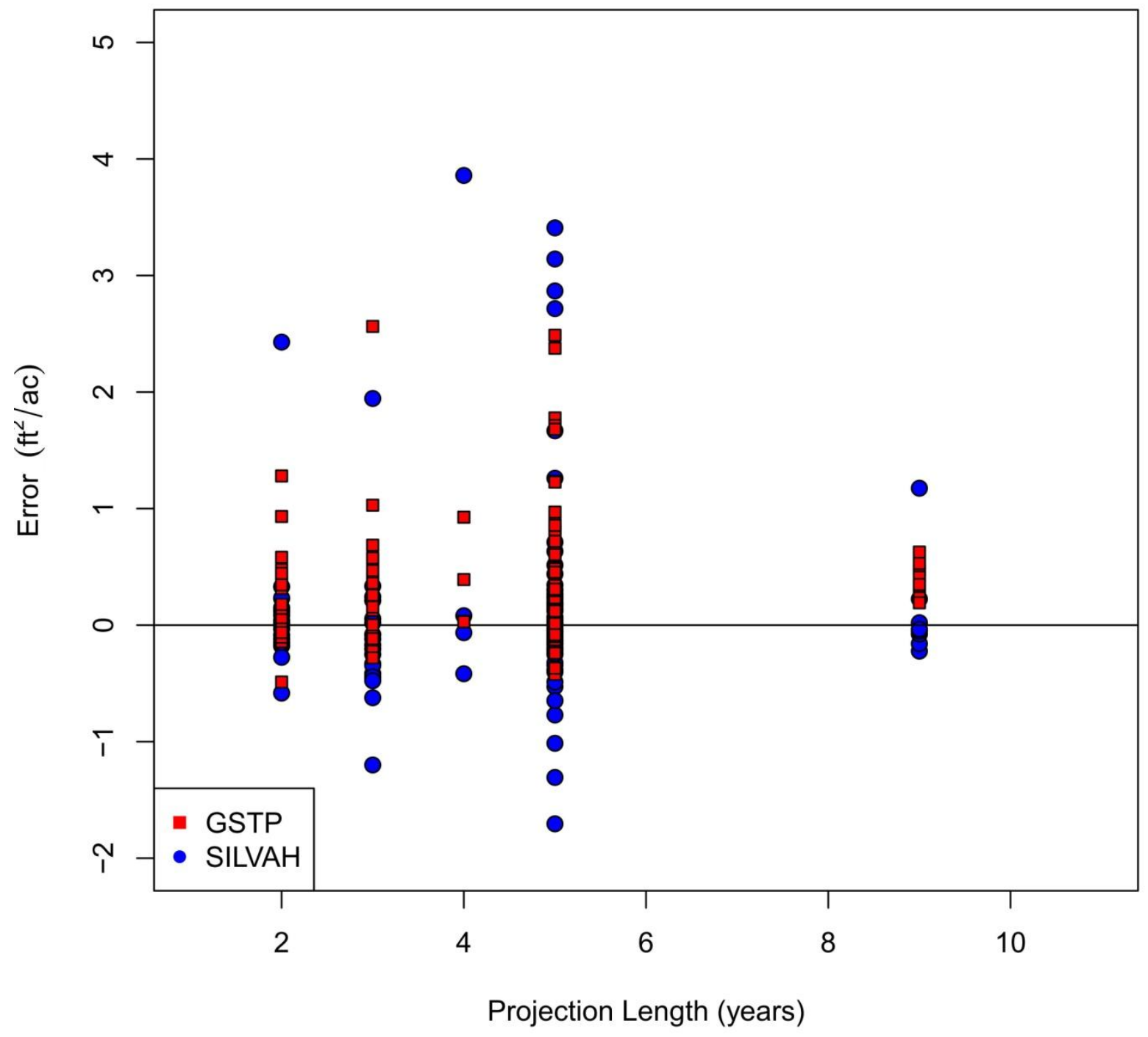

Figure 30. Species group 4 (hickory/ash) projection errors by projection length for thinned overlapping projections. 


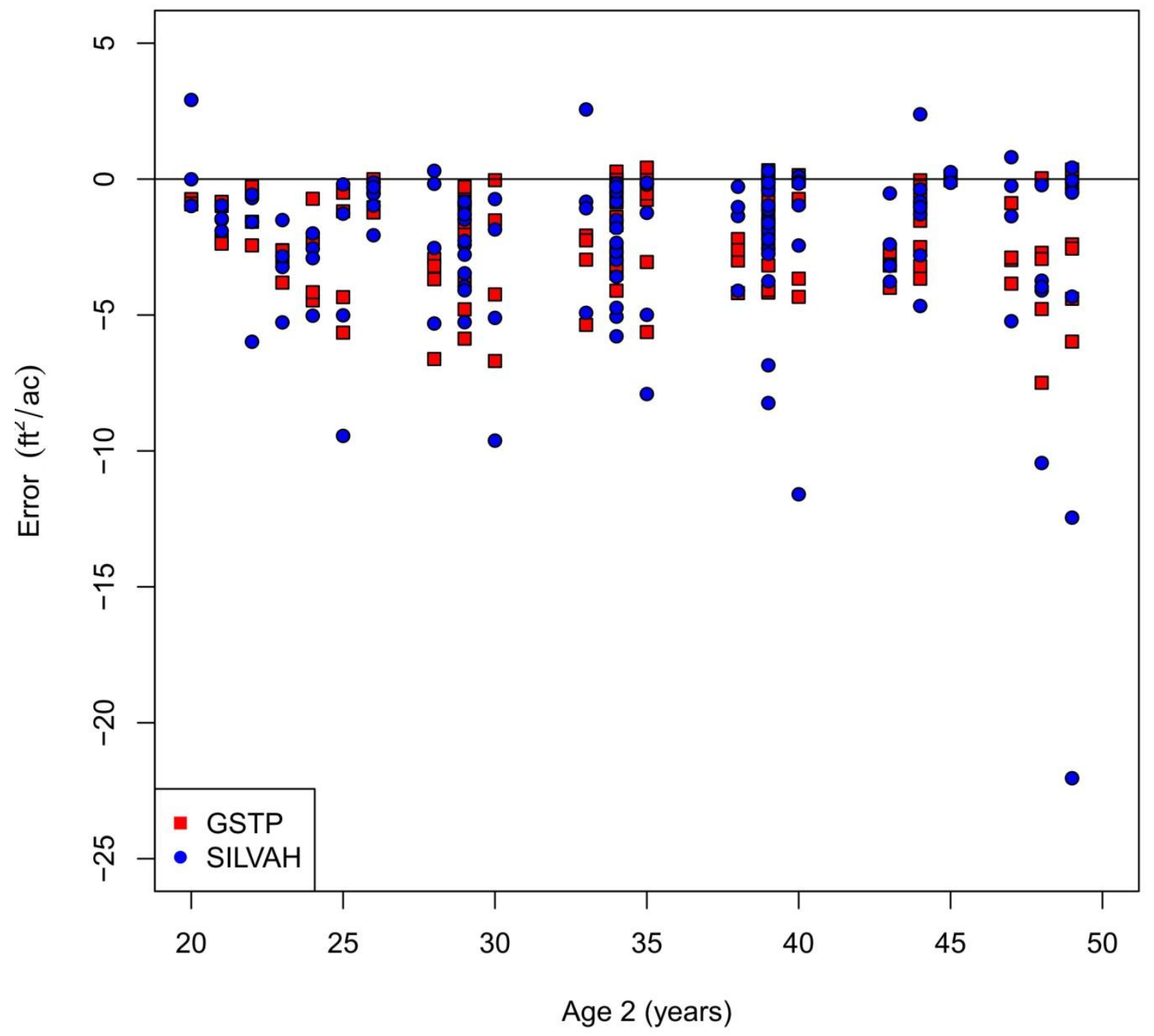

Figure 31. Species group 5 (yellow-poplar) projection errors by projection age (age 2) for thinned overlapping projections. 


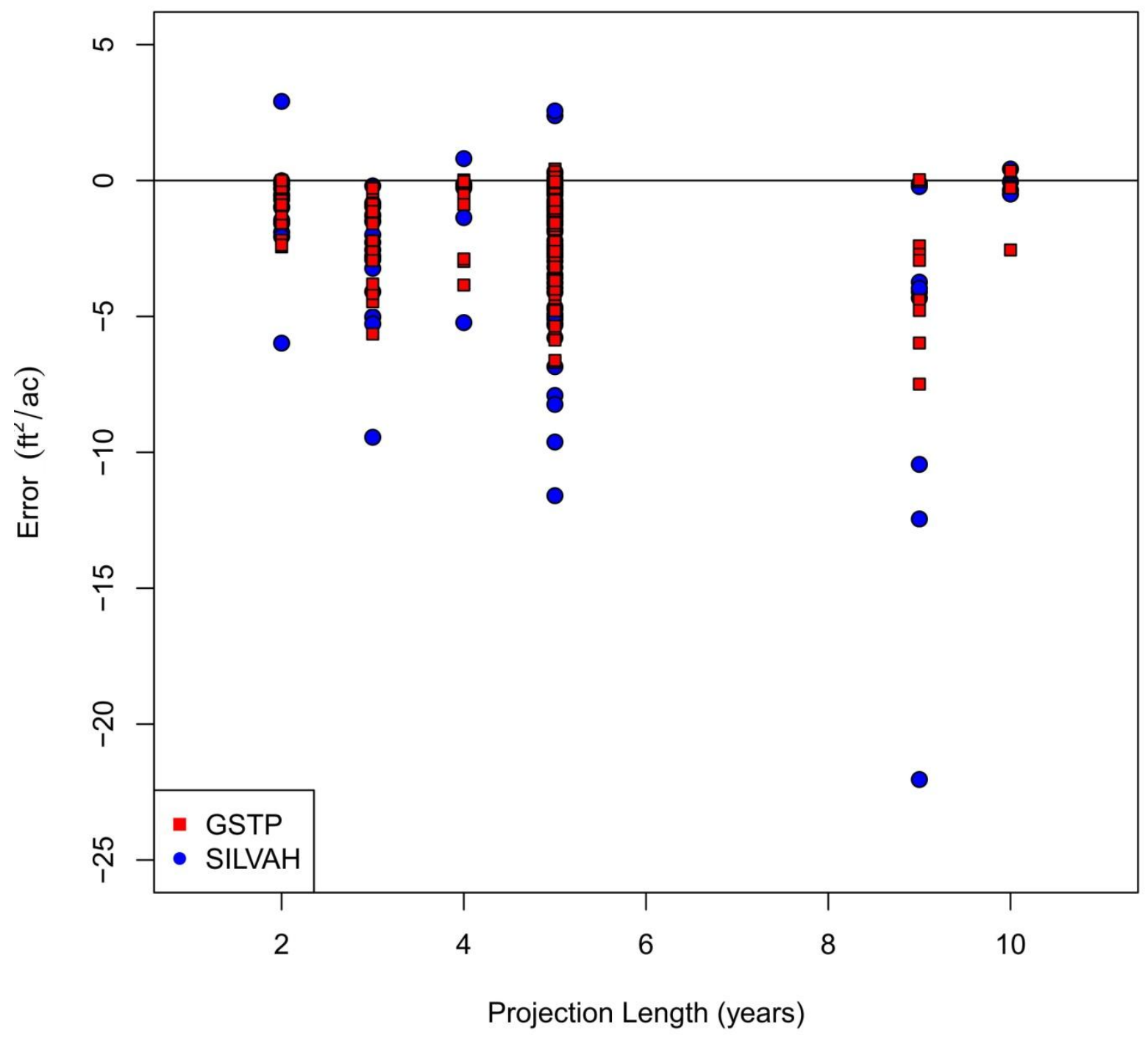

Figure 32. Species group 5 (yellow-poplar) projection errors by projection length for thinned overlapping projections.

\section{Thinned Overlapping Projections}

\section{Plot Level}

The basal area projections for the generalized stand table projection method had a smaller root mean squared error and less variance of bias than SILVAH for the thinned overlapping projections. Table 36 provides summary statistics at the plot level. 
Table 36. Thinned overlapping plot level summary statistics.

\begin{tabular}{|c|c|c|}
\hline & GSTP & SILVAH \\
\hline $\mathbf{n}$ & \multicolumn{2}{|c|}{152} \\
\hline RMSE & 3.259 & 13.361 \\
\hline Avg Abs Bias & 103.217 & 69.234 \\
\hline Avg Bias & -2.490 & -10.836 \\
\hline Var Bias & 4.453 & 61.495 \\
\hline
\end{tabular}

Figures 33 and 34 show that the generalized stand table projection method error was almost exclusively within $5 \mathrm{ft} .2 / \mathrm{ac}$. and was slightly negatively skewed. 


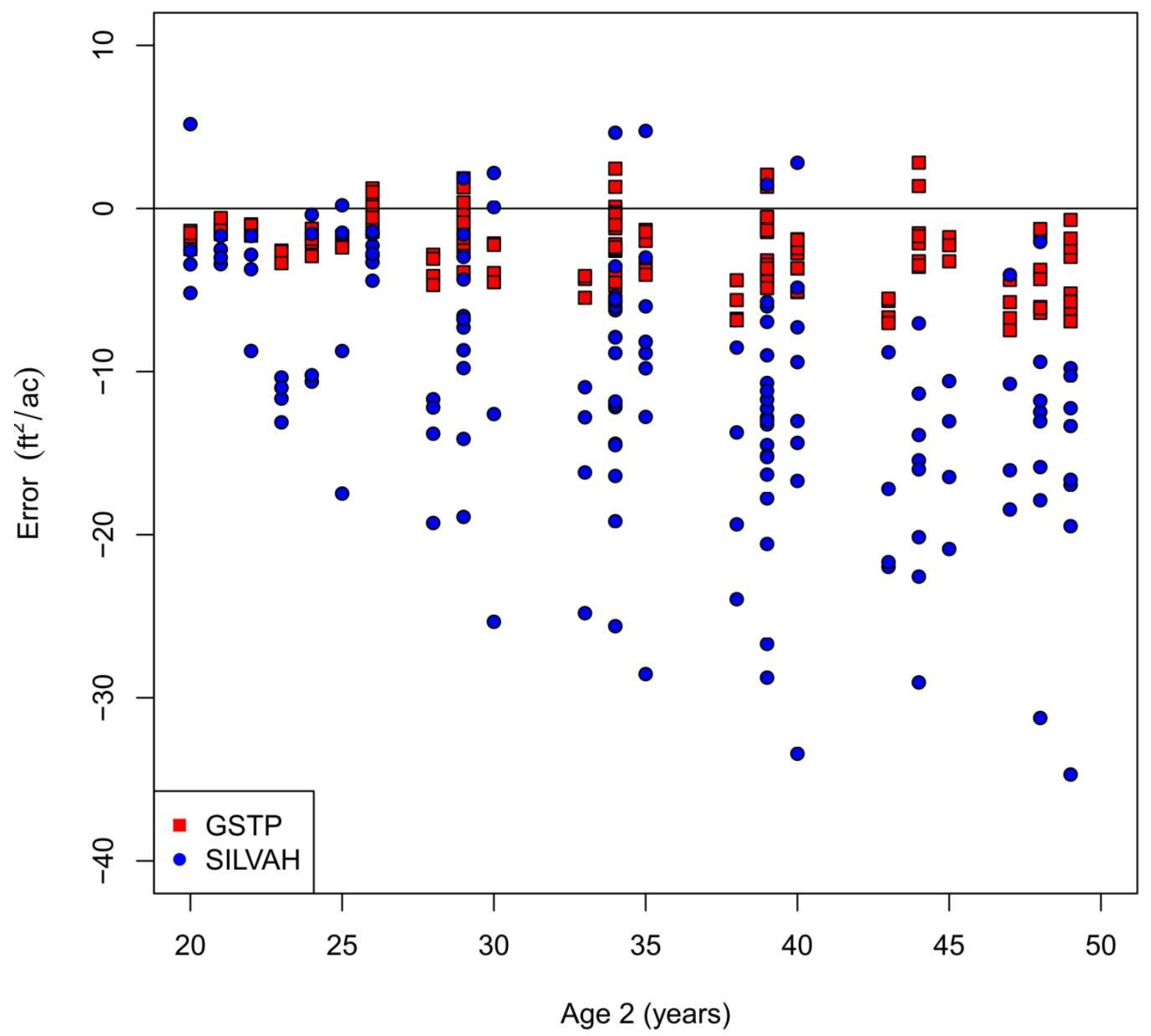

Figure 33. Plot level projection errors by projection age (age 2) for thinned overlapping projections. 


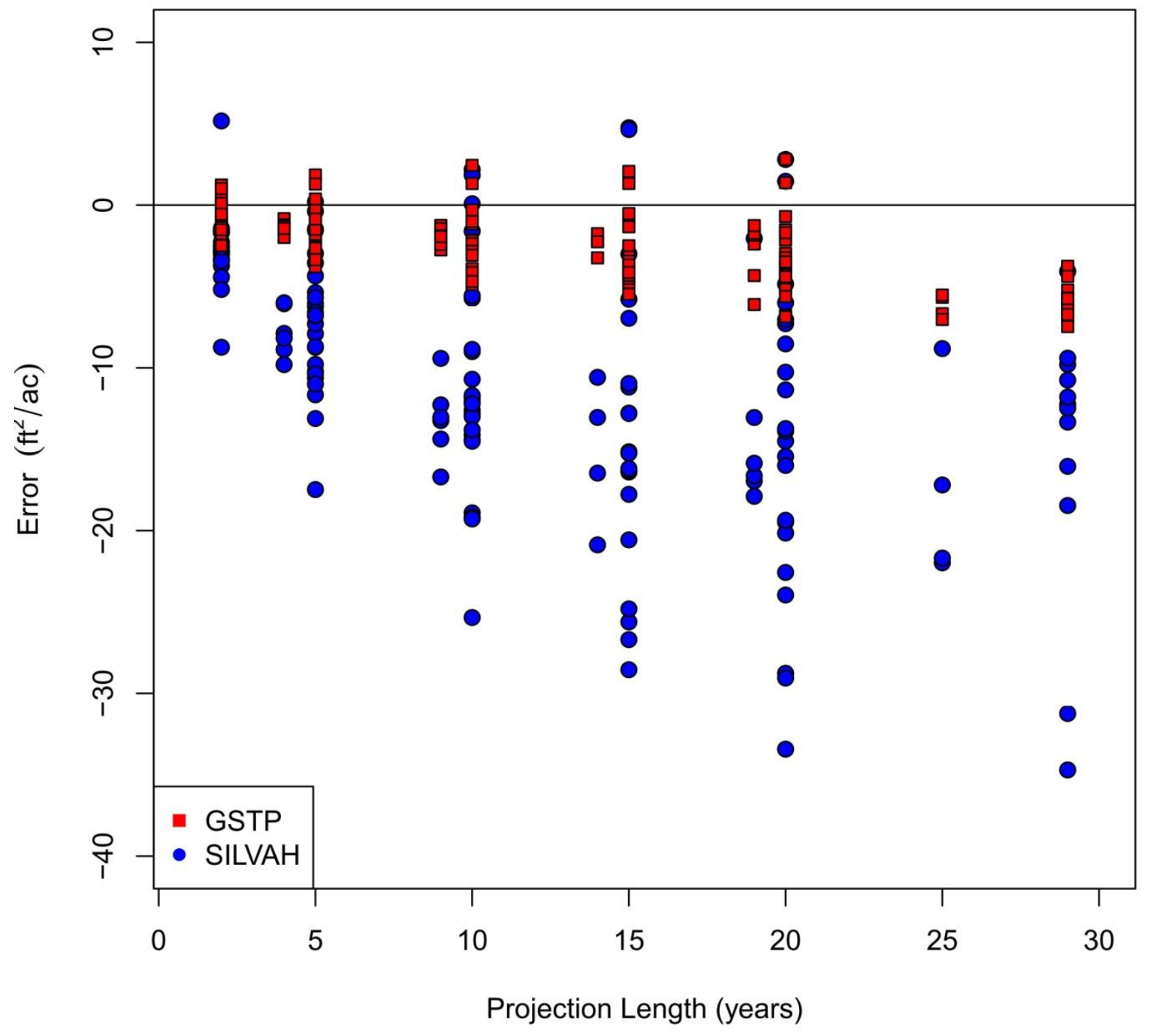

Figure 34. Plot level projection errors by projection length for thinned overlapping projections.

Figures 35 and 36 show that the basal area projection error for the generalized stand table projection method was mostly within \pm 10 percent of total basal area per acre, while SILVAH projection error was mostly within \pm 30 percent, when summed across all species groups and diameter classes at the plot level. 


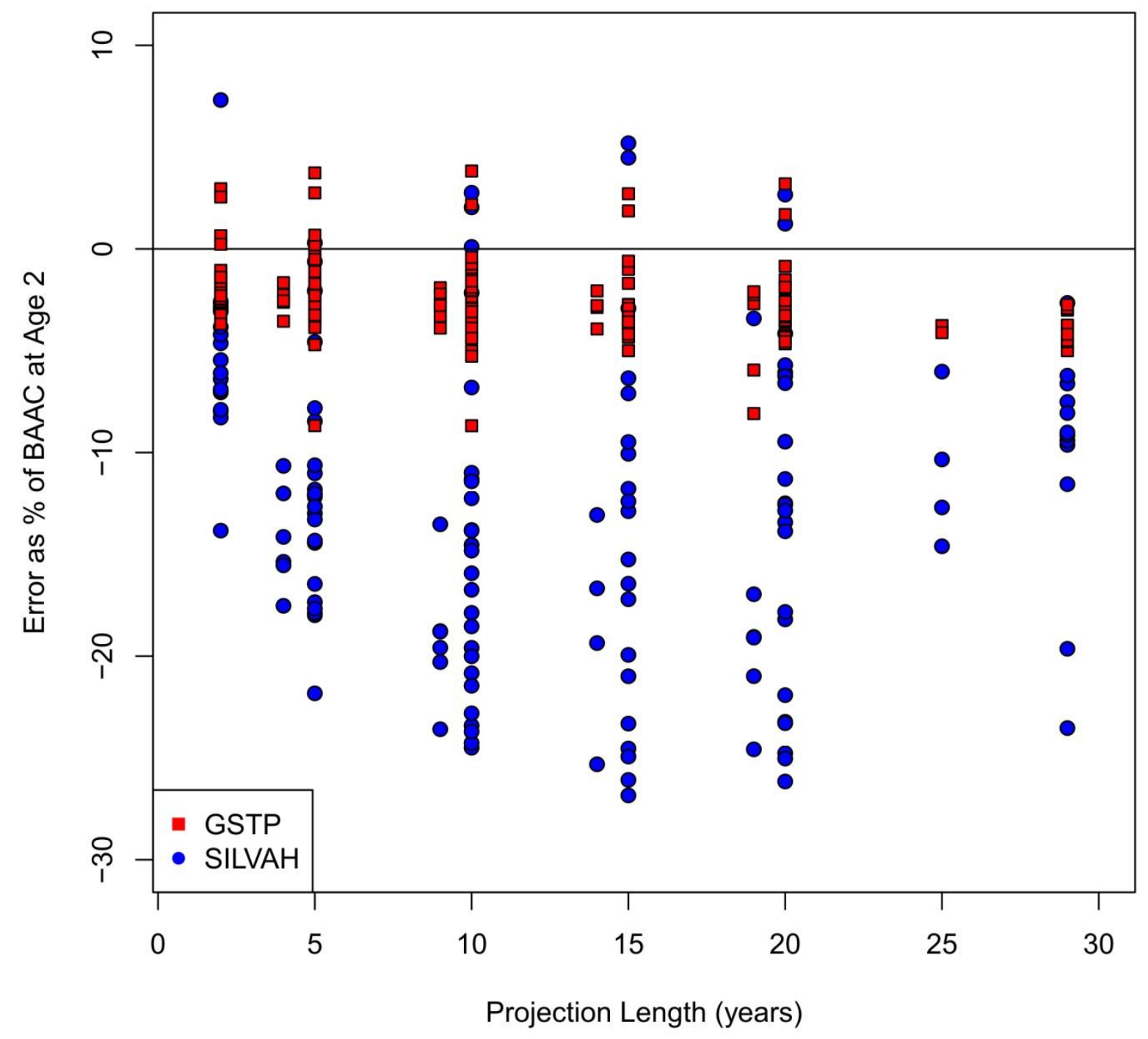

Figure 35. Thinned overlapping plot level projection errors as a percent of total basal area per acre by projection length. 


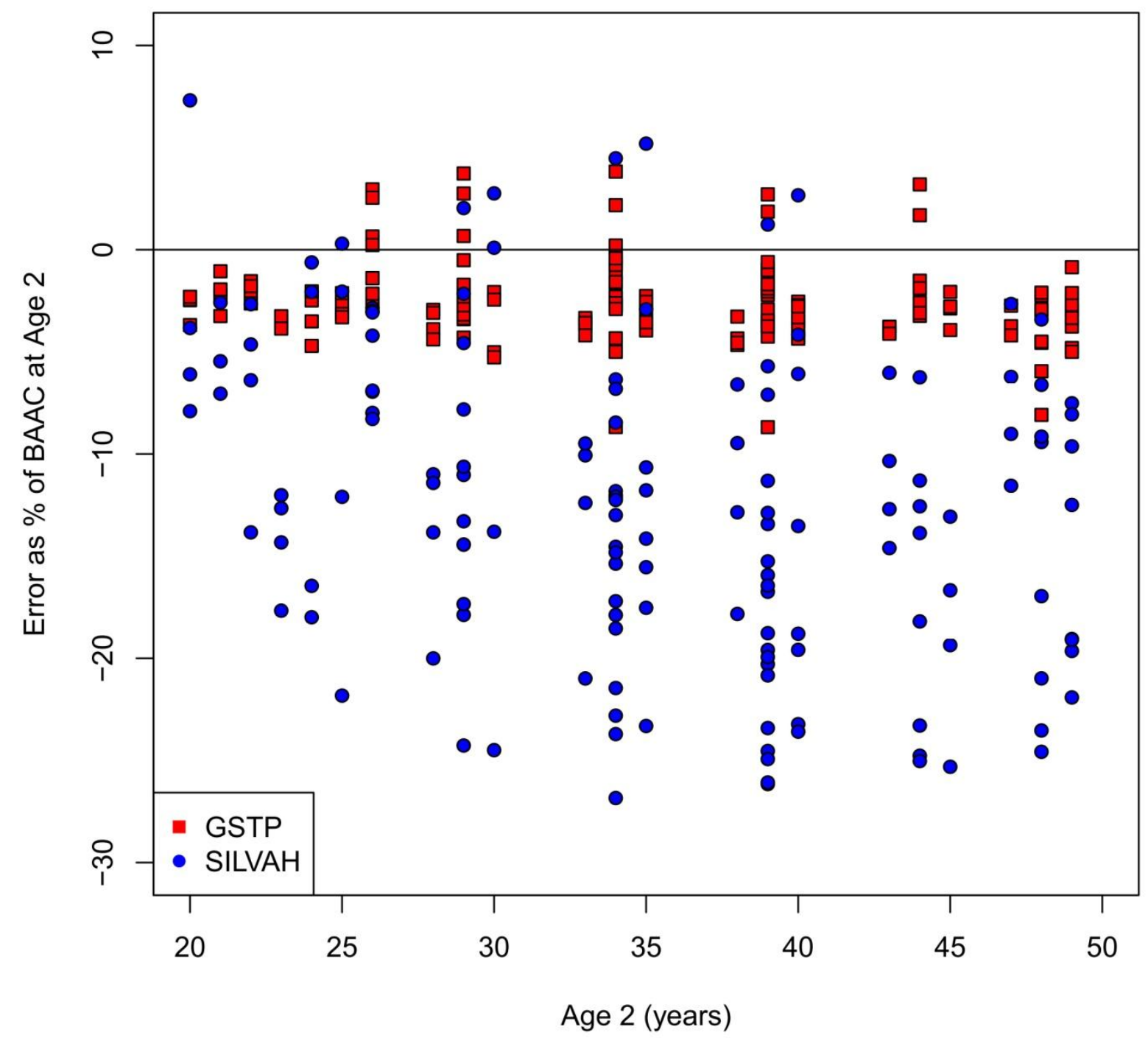

Figure 36. Thinned overlapping plot level projection errors as a percent of total basal area per acre by projection age (age 2).

\section{Species Group 1 - Northern red oak}

SILVAH produced a smaller average absolute bias, a smaller root mean squared error, and a smaller variance of projection bias while having a larger proportion of similar distributions at the 95 percent level, based on the results of the KS test. Table 37 provides summary statistics for species group 1. 
Table 37. Summary statistics for species group 1 in thinned overlapping projections.

\begin{tabular}{|c|c|c|}
\hline & GSTP & $\underline{\text { SILVAH }}$ \\
\hline 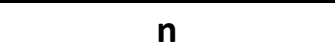 & \multicolumn{2}{|c|}{138} \\
\hline RMSE (ft $\left.{ }^{2} / \mathrm{ac}\right)$ & 4.958 & 4.484 \\
\hline Avg Abs Bias (ft' $/ \mathrm{ac})$ & 11.967 & 9.760 \\
\hline Avg Bias ( $\mathrm{ft}^{2} / \mathrm{ac}$ ) & -2.136 & -2.071 \\
\hline Var Bias $\left(\mathrm{ft}^{2} / \mathrm{ac}\right)^{2}$ & 20.165 & 15.937 \\
\hline \%K-S Similar & $18.8 \%$ & $37.7 \%$ \\
\hline
\end{tabular}

\section{Species Group 2 - Maple}

SILVAH produced a smaller root mean squared error, smaller average absolute bias, and smaller variance of bias. Table 38 provides summary statistics for species group 2 .

Table 38. Summary statistics for species group 2 in thinned overlapping projections.

\begin{tabular}{|c|c|c|}
\hline & GSTP & SILVAH \\
\hline $\mathbf{n}$ & \multicolumn{2}{|c|}{152} \\
\hline RMSE (ft $\left.{ }^{2} / a c\right)$ & 11.811 & 4.674 \\
\hline Avg Abs Bias ( $\mathrm{ft}^{2} / \mathrm{ac}$ ) & 23.961 & 14.574 \\
\hline Avg Bias ( $\left.\mathrm{ft}^{2} / \mathrm{ac}\right)$ & 3.989 & -2.690 \\
\hline $\operatorname{Var}$ Bias $\left(\mathrm{ft}^{2} / \mathrm{ac}\right)^{2}$ & 124.402 & 14.702 \\
\hline \%K-S Similar & $13.2 \%$ & $10.5 \%$ \\
\hline
\end{tabular}

\section{Species Group 3 - White oak}

The generalized stand table projection method produced a larger root mean squared error and larger variance of bias. SILVAH projections produced a smaller average absolute bias, and a larger proportion of similar distributions to observed distributions at the 95 percent level, based on the results of the KS test. Table 39 provides summary statistics for species group 3. 
Table 39. Summary statistics for species group 3 in thinned overlapping projections.

\begin{tabular}{|c|c|c|}
\hline & GSTP & $\underline{\text { SILVAH }}$ \\
\hline $\mathrm{n}$ & \multicolumn{2}{|c|}{75} \\
\hline RMSE (ft $\left.{ }^{2} / a c\right)$ & 2.320 & 1.193 \\
\hline Avg Abs Bias (ft' $/ \mathrm{ac})$ & 6.888 & 5.605 \\
\hline Avg Bias ( $\mathrm{ft}^{2} / \mathrm{ac}$ ) & -0.976 & -0.515 \\
\hline Var Bias $\left(\mathrm{ft}^{2} / \mathrm{ac}\right)^{2}$ & 4.488 & 1.173 \\
\hline \%K-S Similar & $42.7 \%$ & $62.7 \%$ \\
\hline
\end{tabular}

\section{Species Group 4 - Hickory/Ash}

SILVAH produced a smaller root mean squared error, variance of bias, and a larger proportion of similar distributions to observed distributions at the 95 percent level, based on the results of the KS test. Table 40 provides summary statistics for species group 4.

Table 40. Summary statistics for species group 4 in thinned overlapping projections.

\begin{tabular}{|c|c|c|}
\hline & GSTP & SILVAH \\
\hline $\mathbf{n}$ & \multicolumn{2}{|c|}{119} \\
\hline RMSE ( $\left.\mathrm{ft}^{2} / \mathrm{ac}\right)$ & 5.071 & 1.437 \\
\hline Avg Abs Bias ( $\mathrm{ft}^{2} / \mathrm{ac}$ ) & 6.311 & 3.925 \\
\hline Avg Bias ( $\left.\mathrm{ft}^{2} / \mathrm{ac}\right)$ & 2.300 & 0.203 \\
\hline Var Bias $\left(\mathrm{ft}^{2} / \mathrm{ac}\right)^{2}$ & 20.597 & 2.040 \\
\hline \%K-S Similar & $54.6 \%$ & $64.7 \%$ \\
\hline
\end{tabular}

\section{Species Group 5 - Yellow-poplar}

SILVAH produced a smaller root mean squared error, smaller average absolute bias, and smaller variance of bias while having a larger proportion of similar distributions to observed distributions at the 95 percent level, based on the results of the KS test. Table 41 provides summary statistics for species group 5. 
Table 41. Summary statistics for species group 5 in thinned overlapping projections.

\begin{tabular}{|c|c|c|}
\hline & GSTP & SILVAH \\
\hline$n$ & \multicolumn{2}{|c|}{137} \\
\hline RMSE ( $\mathrm{ft}^{2} / \mathrm{ac}$ ) & 14.994 & 9.941 \\
\hline Avg Abs Bias ( $\mathrm{ft}^{2} / \mathrm{ac}$ ) & 28.556 & 20.173 \\
\hline Avg Bias ( $\mathrm{ft}^{2} / \mathrm{ac}$ ) & -9.353 & -5.990 \\
\hline Var Bias $\left(\mathrm{ft}^{2} / \mathrm{ac}\right)^{2}$ & 138.356 & 63.403 \\
\hline \%K-S Similar & $19.0 \%$ & $24.1 \%$ \\
\hline
\end{tabular}

\section{Species Group 6 - Striped maple/Pin cherry}

SILVAH projections produced a smaller average absolute bias, smaller root mean squared error, and a smaller variance of bias. Table 42 provides summary statistics for species group 6 .

Table 42. Summary statistics for species group 6 in thinned overlapping projections.

\begin{tabular}{|c|c|c|}
\hline & GSTP & $\underline{\text { SILVAH }}$ \\
\hline $\mathbf{n}$ & \multicolumn{2}{|c|}{61} \\
\hline RMSE (ft $\left.{ }^{2} / \mathrm{ac}\right)$ & 7.002 & 2.987 \\
\hline Avg Abs Bias ( $\mathrm{ft}^{2} / \mathrm{ac}$ ) & 5.683 & 3.215 \\
\hline Avg Bias ( $\mathrm{ft}^{2} / \mathrm{ac}$ ) & 3.591 & 1.442 \\
\hline Var Bias $\left(\mathrm{ft}^{2} / \mathrm{ac}\right)^{2}$ & 36.740 & 6.955 \\
\hline \%K-S Similar & $65.6 \%$ & $49.2 \%$ \\
\hline
\end{tabular}

\section{Species Group 7 - Black cherry}

The generalized stand table projection procedure produced a larger root mean squared error, larger average absolute bias, and larger variance of bias. However, average bias and proportions of similar distributions were not greatly different between the two projection systems. Table 43 provides summary statistics for species group 7 . 
Table 43. Summary statistics for species group 7 in thinned overlapping projections.

\begin{tabular}{|c|c|c|}
\hline & GSTP & $\underline{\text { SILVAH }}$ \\
\hline $\mathbf{n}$ & \multicolumn{2}{|c|}{124} \\
\hline RMSE (ft $\left.{ }^{2} / \mathrm{ac}\right)$ & 9.357 & 8.773 \\
\hline Avg Abs Bias ( $\left.\mathrm{ft}^{2} / \mathrm{ac}\right)$ & 19.164 & 12.671 \\
\hline Avg Bias ( $\mathrm{ft}^{2} / \mathrm{ac}$ ) & -5.187 & -5.126 \\
\hline Var Bias $\left(\mathrm{ft}^{2} / \mathrm{ac}\right)^{2}$ & 61.140 & 51.102 \\
\hline \%K-S Similar & $37.1 \%$ & $41.1 \%$ \\
\hline
\end{tabular}

\section{Species Group 8 - Other}

SILVAH produced a smaller root mean squared error, smaller variance of bias, and smaller average absolute bias, while having a larger proportion of similar distributions to observed distributions at the 95 percent level, based on the results of the KS test. Table 44 provides summary statistics for species group 8.

Table 44. Summary statistics for species group 8 in thinned overlapping projections.

\begin{tabular}{|c|c|c|}
\hline & GSTP & $\underline{\text { SILVAH }}$ \\
\hline $\mathbf{n}$ & \multicolumn{2}{|c|}{147} \\
\hline RMSE (ft ${ }^{2} / \mathrm{ac}$ ) & 6.106 & 3.660 \\
\hline Avg Abs Bias ( $\mathrm{ft}^{2} / \mathrm{ac}$ ) & 9.419 & 5.697 \\
\hline Avg Bias ( $\mathrm{ft}^{2} / \mathrm{ac}$ ) & 1.713 & 1.046 \\
\hline Var Bias $\left(\mathrm{ft}^{2} / \mathrm{ac}\right)^{2}$ & 34.587 & 12.383 \\
\hline \%K-S Similar & $40.1 \%$ & $47.6 \%$ \\
\hline
\end{tabular}

\section{Species Group 9 - Black and Scarlet oaks}

SILVAH produced a slightly smaller root mean squared error, smaller variance of bias, slightly smaller average absolute bias, and exactly the same proportion of similar distributions to observed distributions at the 95 percent level as did generalized stand table projection. Table 45 provides summary statistics for species group 9 . 
Table 45. Summary statistics for species group 9 in thinned overlapping projections.

\begin{tabular}{|c|c|c|}
\hline & GSTP & $\underline{\text { SILVAH }}$ \\
\hline $\mathbf{n}$ & \multicolumn{2}{|c|}{20} \\
\hline RMSE ( $\left.\mathrm{ft}^{2} / \mathrm{ac}\right)$ & 1.818 & 1.155 \\
\hline Avg Abs Bias ( $\mathrm{ft}^{2} / \mathrm{ac}$ ) & 2.694 & 2.290 \\
\hline Avg Bias ( $\left.\mathrm{ft}^{2} / \mathrm{ac}\right)$ & -1.115 & -0.519 \\
\hline Var Bias $\left(\mathrm{ft}^{2} / \mathrm{ac}\right)^{2}$ & 2.172 & 1.122 \\
\hline \%K-S Similar & $75.0 \%$ & $75.0 \%$ \\
\hline
\end{tabular}

\section{Species Group 10 - Birch}

SILVAH produced a smaller root mean squared error, smaller variance of bias, and smaller average absolute bias. The two methods produced similar proportions of similar distributions at the 95 percent level. Table 46 provides summary statistics for species group 10.

Table 46. Summary statistics for species group 10 in thinned overlapping projections.

\begin{tabular}{|c|c|c|}
\hline & GSTP & SILVAH \\
\hline $\bar{n}$ & \multicolumn{2}{|c|}{142} \\
\hline RMSE ( $\left.\mathrm{ft}^{2} / \mathrm{ac}\right)$ & 7.422 & 5.074 \\
\hline Avg Abs Bias ( $\left.\mathrm{ft}^{2} / \mathrm{ac}\right)$ & 7.036 & 4.362 \\
\hline Avg Bias ( $\left.\mathrm{ft}^{2} / \mathrm{ac}\right)$ & 3.735 & 1.735 \\
\hline Var Bias $\left(\mathrm{ft}^{2} / \mathrm{ac}\right)^{2}$ & 41.427 & 22.899 \\
\hline \%K-S Similar & $50.0 \%$ & $49.3 \%$ \\
\hline
\end{tabular}

\section{Thinned Overlapping Summary}

The generalized stand table projection method produced a combination of smaller errors, smaller variance, or a larger proportion of significant distributions in a manner that would suggest performance as good as or better than SILVAH for species groups 1 (northern red oak), 7 (black cherry), and 9 (scarlet and black oaks), and at the plot level across all species groups and diameter classes. SILVAH produced smaller errors on species groups 2 (maples), 3 (white oaks), 4 (hickory/ash), 5 (yellow-poplar), 6 (striped maple/pin cherry), 8 (other), and 10 (birches). Figures 37 and 38 show projection errors for the species group with lowest generalized stand table projection root mean squared error (species group 9) for 
thinned overlapping projections. Figures 39 and 40 show projection error for the species group with highest generalized stand table projection root mean squared error (species group 5) for thinned overlapping projections. The remaining projection error plots may be found in Appendix C, Figures 100115.

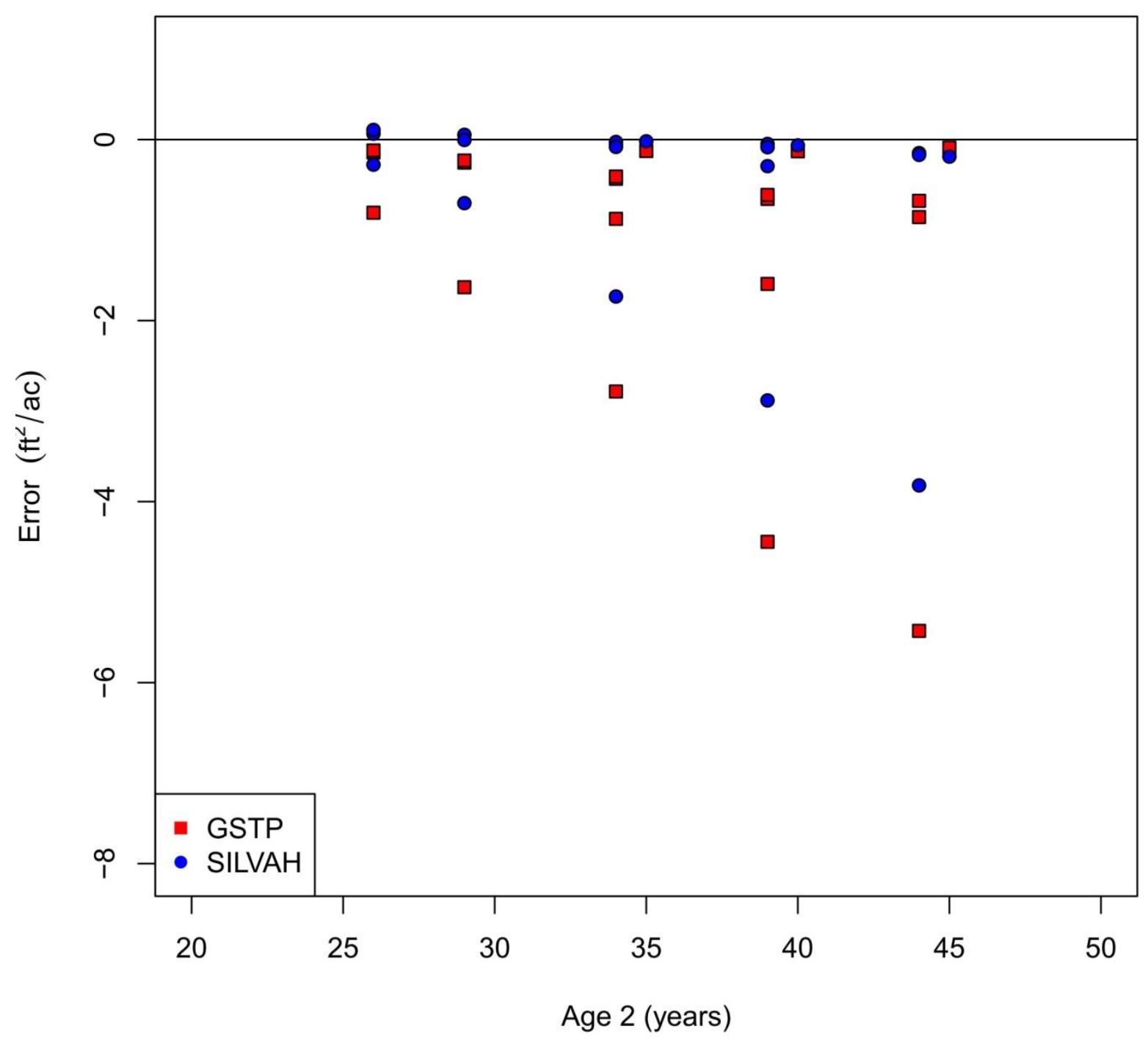

Figure 37. Species group 9 (black and scarlet oaks) projection errors by projection age (age 2) for thinned overlapping projections. 


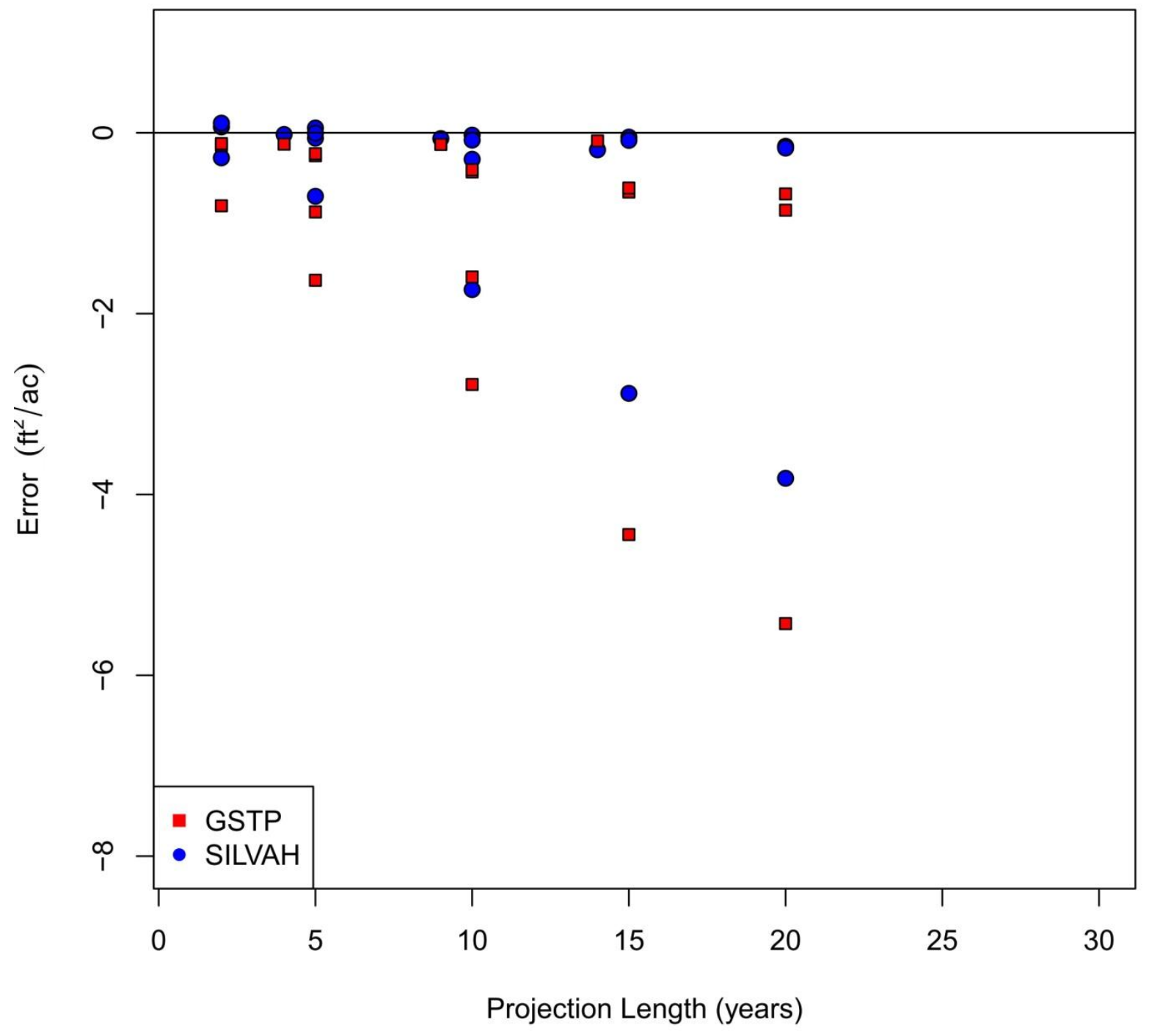

Figure 38. Species group 9 (black and scarlet oaks) projection errors by projection length for thinned overlapping projections. 


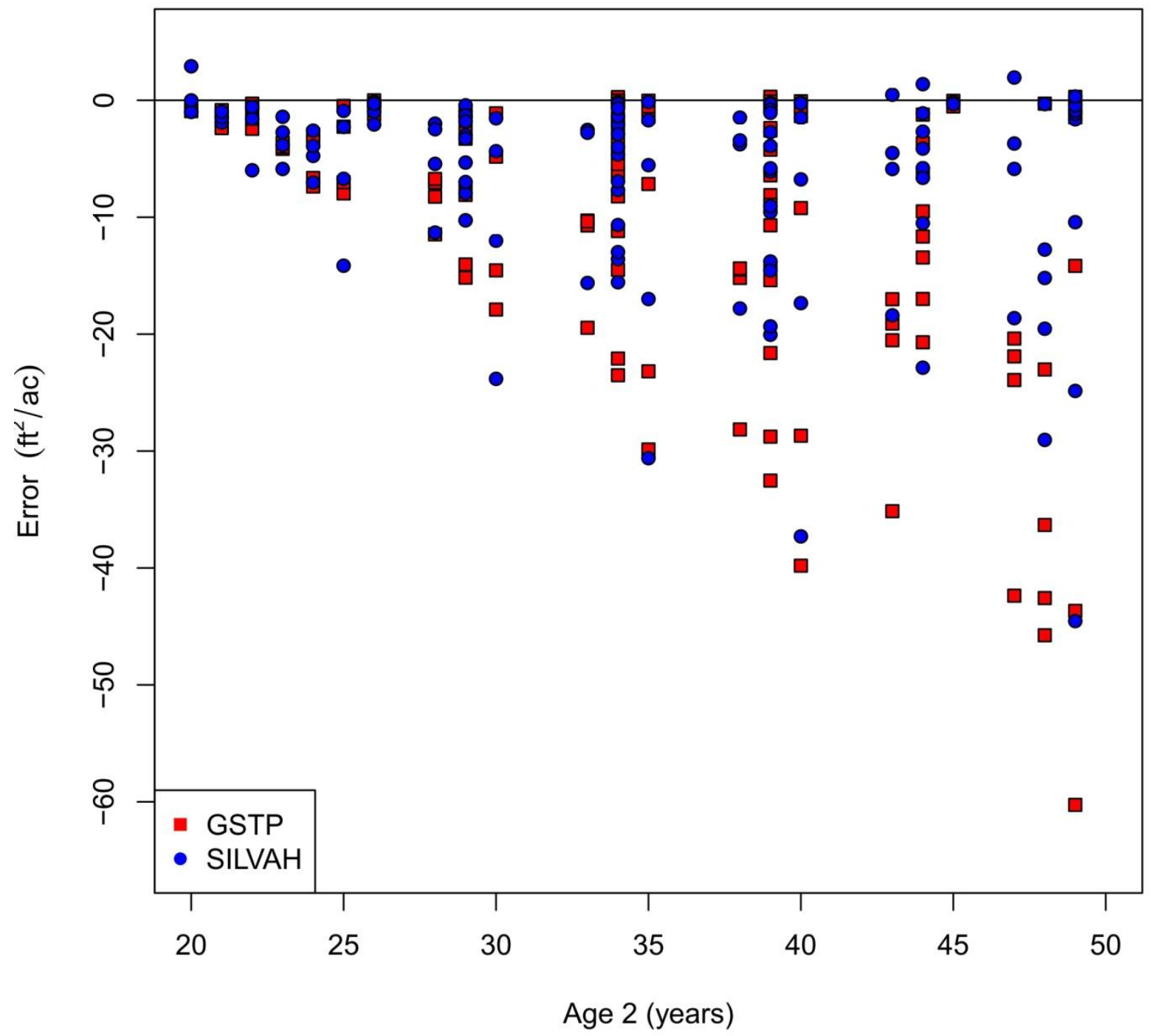

Figure 39. Species group 5 (yellow-poplar) projection errors by projection age (age 2) for thinned overlapping projections. 


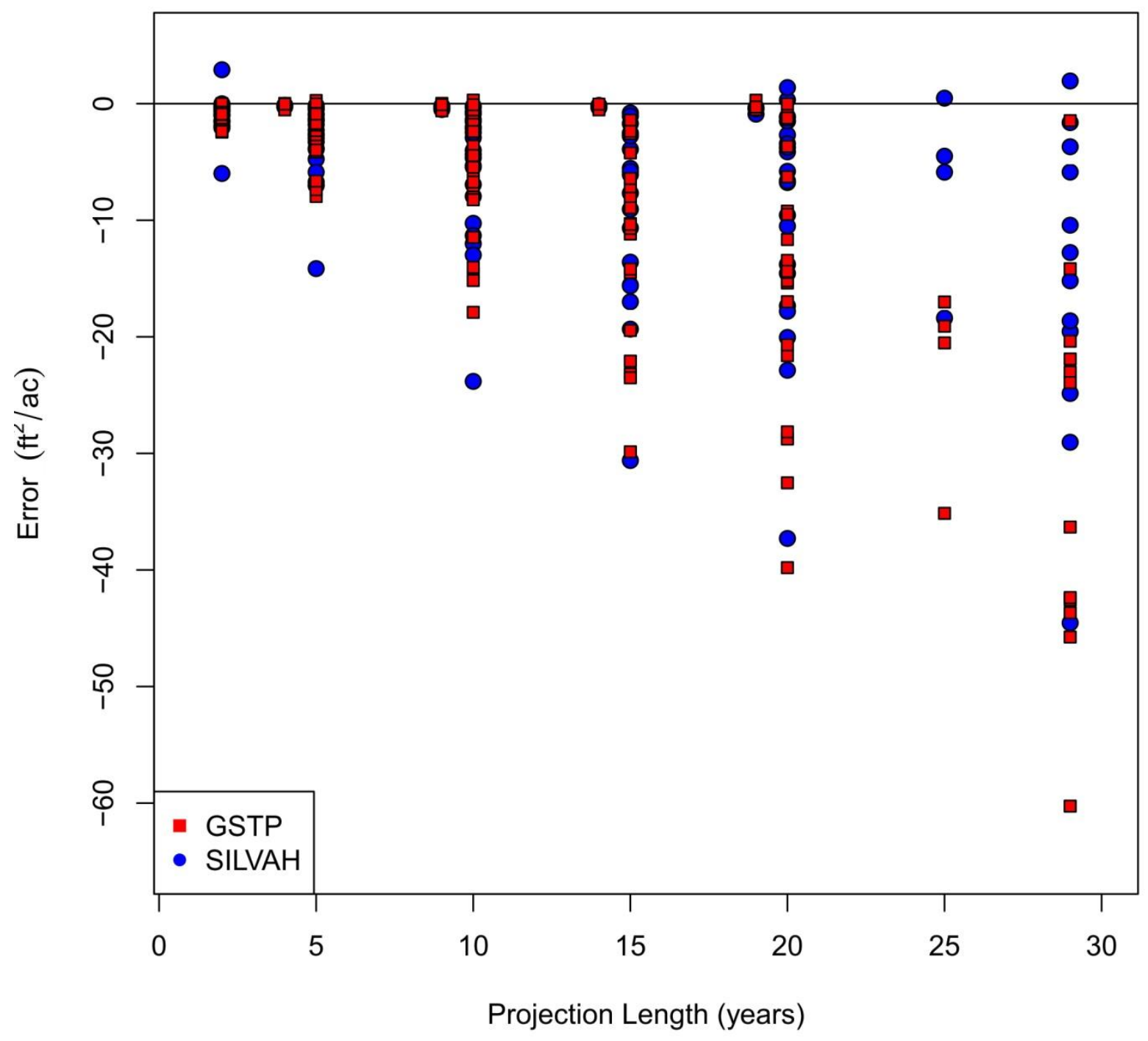

Figure 40. Species group 5 (yellow-poplar) projection errors by projection length for thinned overlapping projections.

\section{Chapter 5. Discussion and Conclusions}

While accurate and efficient growth and yield models are imperative for long term forest management, they are scarce in the Central Appalachian Hardwoods region (Brooks 2008). Previous growth and yield systems for this region disregard the growth differences between thinned and unthinned stands, using the 
same model form and parameter estimates for both projections. Whole stand models have recently become available that provide improved predictions over previous models (Brooks 2012), but the level of information retrievable from whole stand models is still lacking. A disaggregation of whole stand models into species, or groups of species, by diameter class is necessary to provide the information needed for management of multispecies stands.

The purpose of this research was to disaggregate the whole stand models presented by Brooks (2012) into diameter class distributions by groups of species. The feasibility of using a generalized stand table projection as a means of basal area growth projection to disaggregate whole stand data was examined. The same data from the Fernow Experimental Forest used to develop the whole stand models (Brooks 2012) was utilized in this study, and was projected using the generalized stand table projection approach introduced by Pienaar and Harrison (1988). The disaggregation of the whole stand models using the generalized stand table projection process was tested against basal area projections by SILVAH.

Species groups were constructed based on silvical and statistical similarities between species by considering their basal area growth patterns. Ten species groups were constructed. A modification of the Pienaar and Harrison (1988) model was fit to data from both thinned and unthinned stands and parameter estimates were significant at the $\mathrm{p} \leq 0.0001$ level. Many species groups produced similar parameter estimates. Those similar species groups could have been combined into another species group, but with the sacrifice of accuracy. There comes a point of diminishing returns, where further dividing or aggregating species groups adds no additional accuracy to the projections.. While the parameters on several species groups may appear to be similar, it is believed the aggregation of those species groups together would produce less accurate projections when combined, as compared to the species groups presented in this research. The goal was to provide as many species groups that could be supported by the observed basal area growth patterns and the quantity of data available for model fitting. 
When gauging the performance between the generalized stand table projection and SILVAH, several factors were taken into consideration. Root mean squared error, mean absolute bias, mean bias, absolute bias, and variance of projection error were considered. For many growth intervals, SILVAH and the generalized stand table projection method performed similarly. In these instances the error variance was examined to discern differences. If errors were similar between SILVAH and the generalized stand table projection method, the technique providing the smaller error variance was considered superior.

Generalized stand table projection showed a marked improvement over SILVAH at the plot level, when averaged across all species groups and diameter classes. For unthinned non-overlapping growth intervals, the root mean squared error for generalized stand table projection plot level basal area was $2.784 \mathrm{ft}^{2} / \mathrm{ac}$., while SILVAH's root mean squared error was $6.872 \mathrm{ft}^{2} /$ ac. For unthinned overlapping growth intervals, the root mean squared error for generalized stand table projection plot level basal was $4.255 \mathrm{ft}^{2} / \mathrm{ac}$., while SILVAH's root mean squared error was $13.658 \mathrm{ft}^{2} / \mathrm{ac}$. For thinned non-overlapping growth intervals, the root mean squared error for generalized stand table projection plot level basal was $2.657 \mathrm{ft}^{2} / \mathrm{ac}$., while SILVAH's root mean squared error was $6.359 \mathrm{ft}^{2} / \mathrm{ac}$. For thinned overlapping growth intervals, the root mean squared error for generalized stand table projection plot level basal was $3.259 \mathrm{ft}^{2} / \mathrm{ac}$., while SILVAH's root mean squared error was $13.361 \mathrm{ft}^{2} / \mathrm{ac}$.

At the species group level on non-overlapping growth projection intervals, the generalized stand table projection system exhibited similar or smaller average errors than SILVAH for most species groups. For unthinned non-overlapping growth intervals, the generalized stand table projection produced a combination of smaller errors, smaller variance, or a larger proportion of significant distributions in a manner that would suggest better performance than SILVAH for the hickory/ash, other, and birch species groups. For thinned non-overlapping growth intervals, the generalized stand table projection produced a combination of smaller errors, smaller variance, or a larger proportion of significant distributions in a manner that would suggest better performance than SILVAH for the hickory/ash, yellow-poplar, black cherry, and birch species groups. 
While the generalized stand table projection system performed less desirably on overlapping growth intervals for both thinned and unthinned stands, the differences in root mean squared error was not excessive (less than $7.137 \mathrm{ft}^{2} / \mathrm{ac}$ ). For unthinned overlapping growth intervals, the generalized stand table projection system produced a combination of larger errors, larger variance, or a smaller proportion of significant distributions in a manner that would suggest poorer performance than SILVAH for the maple, white oak, hickory and ash, yellow-poplar, black cherry, and other species groups.However, the mean absolute difference in root mean squared error between SILVAH and the generalized stand table projection across all species groups was only $2.572 \mathrm{ft}^{2} / \mathrm{ac}$. For thinned overlapping growth intervals, the generalized stand table projection system produced a combination of larger errors, larger variance, or a smaller proportion of significant distributions in a manner that would suggest poorer performance than SILVAH for the maple, white oak, hickory and ash, yellow-poplar, striped maple and pin cherry, other, and birch species groups. However, the mean absolute difference in root mean squared error between SILVAH and the generalized stand table projection across all species groups was only $2.748 \mathrm{ft}^{2} / \mathrm{ac}$.

Both overlapping and non-overlapping projection lengths were included for analysis. Fitting parameters for non-overlapping projection lengths afford more accurate projections for short intervals. Fitting parameters for overlapping projection lengths afford more accurate projections for longer intervals. An explanation of the lower accuracy of overlapping projection lengths in this research may stem from the fact that species group parameters were fit using only non-overlapping data. The average projection length for non-overlapping data was 4.58 years and ranged from 2 to 10 years, while the average projection length for both overlapping and non-overlapping projection lengths combined is 8.47 years. If the species group parameters were refit using both overlapping and non-overlapping data, then the accuracy of the non-overlapping projections would be expected to increase at the expense of the accuracy of the non-overlapping projections.

The generalized stand table projection method performed somewhat poorly for the yellow-poplar species groups on all projection lengths. This species group produced the highest root mean squared error when 
compared to all other species on all projection lengths, and the largest prediction variance on all projection lengths, except one. The yellow-poplar group had the highest relative basal area prediction mean squared error for the unthinned data and the second highest mean squared error for thinned data. An explanation for these phenomena may due to several factors. First, all the species of the yellow-poplar group sprout prolifically. Potentially, rapid initial sprouting after harvest followed by a slower growth rate could give the species group a somewhat irregular basal area growth pattern. Also, the growth rate for yellow-poplar is highly variable depending upon the site on which it is located (Hicks 1998). Because of the variability of site indices on these plots, yellow-poplar could grow at very different rates across the Fernow dataset from which parameters were fit. Lastly, in plots where the yellow-poplar group was present, the group constituted a large proportion of the total basal area of the stand when other species groups. For example, on the unthinned non-overlapping dataset, the yellow-poplar group contained the highest basal area per acre on 32.2 percent of the age 1 measurements in which the group yellow-poplar is present, the black cherry group contained the highest basal area per acre on 23.0 percent of the age 1 measurements in which the black cherry group is present, and the maple group contained the highest basal area per acre on 33.7 percent of the age 1 measurements in which the maple group is present. These three species groups produced the three largest root mean squared errors on that dataset, and constituted the three species groups that most frequently had the largest basal area on any given projection length. On the thinned non-overlapping dataset, the four largest root mean squared errors by species group were produced by the yellow-poplar, northern red oak, black cherry, and maple groups. The yellow-poplar group contained the highest basal area per acre on 38.7 percent of the age 1 measurements in which the yellow-poplar group is present, the black cherry group contained the highest basal area per acre on 13.6 percent of the age 1 measurements in which the black cherry group is present, and the maple group contained the highest basal area per acre on 44.7 percent of the age 1 measurements in which the maple group is present. These species groups had three of the four highest root mean squared errors on the thinned non-overlapping dataset. This basic analysis may suggest a trend between a larger proportion of 
total stand basal area and a larger root mean squared error. Further investigation would be required to either confirm or deny such claims.

This research indicates that, especially with non-overlapping growth projection intervals, the generalized stand table projection shows promise as a means for basal area projection in mixed species stands in the Central Appalachian Hardwoods region. In general, the generalized stand table projection system provided future basal area estimates as good as SILVAH for all species groups in at least one dataset and projection type combination. Generalized stand table projection also produced more accurate future basal area estimates than SILVAH for the hickory/ash, yellow-poplar, black cherry, other, and birch species groups in at least one dataset and projection type combination. When analyzed across all diameter classes and species groups, the generalized stand table projection methods was always superior. 


\section{$\underline{\text { Bibliography }}$}

Adams, M.B., P.J. Edwards, M.W. Ford, T.M. Schuler, M. Thomas-Van Gundy, F. Wood. 2012. Fernow Experimental Forest: Research History and Opportunities. Experimental Forests and Ranges EFR-2. $26 \mathrm{p}$.

Avery, T.E., and H.E. Burkhart. 2002. Forest measurements. $5^{\text {th }}$-ed. McGraw-Hill, New York. 480 p.

Borders, B.E. and W.D. Patterson. 1990.Projecting stand tables: a comparison of the Weibull diameter distribution method, a percentile-based projection method, and a basal area growth projection method. For. Sci. 36(2):413-424.

Brooks, J. R. 2008. Summary Report: Growth and Yield Systems in the mid-Appalachian Region. Appalachian Hardwood Forest Research Alliance Technical Report. September 2008, 26 pp.

Brooks, J. R. 2012. Central Appalachian hardwood whole stand growth and yield models. Appalachian Hardwood Forest Research Alliance Technical Report. January 2012, 46 pp.

Brooks, John R., L. Jiang, M. Perkowski, and B. Sharma. 2008. A whole stand basal area growth model for Appalachian hardwoods. In Proceedings. 16th Central Hardwood Forest Conference; 2008 April 8-9; Lafayette, IN. Gen. Tech. Rep. NRS-P-24. p. 324-330.

Brooks, J.R. and H.V. Wiant, Jr. 2004. A simple technique for estimating cubic volume yields. Forest Ecology and Management 203:373-380.

Brooks, John R. and H. V. Wiant, Jr. 2008. Ecoregion-based local volume equations for Appalachian hardwoods. North. Jour. Applied Forestry 25(2):87-92.

Bush, R.R. 1995. Northeast (NE) variant overview: Forest Vegetation Simulator. USDA For. Ser. WOTM $37 \mathrm{p}$.

Clutter, J.L. and E.P. Jones, Jr. 1980. Prediction of growth after thinning in old-field slash pine plantations. USDA For. Serv. Res. Pap. SE-217. 14p.

Colbert, J.J. and G. Racin. 1995. User's guide to the Stand Damage Model: a component of the Gypsy Moth Life System Model (Version 1.1). USDA For. Ser. GTR NE-207. 38 p.

Dale, M.E. 1972. Growth and yield predictions for upland oak stands: 10 years after initial thinning. USDA For. Serv. Res. Pap. NE-241. 21p.

Dixon, G. E.; C. E. Keyser, comps. 2008 (revised June 2, 2014). Northeast (NE) Variant Overview Forest Vegetation Simulator. Internal Rep. Fort Collins, CO: U. S. Department of Agriculture, Forest Service, Forest Management Service Center. 47p.

Hilt, Donald E. 1985. OAKSIM: An individual-tree growth and yield simulator for managed, even-aged, upland oak stands. USDA For. Serv. Res. Pap. NE-562. 21p.

Hicks, Ray R., Jr. 1998. Ecology and Management of Central Hardwood Forests. John Wiley and Sons, Inc. New York City, New York. 412 p. 
Massey, F.J., Jr. 1951. The Kolmogorov-Smirnov Test for goodness of fit. Journal of the American Statistical Association. 46(253):68-78.

Knowe, S.A. 1994. Incorporating the effects of interspecific competition and vegetation management treatments in stand table projection models for Douglas-fir saplings. Forest ecology and management. 67(1-3):87-99.

Marquis, David A. 1982. SILVAH: a stand growth simulator for Allegheny Hardwoods. Unpublished office report on file at the Forestry Sciences Laboratory. Northeastern Forest Experiment Station

Marquis, D.A. and R.L. Ernst. 1995. User's guide to SILVAH: Stand analysis, prescription, and management simulator program for hardwood stands of the Alleghenies. USDA For. Ser. GTR NE162. $132 \mathrm{p}$.

Pienaar, L.V., and W.M. Harrison. 1988. A stand table projection approach to yield prediction in unthinned even-aged stands. For. Sci. 34(3):804-808.

Schnur, G.L. 1937. Yield, stand and volume tables for even-aged upland oak forests. US Department of Agriculture Tech. Bulletin 560, 87p.

Shiver, B.D., and B. E. Borders. 1996 Sampling techniques for forest resource inventory. Wiley, New York. 368 p.

Teck, R.M. and D.E. Hilt. 1991.Individual-tree diameter growth model for the Northeastern United States. USDA For. Serv. Res. Pap. NE-649. 11p.

Yandle, D.O., J.R. Myers, J.H. Mayo and N.L. Lamson. 1987. Development and application of a standbased growth model for mixed hardwood stands. In IUFRO Forest Growth Modeling and Prediction Conference, Minneapolis, MN. August 24-28. 231-238.

Zar, J.H. 1999. Biostatistical analysis. $4^{\text {th }}$-ed. Prentice Hall, Upper Saddle River, New Jersey. p. 475-483. 
Appendix A. Initial Stand Parameters 
Table 47. Initial stand parameters.

\begin{tabular}{|c|c|c|c|c|c|c|}
\hline \multirow{2}{*}{ Compartment } & \multirow{2}{*}{ Plot } & \multirow{2}{*}{ Type } & \multicolumn{3}{|c|}{ Initial } & \multirow{2}{*}{ Remeasurments } \\
\hline & & & Age & TPA & BAAC ( $\left.\mathrm{ft}^{2} / \mathrm{ac}\right)$ & \\
\hline 32 & 321 & Thinned & 20 & 1426 & 54.69 & 7 \\
\hline 32 & 322 & Thinned & 20 & 922 & 50.34 & 7 \\
\hline 32 & 323 & Thinned & 20 & 1050 & 49.80 & 7 \\
\hline 32 & 324 & Thinned & 20 & 1426 & 56.77 & 7 \\
\hline 32 & 325 & Unthinned & 20 & 1532 & 79.81 & 7 \\
\hline 32 & 326 & Unthinned & 20 & 1136 & 87.43 & 7 \\
\hline 33 & 331 & Thinned & 19 & 628 & 40.04 & 7 \\
\hline 33 & 332 & Thinned & 19 & 740 & 40.43 & 7 \\
\hline 33 & 333 & Thinned & 19 & 1810 & 57.08 & 7 \\
\hline 33 & 334 & Thinned & 19 & 1090 & 48.84 & 7 \\
\hline 33 & 335 & Unthinned & 19 & 772 & 75.85 & 7 \\
\hline 33 & 336 & Unthinned & 19 & 1736 & 102.51 & 7 \\
\hline 34 & 341 & Thinned & 29 & 244 & 37.77 & 4 \\
\hline 34 & 342 & Thinned & 29 & 262 & 38.09 & 4 \\
\hline 34 & 343 & Thinned & 29 & 246 & 38.14 & 4 \\
\hline 34 & 344 & Thinned & 29 & 290 & 37.93 & 4 \\
\hline 34 & 345 & Unthinned & 19 & 1236 & 82.90 & 6 \\
\hline 34 & 346 & Unthinned & 19 & 1356 & 86.46 & 6 \\
\hline 35 & 351 & Thinned & 29 & 172 & 31.41 & 4 \\
\hline 35 & 352 & Thinned & 29 & 292 & 32.54 & 4 \\
\hline 35 & 353 & Thinned & 29 & 198 & 31.37 & 4 \\
\hline 35 & 354 & Thinned & 29 & 194 & 32.83 & 4 \\
\hline 35 & 355 & Unthinned & 19 & 1172 & 75.45 & 6 \\
\hline 35 & 356 & Unthinned & 19 & 1028 & 82.36 & 6 \\
\hline 36 & 361 & Thinned & 24 & 550 & 47.70 & 6 \\
\hline 36 & 362 & Thinned & 24 & 666 & 48.43 & 6 \\
\hline 36 & 363 & Thinned & 24 & 856 & 50.11 & 6 \\
\hline 36 & 364 & Thinned & 24 & 492 & 46.77 & 6 \\
\hline 36 & 365 & Unthinned & 19 & 1092 & 63.17 & 7 \\
\hline 36 & 366 & Unthinned & 19 & 980 & 58.94 & 7 \\
\hline 37 & 371 & Thinned & 24 & 644 & 41.85 & 6 \\
\hline 37 & 372 & Thinned & 24 & 394 & 36.71 & 6 \\
\hline 37 & 373 & Thinned & 24 & 340 & 35.17 & 6 \\
\hline 37 & 374 & Thinned & 24 & 276 & 34.58 & 6 \\
\hline 37 & 375 & Unthinned & 19 & 1220 & 76.94 & 7 \\
\hline 37 & 376 & Unthinned & 19 & 756 & 73.69 & 7 \\
\hline 38 & 381 & Thinned & 30 & 252 & 42.78 & 4 \\
\hline 38 & 382 & Thinned & 30 & 230 & 41.20 & 4 \\
\hline 38 & 383 & Thinned & 30 & 362 & 42.54 & 4 \\
\hline 38 & 384 & Thinned & 30 & 396 & 43.43 & 4 \\
\hline 38 & 385 & Unthinned & 20 & 1556 & 84.44 & 6 \\
\hline 38 & 386 & Unthinned & 20 & 1612 & 83.09 & 6 \\
\hline 43 & 431 & Thinned & 18 & 1506 & 25.88 & 8 \\
\hline 43 & 432 & Thinned & 18 & 856 & 48.73 & 8 \\
\hline 43 & 433 & Thinned & 18 & 1182 & 55.65 & 8 \\
\hline 43 & 434 & Thinned & 18 & 1390 & 59.23 & 8 \\
\hline 43 & 435 & Unthinned & 18 & 1340 & 86.68 & 8 \\
\hline 43 & 436 & Unthinned & 18 & 1224 & 64.22 & 8 \\
\hline
\end{tabular}


Appendix B. Additional Species Group Parameter Relative Basal Area

Projection Error Plots 
Unthinned Parameters Relative Basal Area Projection Error Plots

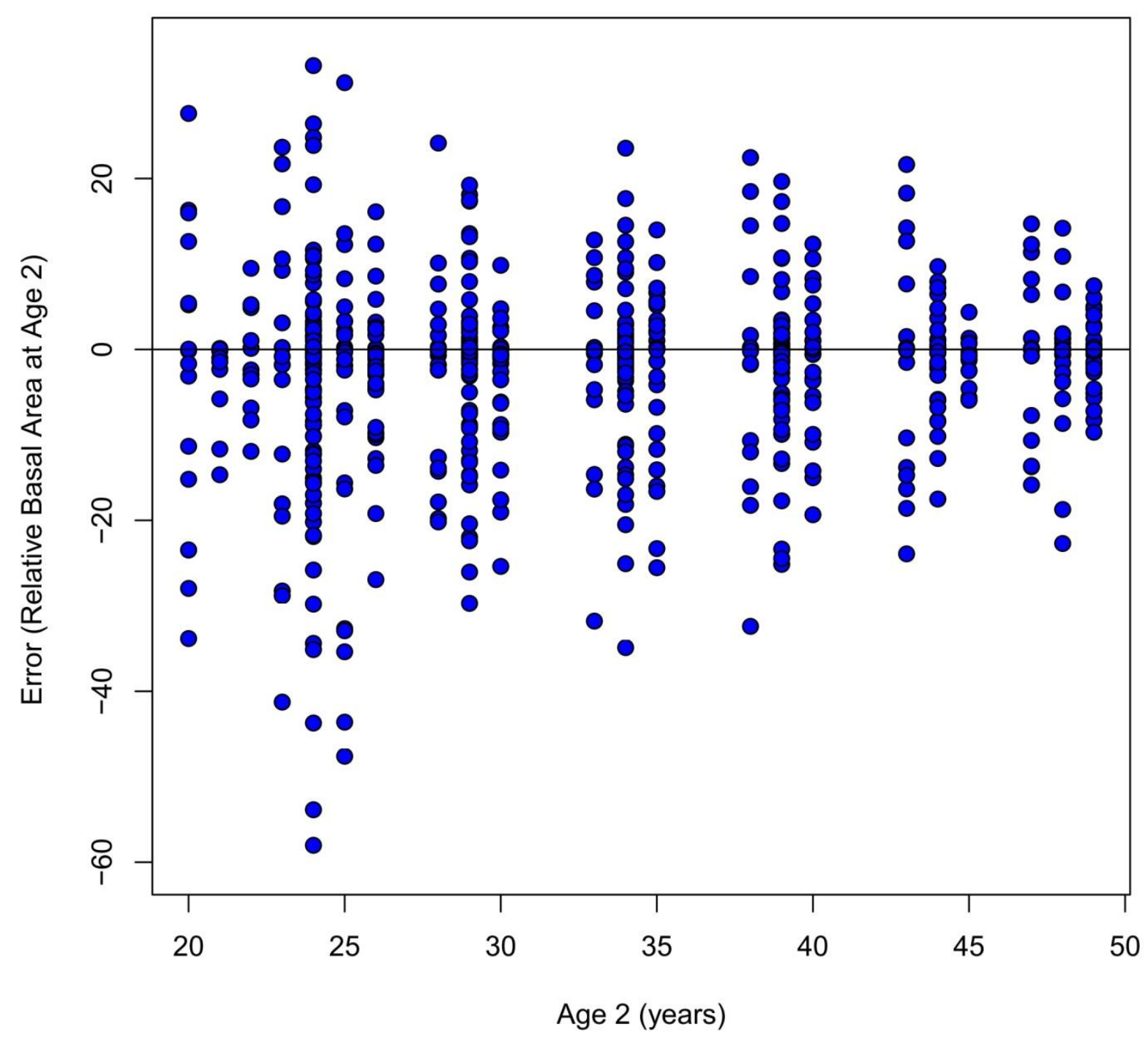

Figure 41. Species group 1 (northern red oak) relative basal area prediction error by age 2 for unthinned plots. 


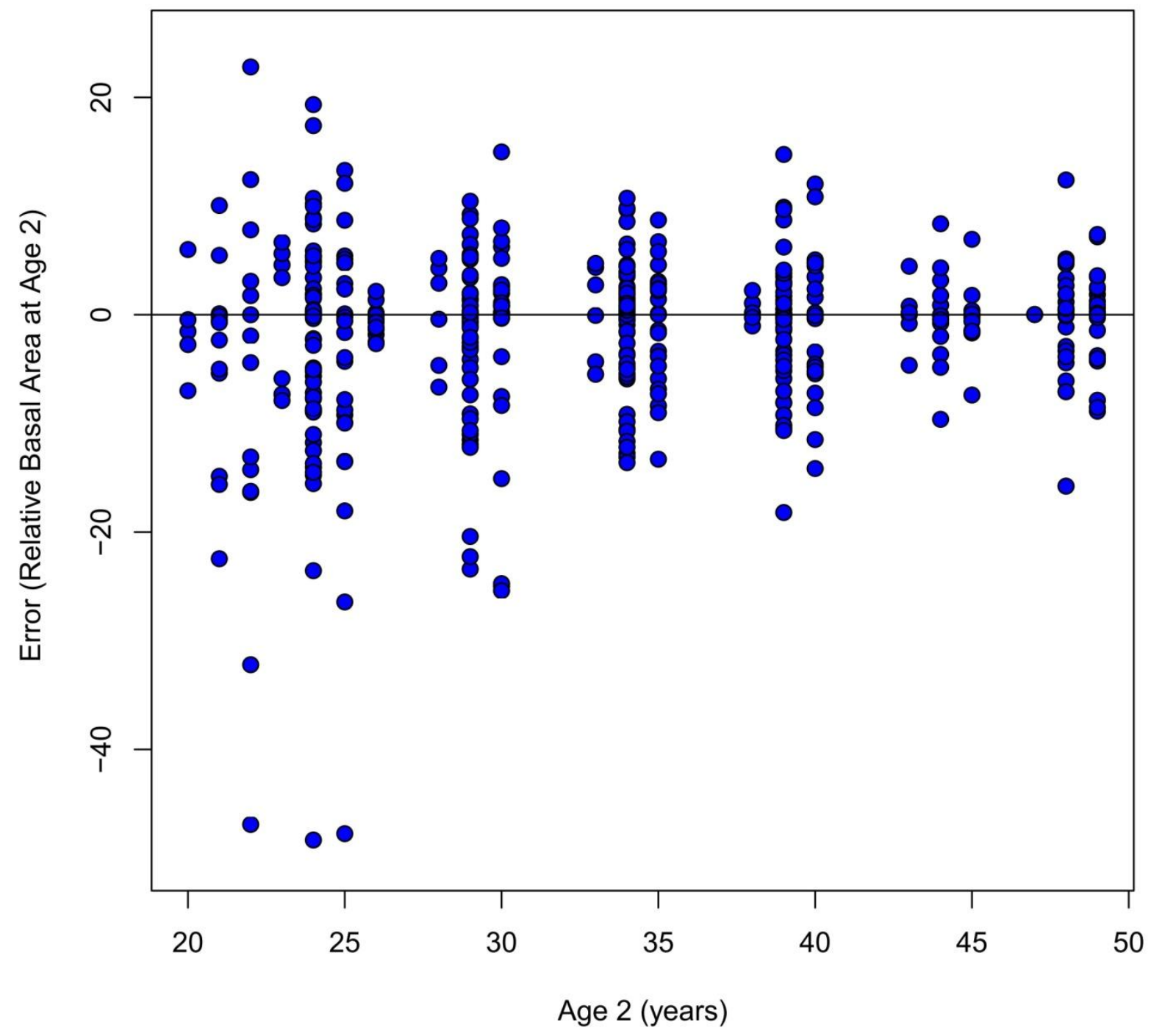

Figure 42. Species group 2 (maples) relative basal area prediction error by age 2 for unthinned plots. 


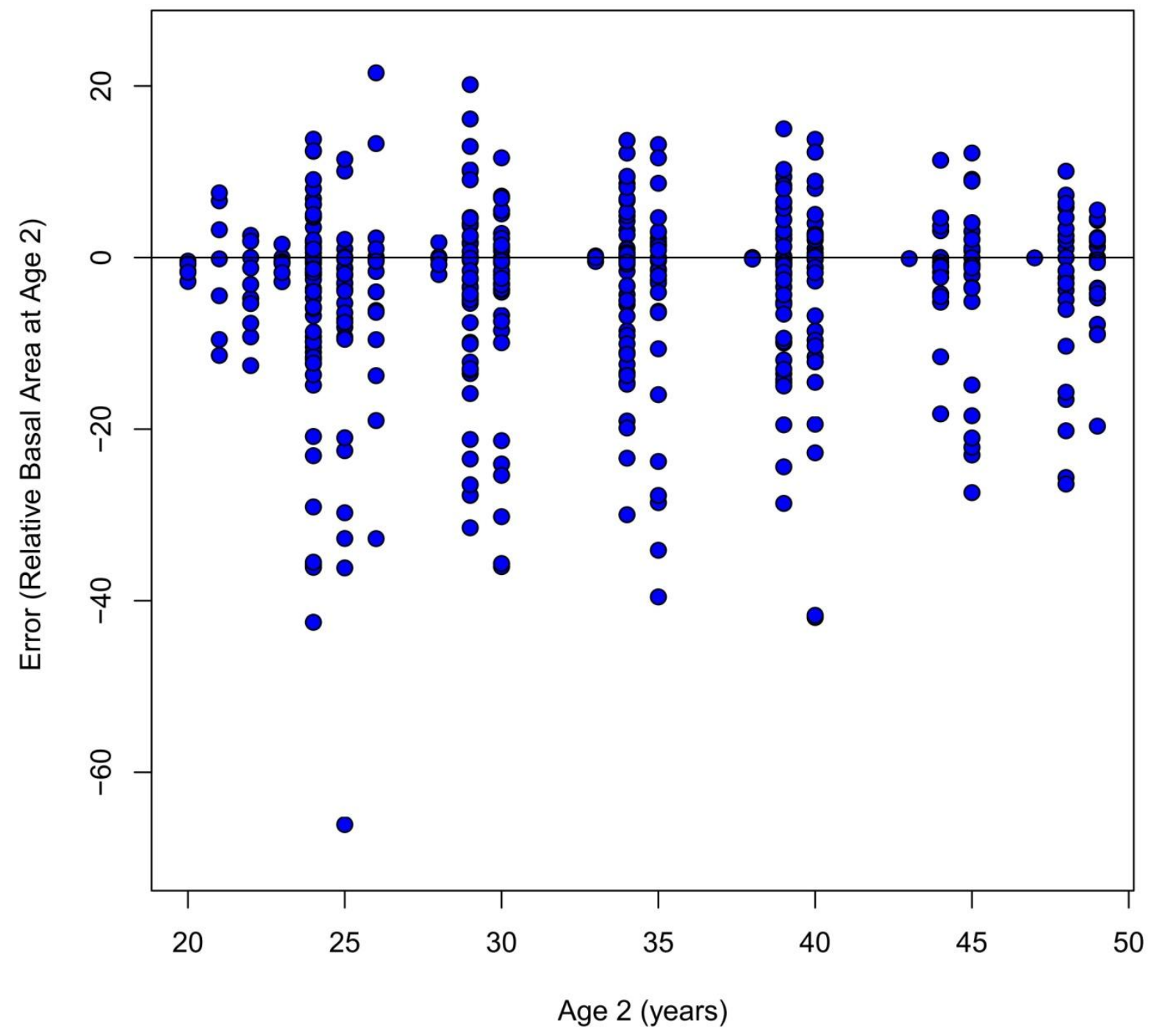

Figure 43. Species group 3 (white oaks) relative basal area prediction error by age 2 for unthinned plots. 


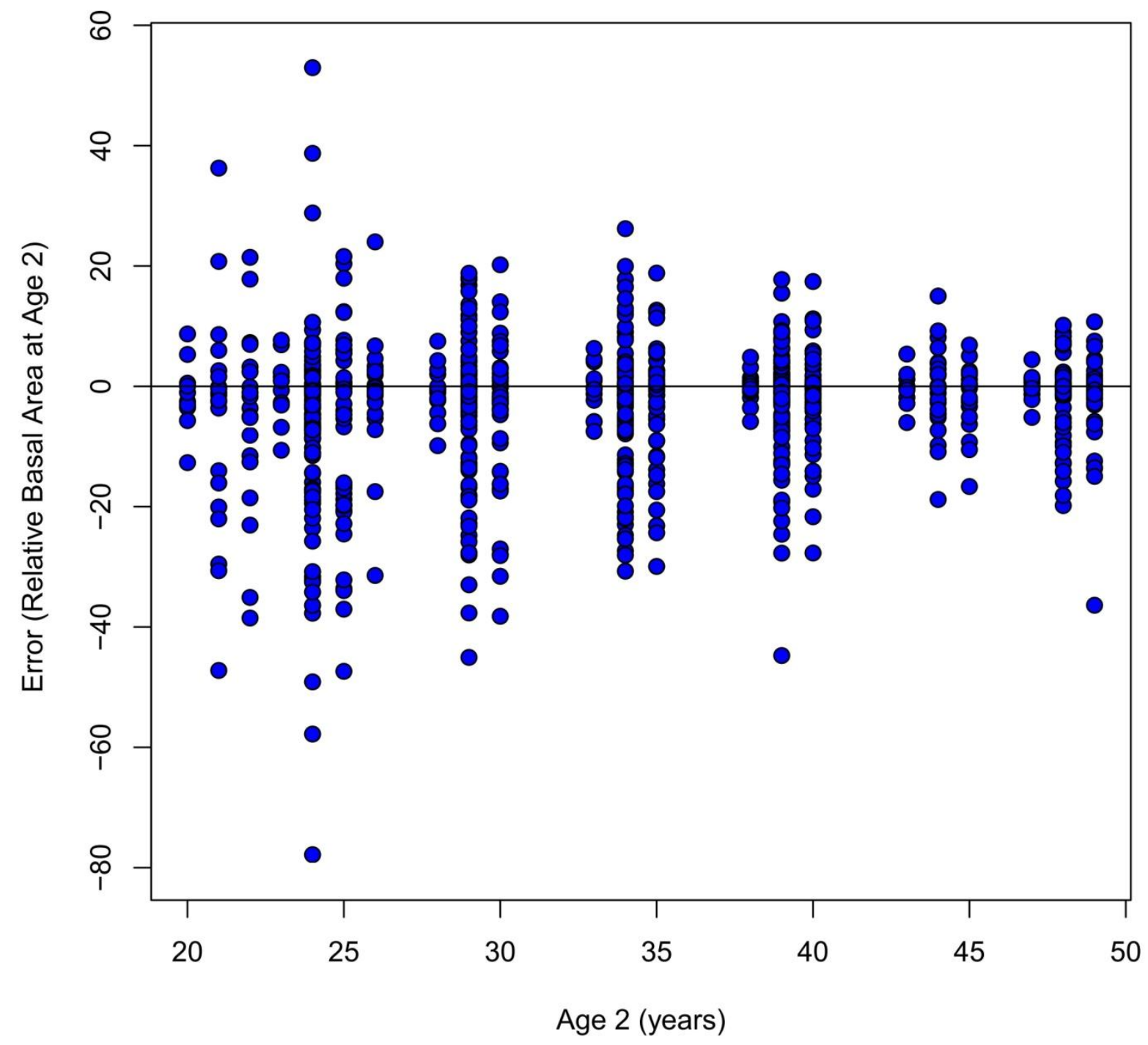

Figure 44. Species group 5 (yellow-poplar) relative basal area prediction error by age 2 for unthinned plots. 


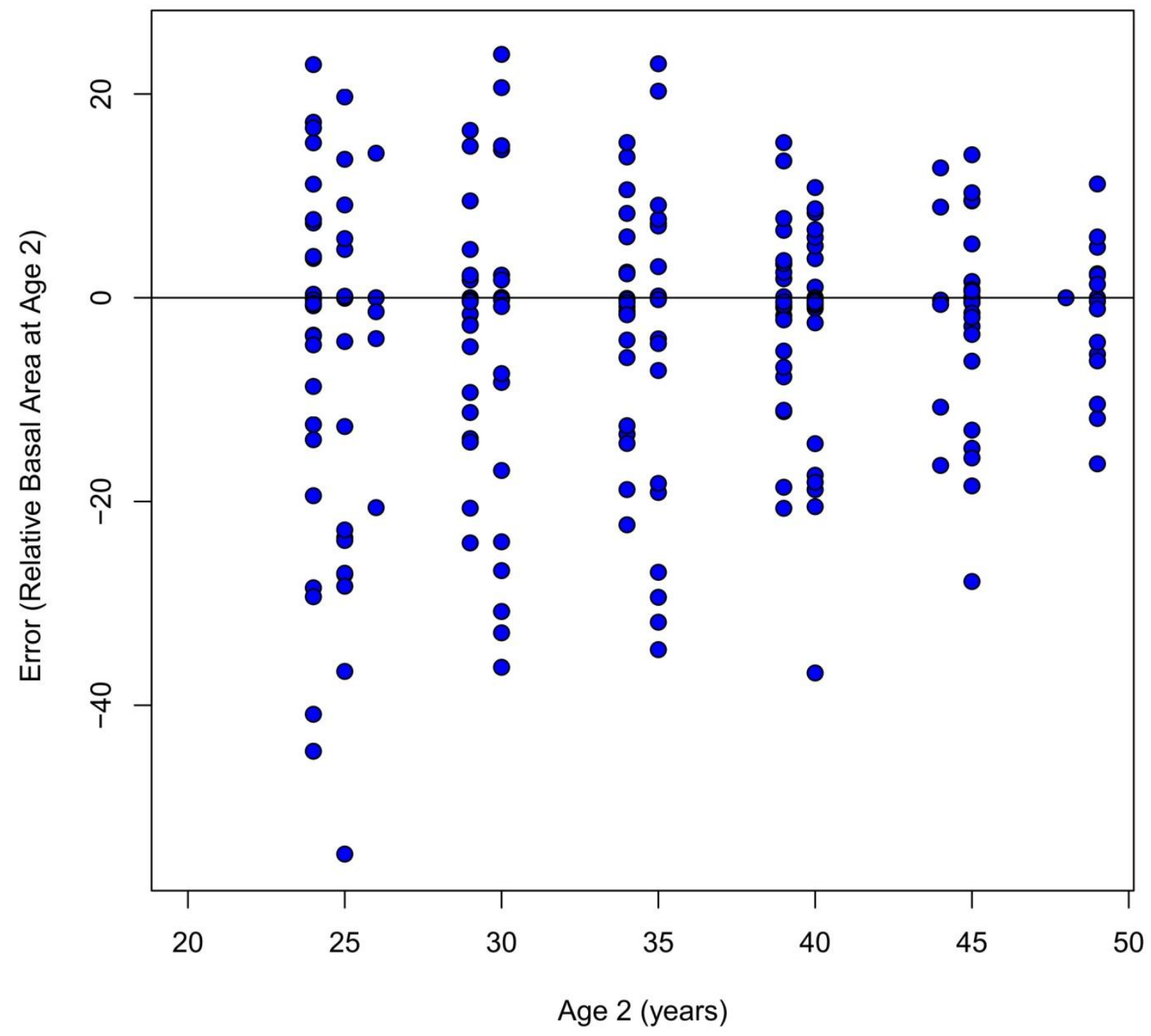

Figure 45. Species group 6 (striped maple/pin cherry) relative basal area prediction error by age 2 for unthinned plots. 


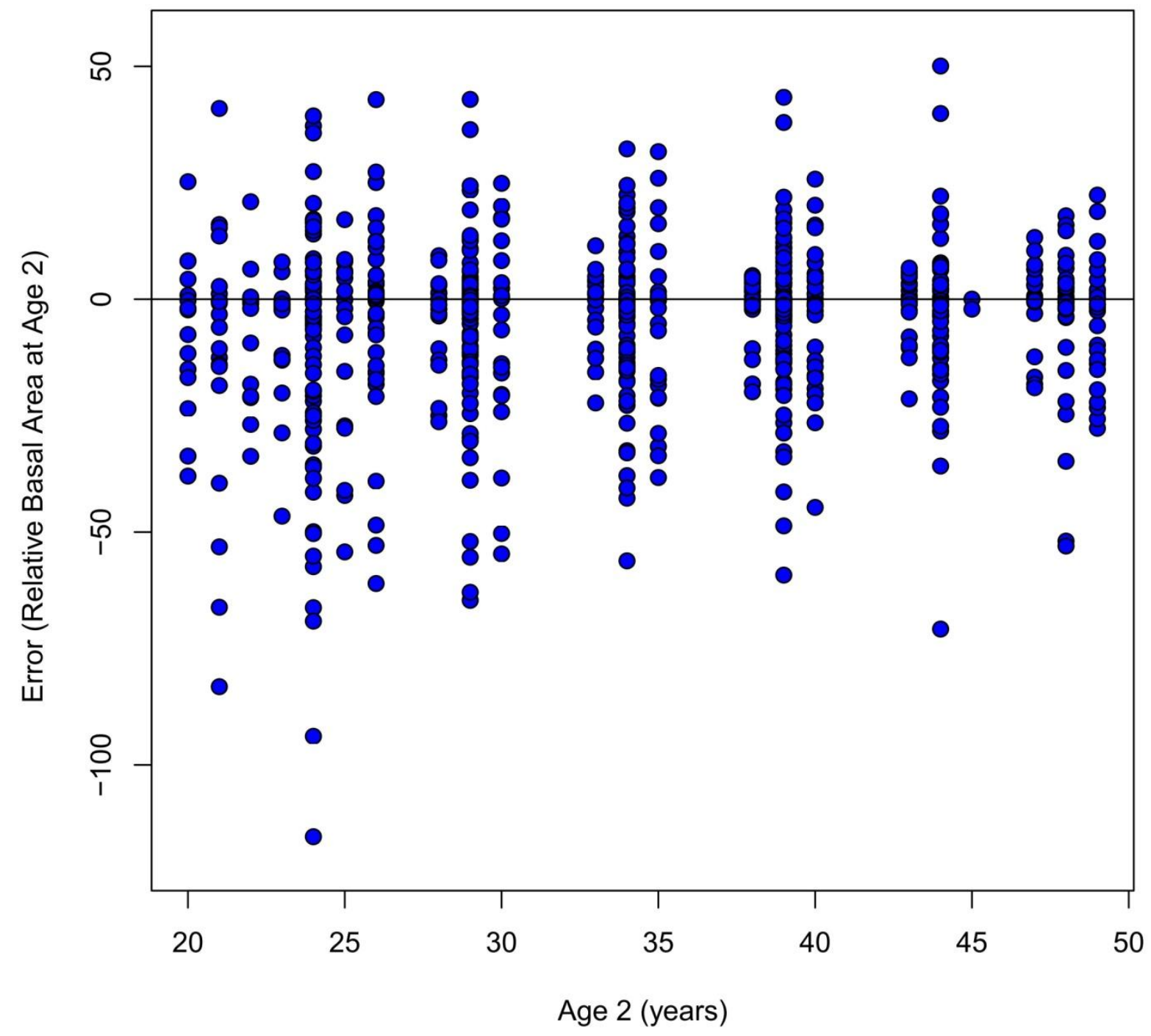

Figure 46. Species group 8 (other) relative basal area prediction error by age 2 for unthinned plots. 


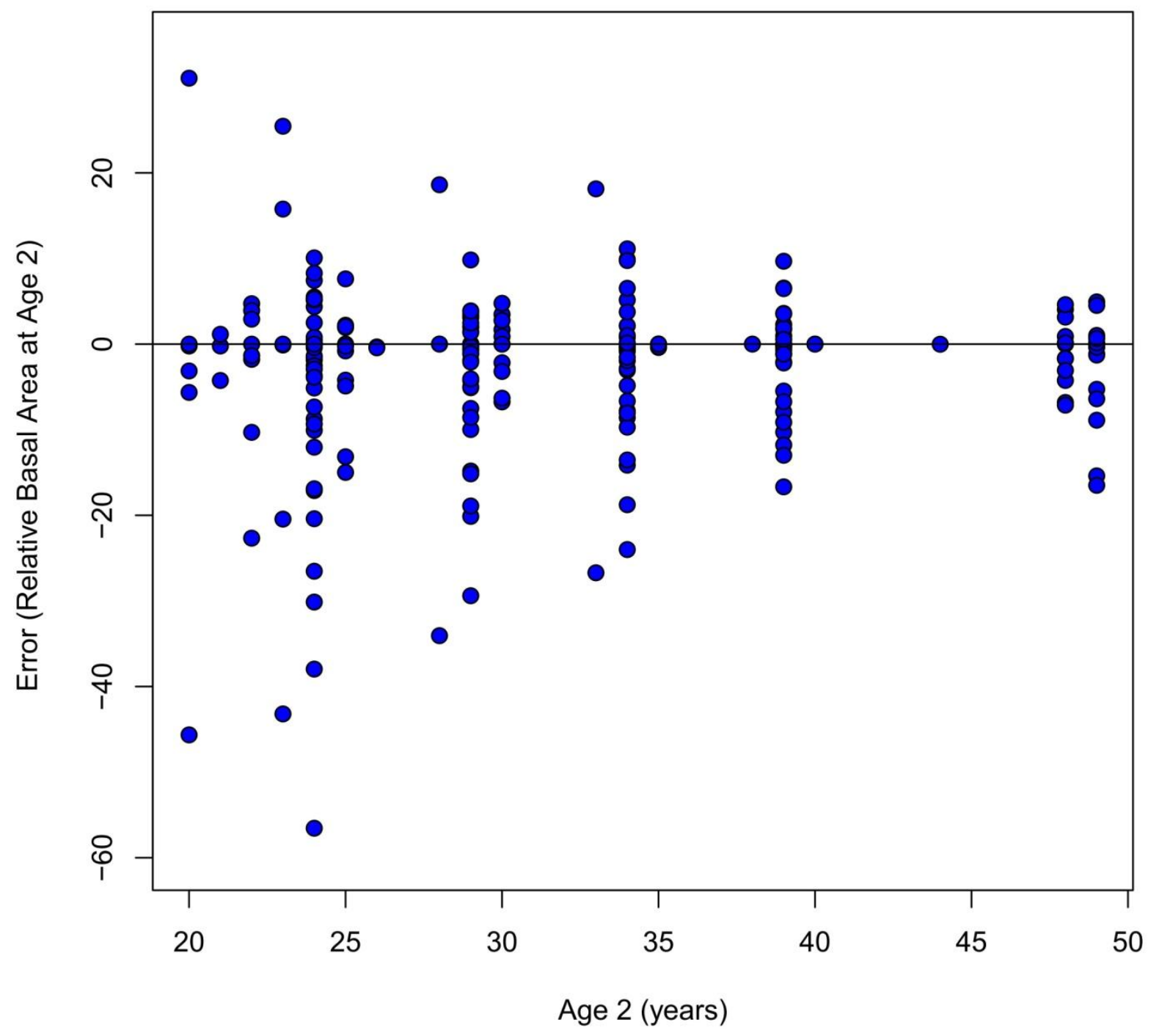

Figure 47. Species group 10 (birches) relative basal area prediction error by age 2 for unthinned plots. 
Thinned Parameter Relative Basal Area Prediction Error Plots

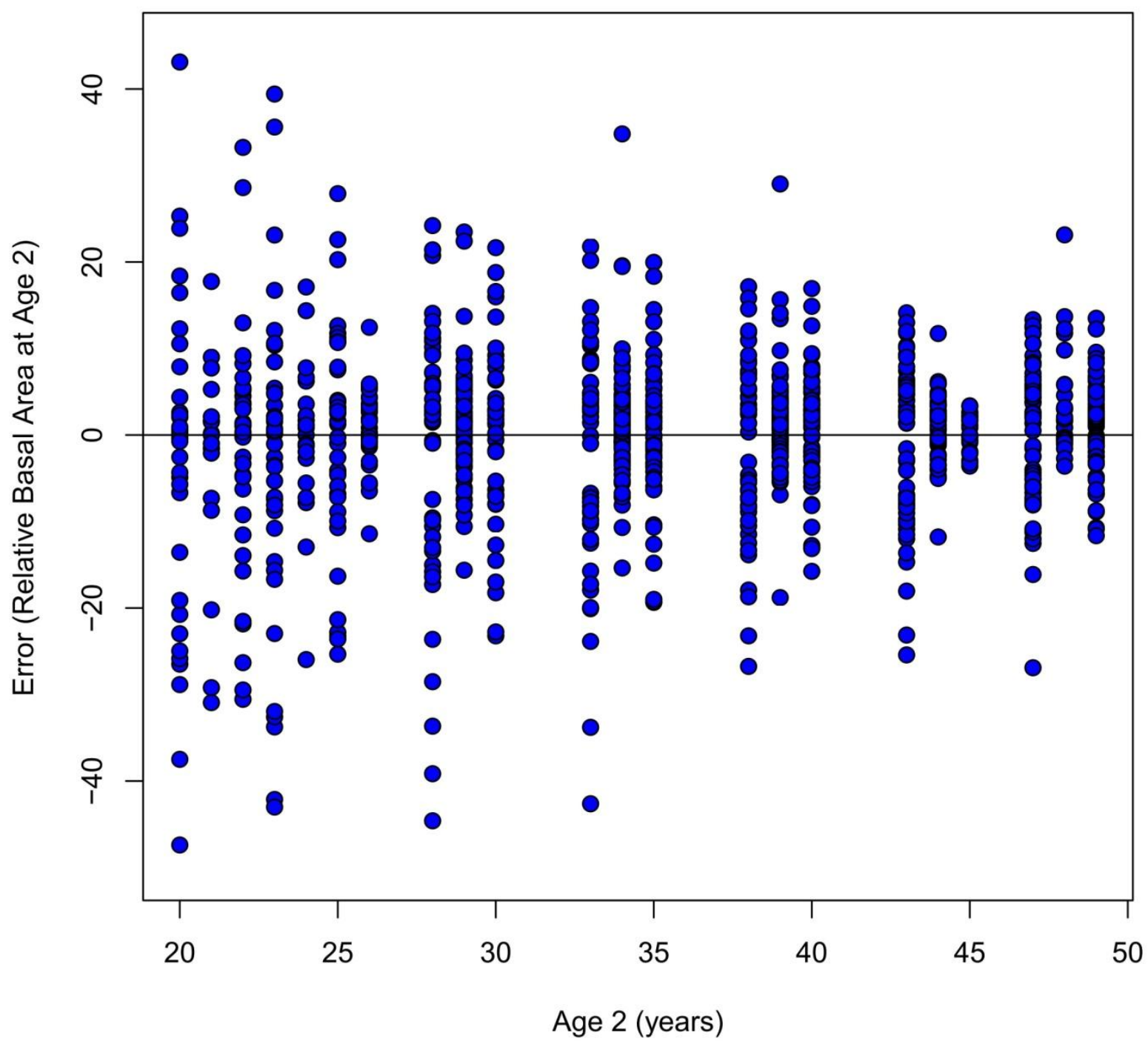

Figure 48. Species group 1 (northern red oak) relative basal area prediction error by age 2 for thinned plots. 


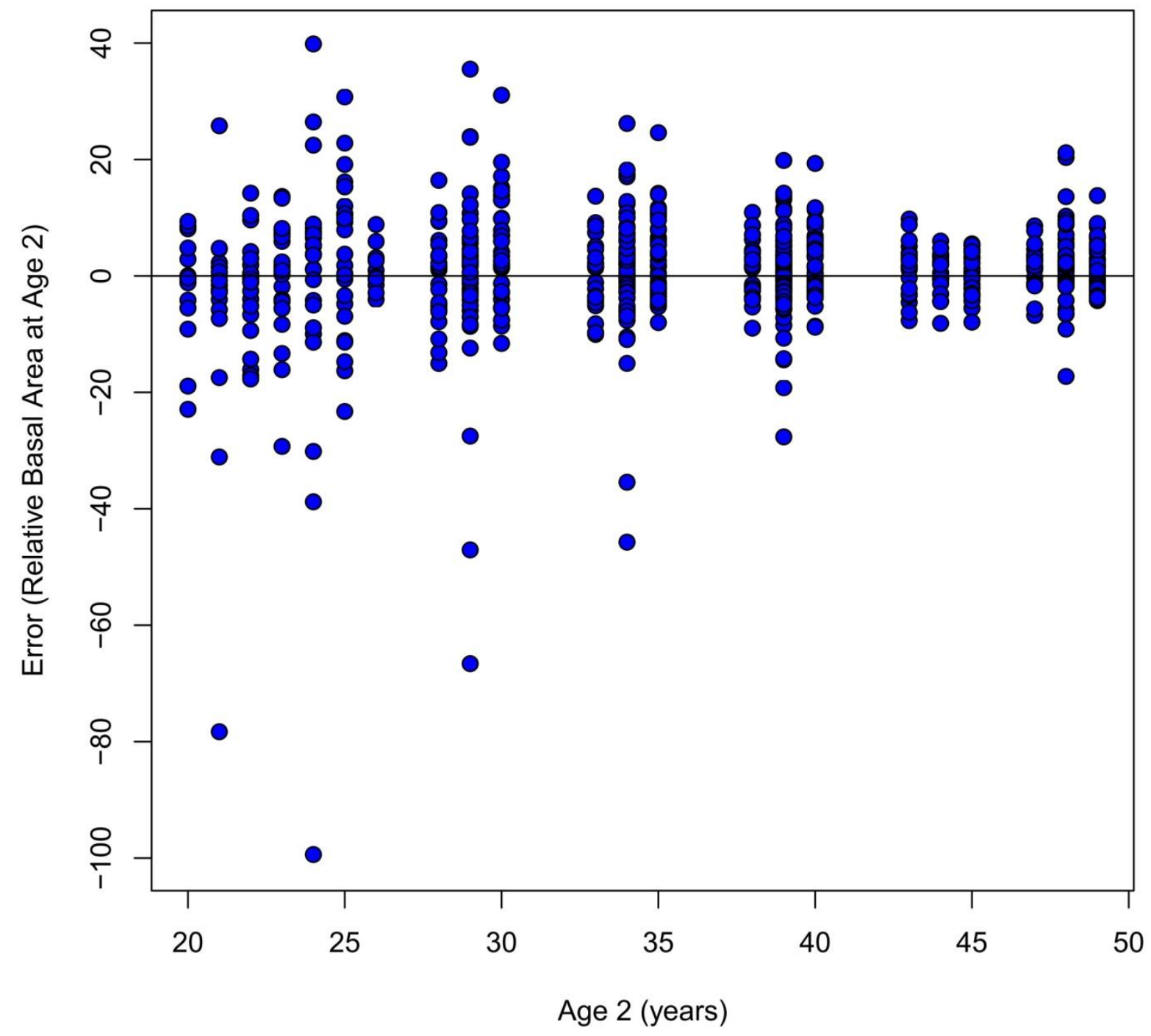

Figure 49. Species group 2 (maples) relative basal area prediction error by age 2 for thinned plots. 


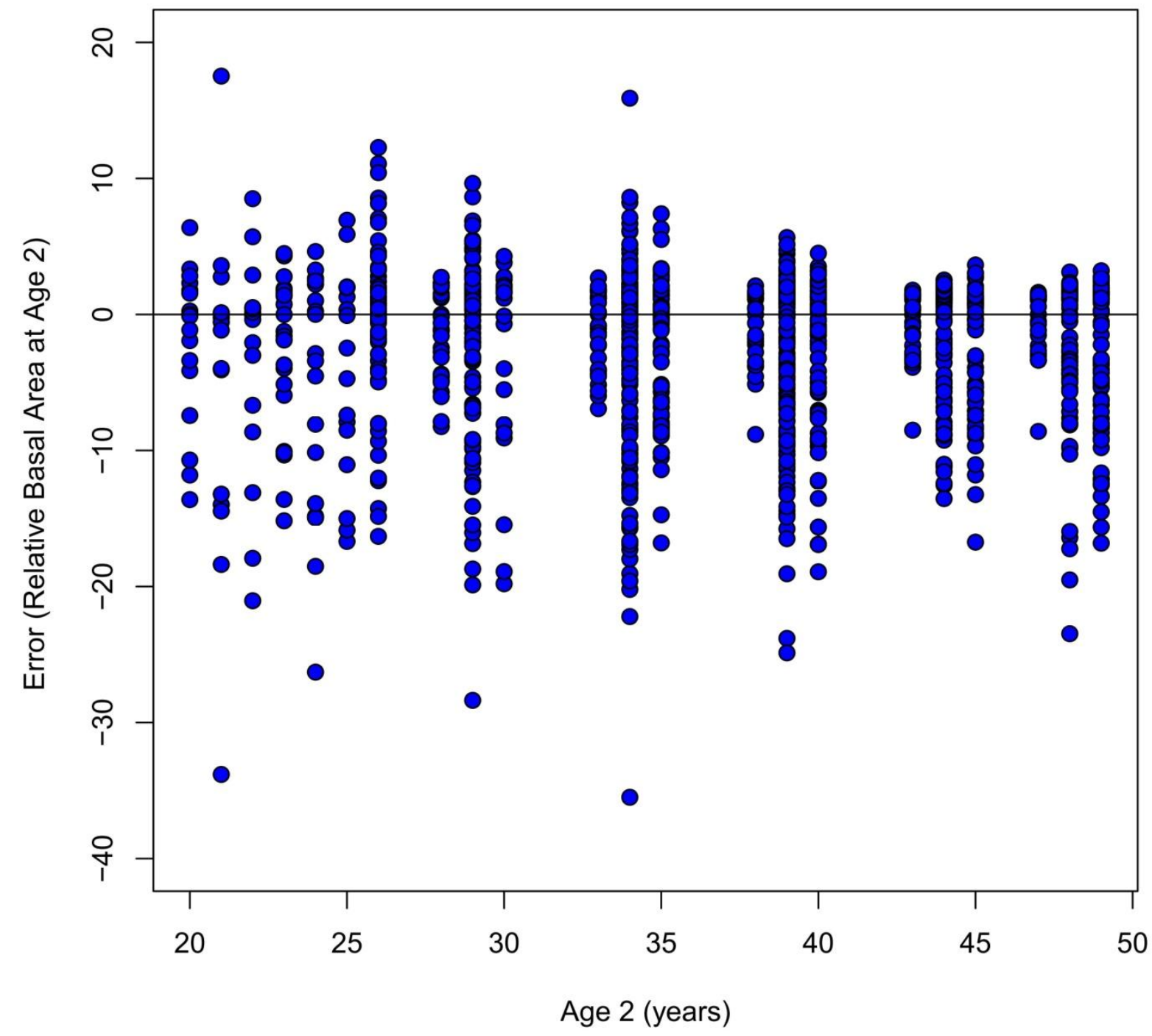

Figure 50. Species group 3 (white oaks) relative basal area prediction error by age 2 for thinned plots. 


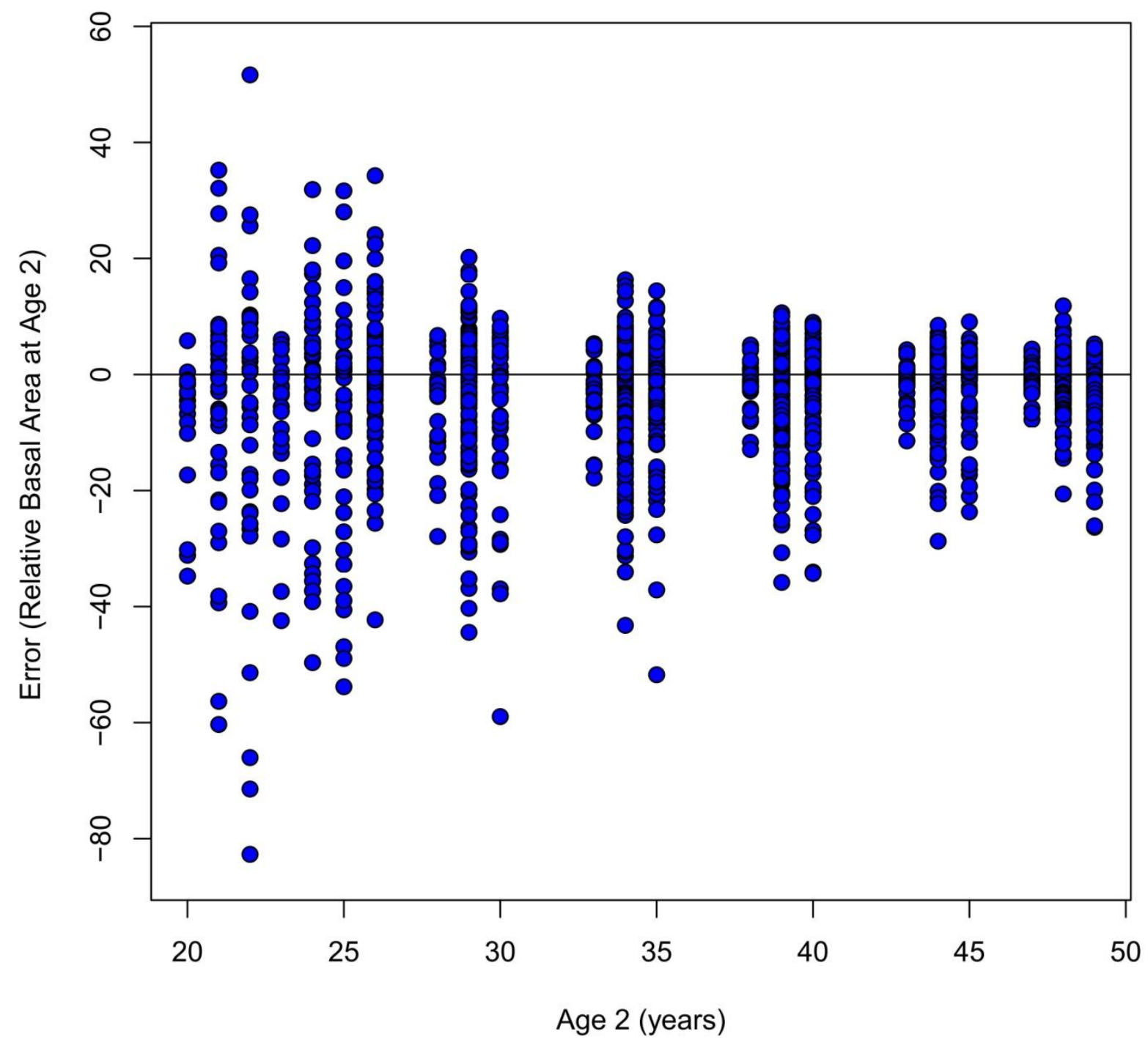

Figure 51. Species group 4 (hickory/ash) relative basal area prediction error by age 2 for thinned plots. 


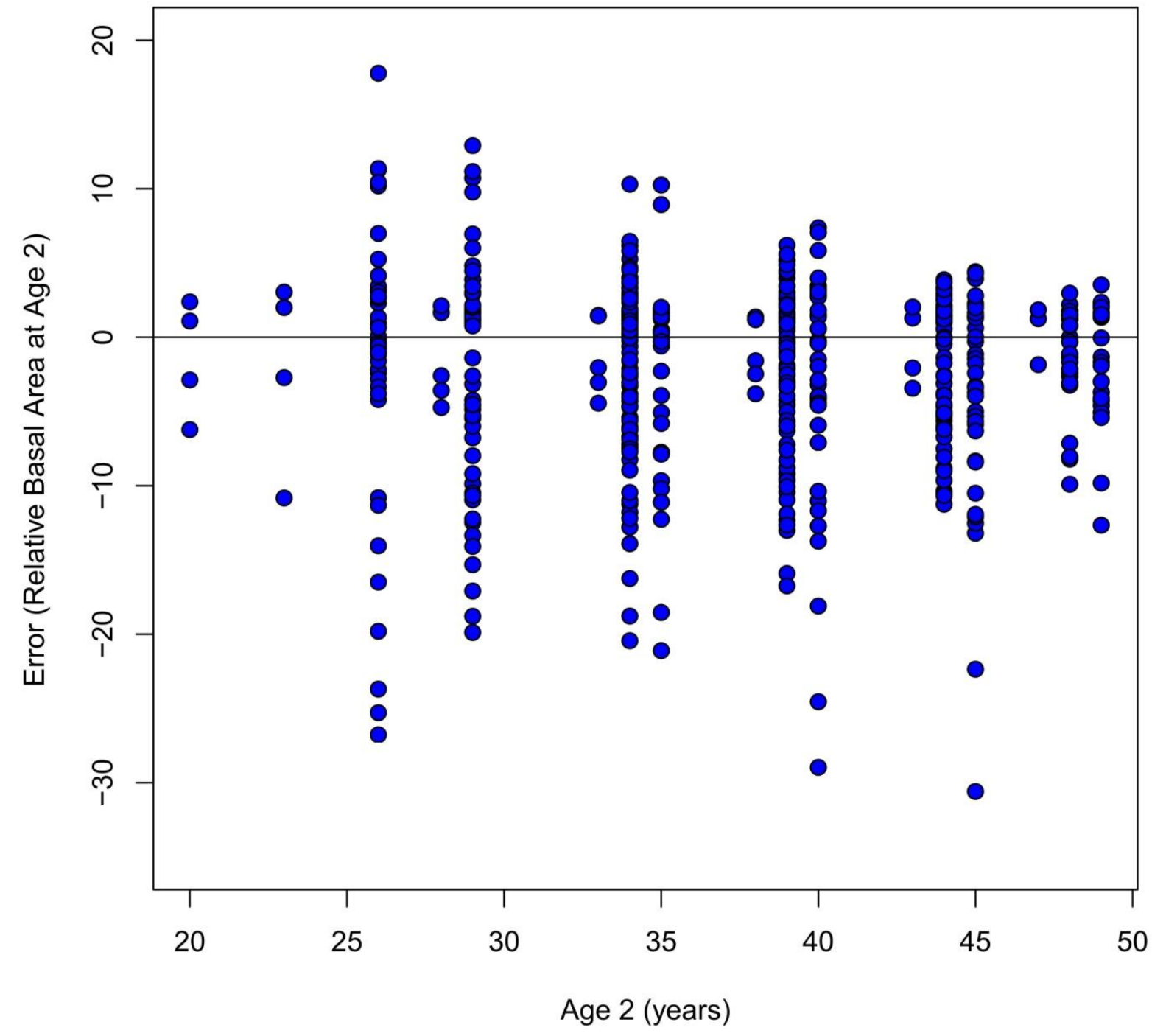

Figure 52. Species group 6 (striped maple/pin cherry) relative basal area prediction error by age 2 for thinned plots. 


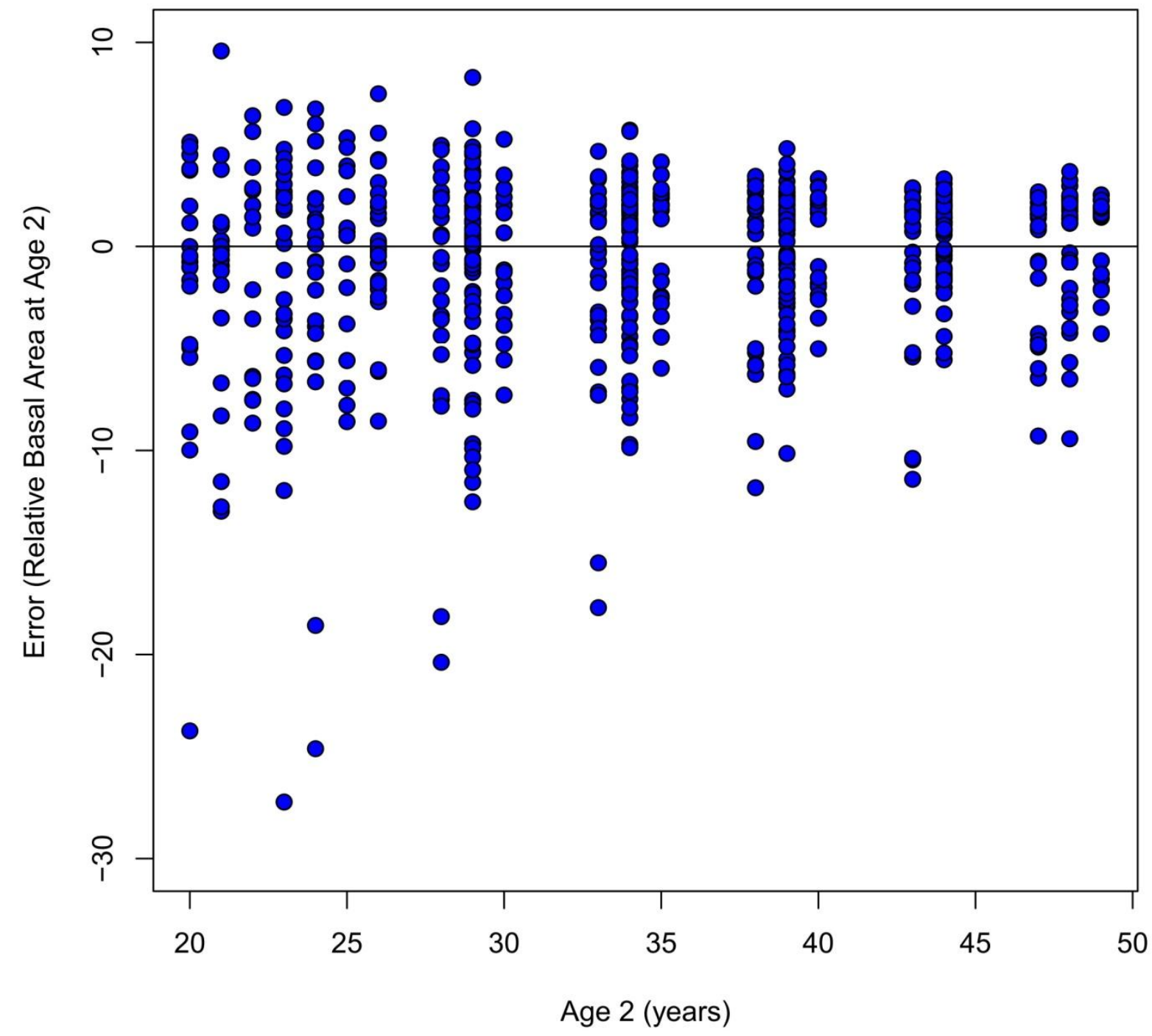

Figure 53. Species group 7 (black cherry) relative basal area prediction error by age 2 for thinned plots. 


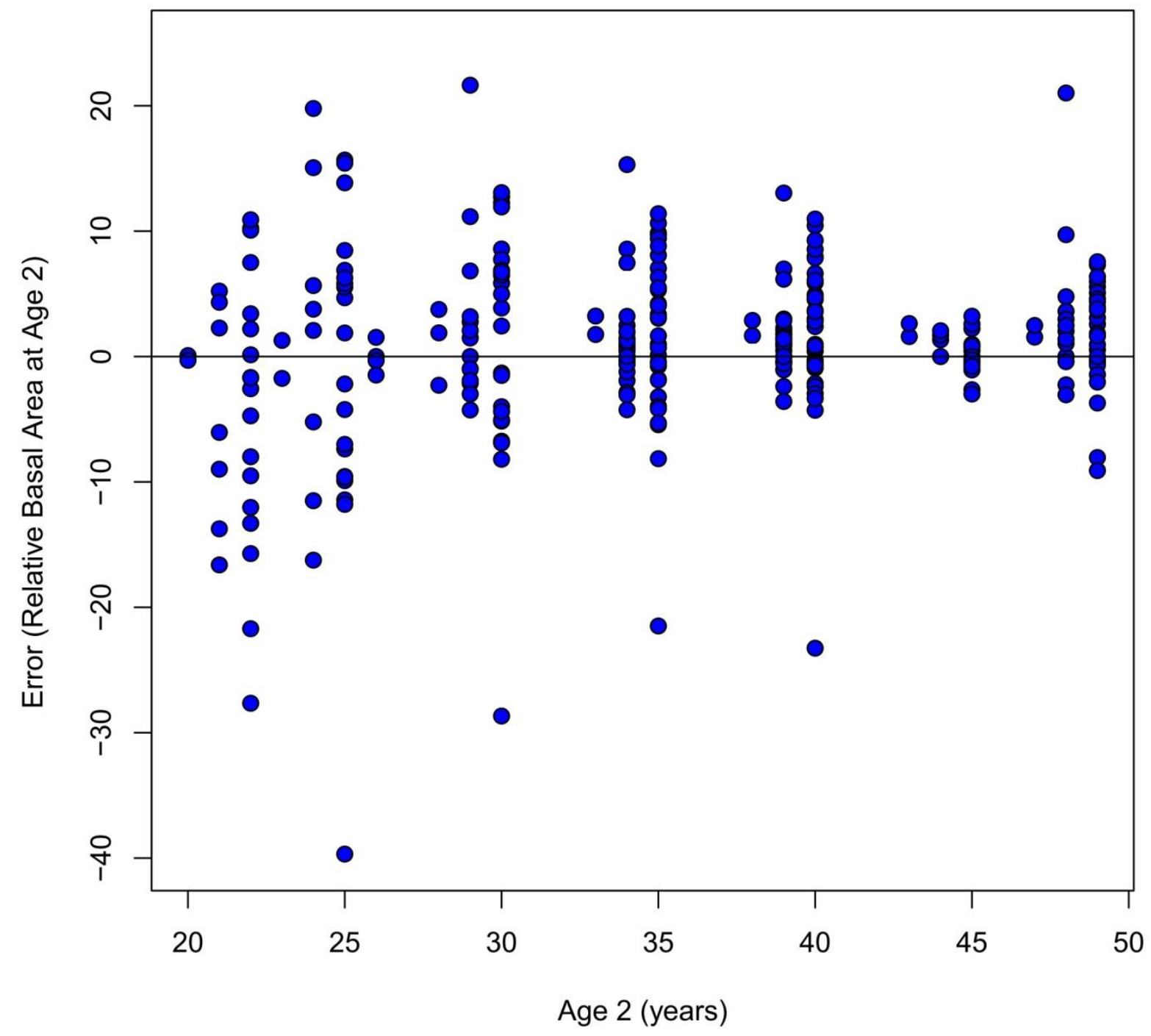

Figure 54. Species group 8 (other) relative basal area prediction error by age 2 for thinned plots. 


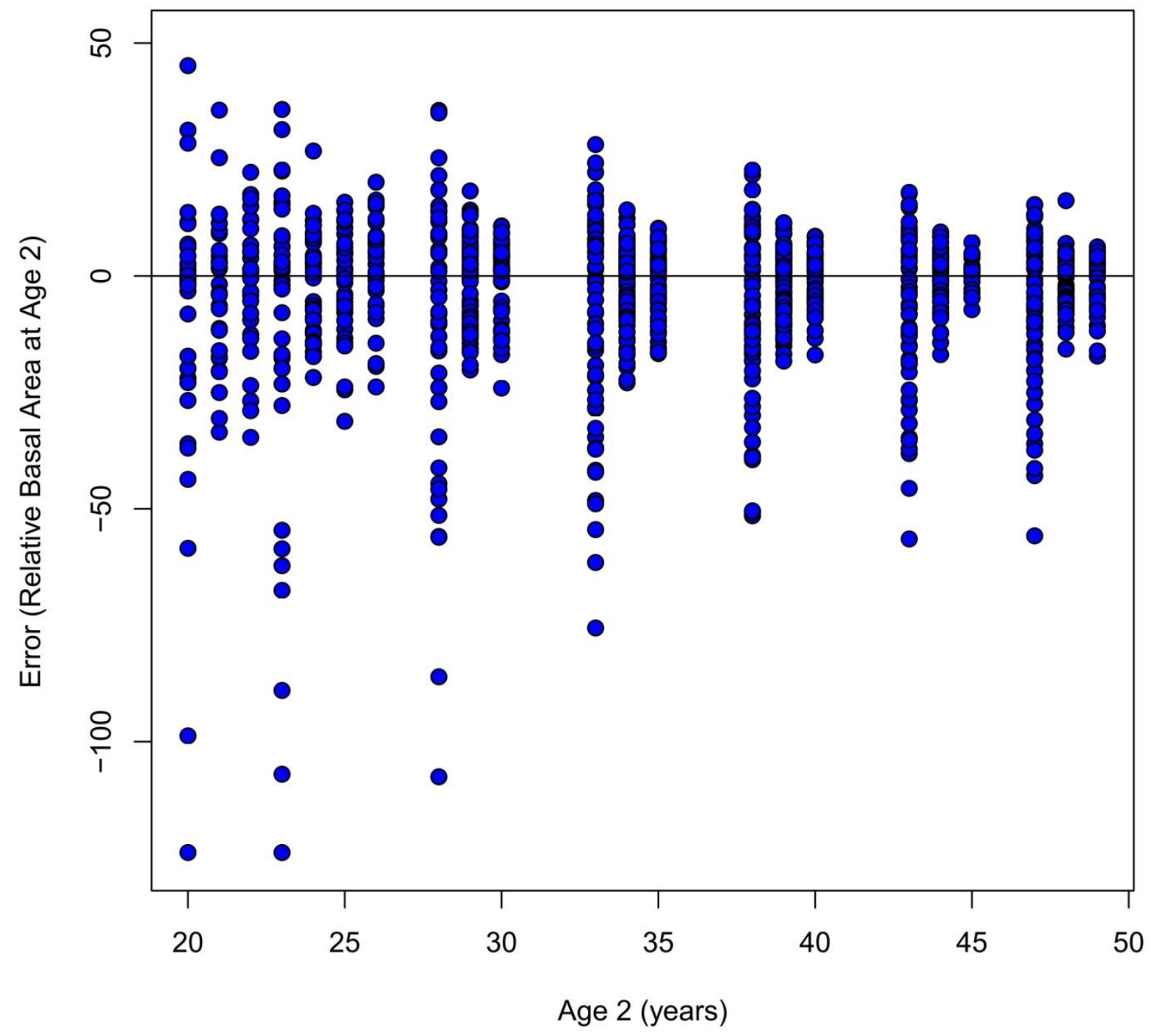

Figure 55. Species group 10 (birches) relative basal area prediction error by age 2 for thinned plots. 
$\underline{\text { Appendix C. Additional Basal Area Projection Graphs }}$ 


\section{Unthinned Plots Basal Area Projection Error Plots}

\section{Non-overlapping Projection Lengths}

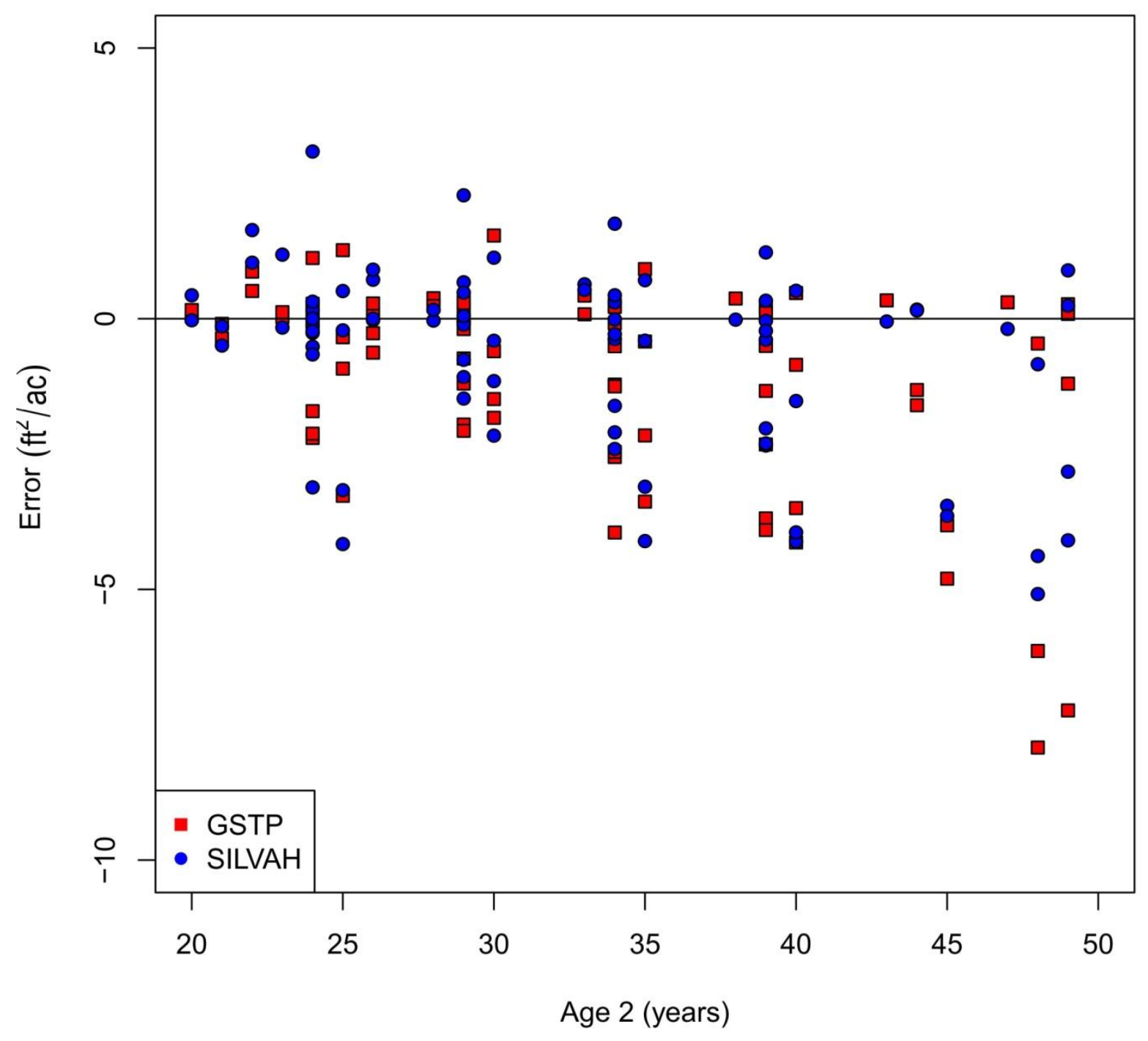

Figure 56. Species group 1 (northern red oak) projection error by projection age (age 2) for unthinned non-overlapping projections. 


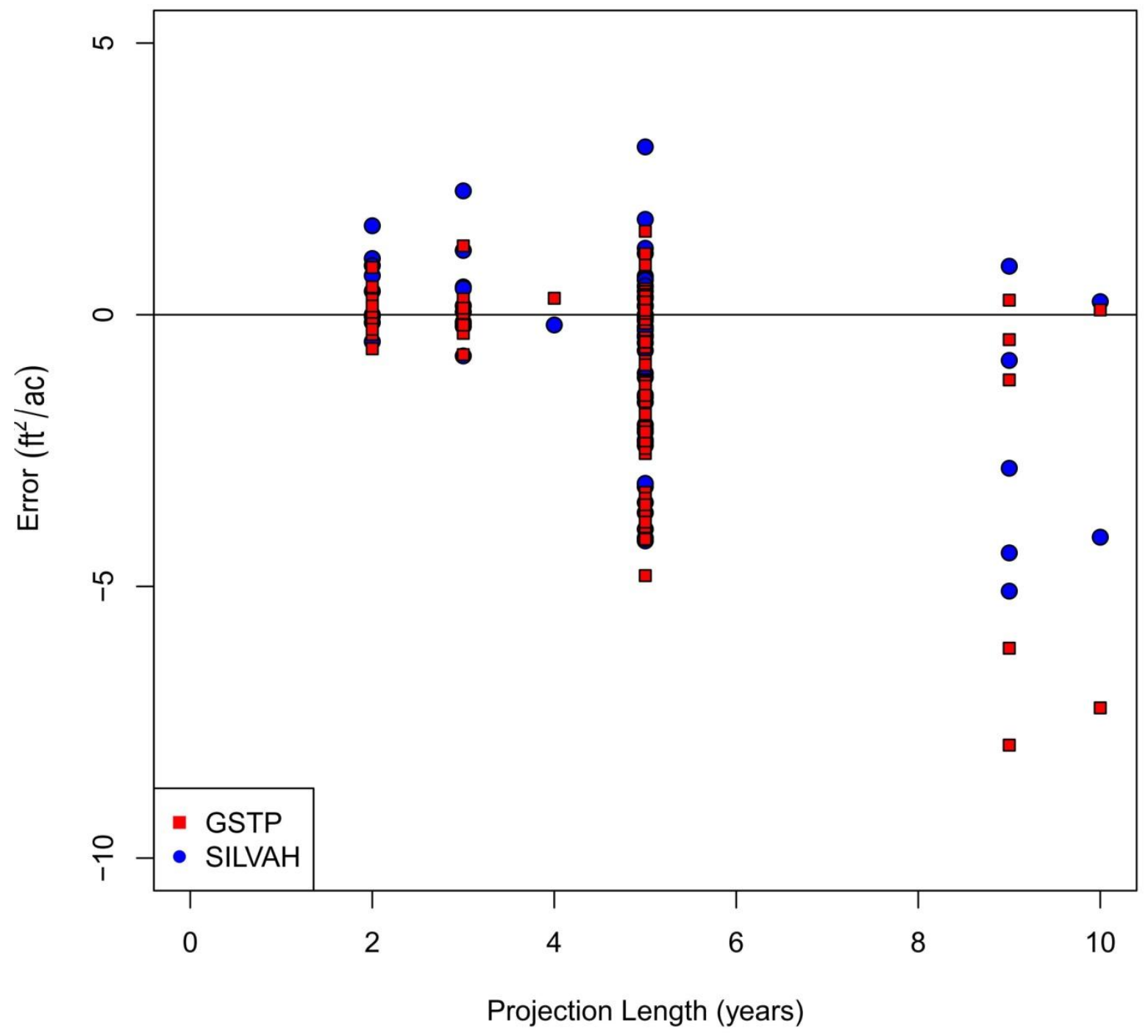

Figure 57. Species group 1 (northern red oak) projection error by projection length for unthinned non-overlapping projections. 


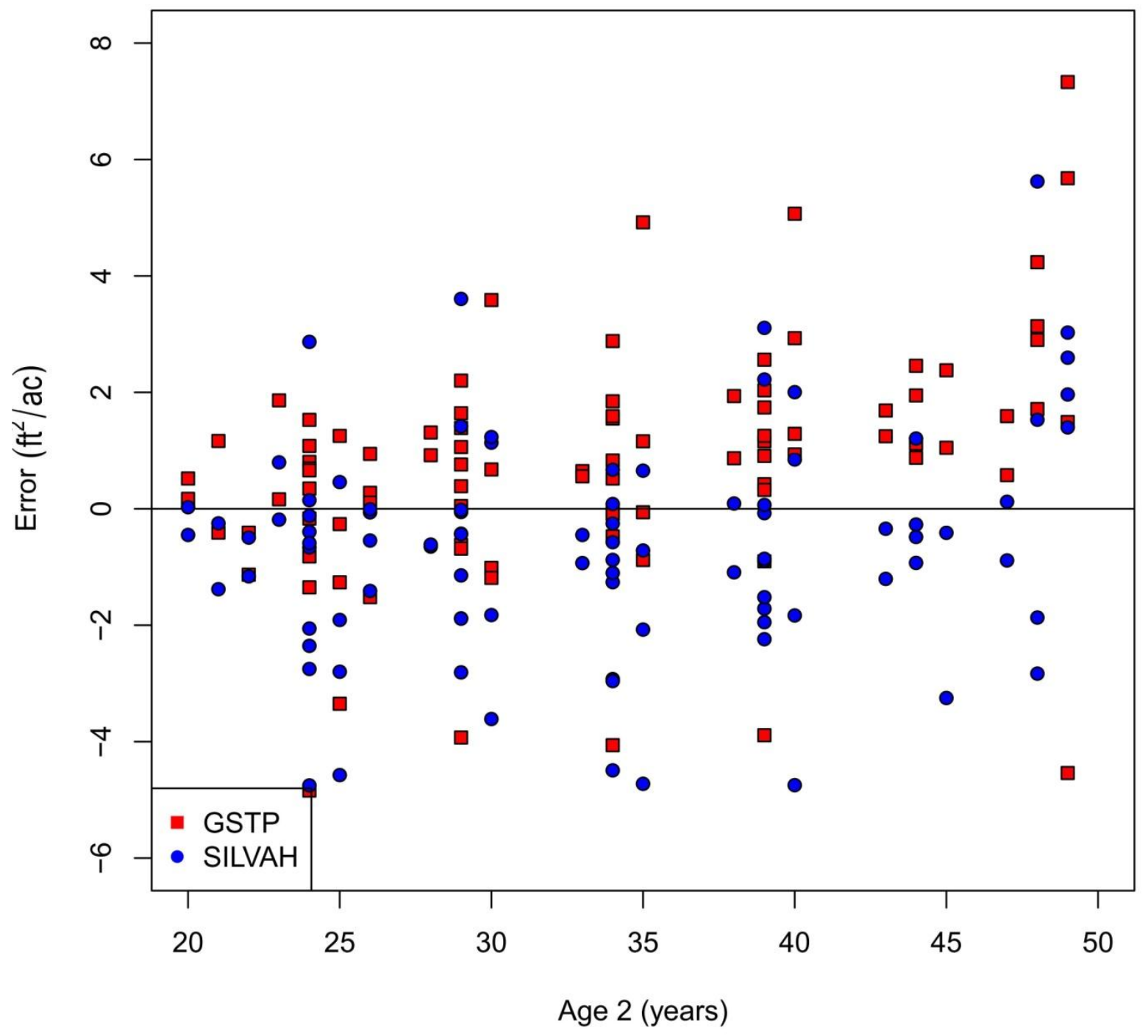

Figure 58. Species group 2 (maples) projection error by projection age (age 2) for unthinned non-overlapping projections. 


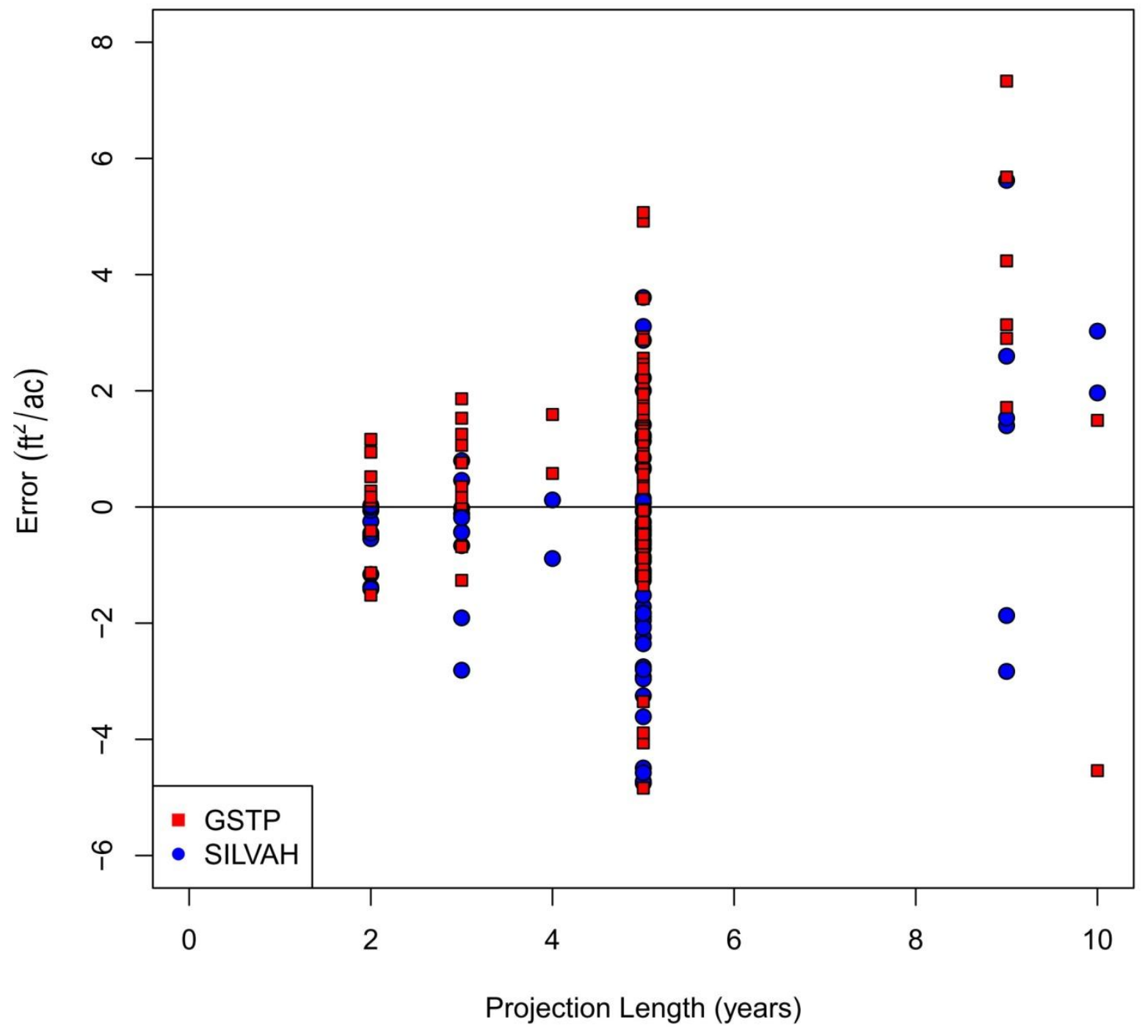

Figure 59. Species group 2 (maples) projection error by projection length for unthinned non-overlapping projections. 


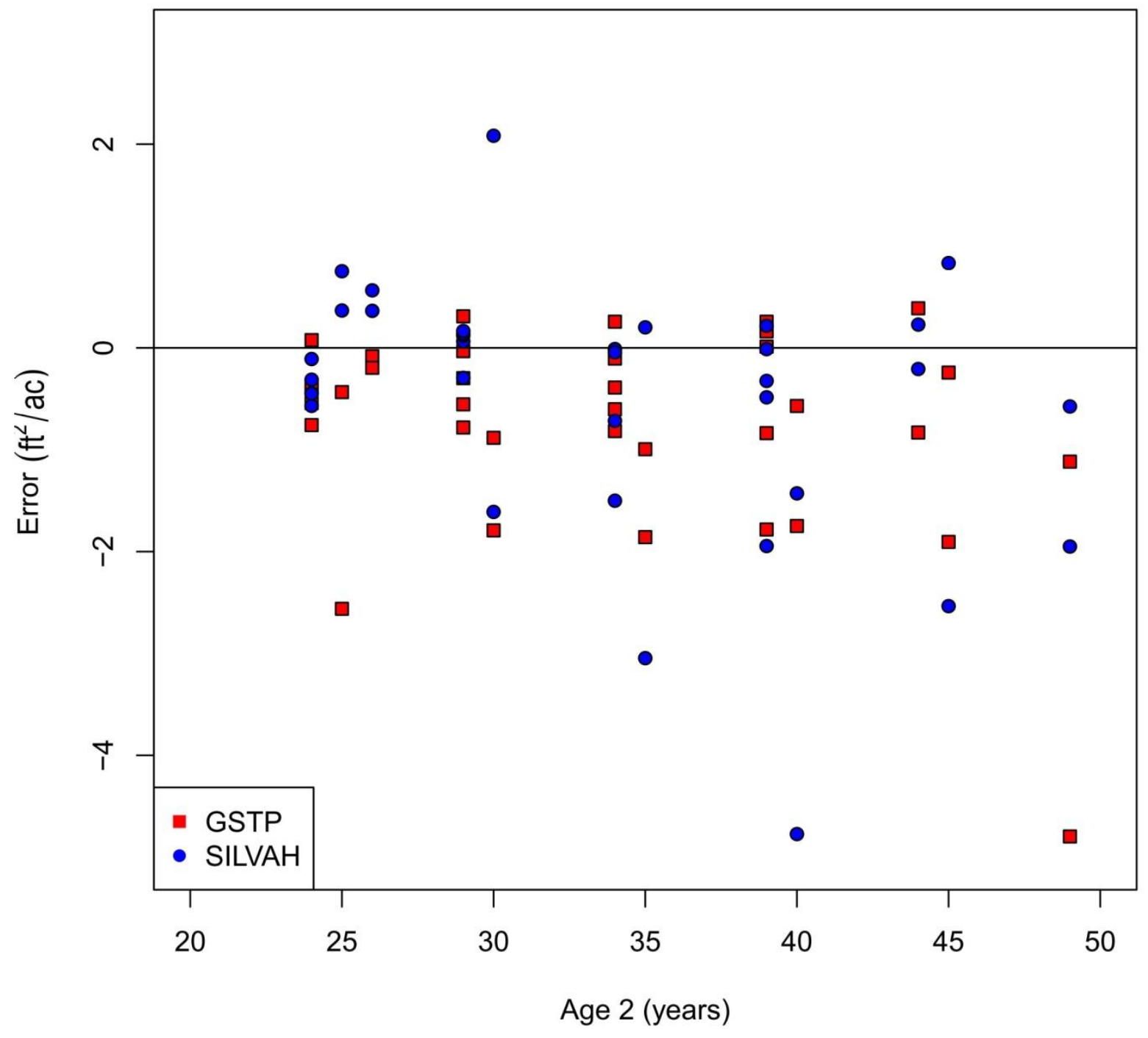

Figure 60. Species group 3 (white oaks) projection error by projection age (age 2) for unthinned non-overlapping projections. 


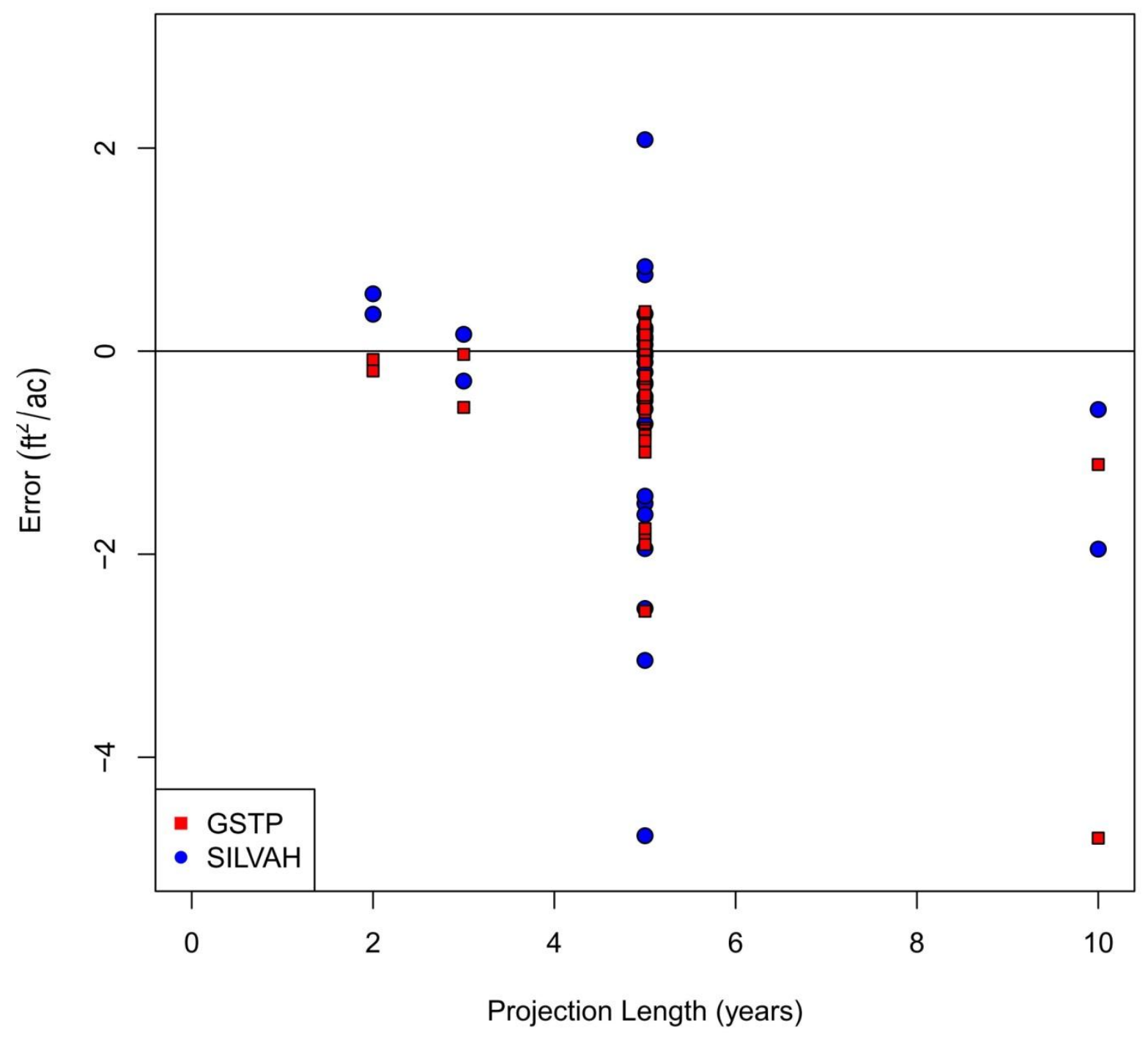

Figure 61. Species group 3 (white oaks) projection error by projection length for unthinned non-overlapping projections. 


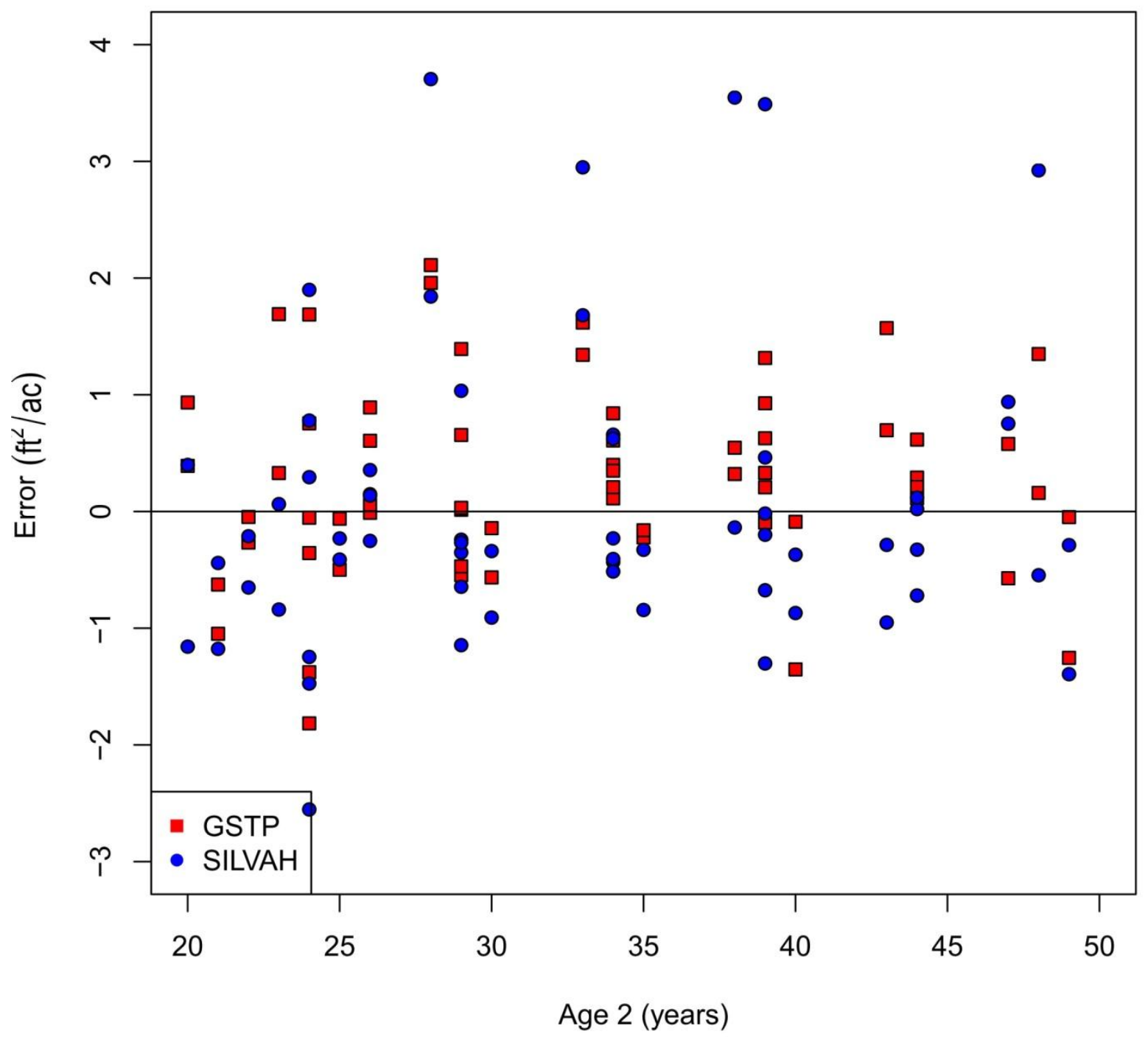

Figure 62. Species group 4 (hickory.ash) projection error by projection age (age 2) for unthinned non-overlapping projections. 


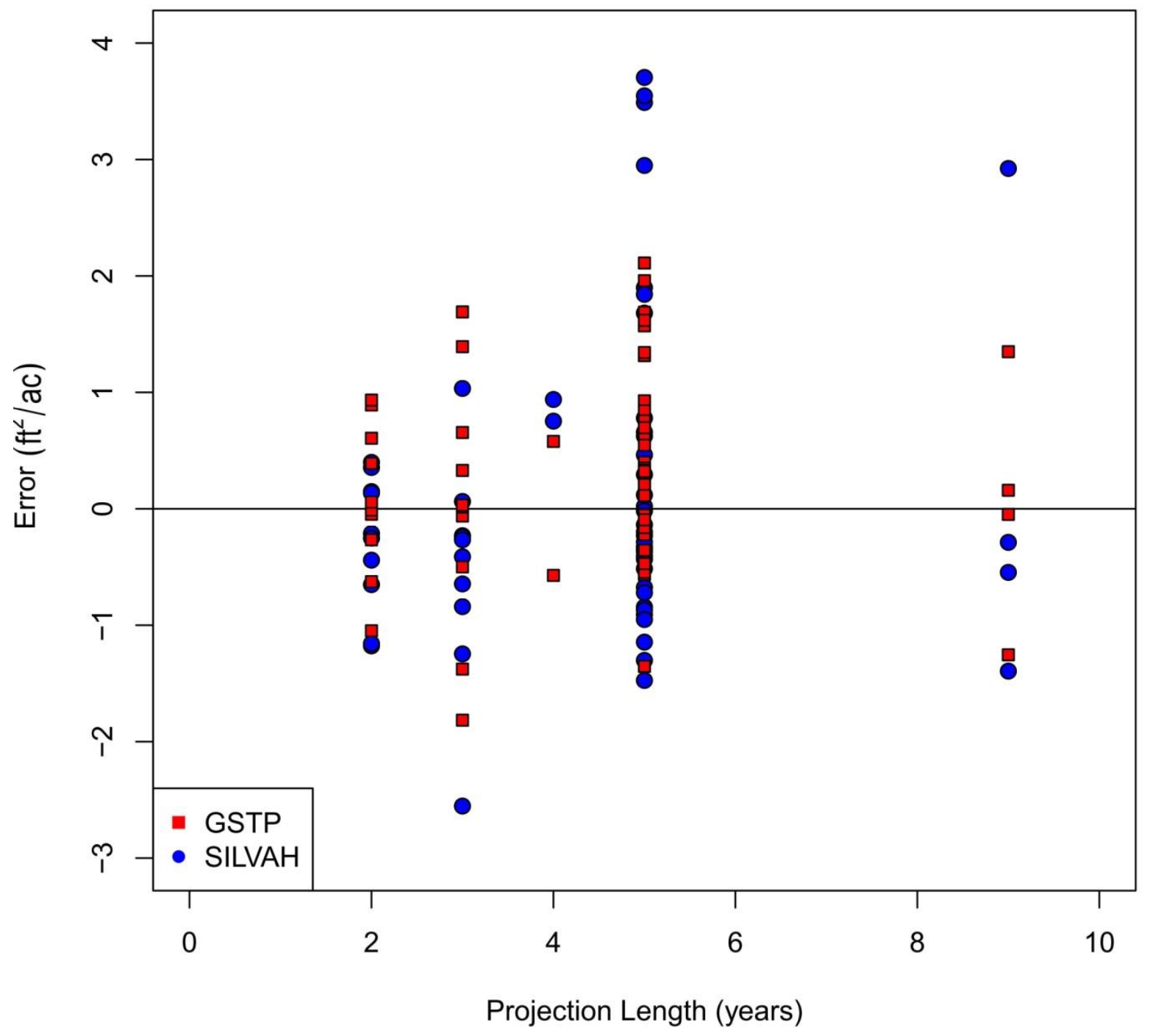

Figure 63. Species group 4 (hickory/ash) projection error by projection length for unthinned non-overlapping projections. 


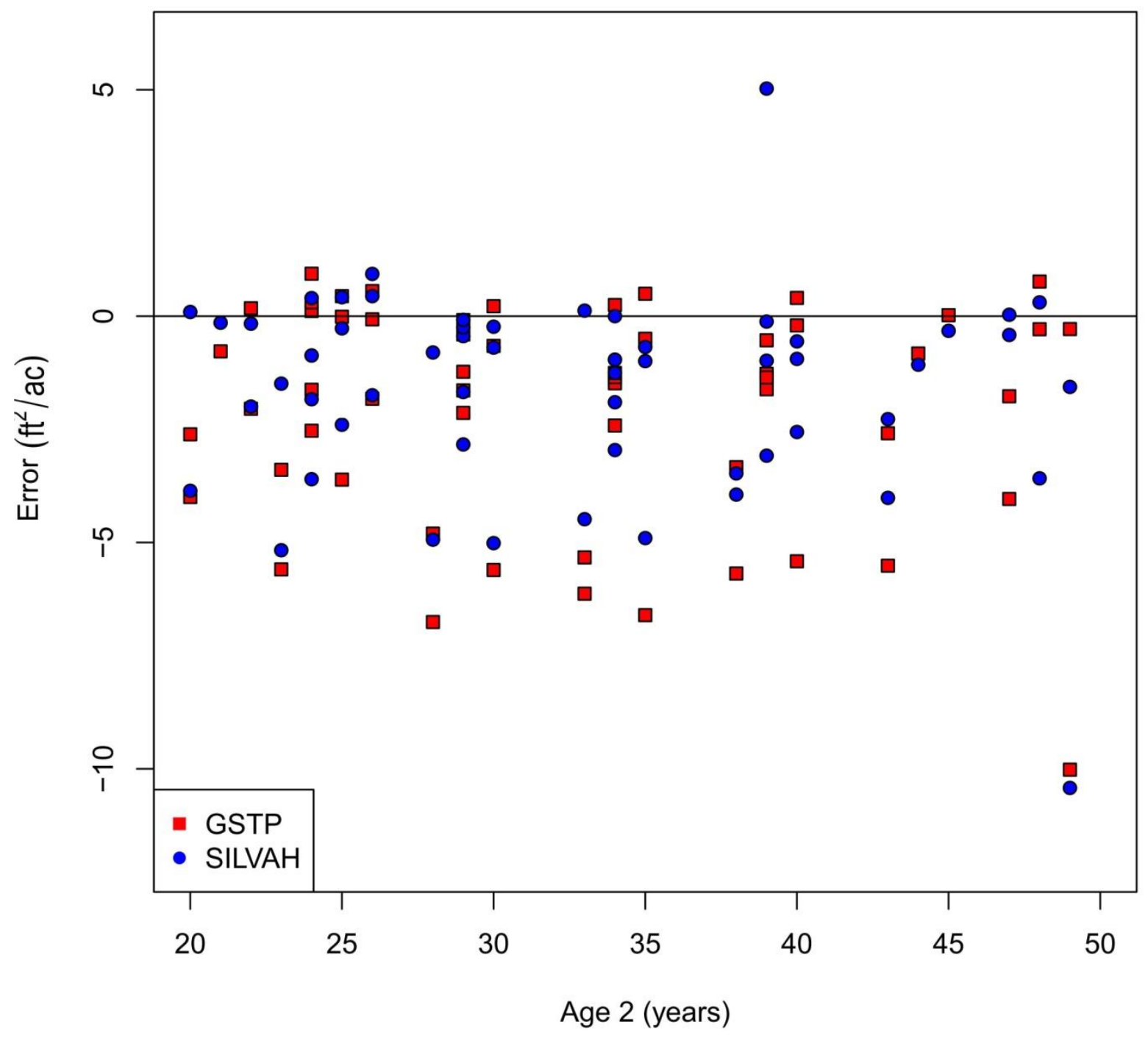

Figure 64. Species group 7 (black cherry) projection error by projection age (age 2) for unthinned non-overlapping projections. 


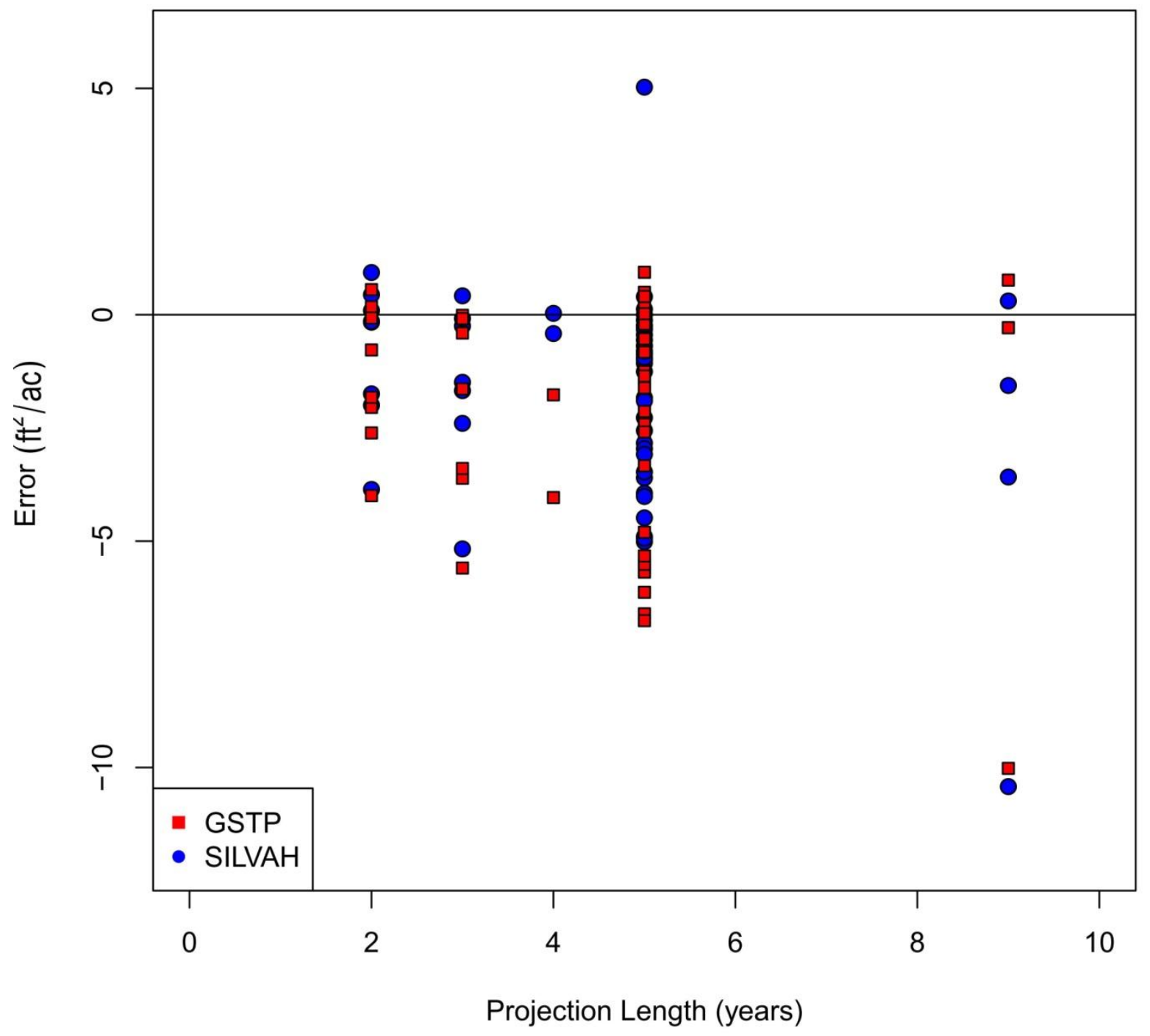

Figure 65. Species group 7 (black cherry) projection error by projection length for unthinned non-overlapping projections. 


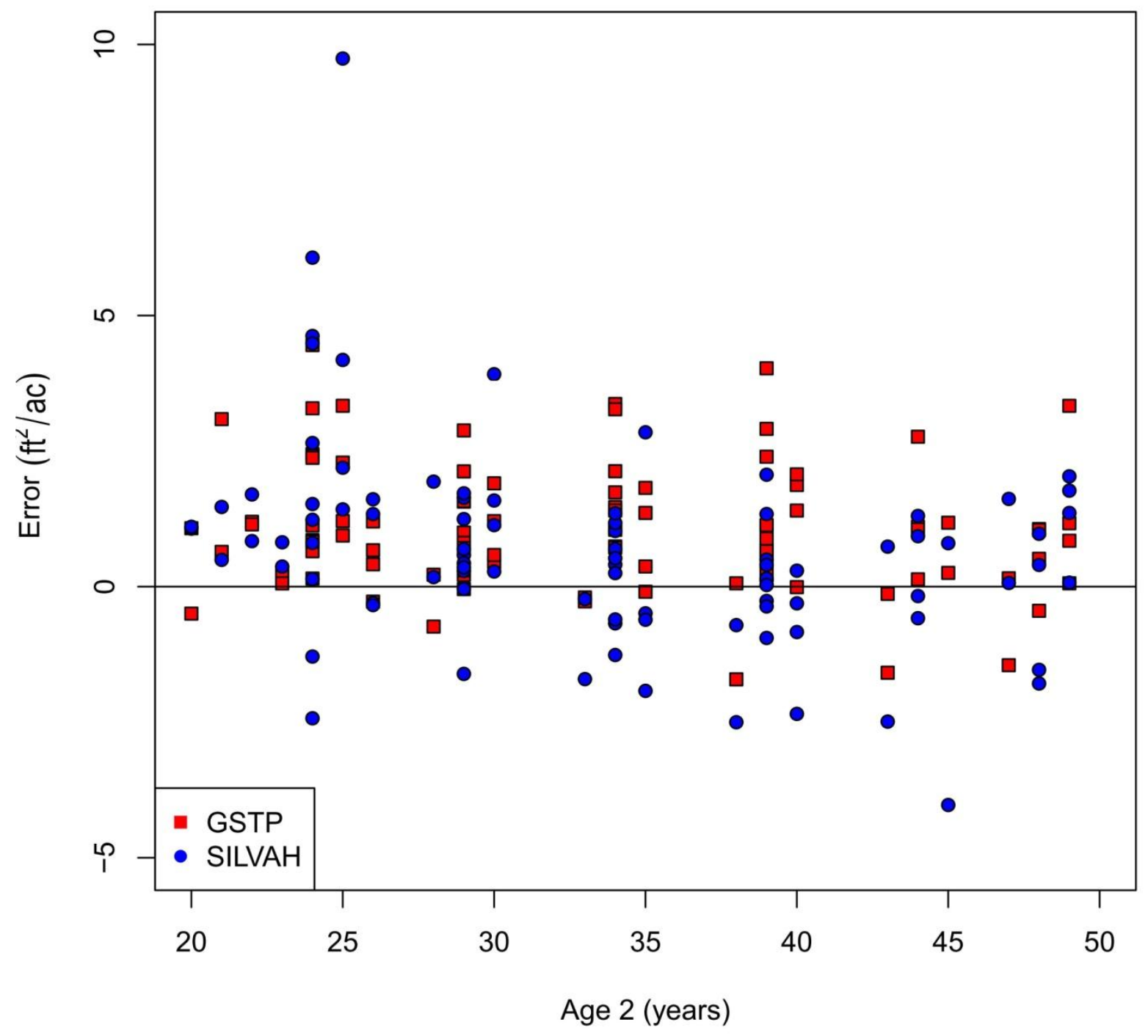

Figure 66. Species group 8 (other) projection error by projection age (age 2) for unthinned non-overlapping projections. 


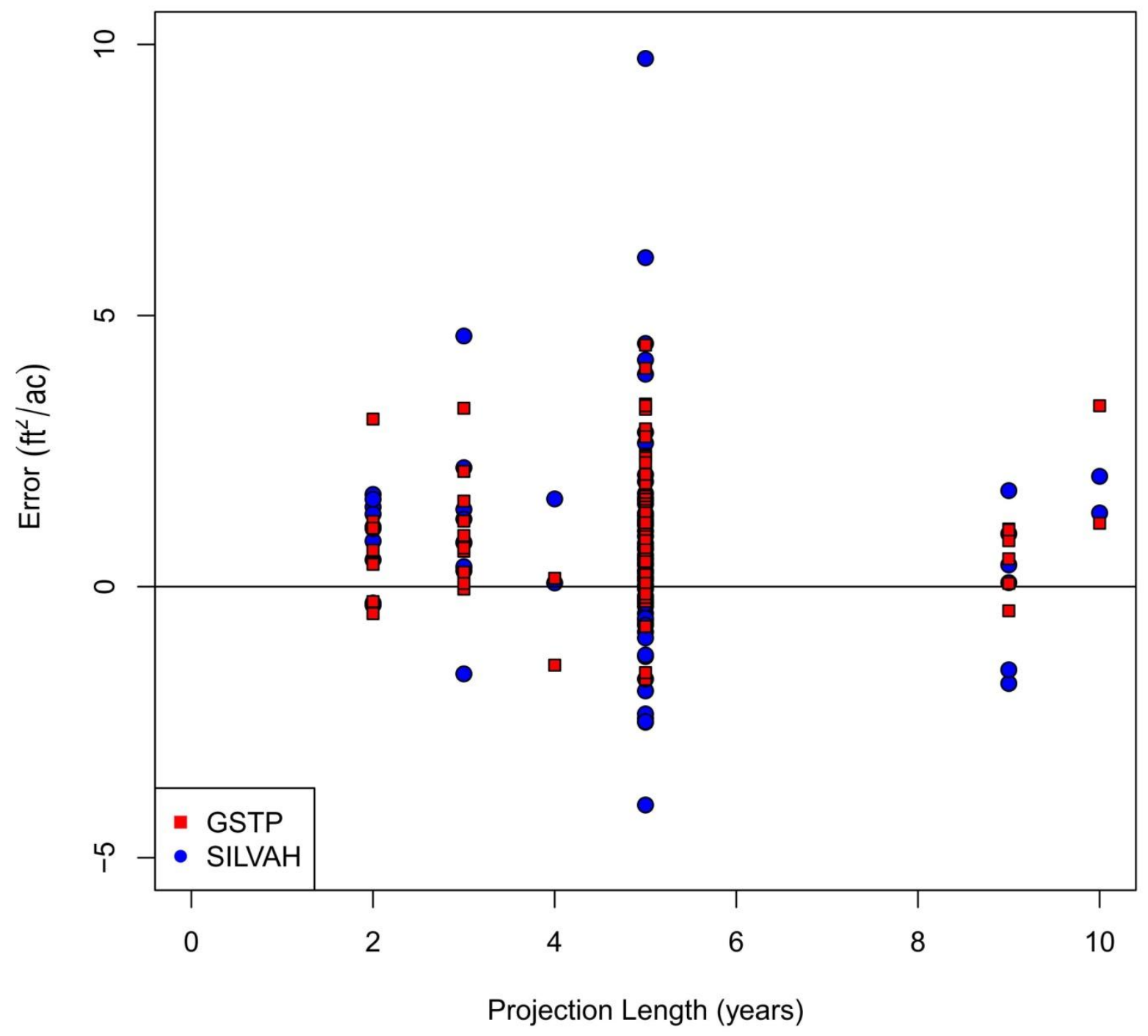

Figure 67. Species group 8 (other) projection error by projection length for unthinned non-overlapping projections. 


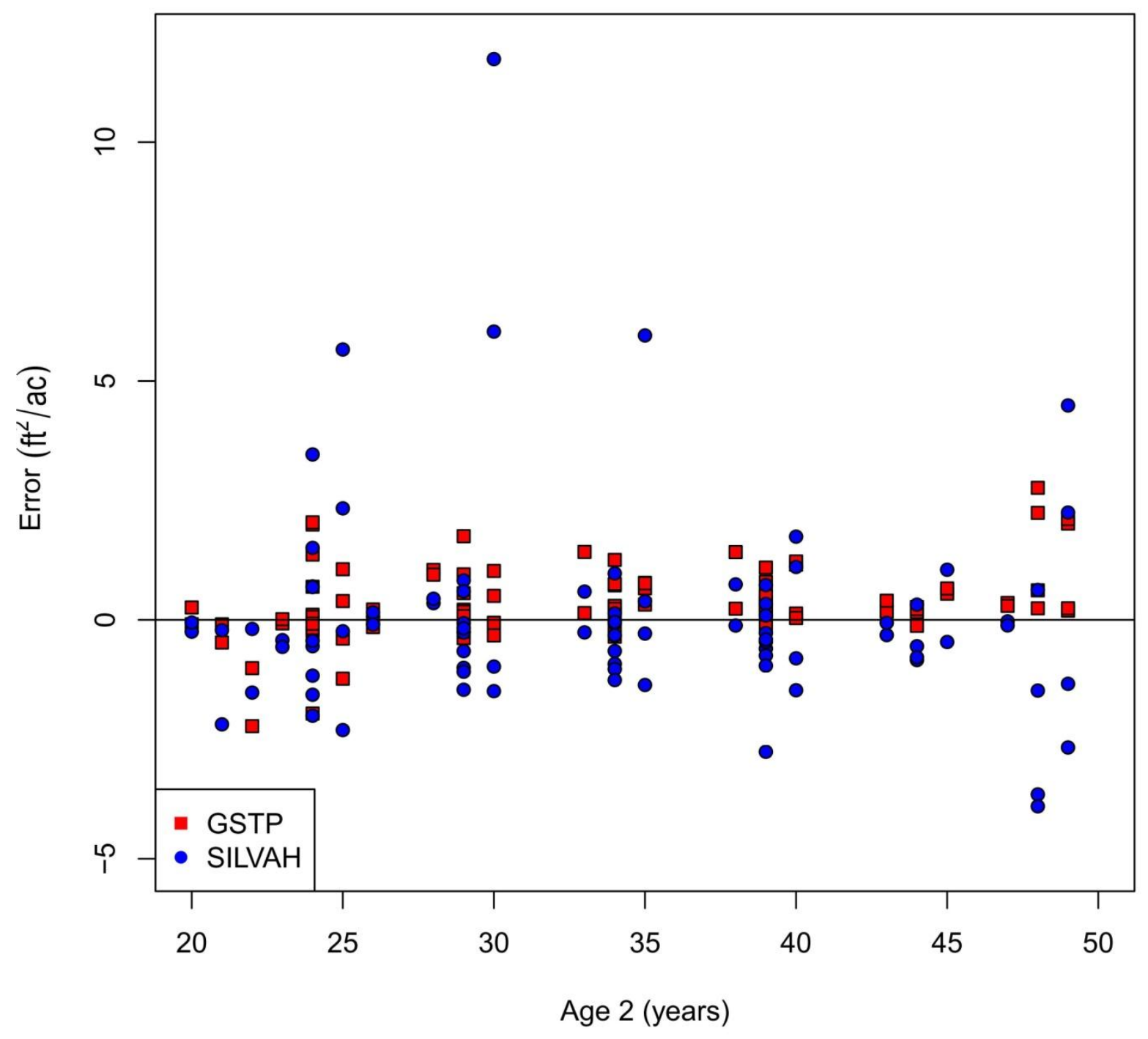

Figure 68. Species group 10 (birches) projection error by projection age (age 2) for unthinned non-overlapping projections. 


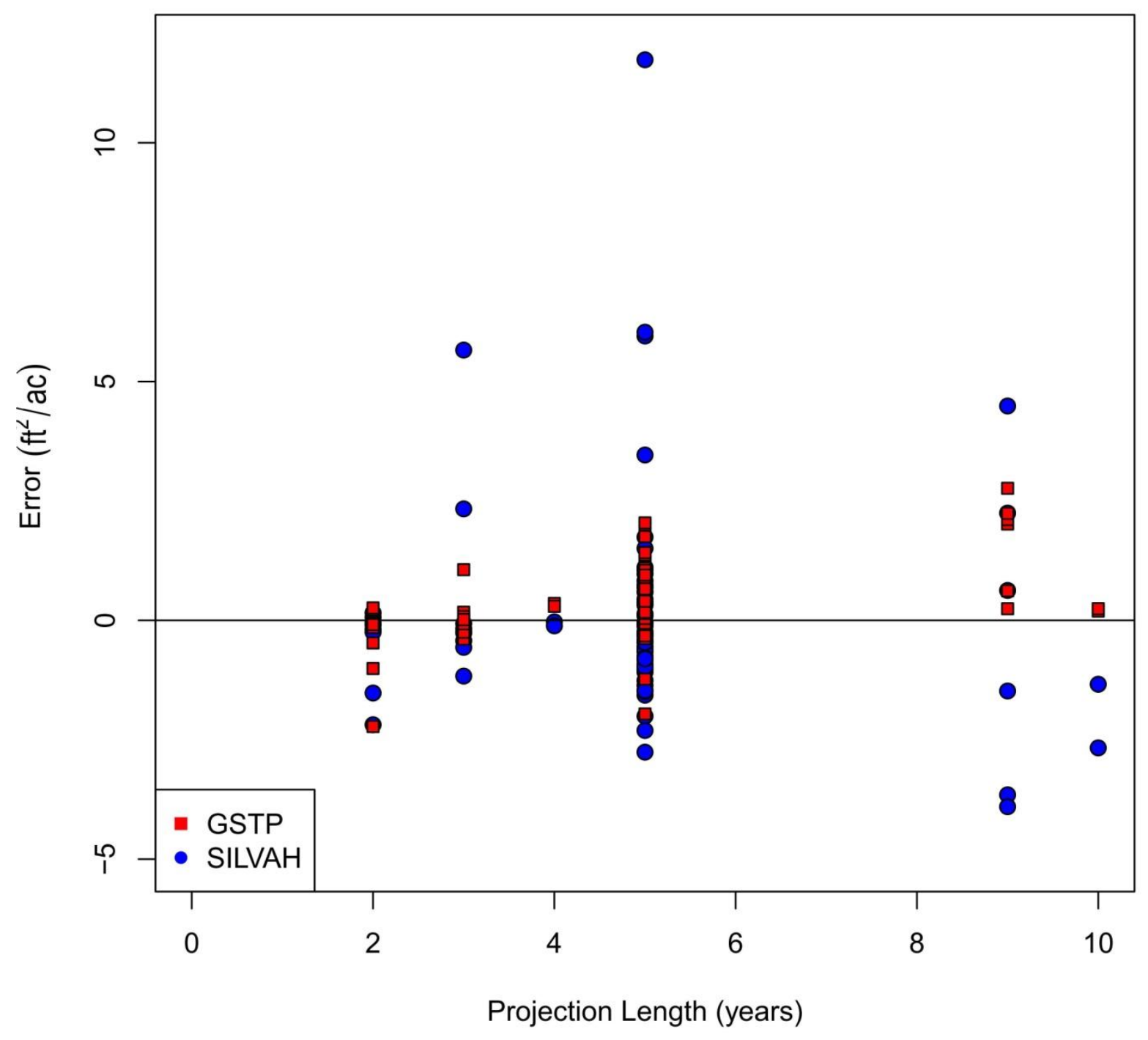

Figure 69. Species group 10 (birches) projection error by projection length for unthinned non-overlapping projections. 


\section{Overlapping Projection Lengths}

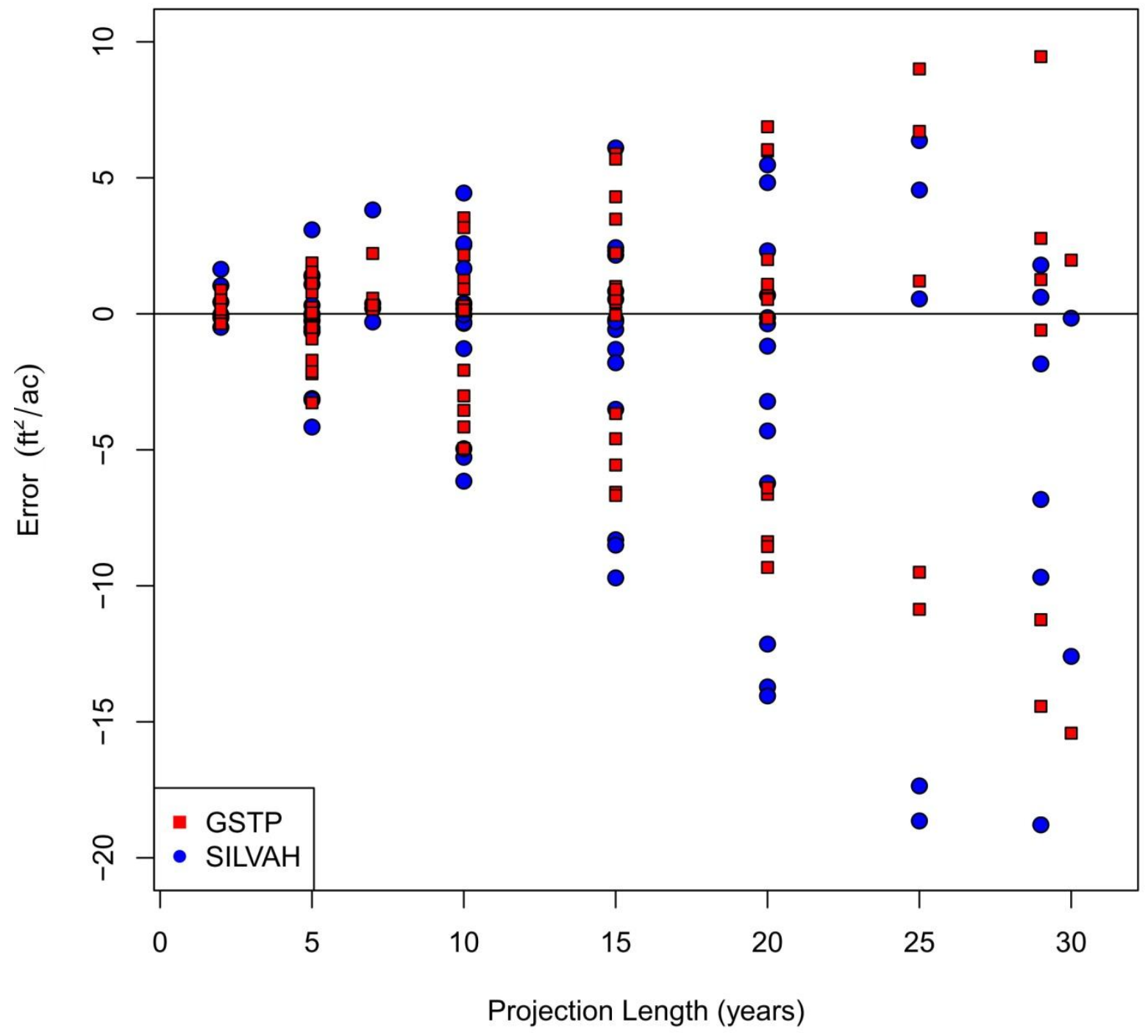

Figure 70. Species group 1 (northern red oak) projection error by projection length for unthinned overlapping projections. 


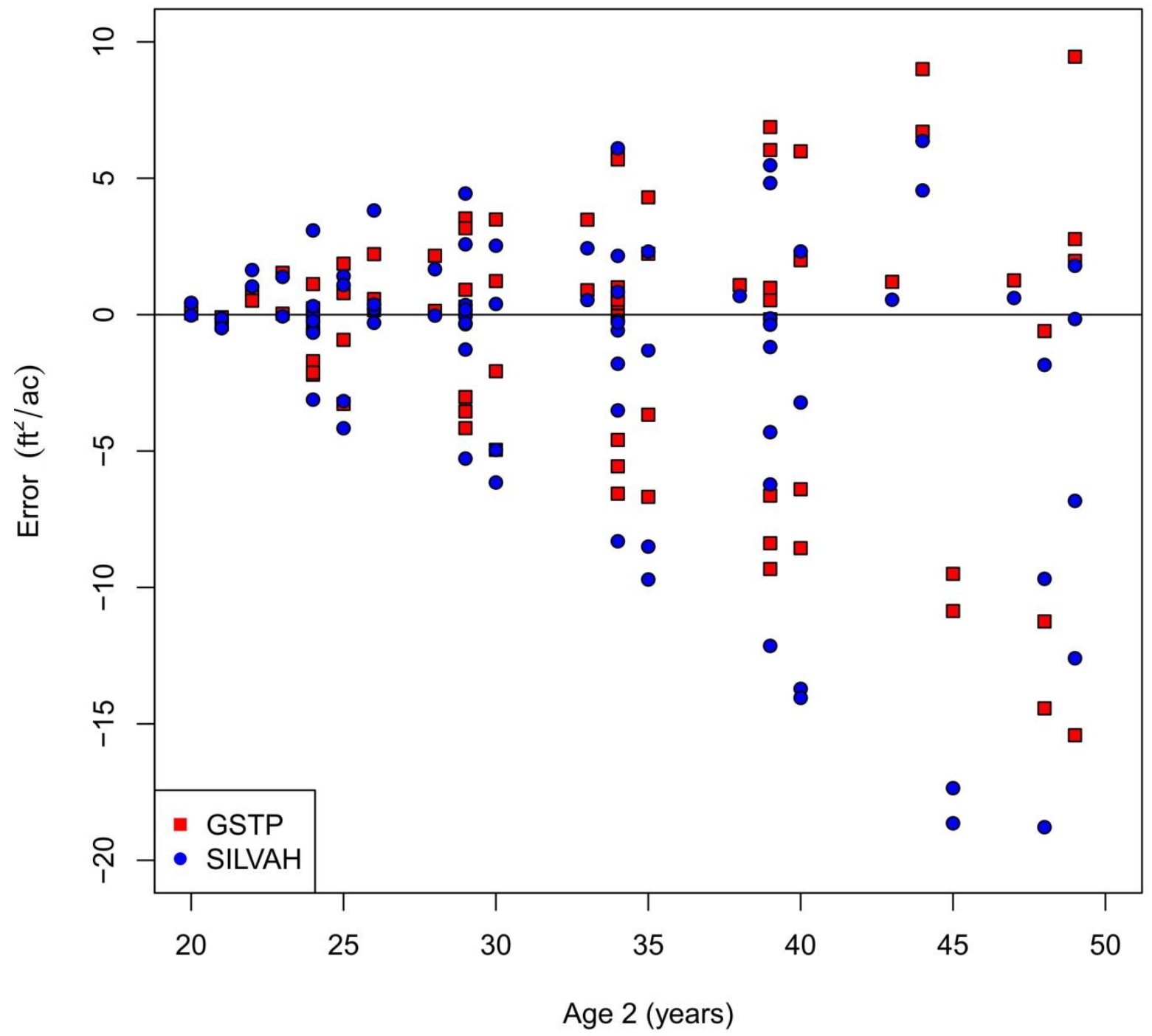

Figure 71. Species group 1 (northern red oak) projection error by projection age (age 2) for unthinned overlapping projections. 


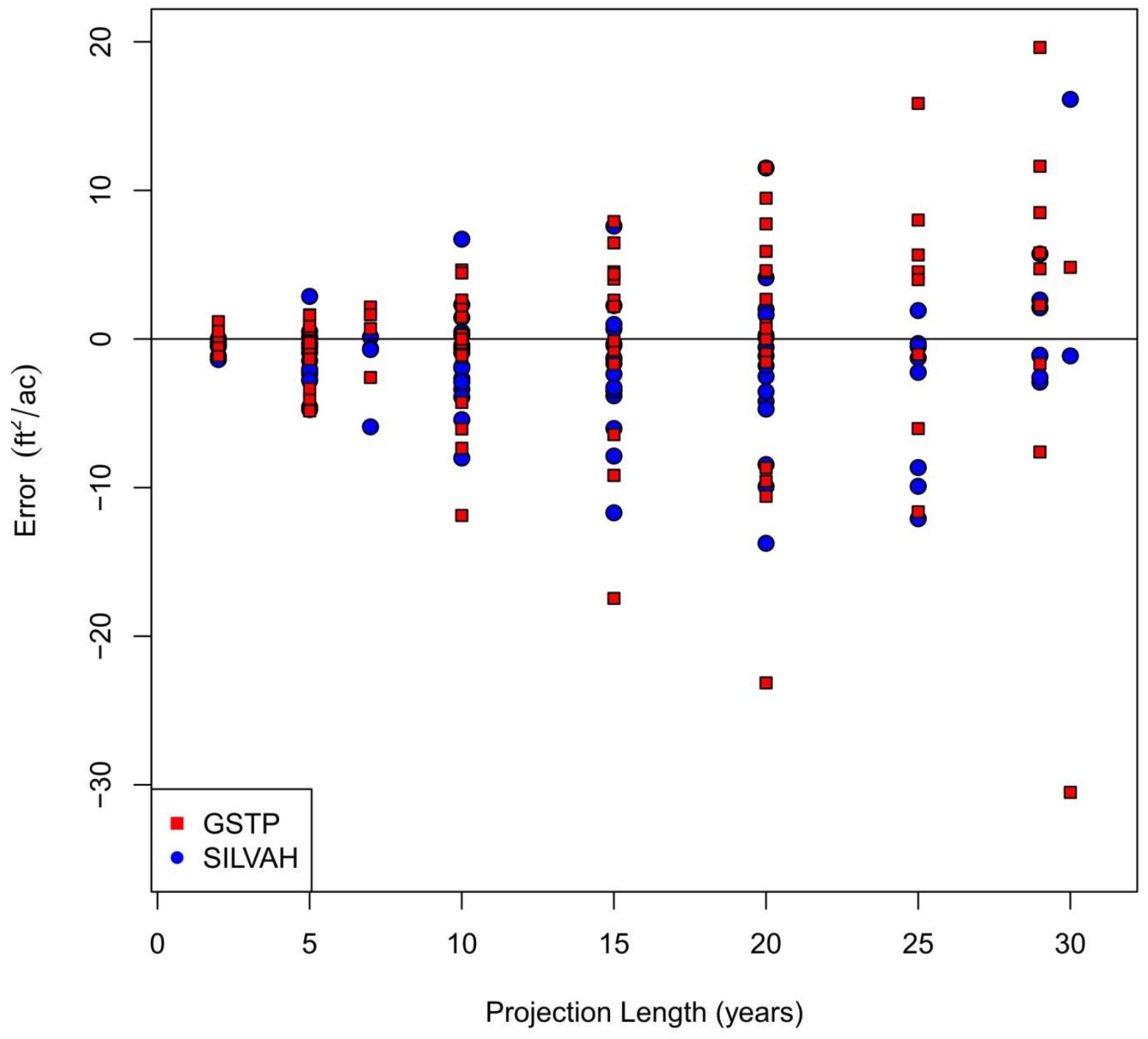

Figure 72. Species group 2 (maples) projection error by projection length for unthinned overlapping projections. 


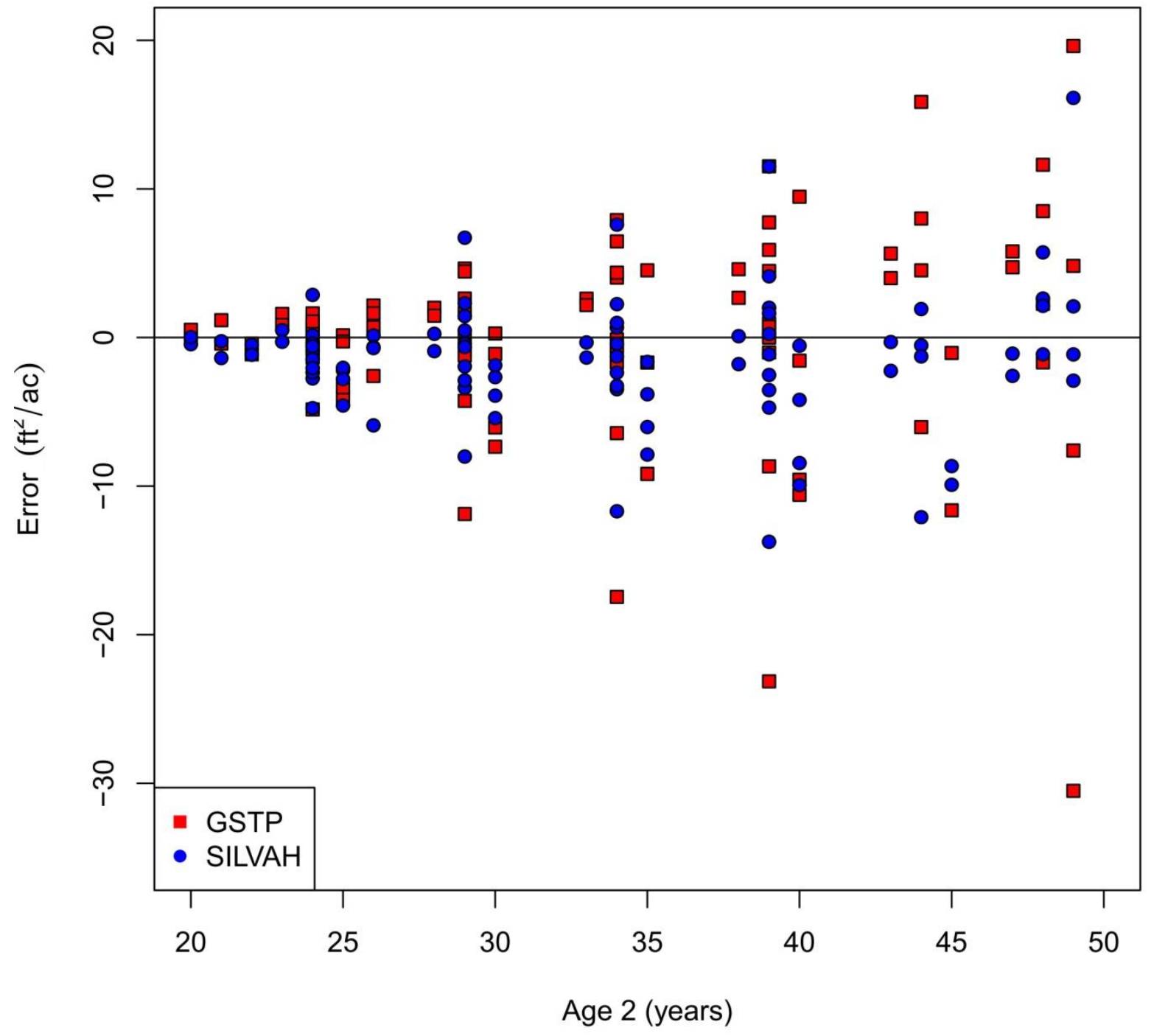

Figure 73. Species group 2 (maples) projection error by projection age (age 2) for unthinned overlapping projections. 


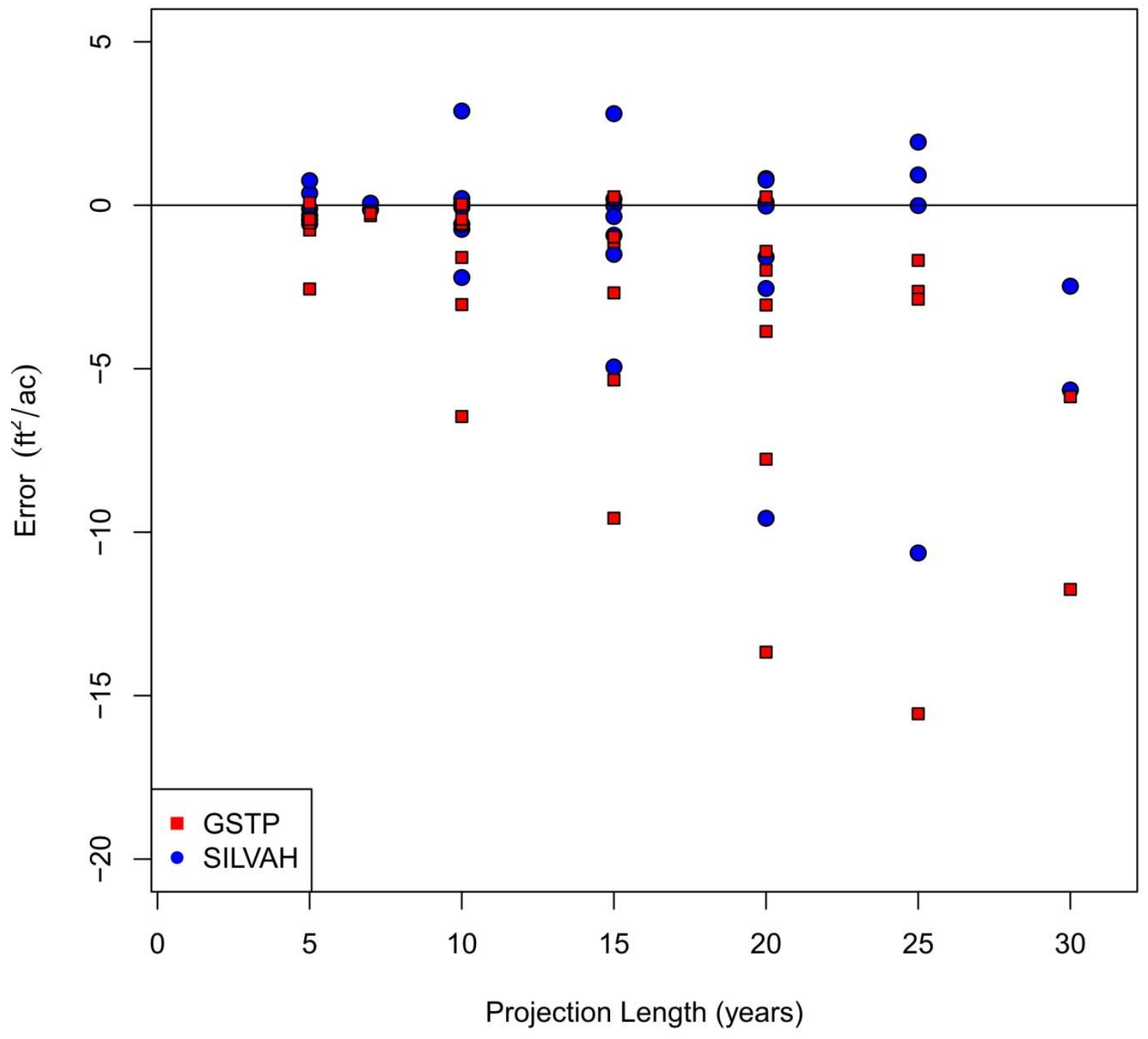

Figure 74. Species group 3 (white oaks) projection error by projection length for unthinned overlapping projections. 


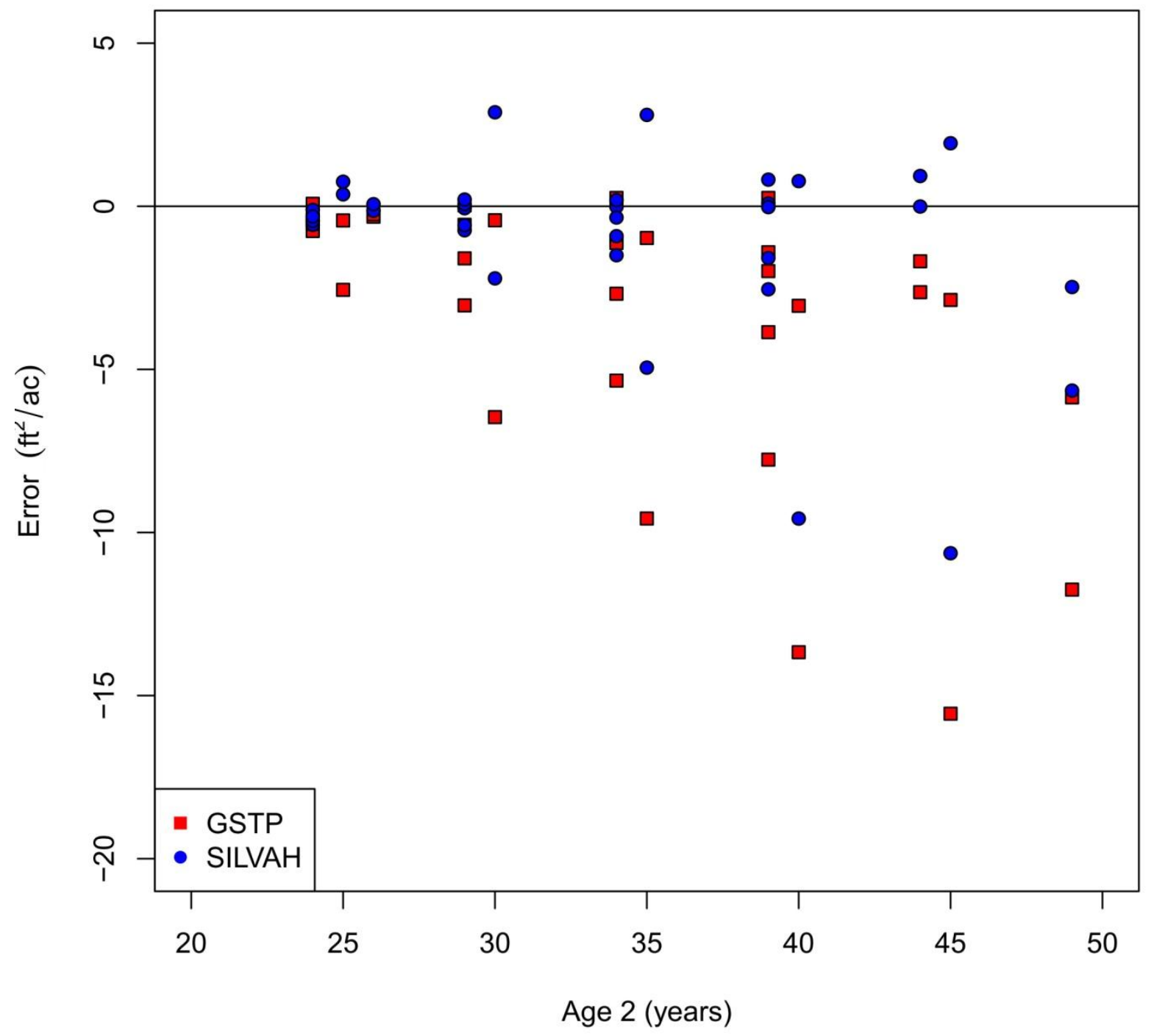

Figure 75. Species group 3 (white oaks) projection error by projection age (age 2) for unthinned overlapping projections. 


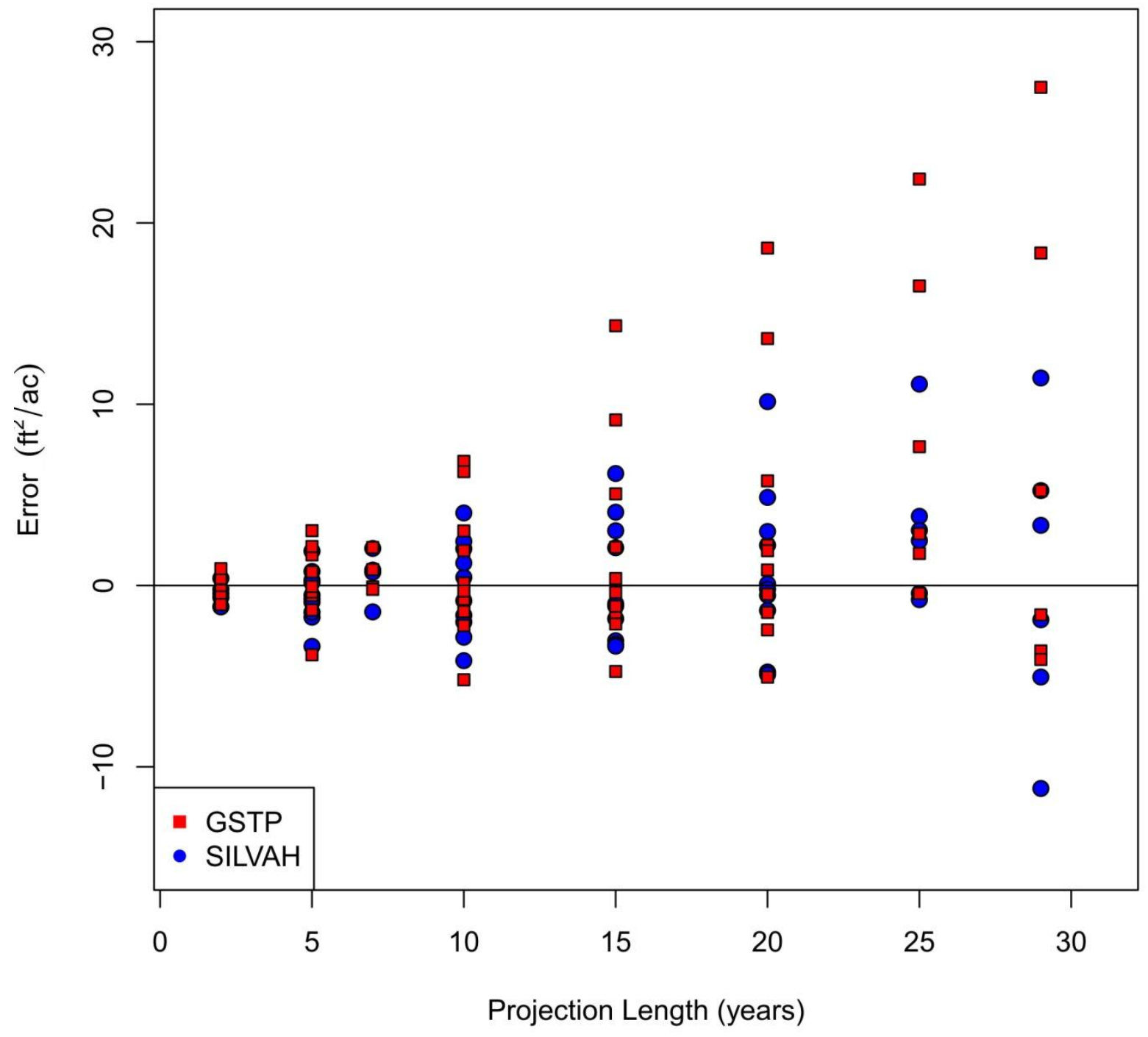

Figure 76. Species group 4 (hickory/ash) projection error by projection length for unthinned overlapping projections. 


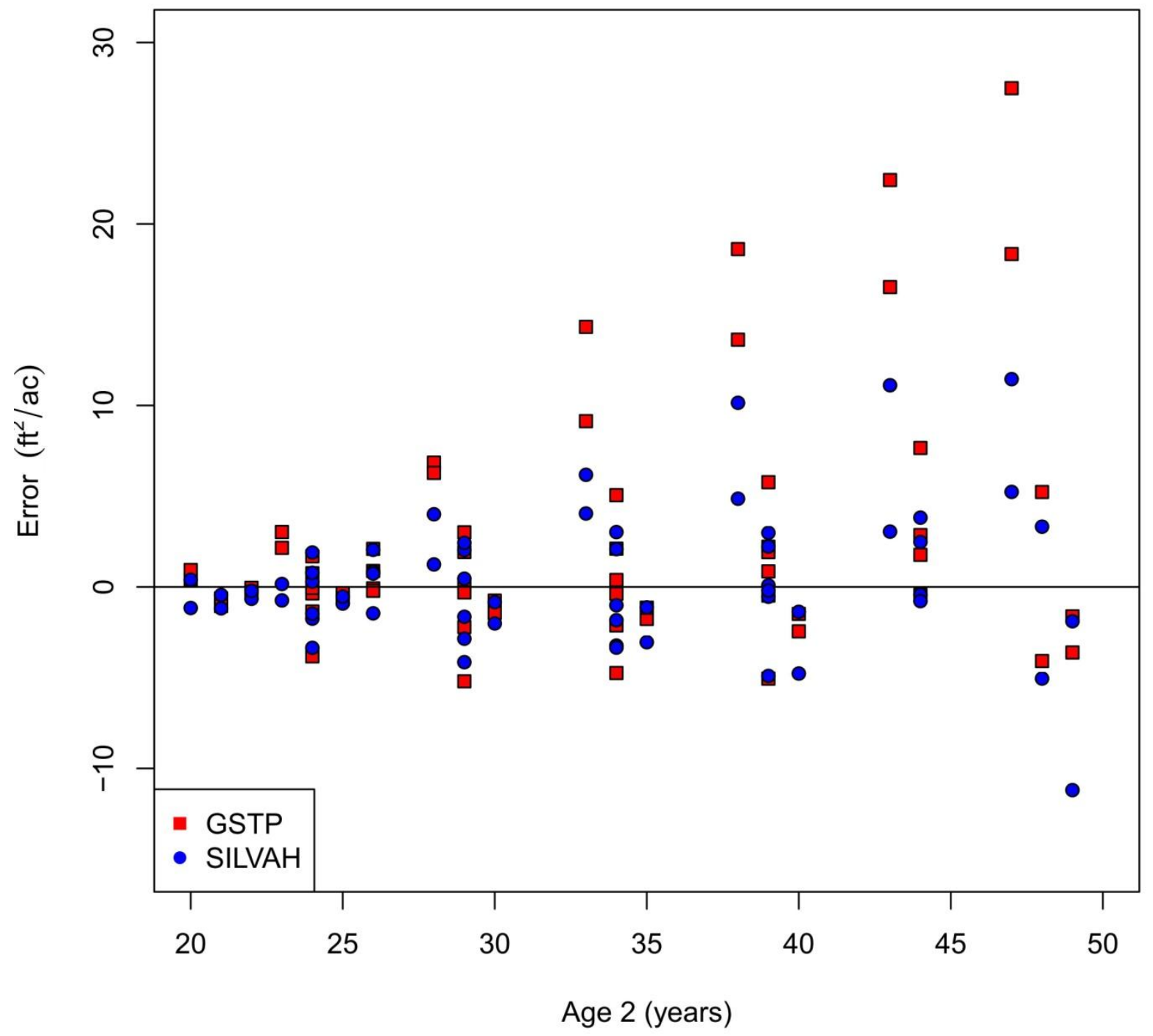

Figure 77. Species group 4 (hickory/ash) projection error by projection age (age 2) for unthinned overlapping projections. 


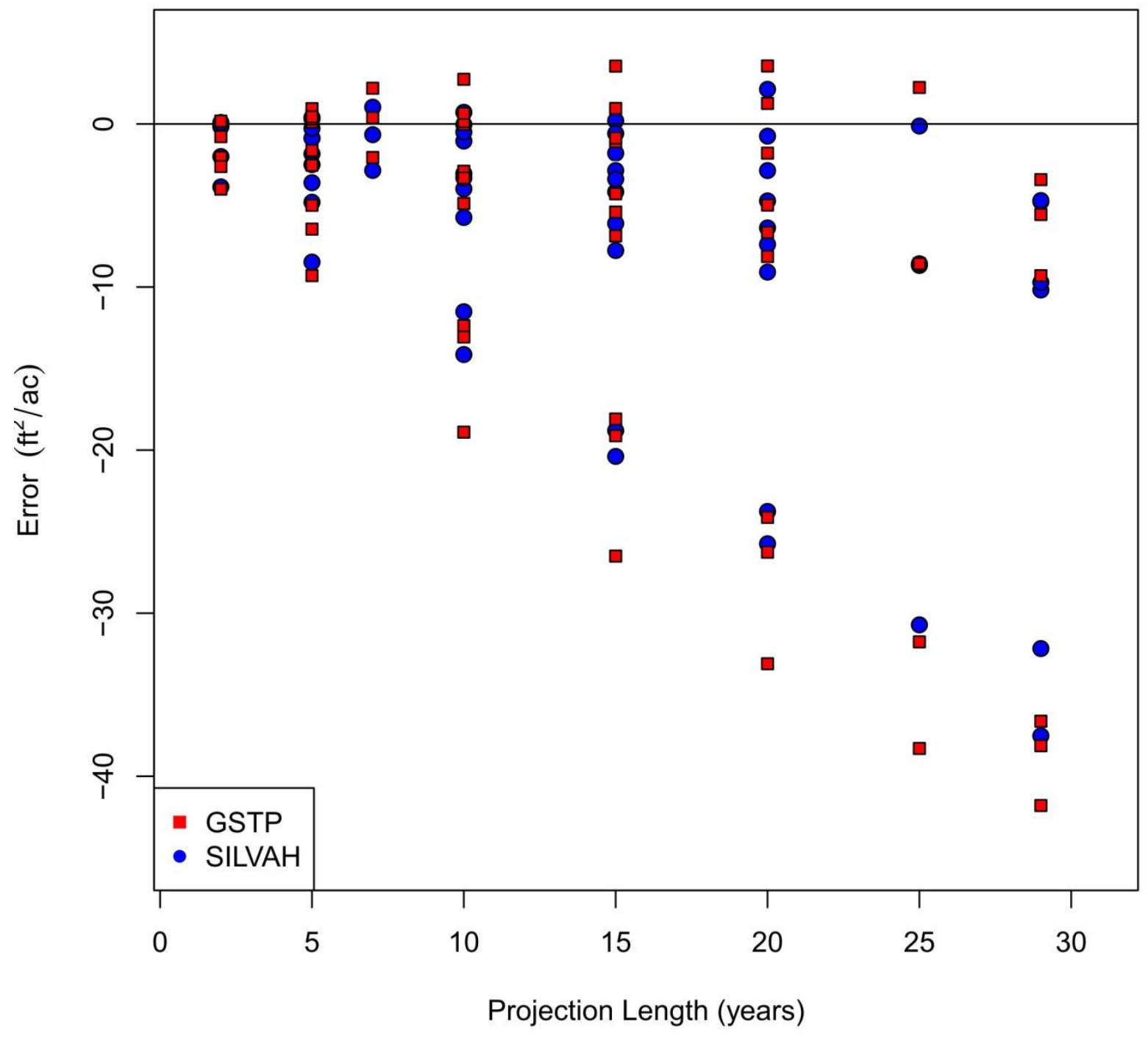

Figure 78. Species group 7 (black cherry) projection error by projection length for unthinned overlapping projections. 


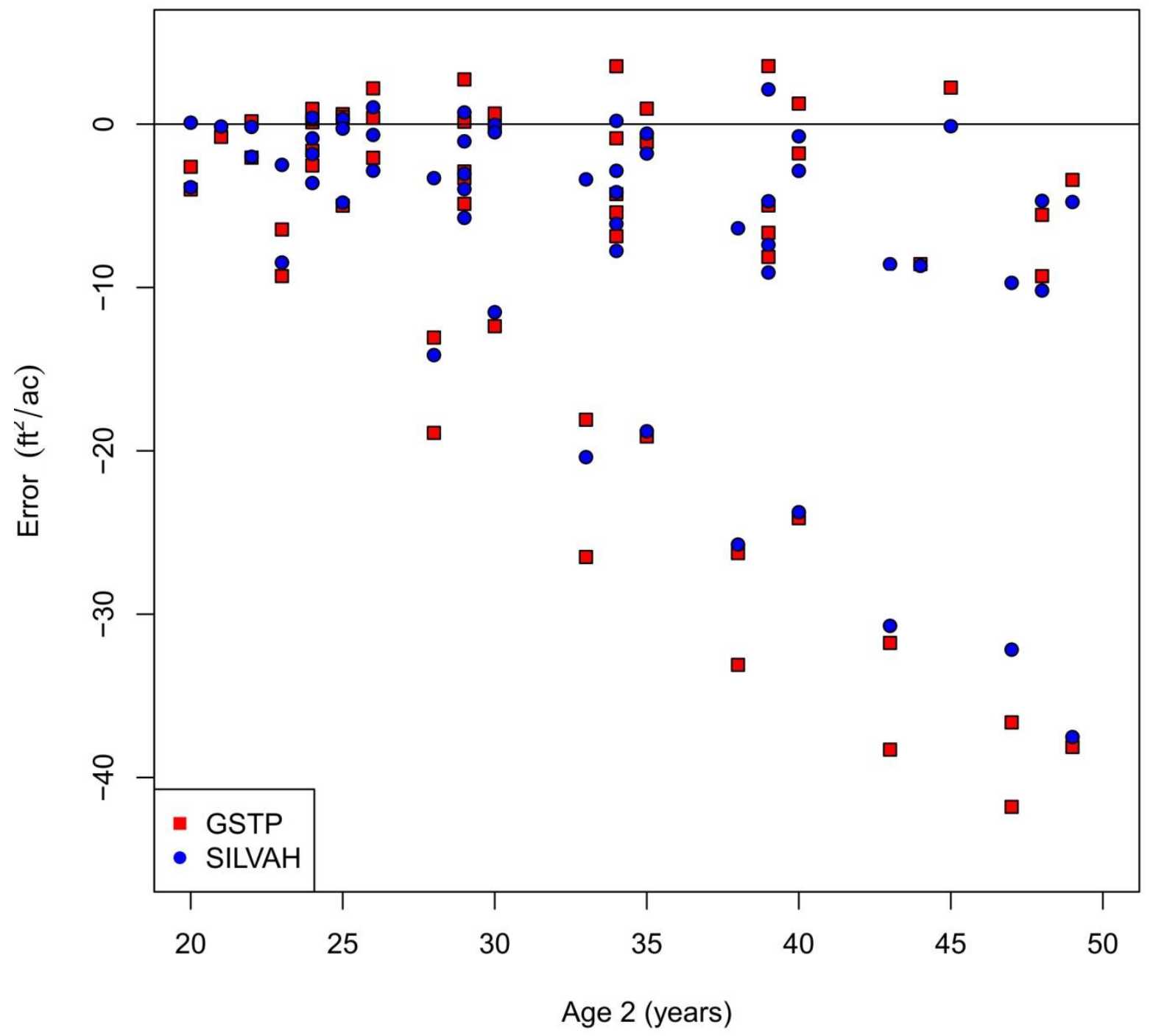

Figure 79. Species group 7 (black cherry) projection error by projection age (age 2) for unthinned overlapping projections. 


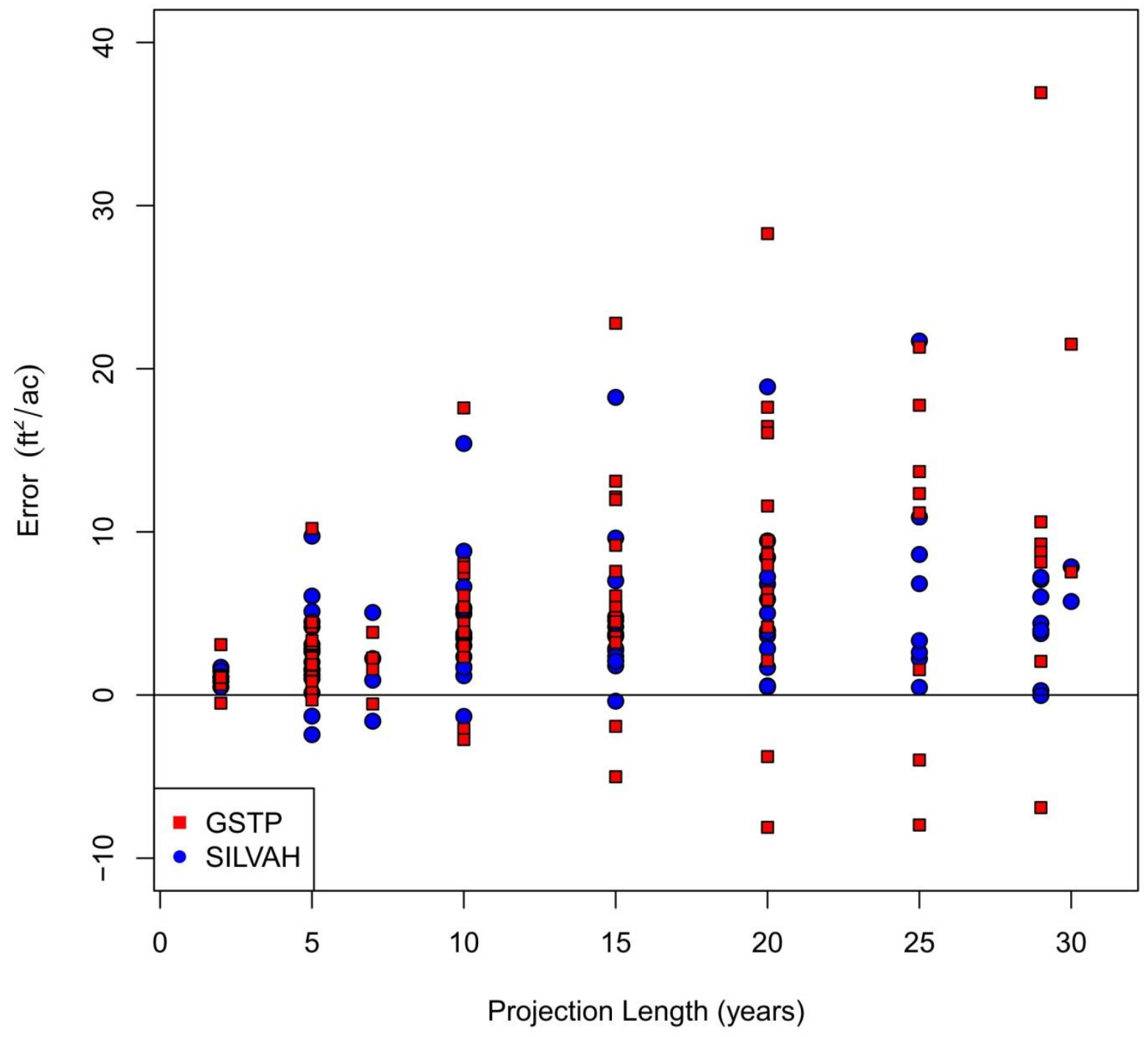

Figure 80. Species group 8 (other) projection error by projection length for unthinned overlapping projections. 


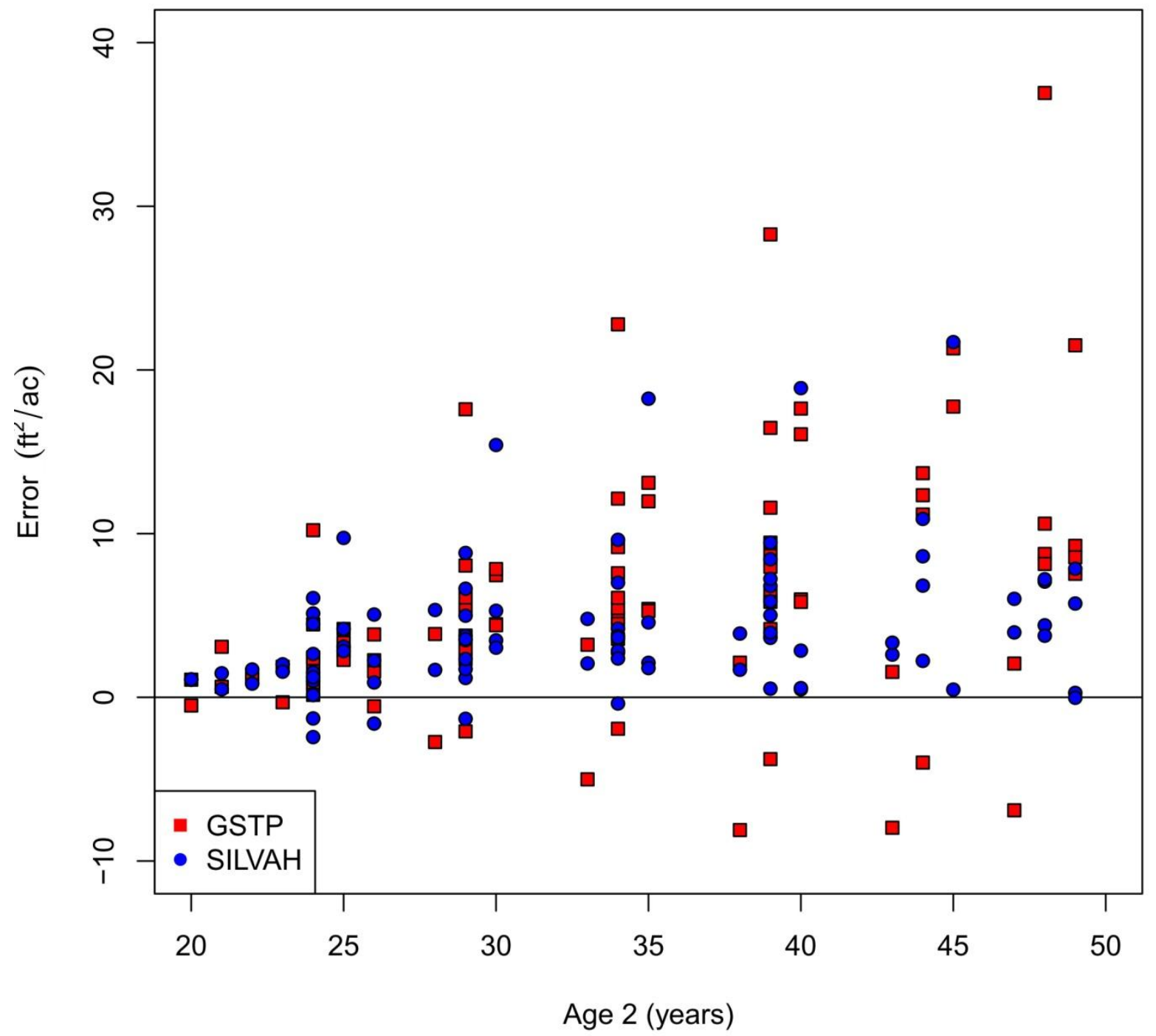

Figure 81. Species group 8 (other) projection error by projection age (age 2) for unthinned overlapping projections. 


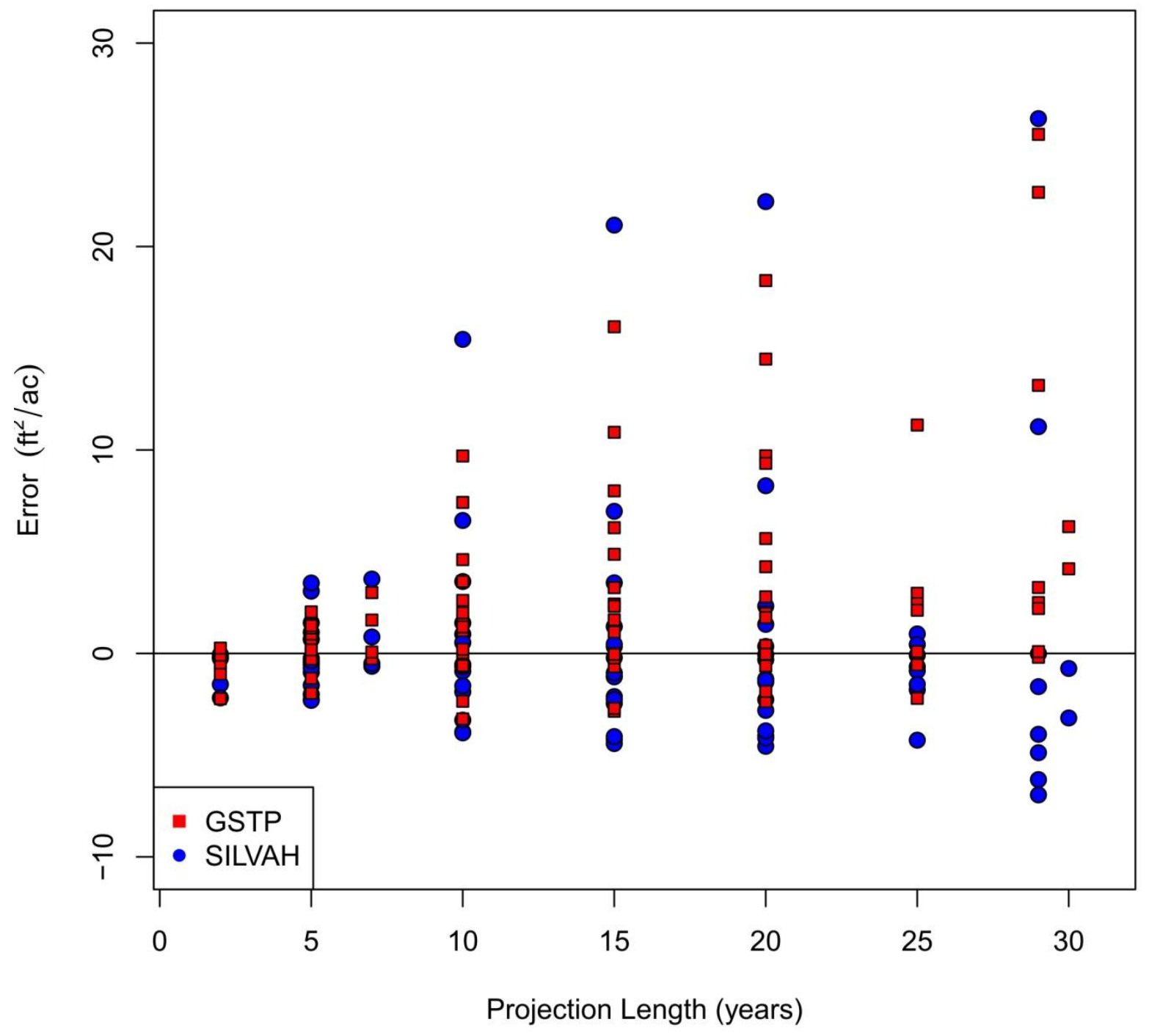

Figure 82. Species group 10 (birches) projection error by projection length for unthinned overlapping projections. 


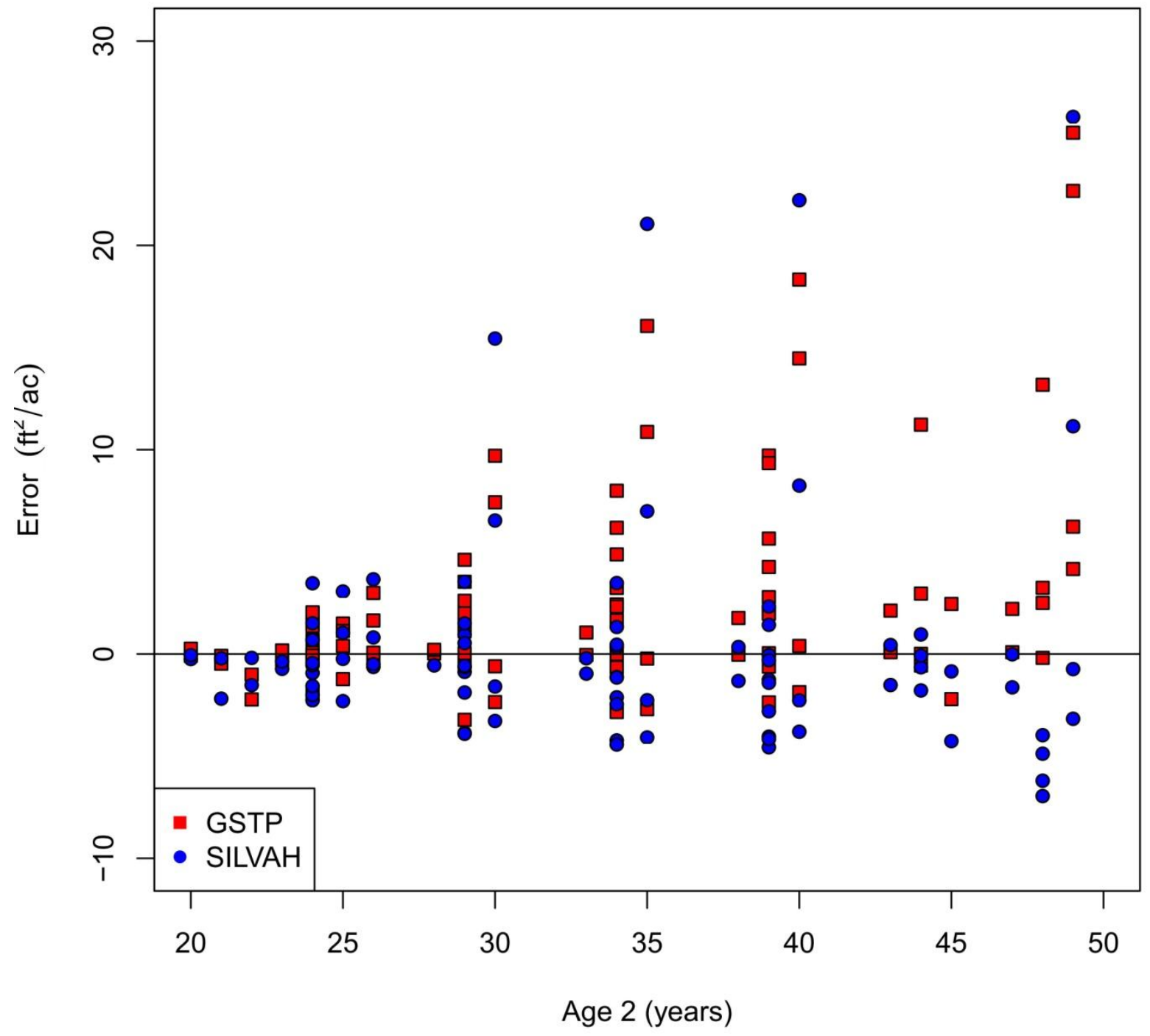

Figure 83. Species group 10 (birches) projection error by projection age (age 2) for unthinned overlapping projections. 


\section{Thinned Plots Basal Area Projection Error Plots}

\section{Non-overlapping Projection Lengths}

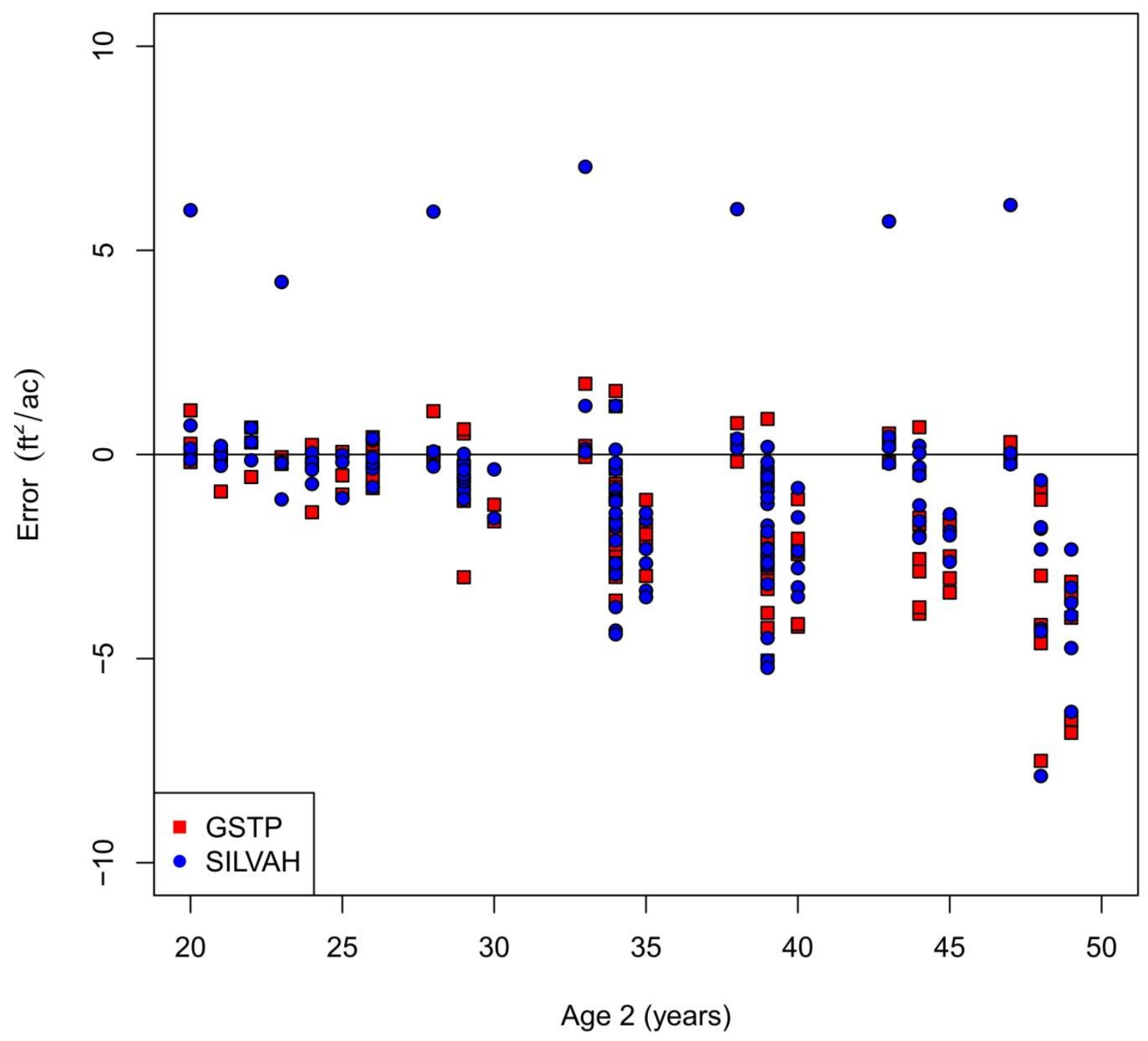

Figure 84. Species group 1 (northern red oak) projection error by projection age (age 2) for thinned non-overlapping projections. 


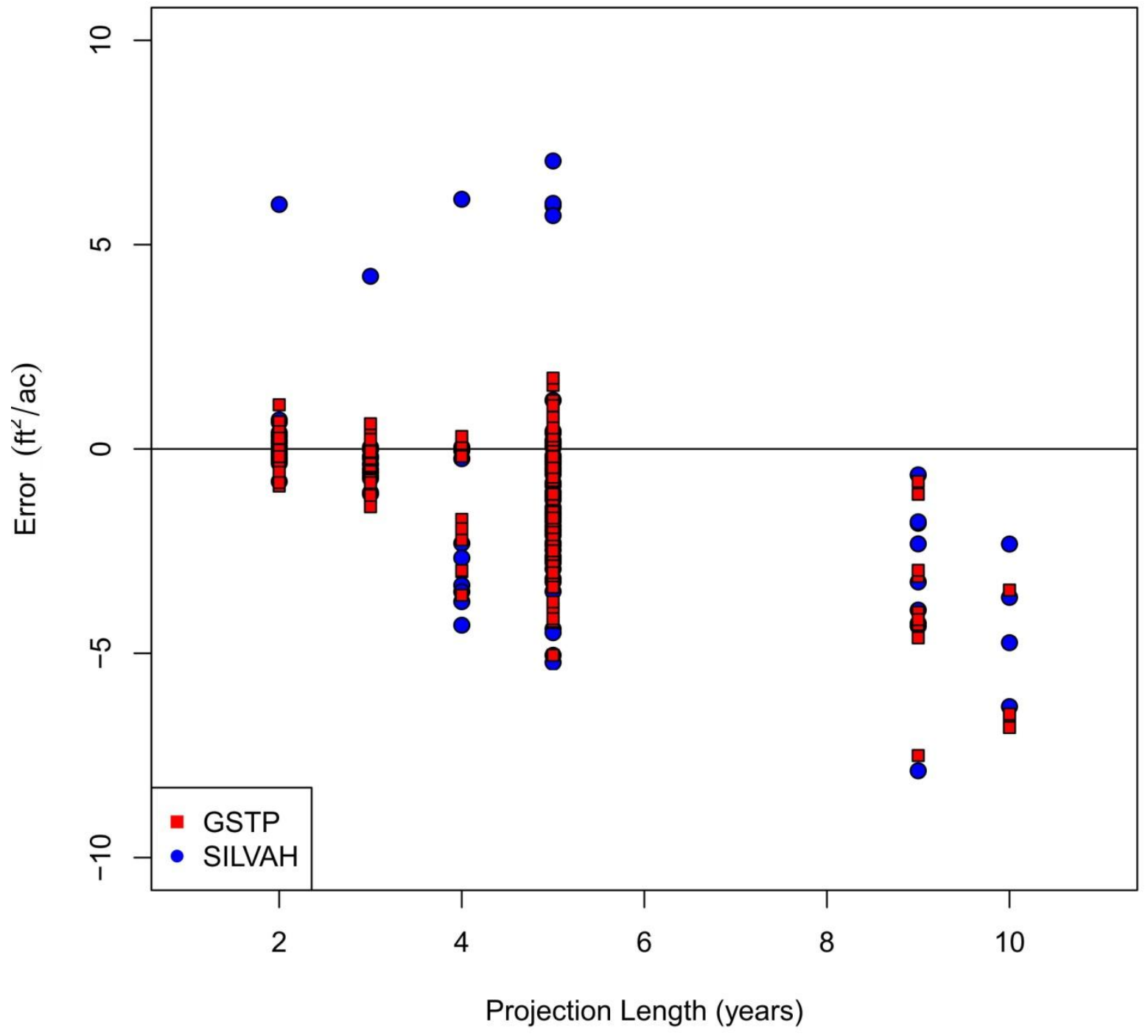

Figure 85. Species group 1 (northern red oak) projection error by projection length for thinned non-overlapping projections. 


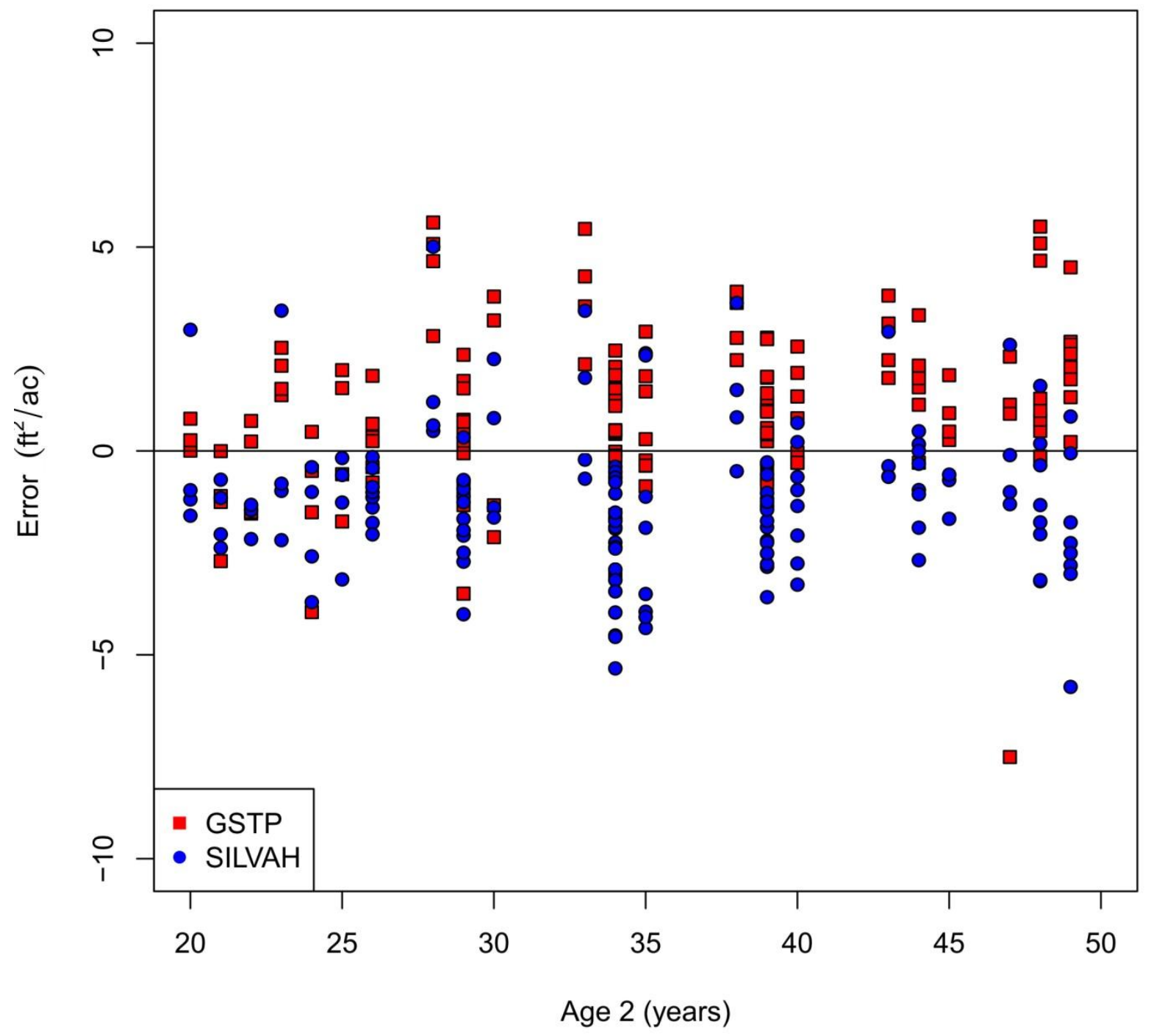

Figure 86. Species group 2 (maples) projection error by projection age (age 2) for thinned non-overlapping projections. 


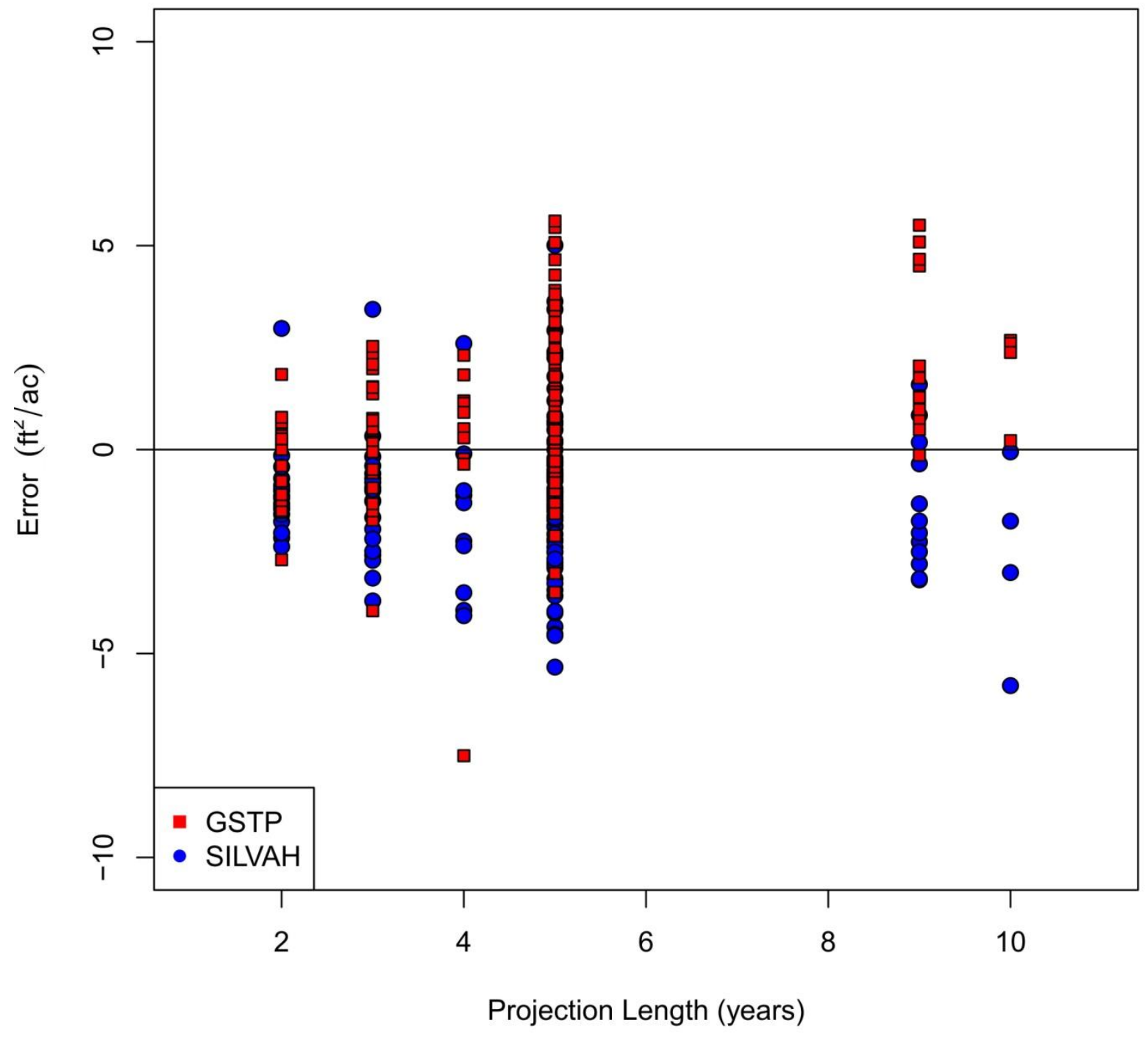

Figure 87. Species group 2 (maples) projection error by projection length for thinned non-overlapping projections. 


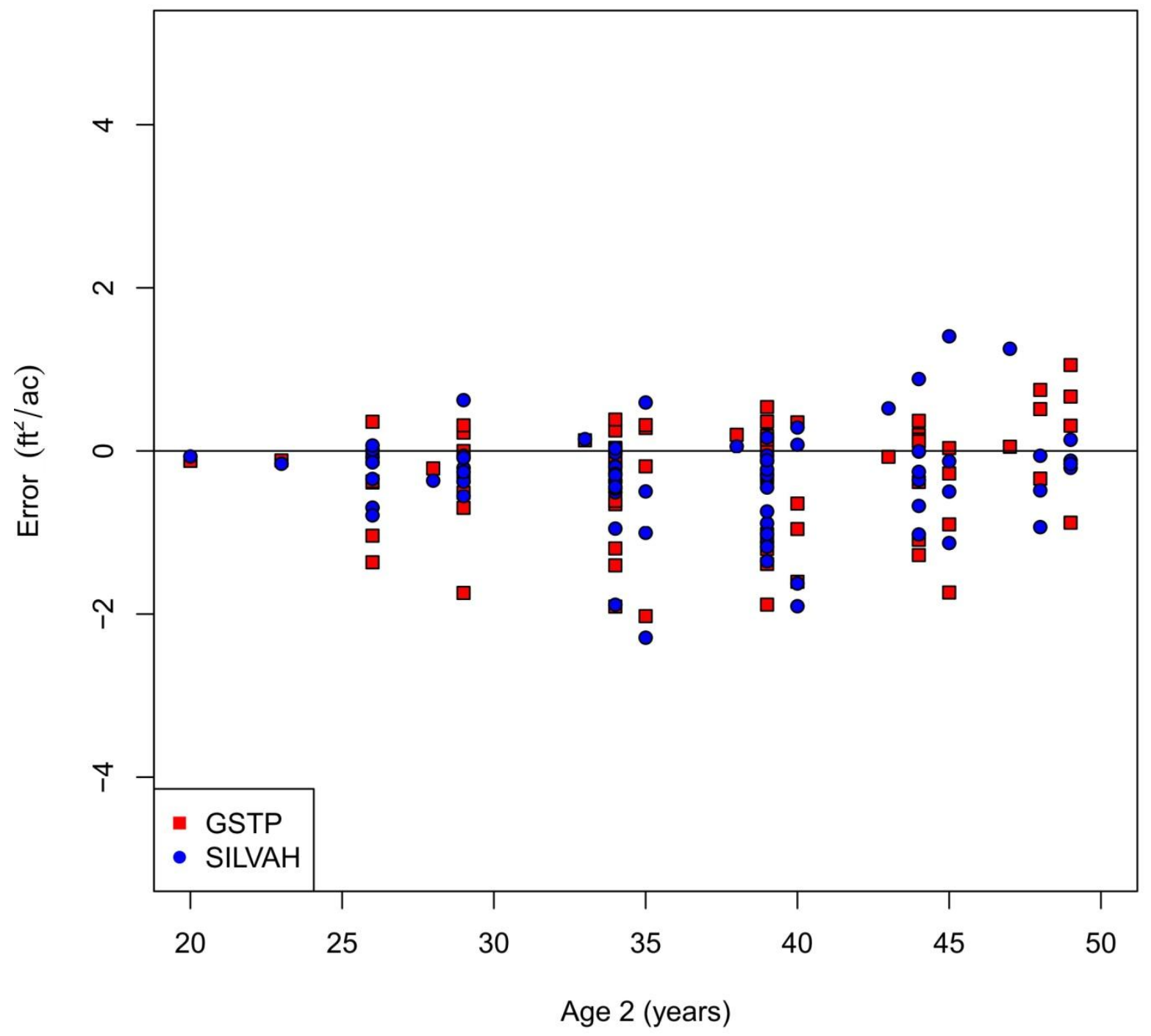

Figure 88. Species group 3 (white oaks) projection error by projection age (age 2) for thinned non-overlapping projections. 


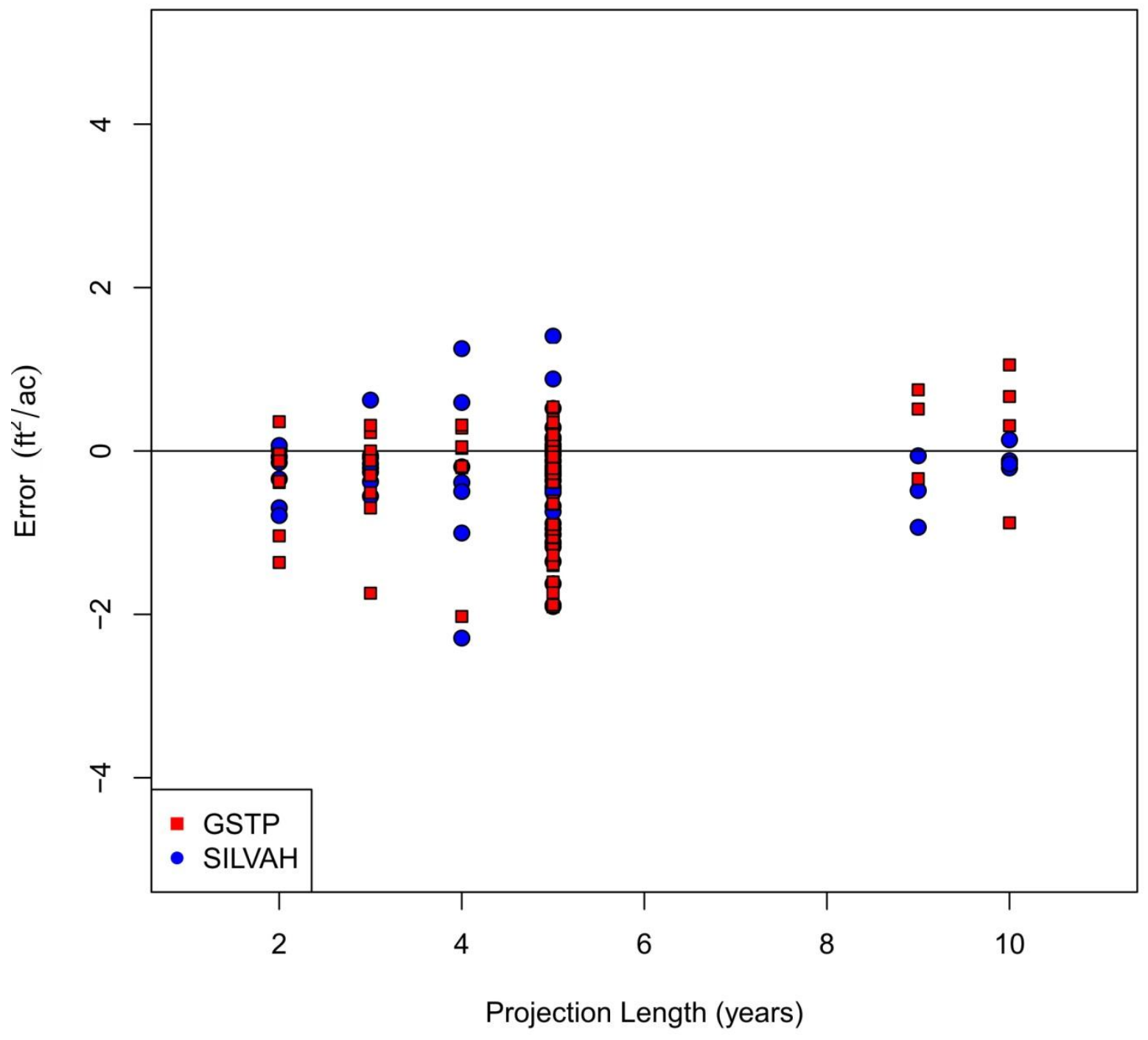

Figure 89. Species group 3 (white oaks) projection error by projection length for thinned non-overlapping projections. 


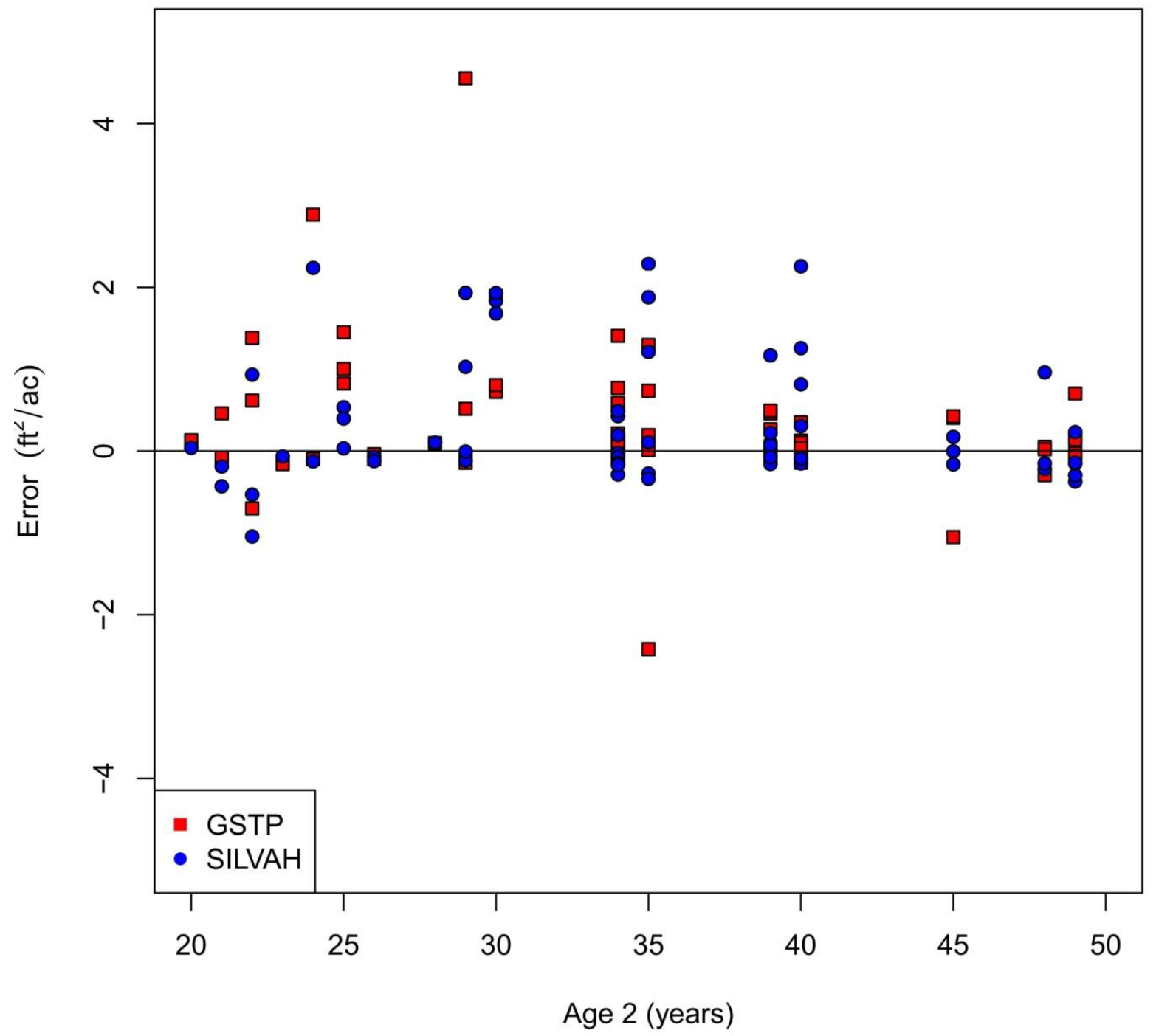

Figure 90. Species group 6 (striped maple/pin cherry) projection error by projection age (age 2) for thinned non-overlapping projections. 


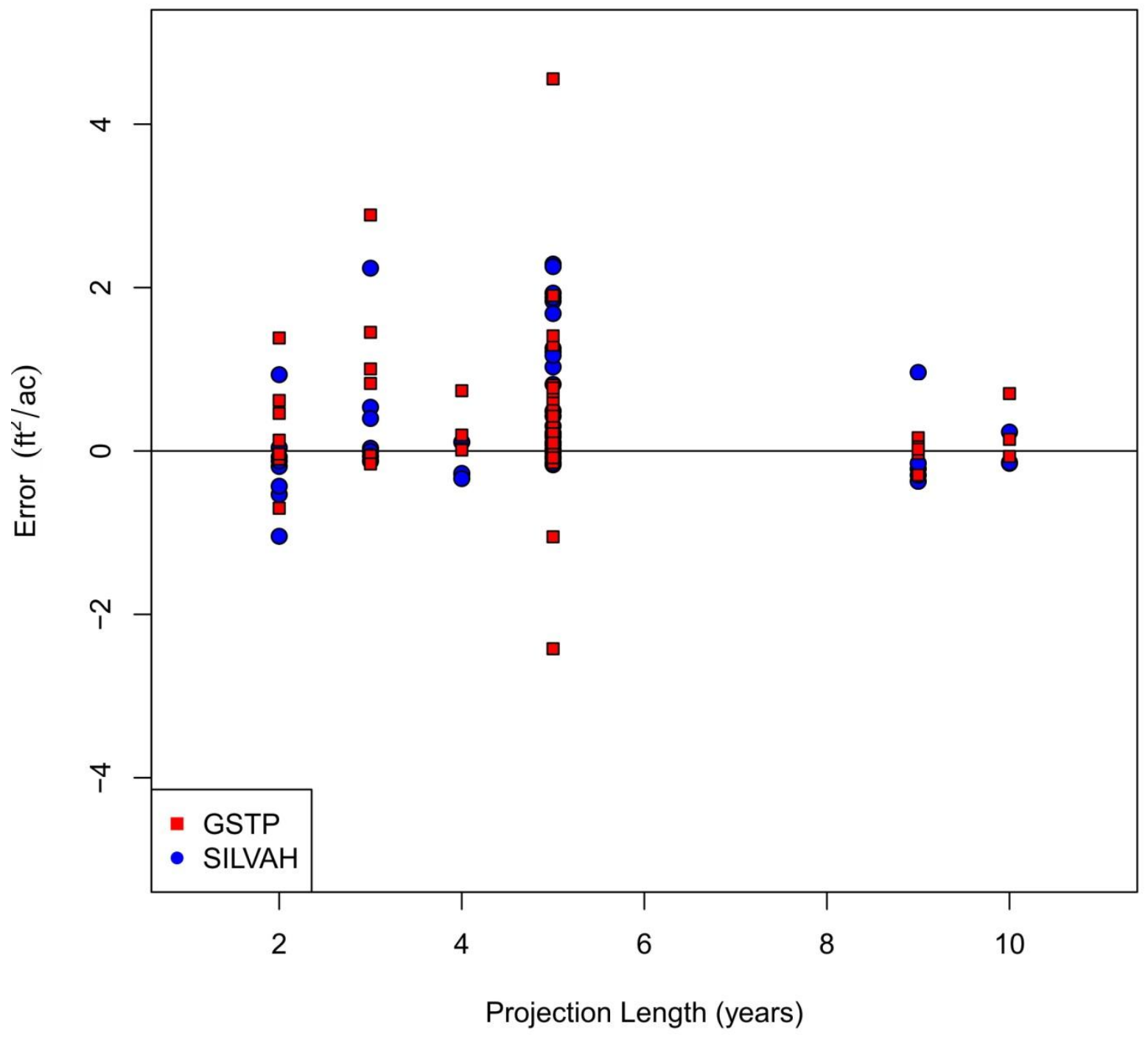

Figure 91. Species group 6 (striped maple/pin cherry) projection error by projection length for thinned non-overlapping projections. 


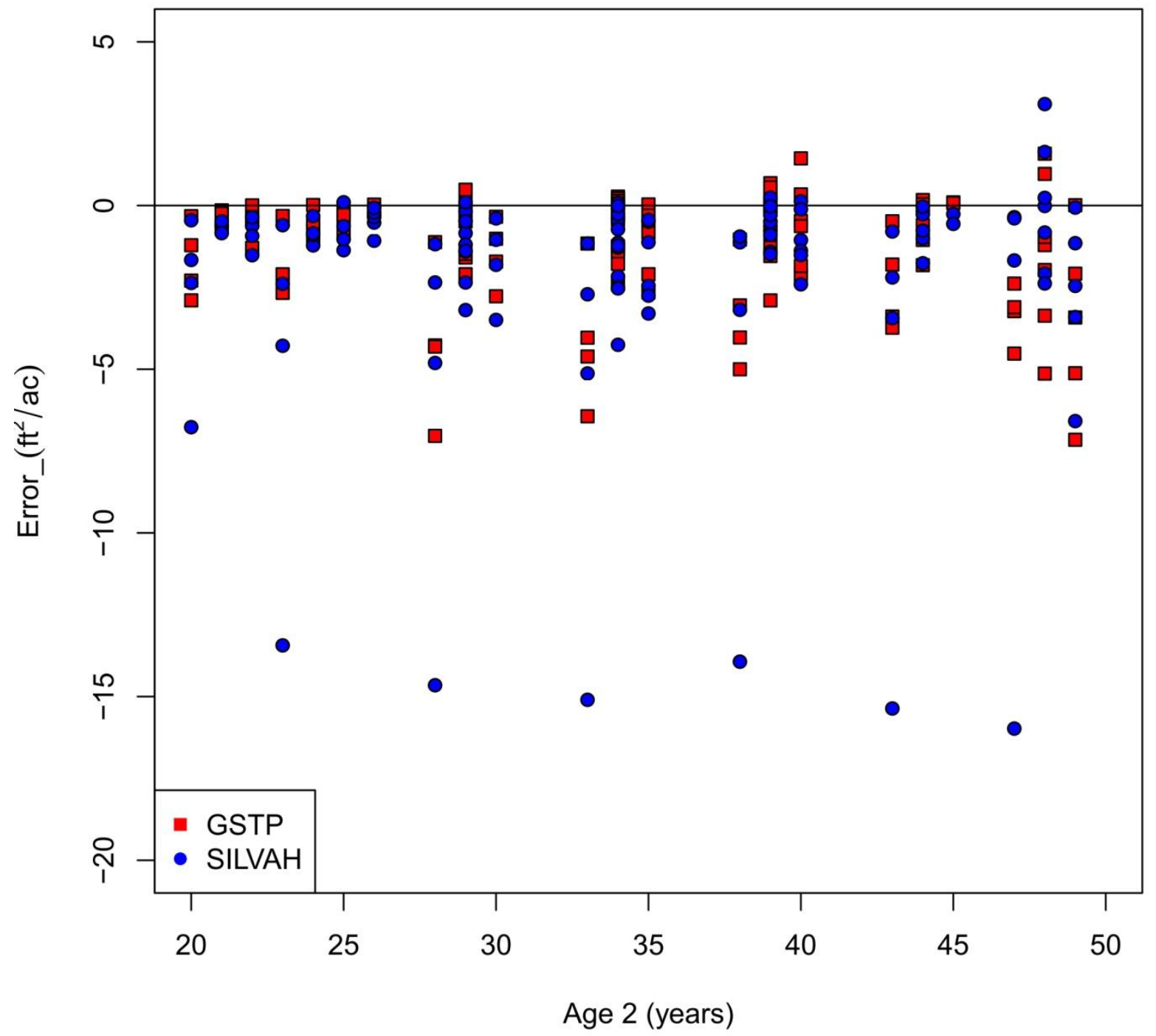

Figure 92. Species group 7 (black cherry) projection error by projection age (age 2) for thinned non-overlapping projections. 


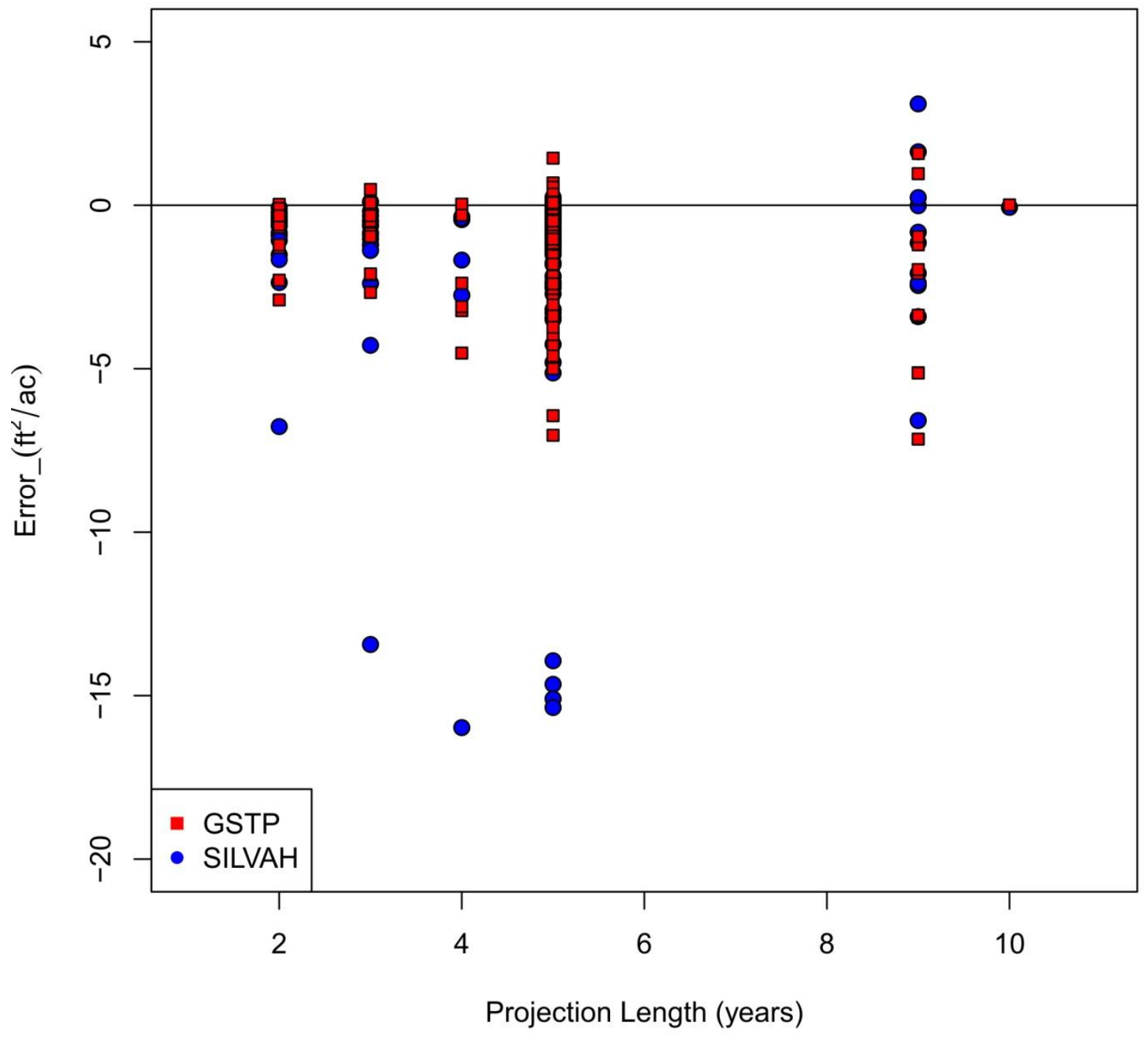

Figure 93. Species group 7 (black cherry) projection error by projection length for thinned non-overlapping projections. 


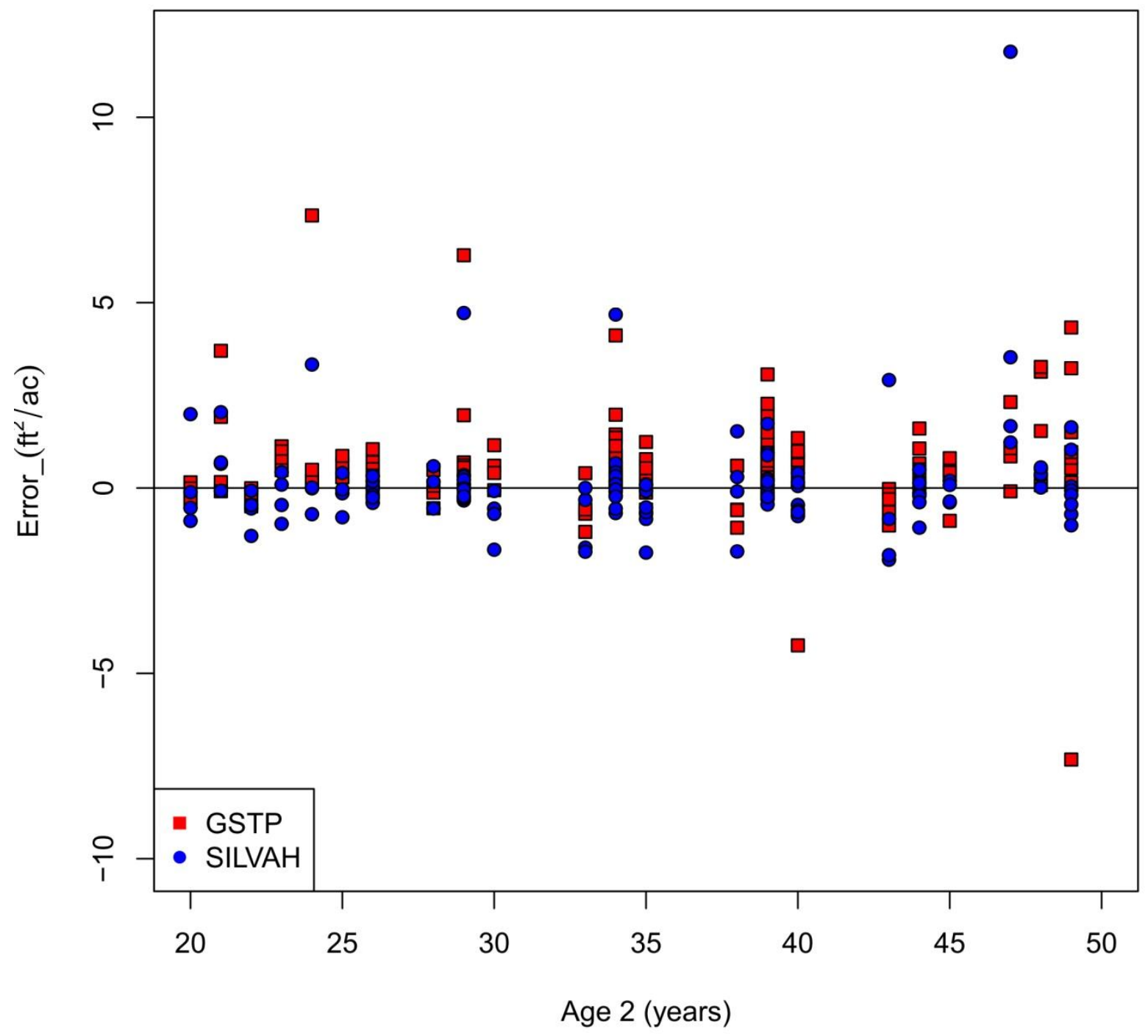

Figure 94. Species group 8 (other) projection error by projection age (age 2) for thinned non-overlapping projections. 


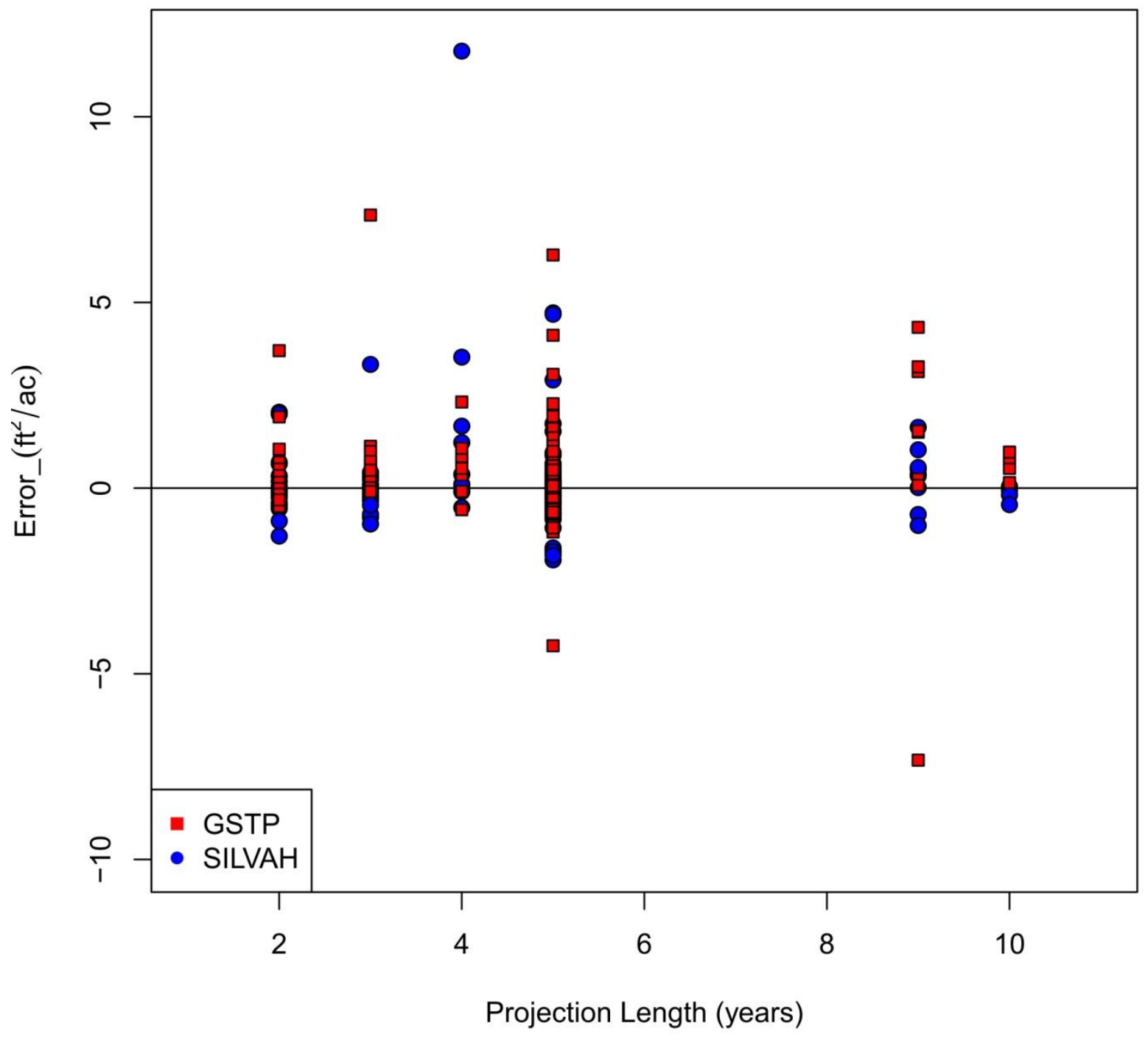

Figure 95. Species group 8 (other) projection error by projection length for thinned non-overlapping projections. 


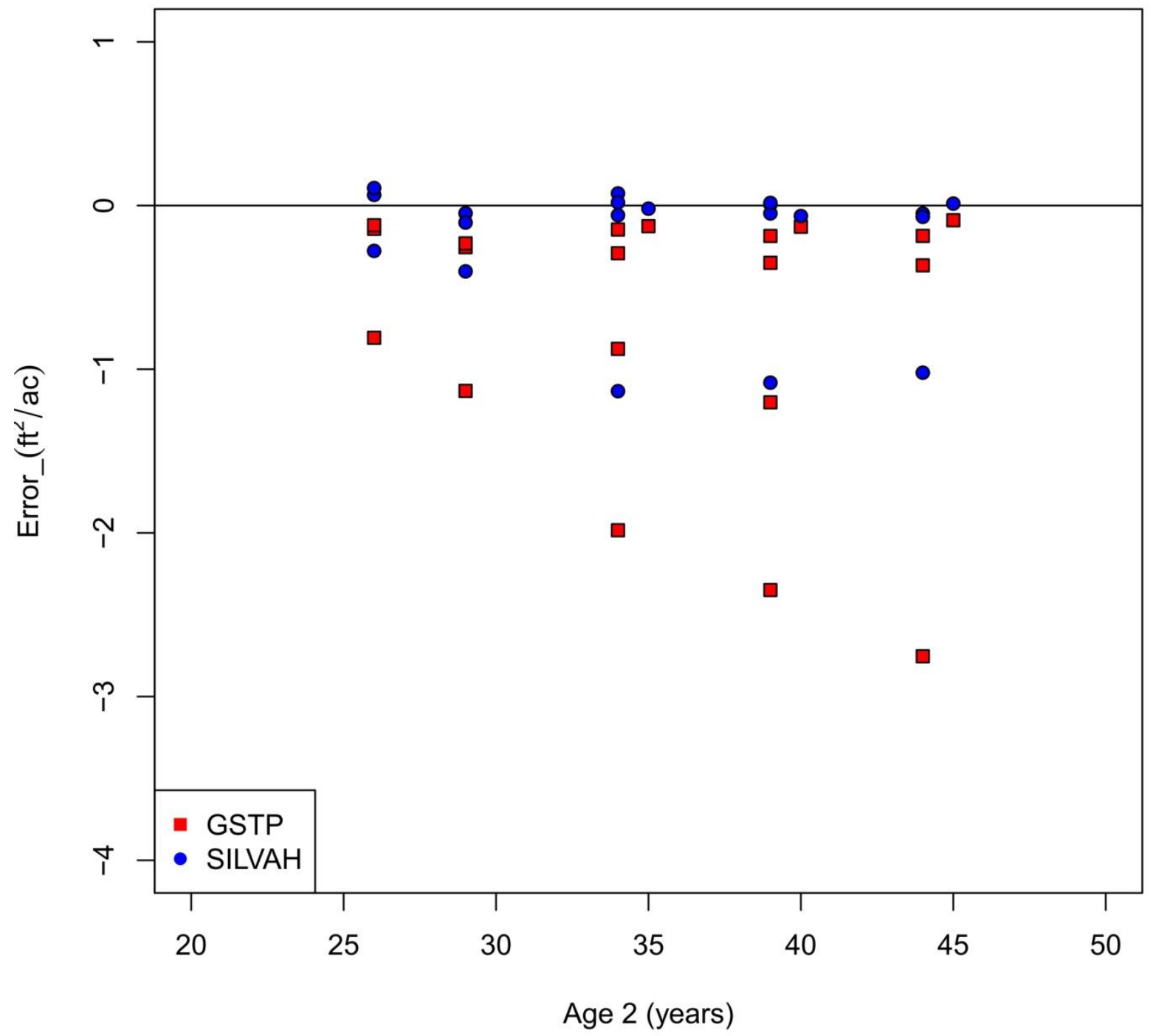

Figure 96. Species group 9 (black and scarlet oaks) projection error by projection age (age 2) for thinned non-overlapping projections. 


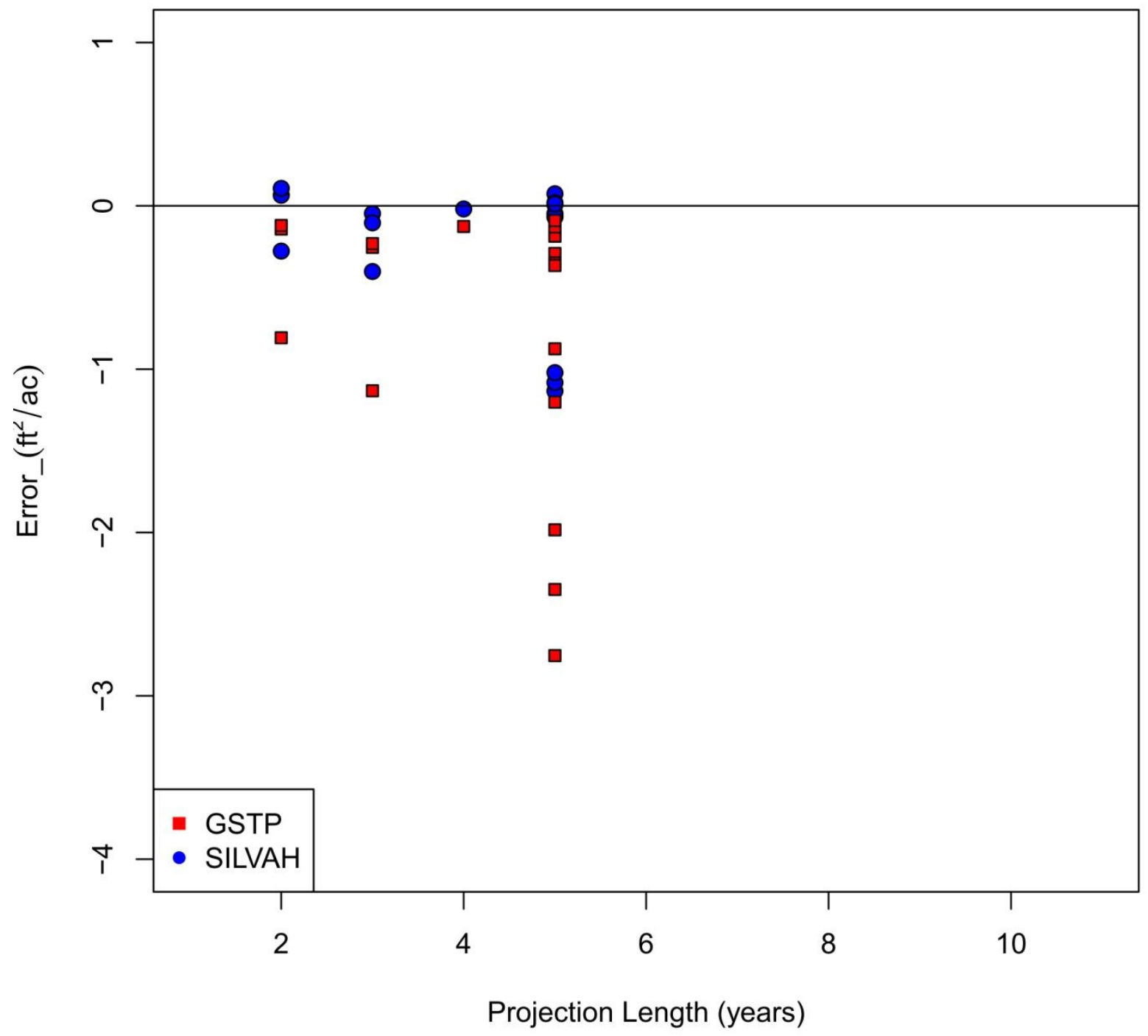

Figure 97. Species group 9 (black and scarlet oaks) projection error by projection length for thinned non-overlapping projections. 


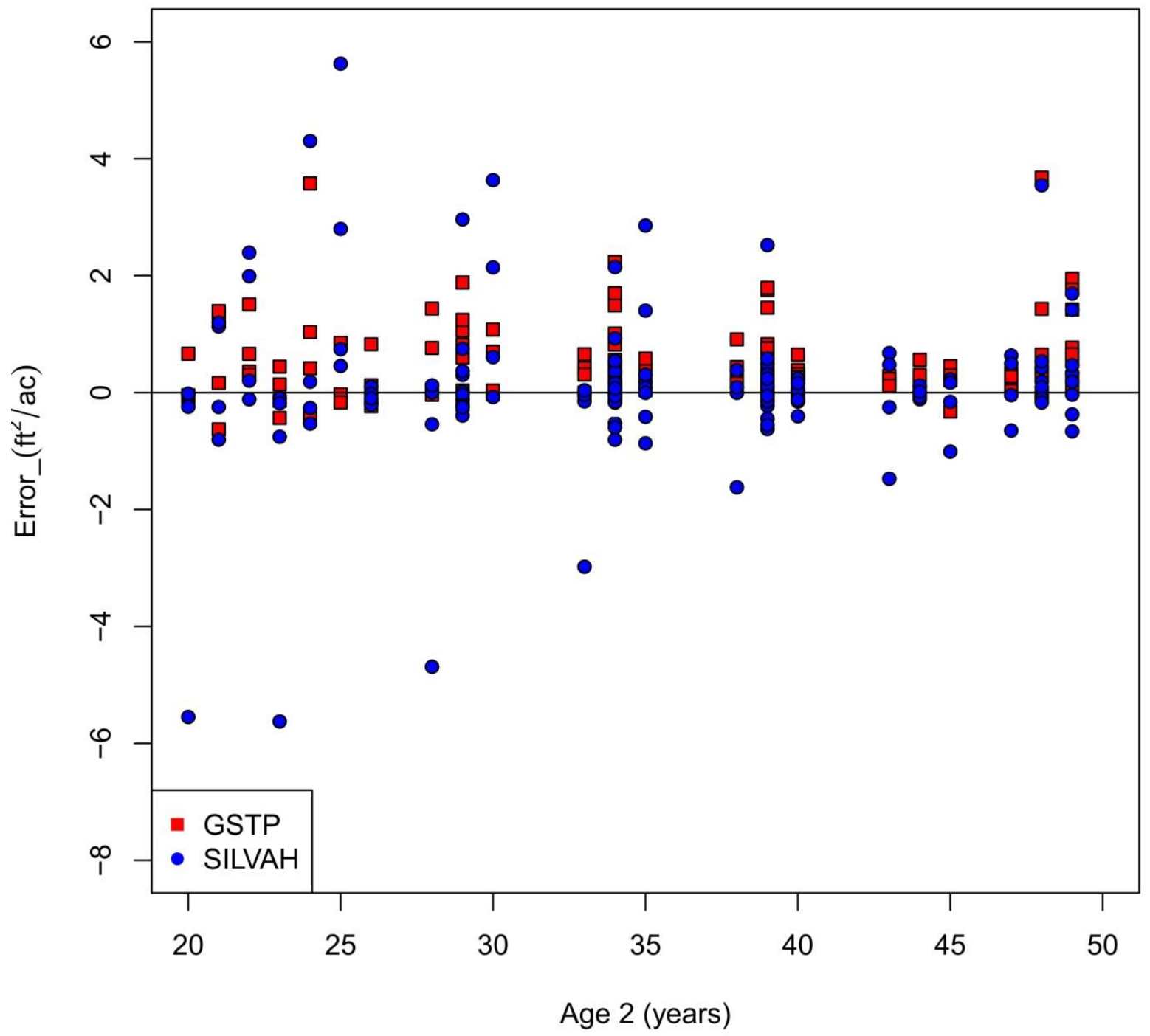

Figure 98. Species group 10 (birches) projection error by projection age (age 2) for thinned non-overlapping projections. 


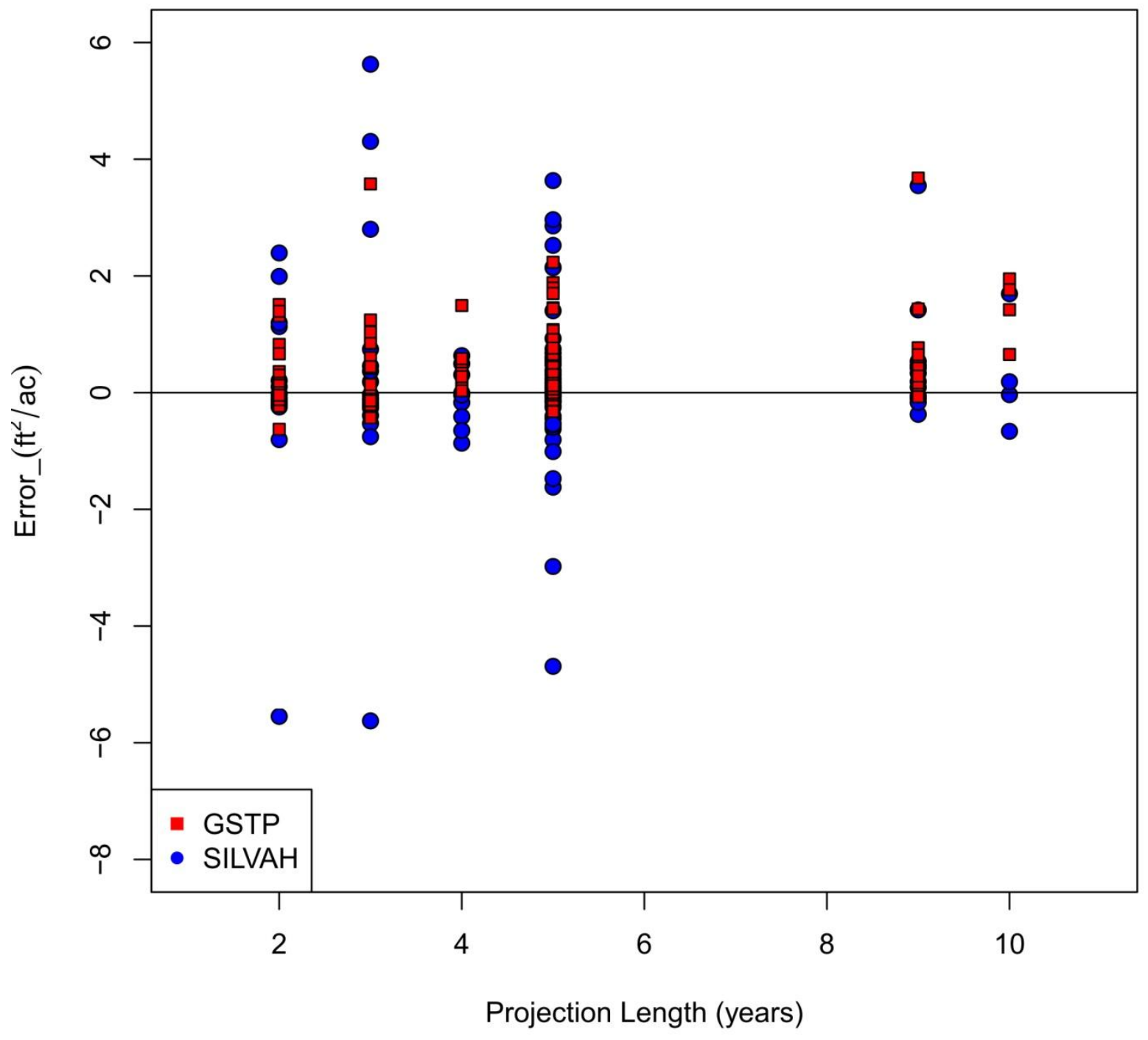

Figure 99. Species group 10 (birches) projection error by projection length for thinned non-overlapping projections. 
Overlapping Projection Lengths

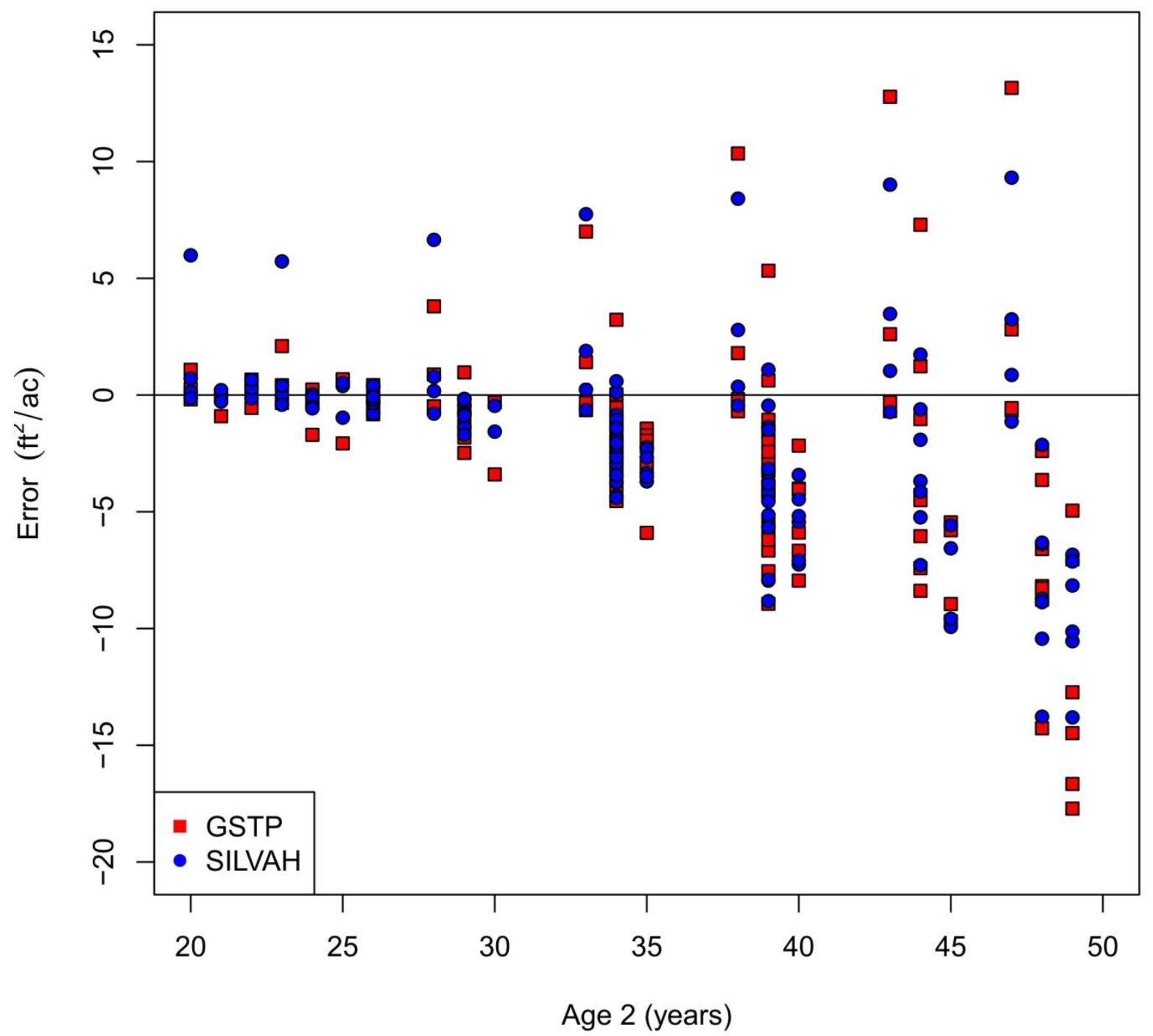

Figure 100. Species group 1 (northern red oak) projection error by projection age (age 2) for thinned overlapping projections. 


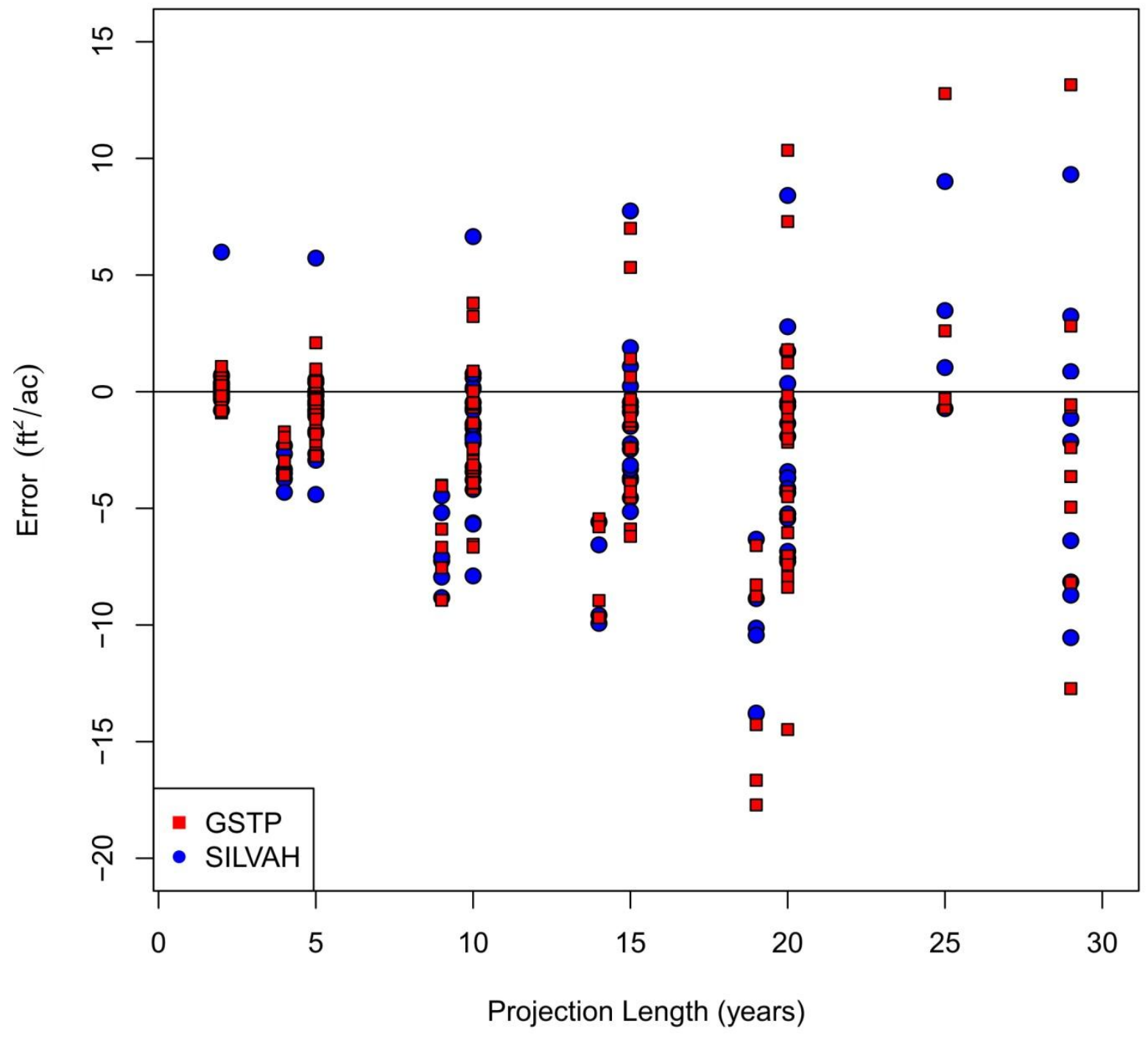

Figure 101. Species group 1 (northern red oak) projection error by projection length for thinned overlapping projections. 


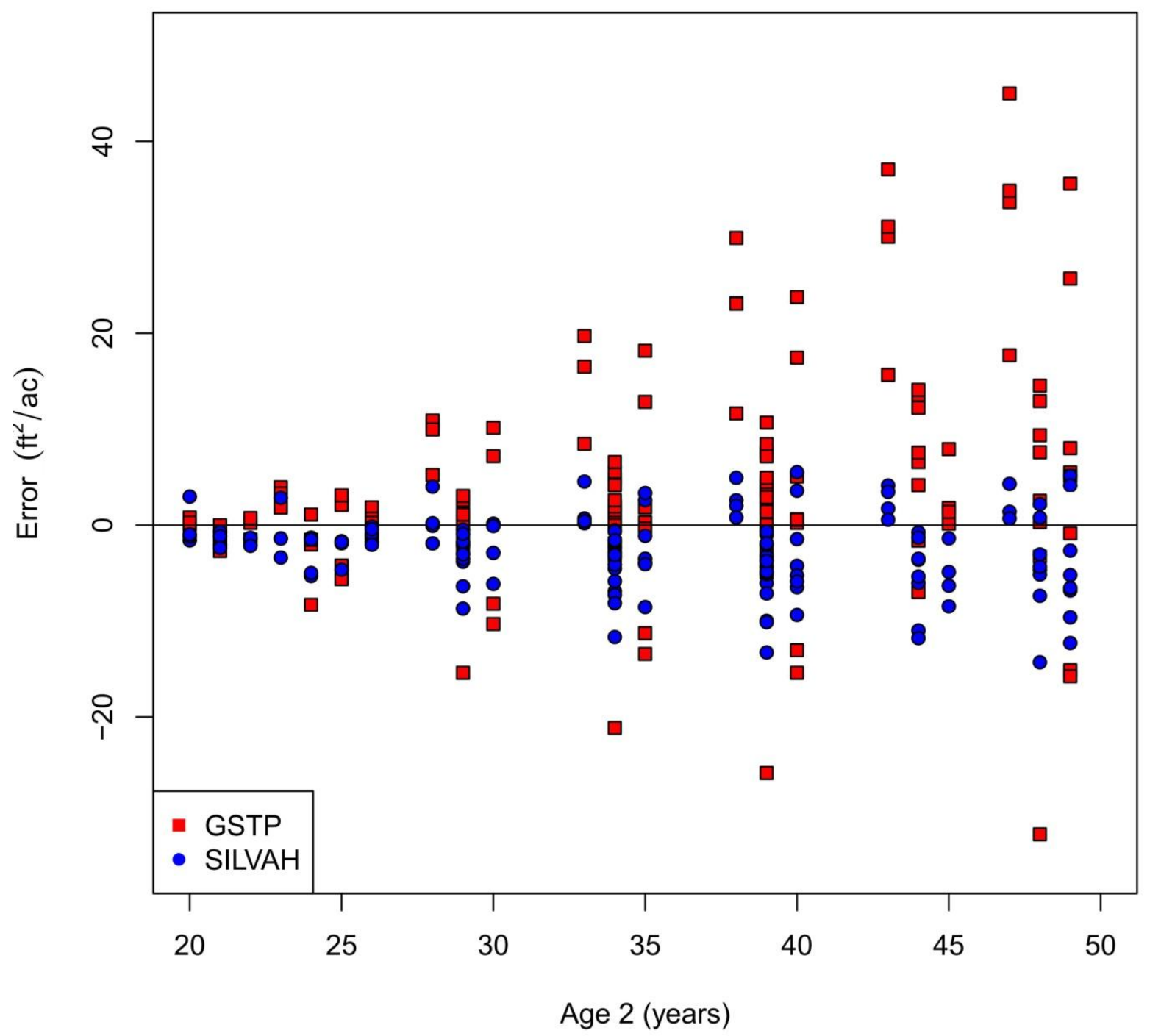

Figure 102. Species group 2 (maples) projection error by projection age (age 2) for thinned overlapping projections. 


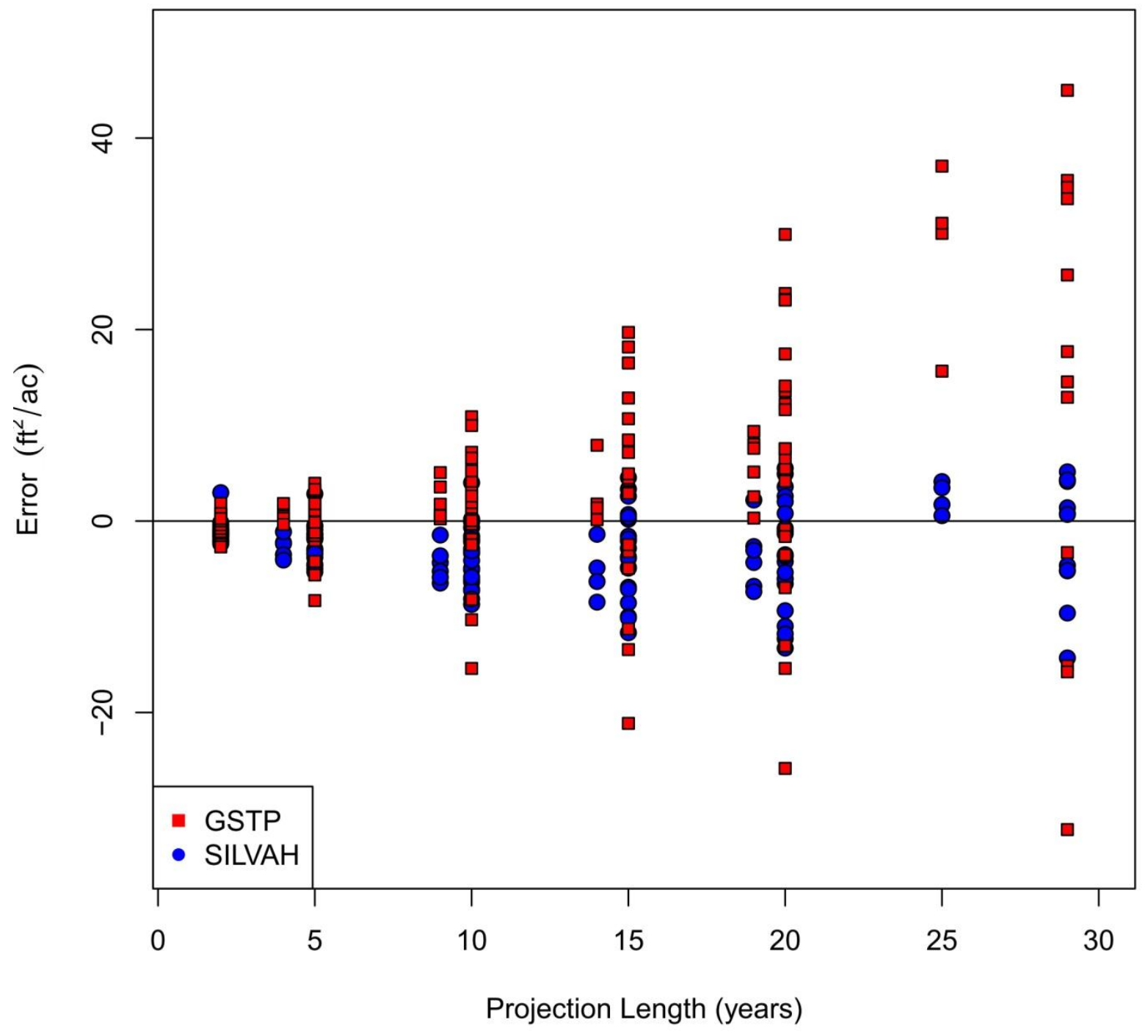

Figure 103. Species group 2 (maples) projection error by projection length for thinned overlapping projections. 


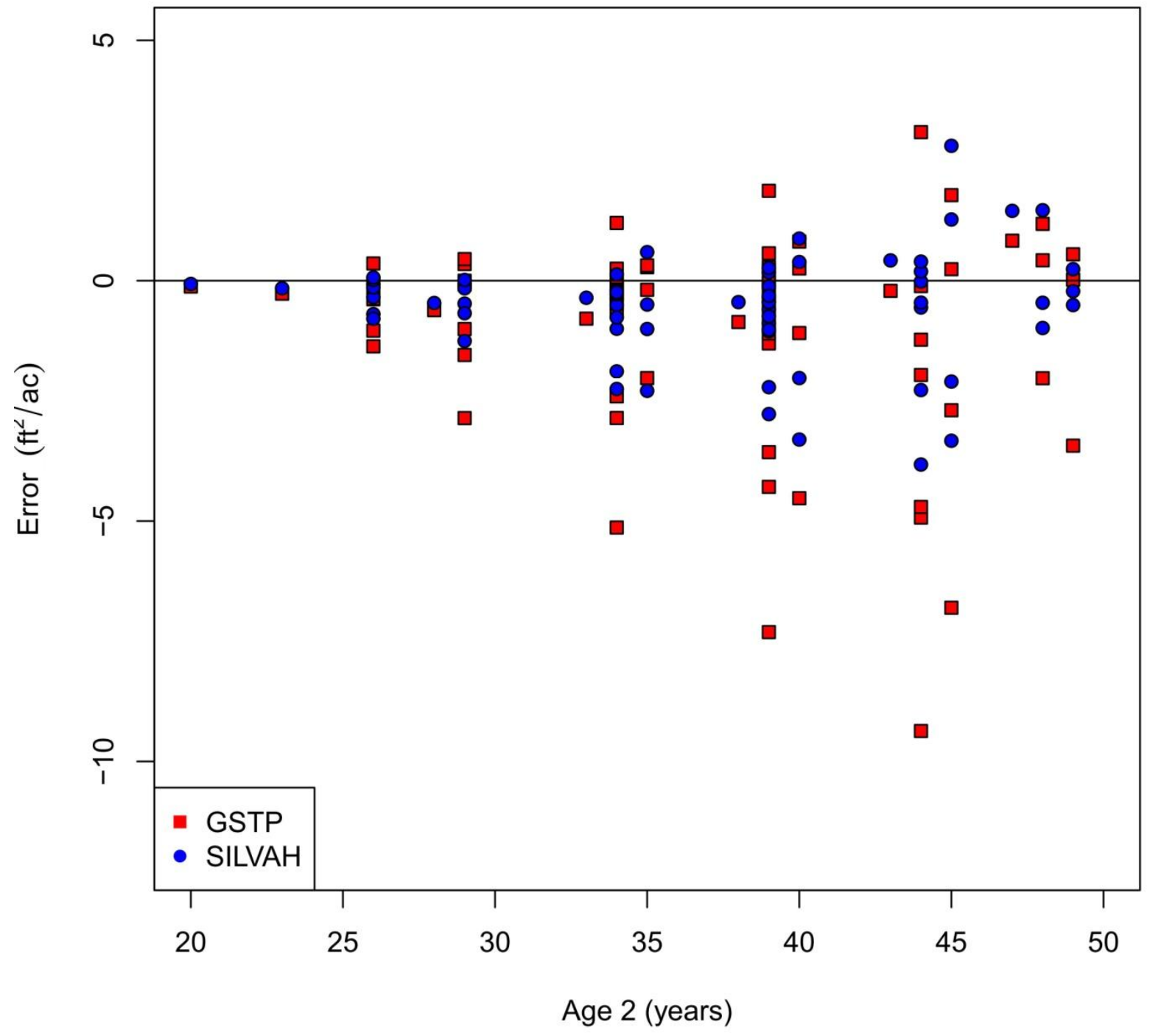

Figure 104. Species group 3 (white oaks) projection error by projection age (age 2) for thinned overlapping projections. 


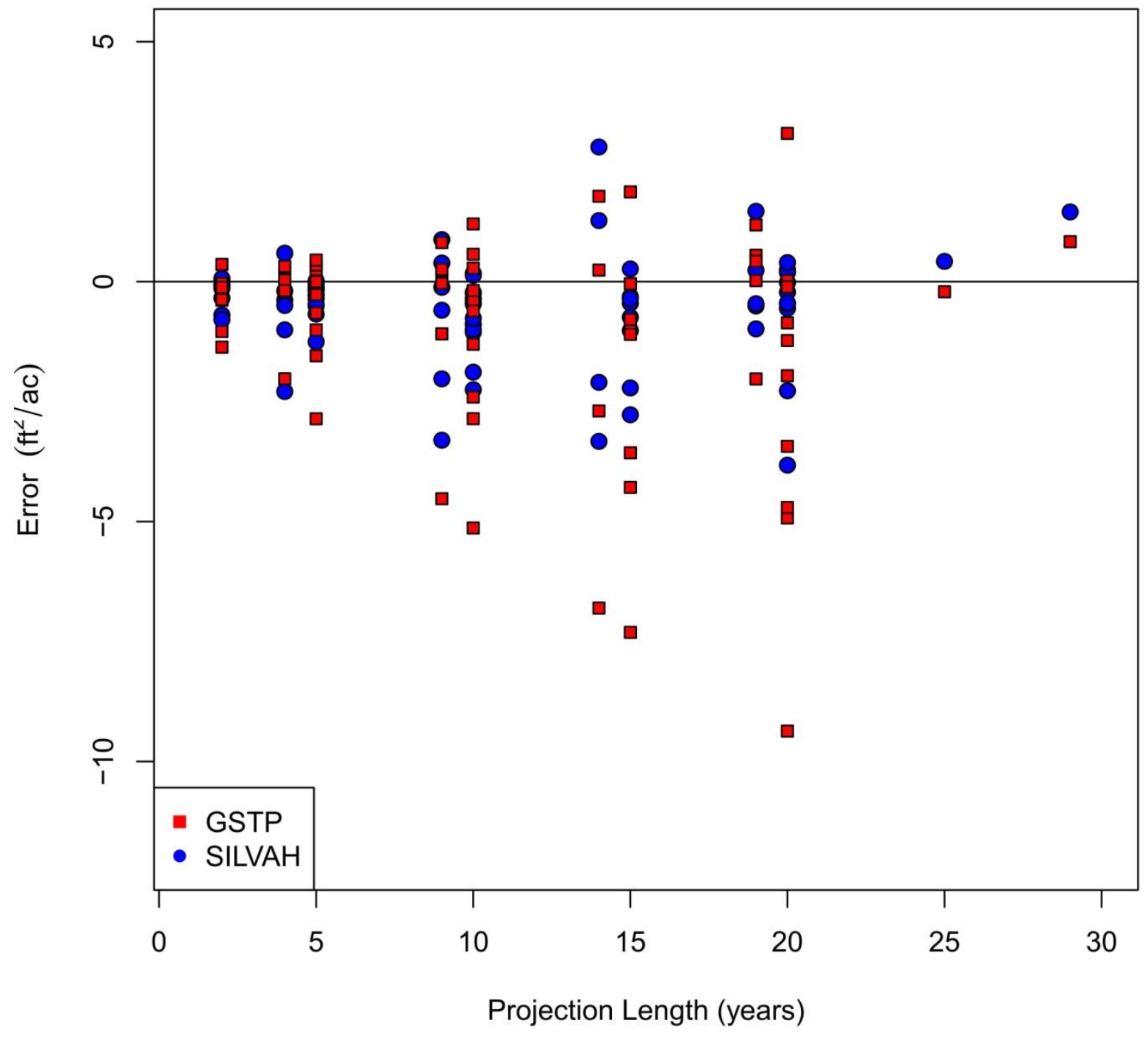

Figure 105. Species group 3 (white oaks) projection error by projection length for thinned overlapping projections. 


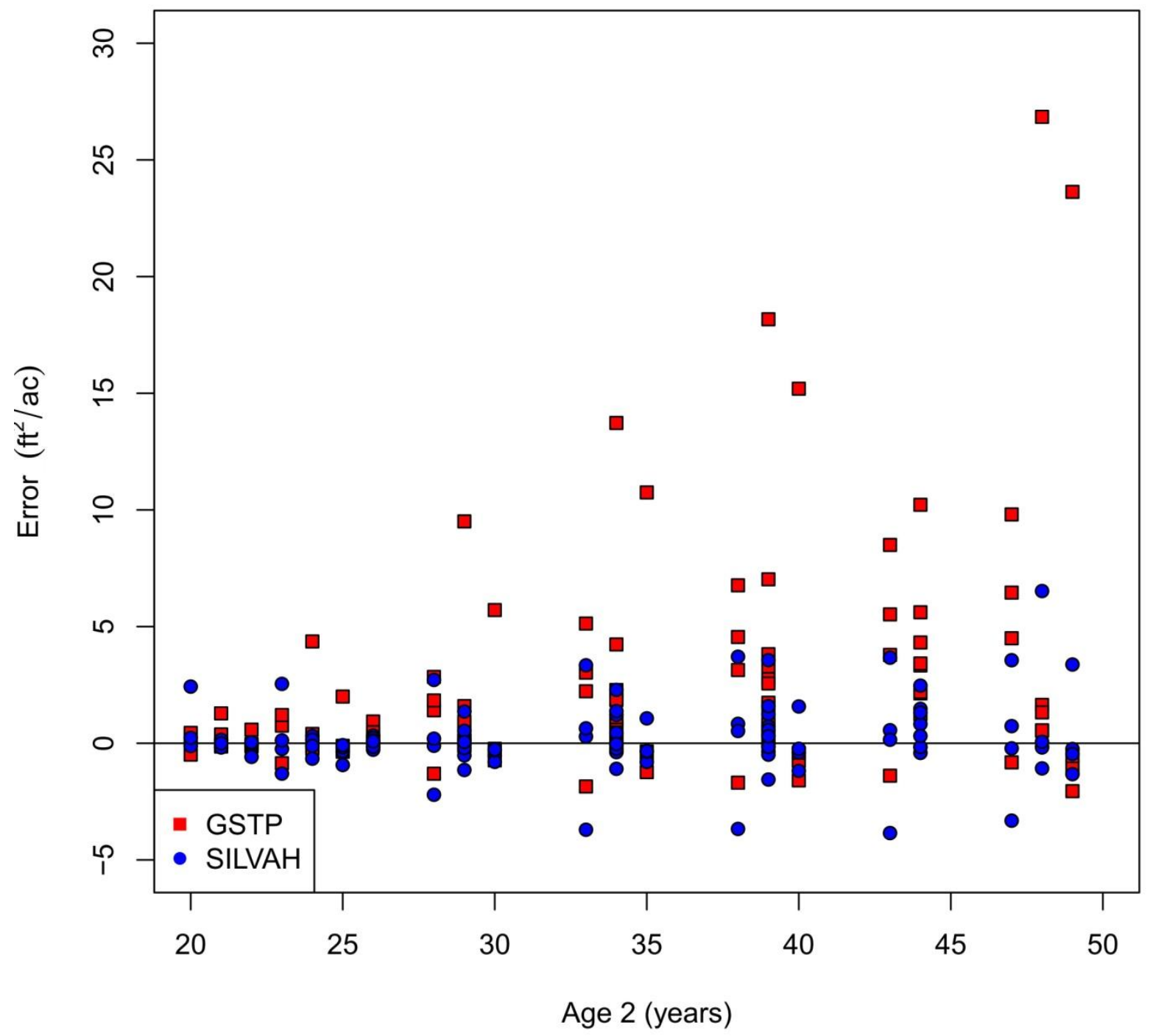

Figure 106. Species group 4 (hickory/ash) projection error by projection age (age 2) for thinned overlapping projections. 


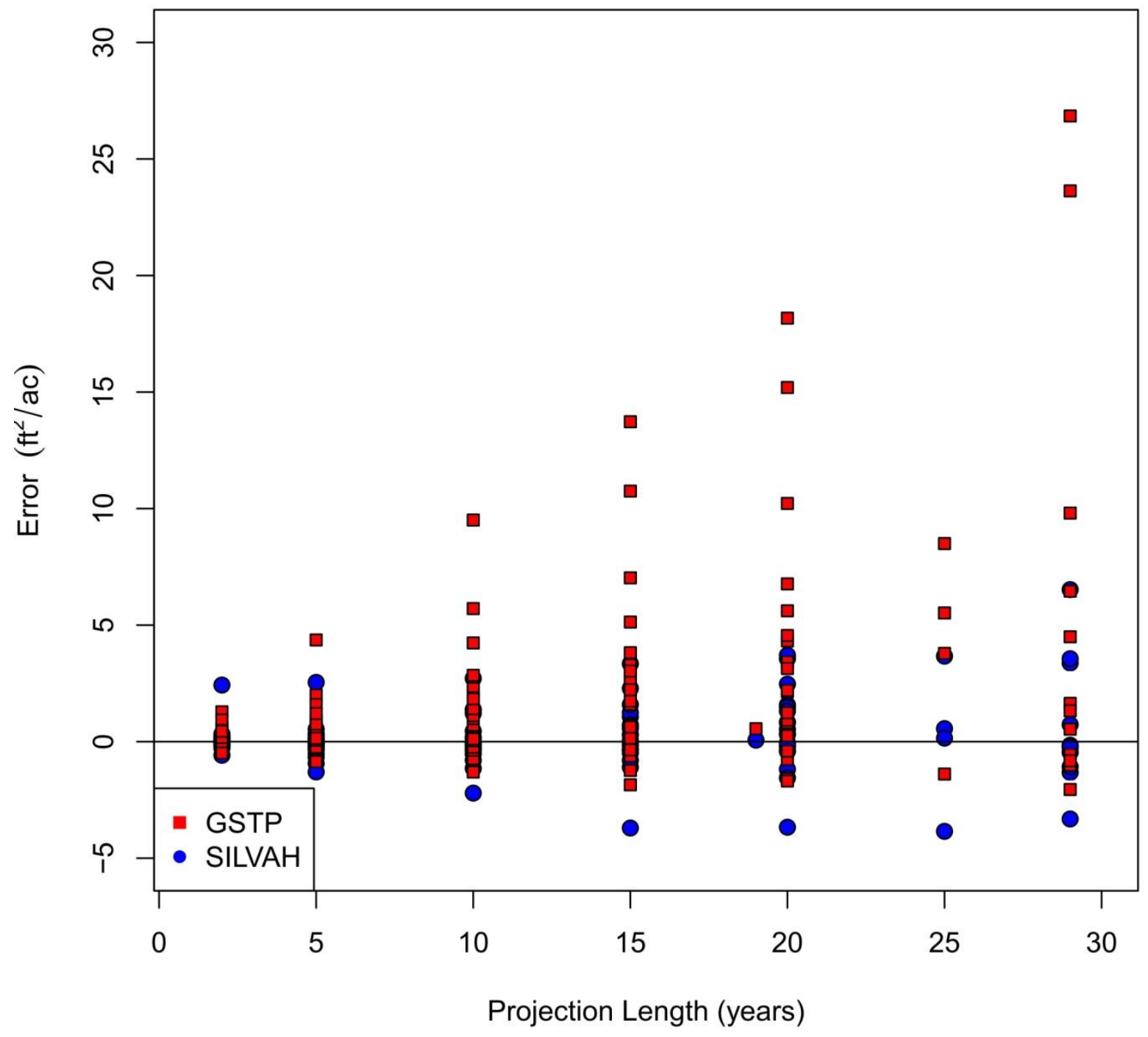

Figure 107. Species group 4 (hickory/ash) projection error by projection length for thinned overlapping projections. 


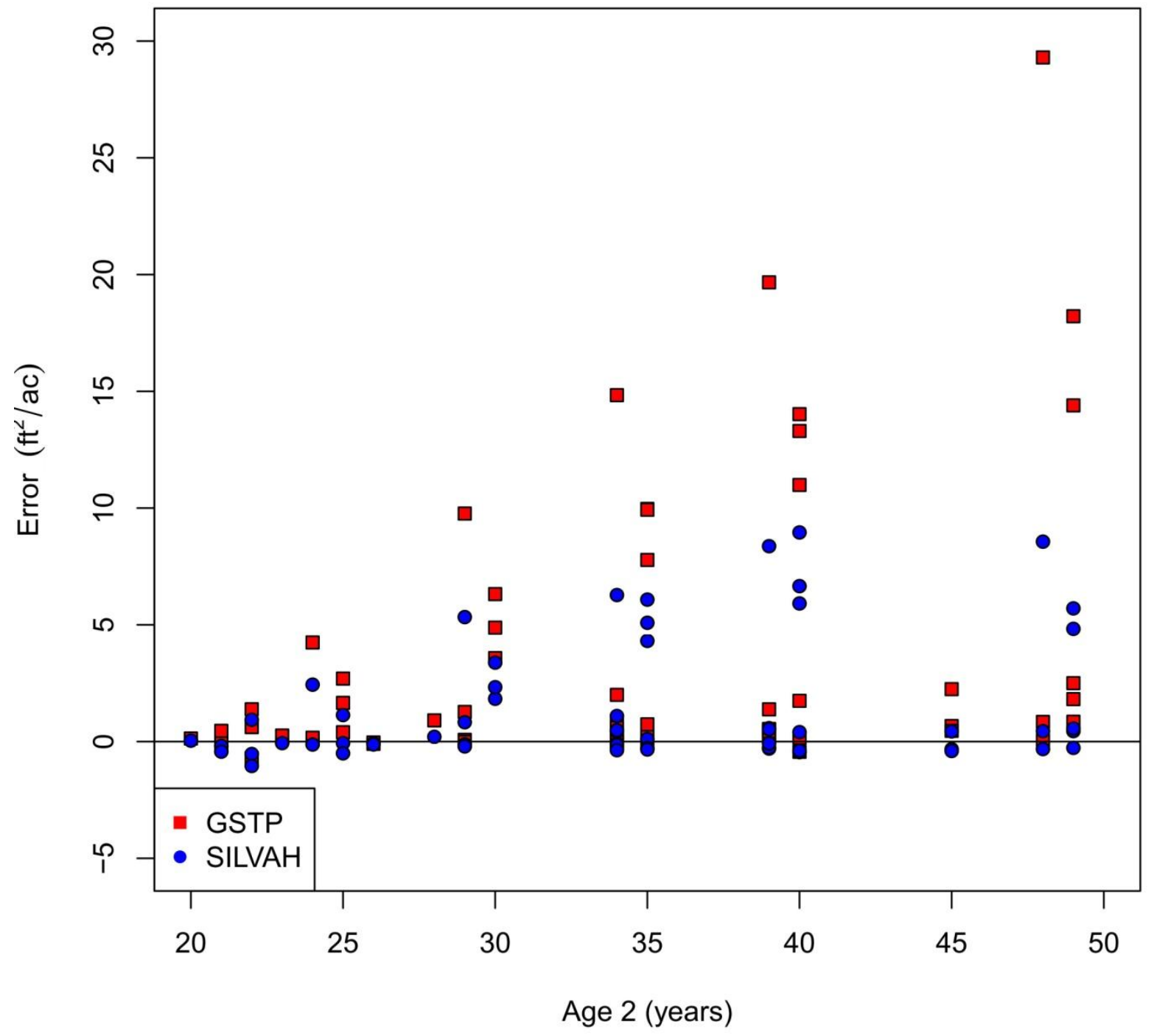

Figure 108. Species group 6 (striped maple/pin cherry) projection error by projection age (age 2) for thinned overlapping projections. 


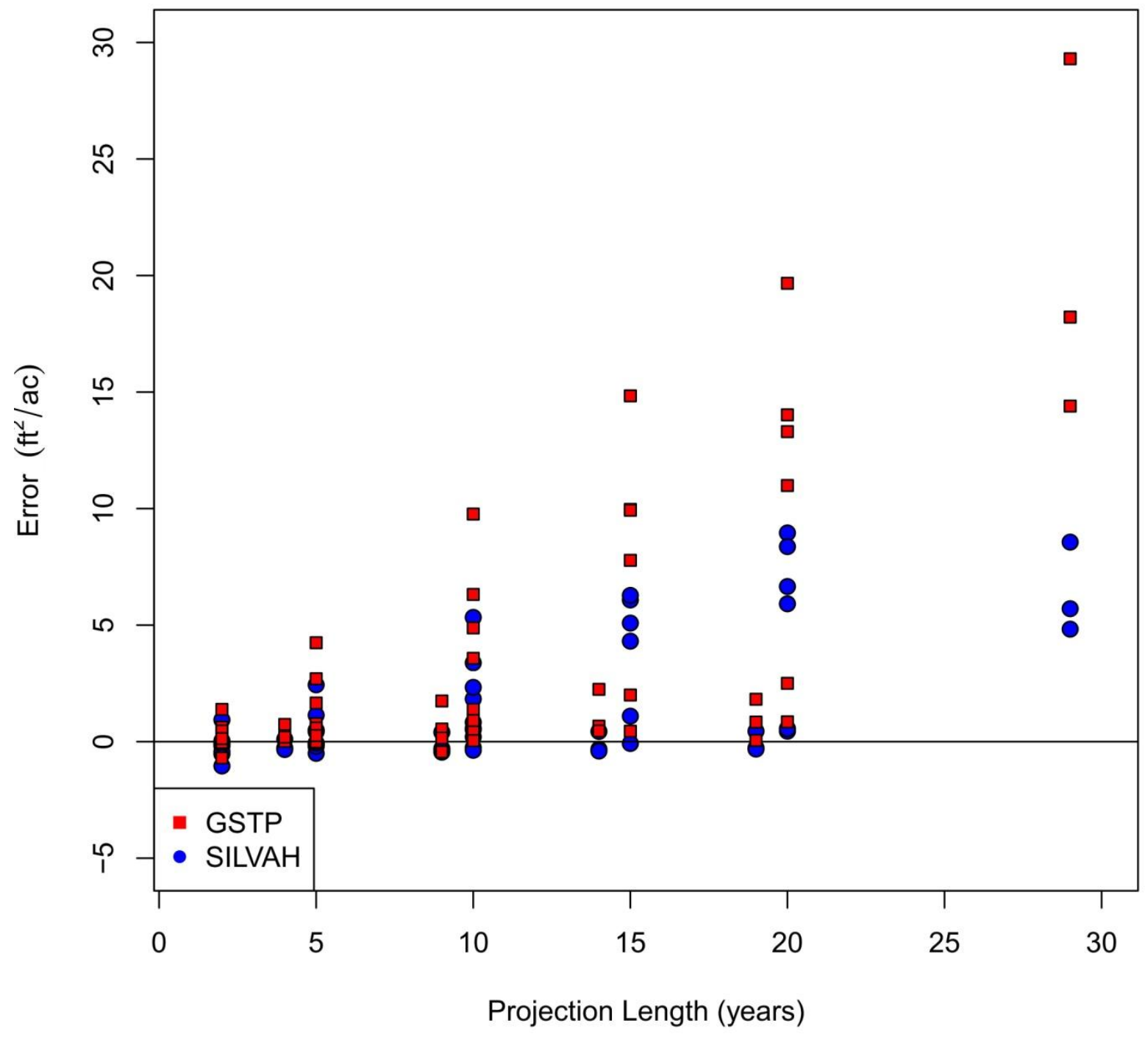

Figure 109. Species group 6 (striped maple/pin cherry) projection error by projection length for thinned overlapping projections. 


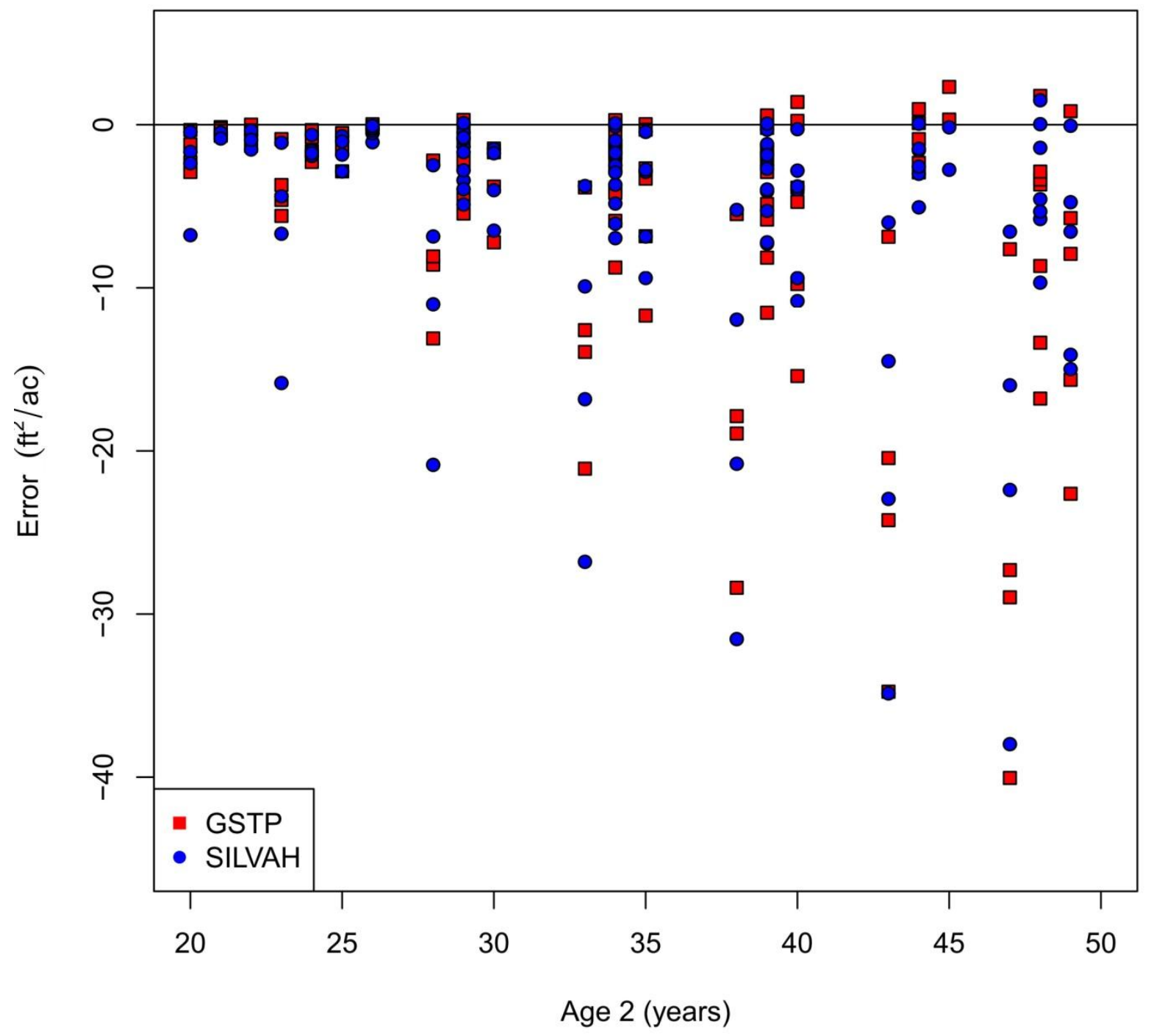

Figure 110. Species group 7 (black cherry) projection error by projection age (age 2) for thinned overlapping projections. 


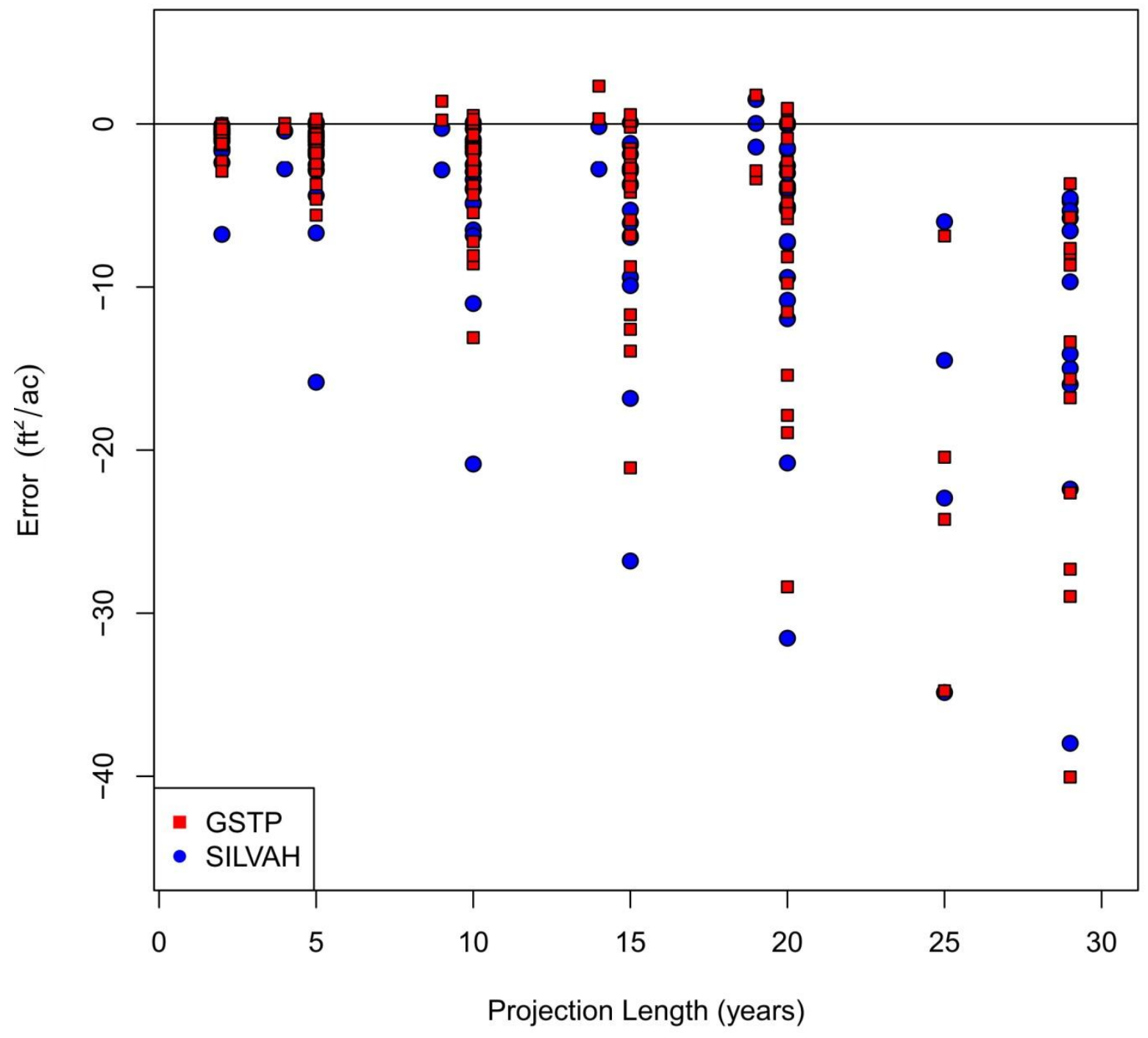

Figure 111. Species group 7 (black cherry) projection error by projection length for thinned overlapping projections. 


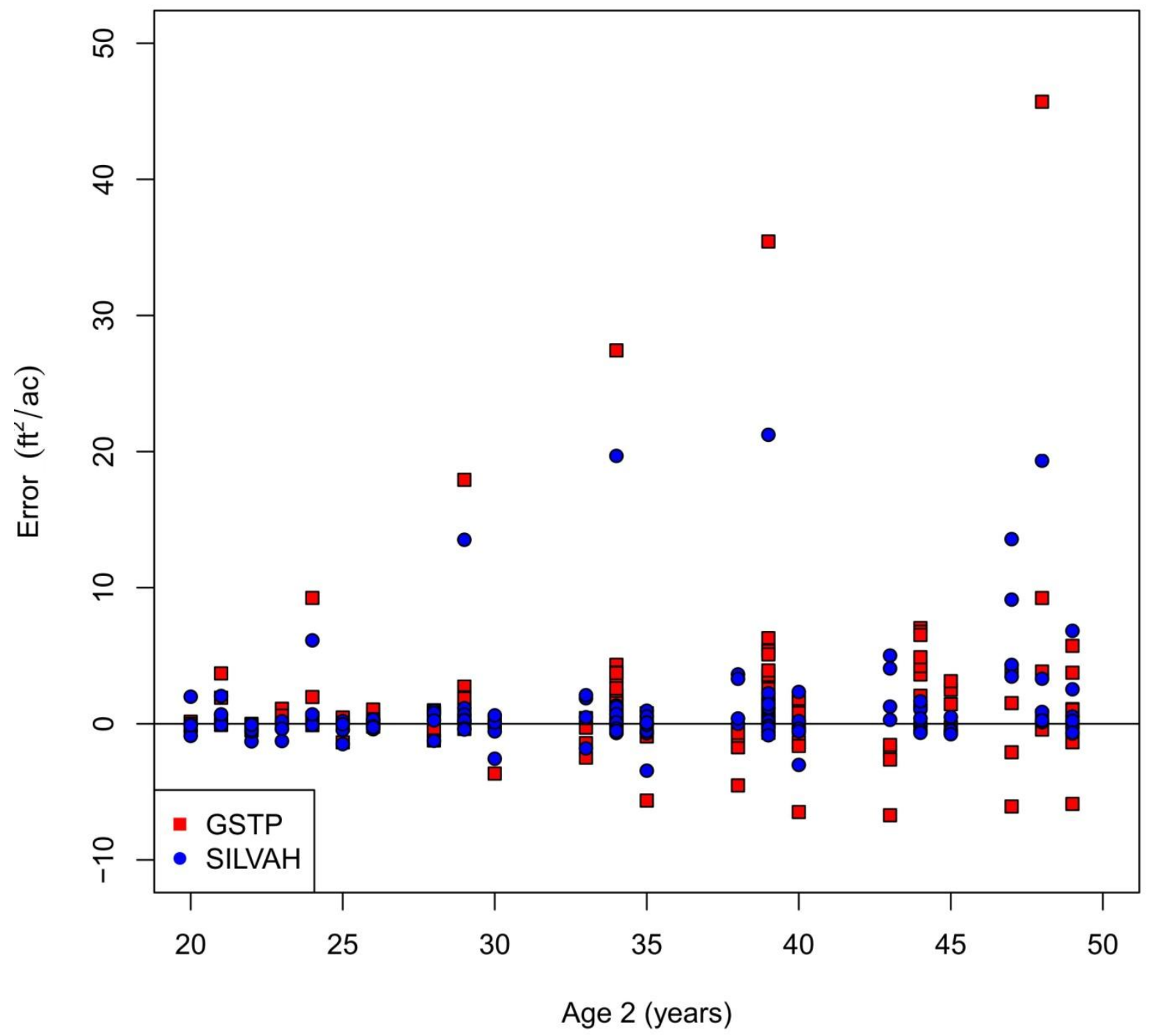

Figure 112. Species group 8 (other) projection error by projection age (age 2) for thinned overlapping projections. 


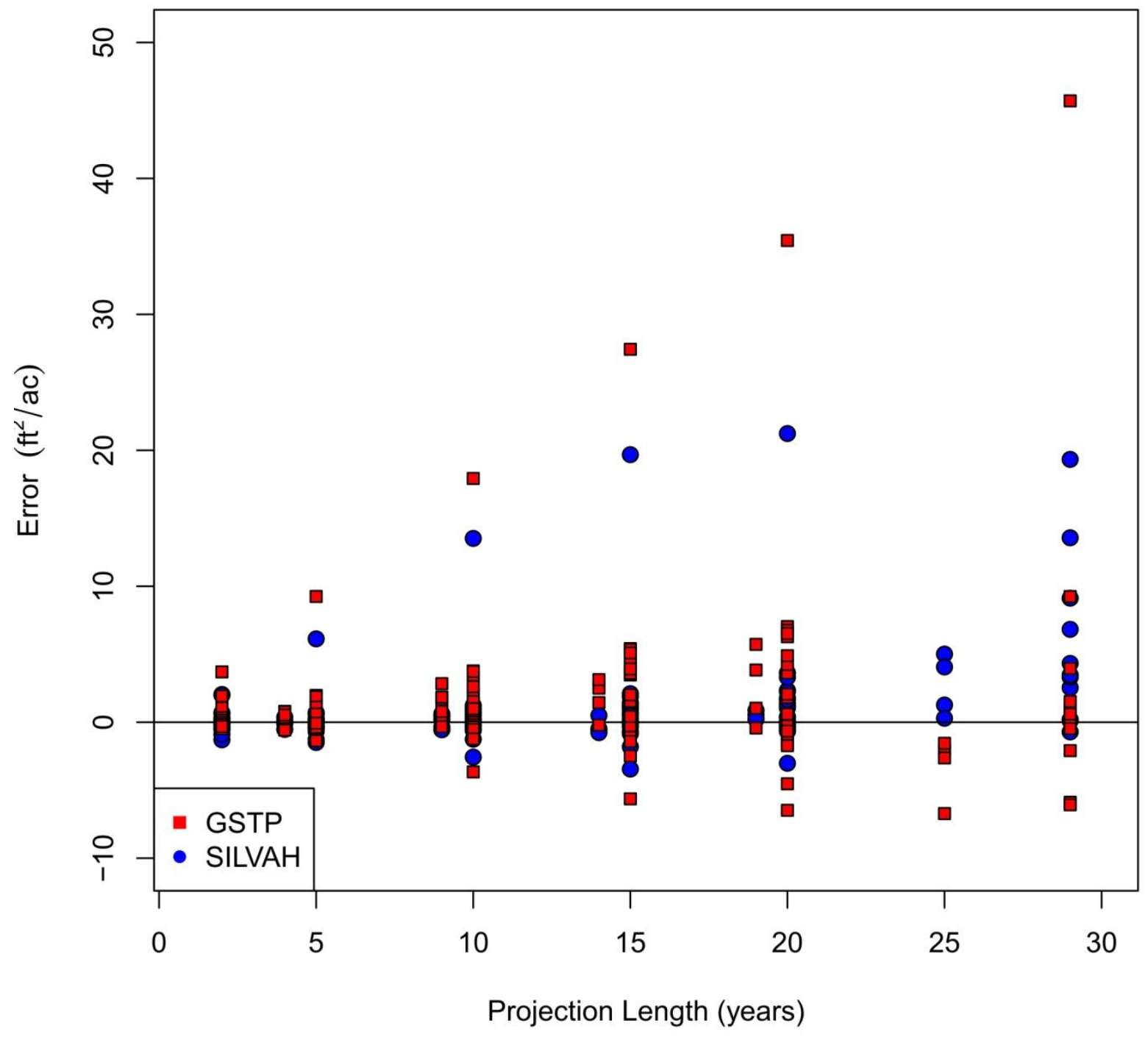

Figure 113. Species group 8 (other) projection error by projection length for thinned overlapping projections. 


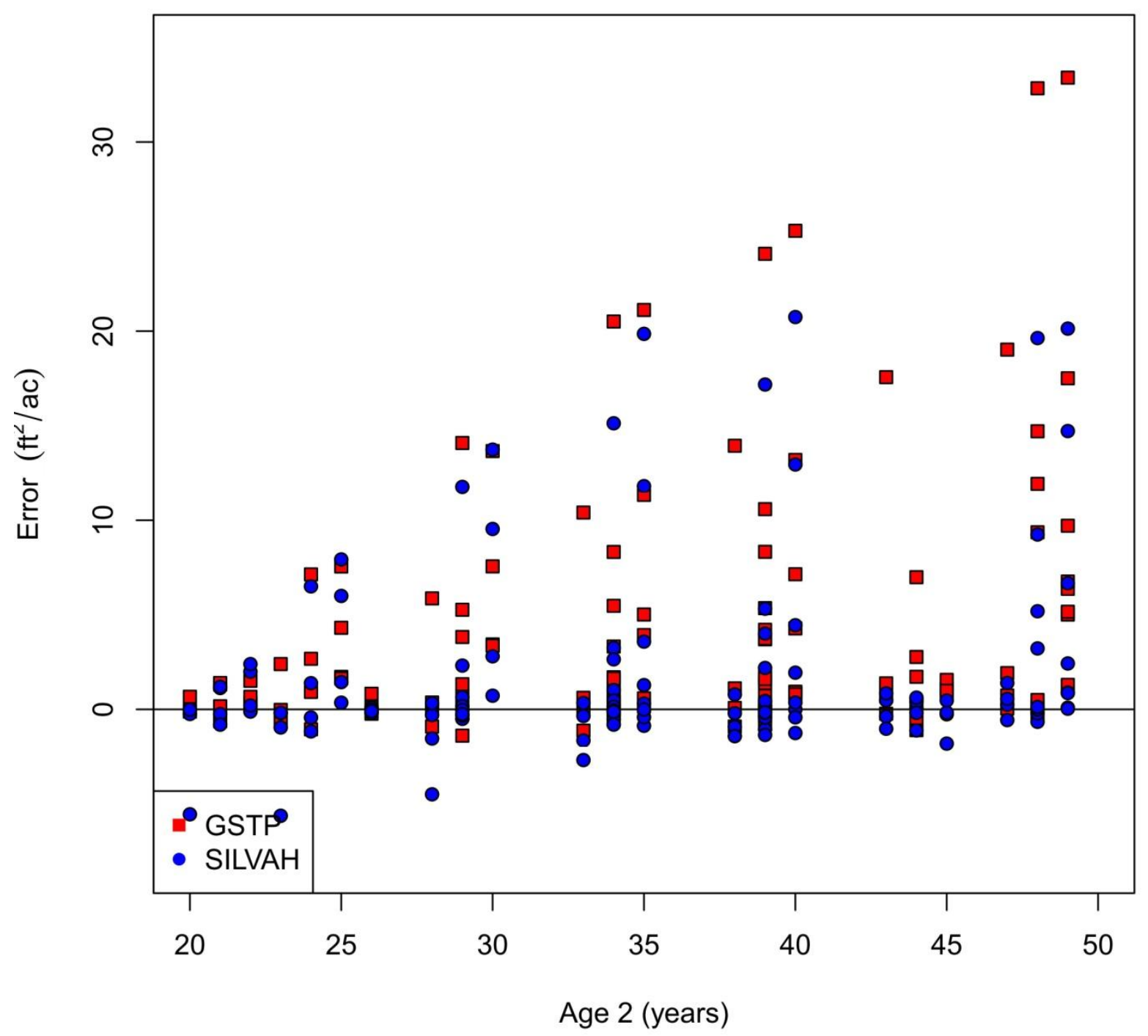

Figure 114. Species group 10 (birches) projection error by projection age (age 2) for thinned overlapping projections. 


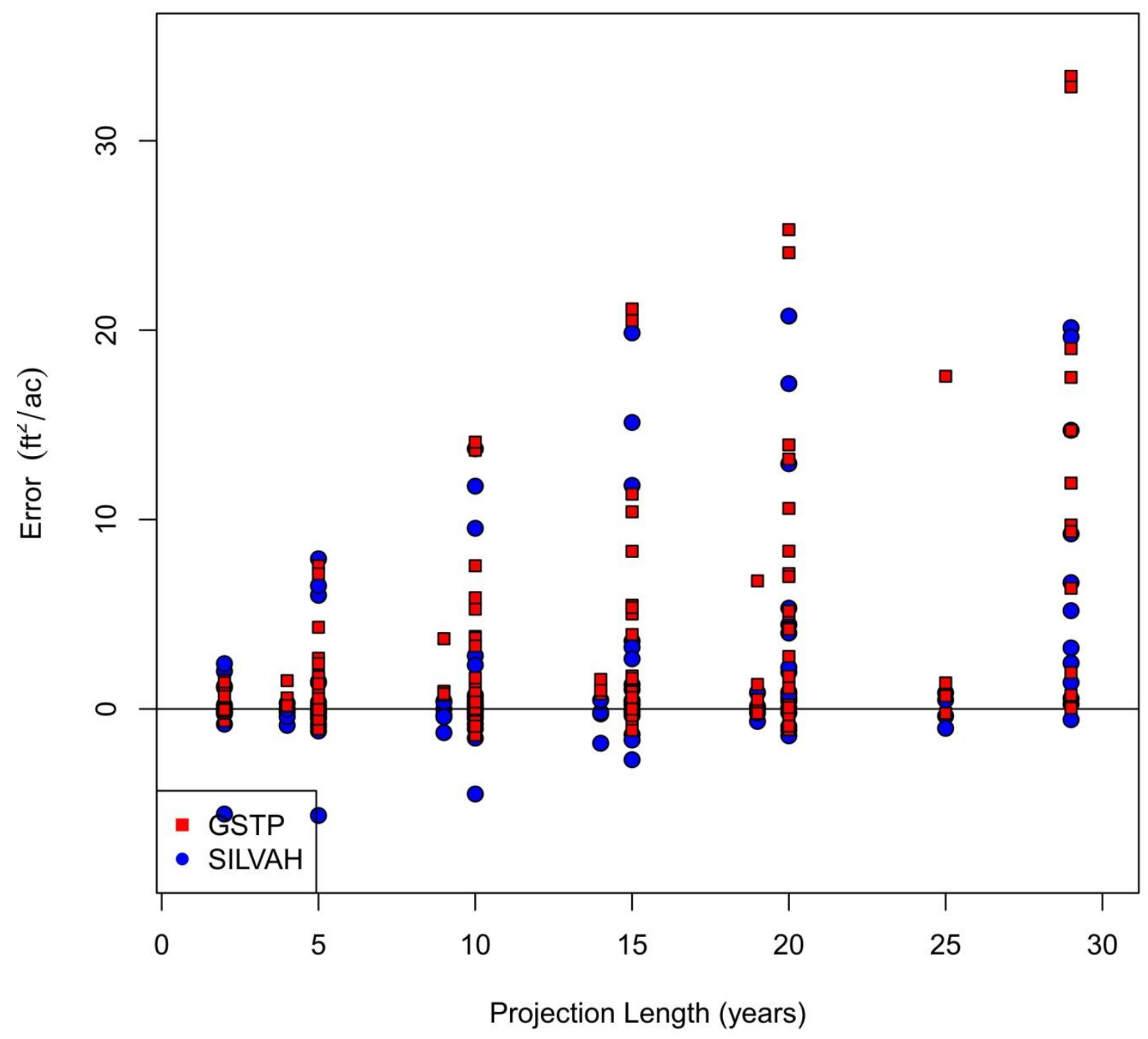

Figure 115. Species group 10 (birches) projection error by projection length for thinned overlapping projections. 